\title{
Incidence, risk factors and quality of life in IBD : Inflammatory Bowel Disease registry South Limburg
}

Citation for published version (APA):

Russel, M. G. V. M. (1997). Incidence, risk factors and quality of life in IBD : Inflammatory Bowel Disease registry South Limburg. [Doctoral Thesis, Maastricht University]. https://doi.org/10.26481/dis.19970703mr

Document status and date:

Published: 01/01/1997

DOI:

10.26481/dis.19970703mr

Document Version:

Publisher's PDF, also known as Version of record

\section{Please check the document version of this publication:}

- A submitted manuscript is the version of the article upon submission and before peer-review. There can be important differences between the submitted version and the official published version of record.

People interested in the research are advised to contact the author for the final version of the publication, or visit the DOI to the publisher's website.

- The final author version and the galley proof are versions of the publication after peer review.

- The final published version features the final layout of the paper including the volume, issue and page numbers.

Link to publication

\footnotetext{
General rights rights.

- You may freely distribute the URL identifying the publication in the public portal. please follow below link for the End User Agreement:

www.umlib.nl/taverne-license

Take down policy

If you believe that this document breaches copyright please contact us at:

repository@maastrichtuniversity.nl

providing details and we will investigate your claim.
}

Copyright and moral rights for the publications made accessible in the public portal are retained by the authors and/or other copyright owners and it is a condition of accessing publications that users recognise and abide by the legal requirements associated with these

- Users may download and print one copy of any publication from the public portal for the purpose of private study or research.

- You may not further distribute the material or use it for any profit-making activity or commercial gain

If the publication is distributed under the terms of Article $25 \mathrm{fa}$ of the Dutch Copyright Act, indicated by the "Taverne" license above, 


\section{Incidence, risk factors and quality of life in IBD}

Inflammatory Bowel Disease Registry South Limburg 
Russel, Maurice, George, Vincentius, Maria ISBN 90-9010684-7

Cover design: Hans Muller

The scientific work was supported by grants from the pharmaceutical companies Astra Pharmaceutica BV, Byk Nederland BV, Glaxo Wellcome BV, Pharmacia \& Upjohn BV, Tramedico BV, Yamanouchi Pharma BV, from the Medical Faculty of the University Maastricht, and during the period April 1995 to April 1997 by the University Hospital Maastricht in Corm of a full-time research grant.

Printing of this thesis was made possible by Byk Nederland BV. 


\title{
Incidence, risk factors and quality of life in IBD
}

\section{Inflammatory Bowel Disease Registry South Limburg}

\author{
PROEFSCHRIFT \\ ter verkrijging van de graad van doctor \\ aan de Universiteit Maastricht, \\ op gezag van de Rector Magnificus, Prof. Mr. M.J. Cohen, \\ volgens het besluit van het College van Decanen, \\ in het openbaar te verdedigen \\ op donderdag 3 juli 1997 om 16.00 uur
}

door

\section{G M Russel}

1.

geboren op 01-03-1958 te 's Gravenhage 


\section{Promotor}

Prof dr RW Stockbrügger

\section{Co-promotores}

Dr R-JM Brummer

Dr Ir ChBG Limonard

\section{Beoordelingscommissie}

Prof ar JW Arends, voorzitter

Prof dr JBMJ Jansen (Katholieke Universiteit Nijmegen)

Prof dr JA Knottnerus

Dr RF Logan (University of Nottingham, United Kingdom)

Prof dr PB Soeters 
*

Aan: minn ouders:

Liesbeth

Carine, Nicoline, Lisanme, Maurice 


\section{Chapter Ia}

\section{Introduction}

\section{Epidemiology of Inflammatory Bowel Disease: an update}

MGVM Russel, RW Stockbrügger *

Scand J Gastroenterol 1996; 31: 417-427 


\section{Introduction}

The terms ulcerative colitis (UC) and Crohn's disease (CD) designate a group of inflammatory diseases of the large and small intestine whose interrelationships remain obscure. The term "Inflammatory Bowel Disease" (IBD) is often used to delineate these two chronic diseases of unknown origin. UC is primarily a mucosal disease with almost exclusive colonic involvement, whereas $C D$ can appear with mucosal to transmural inflammation in every part of the gastrointestinal tract, but is mainly localized in the lleocolonic area. Current therapy for CD and UC is supportive, immuno-suppressive and non-specific. The first signs of these chronic diseases often develop at an early age; early recognition, good management and continuity of care may have important consequences for the quality of the individual's life.

\section{Descriptive epidemiology}

IBD is relatively common in most industrialized countries in the world. Differences in geographical distribution and, particularly changes in incidence over time within one area, may provide insights into possible aetiologic factors.

\section{Incidence}

The incidence varies greatly with geographic location and ranges from about 1 to 10 per 100.000 and year for $C D$ and from 5 to 18 for $\mathrm{UC}$. The highest rates are reported in Scandinavian countries and Scotland, followed by England and North America while IBD seems to be less common in Central and Southern Europe ${ }^{1-16}$. IBD appears to be uncommon in developing countries, but accurate data are lacking for most of those areas ${ }^{17,18}$.

\section{Comparing incidence rates}

Comparing incidence rates between different areas can be misleading because of differences in diagnostic facilities and disease definition. As case ascertainment improves in rural and developing areas, incidence rates may show an artificial increase. As most locations do not have true population-based registries, surrogates (such as hospitalization figures) are sometimes used to estimate incidence ${ }^{6,19}$.

The variation in the reported series on UC incidence is partly determined by whether or not ulcerative proctitis is seen and recognized by a physician and whether it is included in the UC group ${ }^{20,21}$. Another important factor that has to be considered is the method of case collection (prospective or retrospective or both).

Table la.1 summarizes incidence rates from a number of registries. There seems 
to be little doubt that the disease varies with geography. The incidence of IBD seems to have a relation to the degree of industrialization. The distribution also suggests a North-South gradient in Europe and in the United States. The results of a study of Sonnenberg, using data on hospital discharges over a 2-year period and mortality statistics, are in favour of the latter hypothesis ${ }^{22}$. The recent European Study on IBD detected some differences between the North, Middle and South of Europe but not as large as was expected ${ }^{23}$. The mean annual incidence for the two diseases in all areas together was 11.2 for $\mathrm{UC}$ and 5.9 for $\mathrm{CD}$.

Table 1a.1 Recent incidence rates (per 100.000 person years) of Inflammatory Bowel Disease of selected

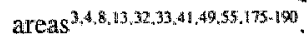

\begin{tabular}{|c|c|c|c|c|c|}
\hline Country & Area & Study Period & CD & UC & Collection" \\
\hline Norway & Western Norway & $1983-1986$ & 5.3 & 14.8 & $\mathrm{P}$ \\
\hline Sweden & Orebro & $1978-1987$ & 6.8 & 13.1 & $\mathrm{R}$ \\
\hline \multirow[t]{2}{*}{ Denmark } & Copenhagen & $1979-1987$ & 4.1 & & $P$ \\
\hline & & $1962-1987$ & 8.1 & & $\mathrm{P}$ \\
\hline \multirow[t]{3}{*}{ Britain } & Aberdeen & $1985-1987$ & 11.6 & & p \\
\hline & Blackpool & $1981-1990$ & 6.7 & & $P$ \\
\hline & Cardiff & $1981-1985$ & 8.3 & 7.2 & R \\
\hline \multirow[t]{2}{*}{ Netherlands } & Leiden & $1979-1983$ & 3.9 & 6.8 & $\mathrm{R}$ \\
\hline & South Limburg & 1988-1992 & 5.5 & 7.6 & $\mathbf{R}$ \\
\hline France & Northern France & $1988-1990$ & 4.9 & 3.2 & P \\
\hline Germany & Rurh area & $1980-1984$ & 4.0 & 2.9 & $\mathrm{P}$ \\
\hline Italy & Florence & $1978-1987$ & 1.5 & 4,0 & $\mathrm{R}$ \\
\hline Spain & Granada & 1979.1988 & 0.9 & 2.0 & $\mathrm{R}$ \\
\hline Yugoslavia & Zagreb & $1980-1989$ & 0.7 & 1.5 & $\mathrm{p}$ \\
\hline Greece & Epirus & $1982 \cdot 1991$ & 0.3 & 4.0 & $\mathrm{R}$ \\
\hline \multirow[t]{2}{*}{ Israel } & Southern Israel & 1987.1992 & 4.2 & 5.8 & $\mathbb{R}$ \\
\hline & Beer Shiva & $1980-1985$ & & . & R \\
\hline \multirow[t]{2}{*}{ USA } & Olmsted County & $1978-1982$ & 4.3 & & $\mathbb{R}$ \\
\hline & Baltimore & 1977979 & 3.1 & 2.2 & $\mathrm{H}, \mathrm{R}$ \\
\hline South Africa & Capetown (whites) & $1980-1984$ & 2.6 & 5.0 & $\mathbb{R}$ \\
\hline
\end{tabular}

"Collection of cases: P: prospectively; R: retrospectively : H: hospital serie 


\section{Time trends in incidence}

Analysing time trends within an area prevents most of the difficulties described. Figure 1a.1 illustrates longitudinal data of some centres ${ }^{3,7,8,24}$. In the Western world, the most rapid increase in the frequency of $\mathrm{CD}$ occurred during the period 1965-1980, and, after a slower increase, reached a plateau in most centres and subsequently decreased in some $e^{25}$. Part of this increase could be due to changing diagnostic practices, shortening the time interval between disease onset and diagnosis. A diagnostic transfer from UC to CD is not likely given the fairly steady rates for colitis. The impact of changing diagnostic practices, however, like an increased recognition of $\mathrm{CD}$ limited to the colon, cannot be totally ignored. However, most of the increase seems to be real and the rapidity of change suggests that some environmental factor(s) are responsible, since changes in genetic factors are not expressed that quickly ${ }^{25}$.

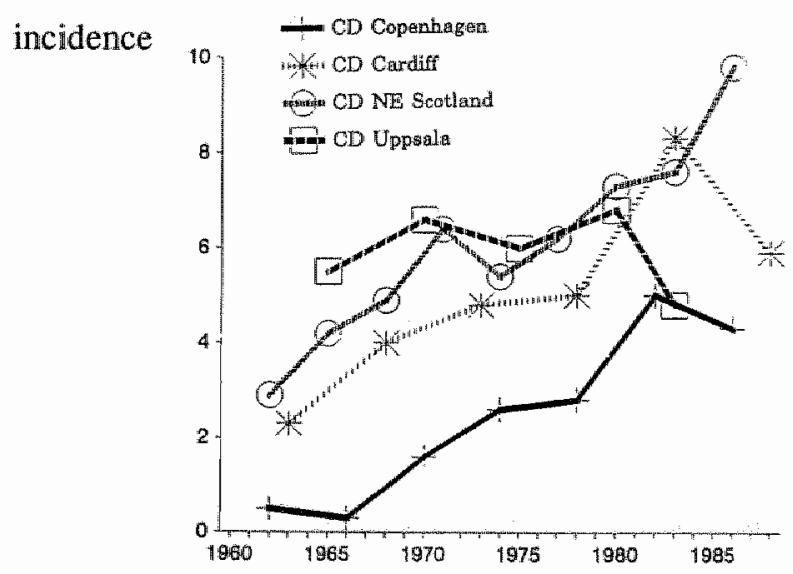

Figure 1a.1 Incidence rates (per 100.000 and year) of Crohn's disease of some selected areas ${ }^{37,8,24}$.

The incidence of UC has remained fairly stable in those centres where data have been available for a number of years. However, as shown in Figure 1a.2, also in UC there is a tendency towards increasing incidence over the years ${ }^{4,26.27}$. Epidemiologic data of the county of Copenhagen indicate a six-fold increase in CD, in all age groups and both sexes, in the 25 year interval from 1962 to 1987 , with a more stable incidence pattern for UC during the same period ${ }^{3,27}$. One epidemiological feature of interest is the fact that the incidence of $U C$ is always greater than that of $\mathrm{CD}$ when first studied, but that over successive decades the incidence of $\mathrm{UC}$ tends to level off, whereas that for $\mathrm{CD}$ tends to increase steadily ${ }^{28-30}$. The different time trend for $C D$ and UC suggest that the causal agent(s) or risk factor(s) for UC and $\mathrm{CD}$ are different. 


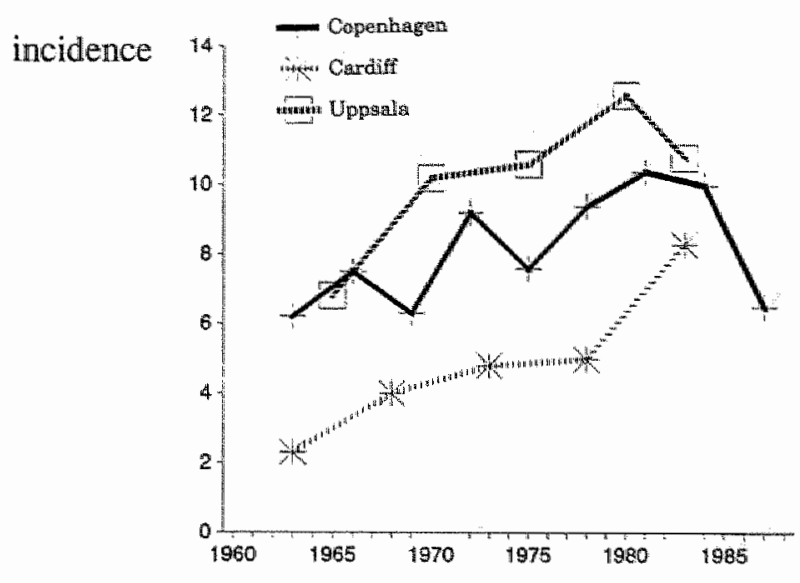

Figure 1a.2 Incidence rates (per $\mathbb{1 0 0 , 0 0 0}$ and year) of ulceratiwe colitis of some selected areas ${ }^{46,27}$.

\section{Prevalence}

Determining accurate prevalence rates, referring to the number of cases at one moment, creates certain problems. For example, how to be aware of the number of all patients with UC in remission after colectomy? And should this group be considered in prevalence figures at all? Chronic proctitis can have long periods of disease-free interval, during which time no medical consultation takes place. Follow-up of the initial incident cohort can be rather difficult and asymptomatic patients are probably underestimated in prevalence figures. Incidence figures, especially of prospective studies, are therefore more likely to be correct than prevalence figures.

\section{Age}

Both $\mathrm{CD}$ and $\mathrm{UC}$ mainly become manifest during late adolescence or early adulthood, with a peak onset between 15 and 30 years of age. In most, but not all, series there also appears to be a second, smaller peak at ages between 55 to $80^{1,2,31-36}$. Bimodality is more consistently evident for $\mathrm{CD}$ than for $\mathrm{UC}$ and is mainly observed in some smaller American series. A bimodal age distribution could imply different risks at different ages or also a heterogenous disease entity. The suggestion that mesenteric vascular disease may account for the secondary rise is attractive, but so far pathologic findings do not support this hypothesis $\mathrm{s}^{37-39}$.

The incidence of UC in patients under the age of 10 is rare, but far exceeds that of $\mathrm{CD}$. Case ascertainment in the paediatric population may be more difficult since 
children with minimal symptoms will probably never be seen by a physician ${ }^{40}$.

\section{Sex}

Women are in general at a $20-30 \%$ greater risk than men of developing $\mathrm{CD}$. The reports on sex differences in UC are variable, but there seems to be a tendency to a male preponderance ${ }^{16,25,41}$. It is not clear what implications the sex difference has on the aetiology of either disease, but it suggests that susceptibility for the two diseases may be different.

\section{Mortality}

Death rates in IBD patients in the United States and Europe are currently in the range of 2 to 6 per million per year ${ }^{42}$. In particular the elderly and those who have undergone a colectomy in the preceding year seem to be at increased risk of death $^{43}$. Longterm survival has greatly changed over the decades. While a cumulative 20-year mortality rate of $40 \%$ was published in 1963, more recent studies report much better survival, and some even suggest there is no increased mortality in subjects with IBD, compared to the general population ${ }^{44-46}$. Some of the reported difference in survival between studies can be attributed to differences in disease severity. It seems likely that several other factors, like better medical management and earlier surgery with improved postoperative care, at least partly account for the observed improvement in survival during the last two decades.

\section{Pathogenesis}

The pathogenesis of $C D$ and $U C$ probably involves an interaction between genetic and environmental factors (Figure 1a.3). While the precise mechanism responsible for initiating intestinal inflammation remains unclear, there is ample evidence for a perpetuation of the disease by an intense and prolonged local mucosal immune response, associated with recruitment and activation of lymphocytes and macrophages ${ }^{47}$. In other words IBD seems to be characterized by a failure to downregulate a normally self-limited inflammatory response of the gut. The factor(s) triggering this response is (are) presently unknown, but are most probably multiple. Therefore hypotheses based on single aetiological factors might not lead to efficient therapeutic strategies ${ }^{48}$. 


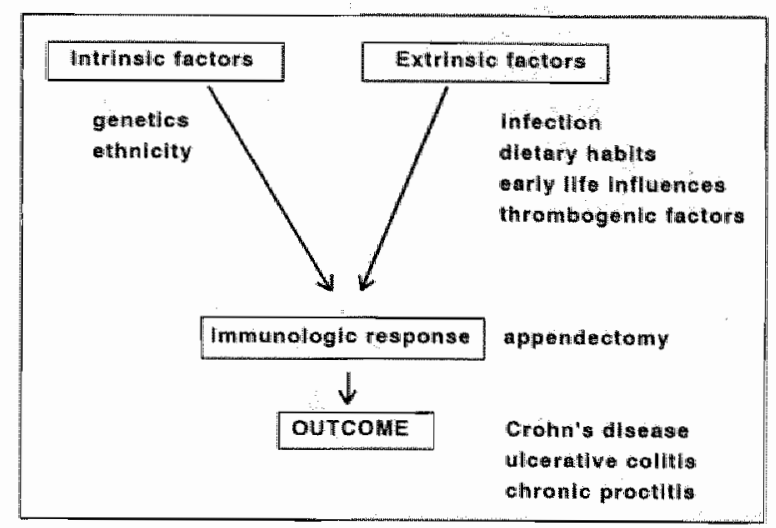

Figure 1a.3 Theoretical model of interactions between genetical and environmental factors in IBD.

\section{Intrinsic aetio-pathogenetic factors}

\section{Ethnicity}

Within geographic areas there are ethnic and racial variations in the incidence of $\mathbb{I B D}$. There is a remarkable predominance of Jewish patients in the North American and South African series ${ }^{49-52}$. Incidence rates of UC and CD in Israel are higher among those born in Europe or America, compared to those born in Israel ${ }^{53,54}$. The much lower incidence among Jews elsewhere, and the inconspicuous incidence of IBD in Israel, with even a low incidence in the Israeli-born population, are in agreement with a role of environmental factors in the pathogenesis of IBD. The previously observed difference in $\mathrm{CD}$ seems to narrow according to recent studies from Israel reporting that $\mathrm{CD}$ has become more common in Jews in Israel -losing ethnic differences of frequency- and that it occurs at an earlier age than before ${ }^{55,56}$.

In England Hindus and Sikhs appear to have a lower incidence of $\hat{C D}$ and a higher incidence of UC than the general population; a firm association could not be detected with differences in dietary intake of smoking habits ${ }^{57.59}$.

From 1960 to 1980 American black and Indian populations were at low risk for IBD. The difference to the American Caucasian population appears to be closing with time, possibly reflecting the disappearance of a differential quality of health care in some areas ${ }^{40}$. 


\section{Genetics}

There is an increased frequency of positive family histories of IBD among cases of IBD compared to controls ( 10 to $20 \%$ ), compatible with a role of genetic factors involved in the susceptibility to $C D$ and $U C^{60}$. UC is increased among the relatives of UC patients, and $C D$ to a somewhat greater extent- among $C D$ relatives. The two diseases also do occur in the same family with an increased frequency higher than just the co-occurrence by chance alone, suggesting an aetiological relationship between $U C$ and $C D^{61}$. The most useful data are ermpiric risk rates that have been adjusted for the ages of the relatives at risk, thus creating life time adjusted risks as reported by Roth $^{62}$. The age adjusted risk for relatives is highest for siblings and offspring ( $8-9 \%)$, followed by that for parents $(3-4 \%)$, while the risk for seconddegree relatives seems not to be increased ${ }^{63}$. Family aggregation can have both genetic and environmental causes. The higher concordance rates of $I B D$, in $C D$ more than in UC, in monozygotic twins than in dizygotic twins, support the argument that genetic factors are an important component in the development of $I B D$, and that such genetic factors account for much of the familial aggregation ${ }^{63-65}$.

Recently Toyoda published the important observation that particular phenotypes of disease may have defined genotypic association ${ }^{66}$. It has been firmly established that perinuclear antineutrophill cytoplasmic antibody (P-ANCA) is a frequent finding in UC but not in $\mathrm{CD}^{67.71}$. The increased frequency of P-ANCA in healthy first-degree relatives to probands with UC raised the hypothesis that $P$-ANCA may be genetically determined ${ }^{72,73}$. The role of P-ANCA as a subclinical marker of genetic susceptibility to UC was not confirmed in a recent study in monozygotic twins with $\mathrm{IBD}^{74}$.

Studies on the role of the HLA system, using serological techniques, have been largely inconclusive for $\mathrm{CD}$, and have shown an increase in the frequency of the HLA-DR2 allele in UC ${ }^{66,75}$. This increased frequency of HLA-DR2 may provide important clues to aetiology, as this antigen has been associated with increased susceptibility to infection and with increased susceptibility to multiple sclerosis. HLA-B27 and -B8DR3 are only present in cases of IBD in association with ankylosing spondylitis or primary sclerosing cholangitis.

\section{Extrinsic aetio-pathogenetic factors}

\section{Infection}

Inflammatory bowel disease might be precipitated by infections that either are not searched for at onset, or have been transient, or are still not identifiable by current laboratory methods. The increased incidence of IBD in centres in the Western 
world over a relative short period after the Second World War may in part be explained by an infectious agent ${ }^{3,4,7,8,76}$. The same is true for clustering of cases in time and space and the observed, but also challenged, seasonal variation in the clinical presentation of $\mathrm{IBD}^{7,77-80}$. Finally, the recently described pattern of emergence of IBD in ten married couples in France and Belgium suggest a role for an infectious agent, yet to be identified ${ }^{81}$.

A low exposure of infants to enteric organisms (programming the immune system of the gut) as a consequence of improved domestic hygiene could render the bowel more susceptible to a triggering infection later in life. This hypothesis is supported by a case-control study from the UK, showing that $\mathrm{CD}$ (but not UC) was more common in subjects with a hot water supply and bathroom in the childhood home ${ }^{82}$. Such findings may explain why the incidence of $C D$ has risen in the developed countries over the past 50 years. The incidence of $C D$ in developing countries may increase as domestic hygiene improves.

Infection with Mycobacteria paratuberculosis has strongly been invoked as a cause for $\mathrm{CD}^{83-86}$. The organism has been isolated from the tissues of only a few patients and attempts to show Mycobacteria paratuberculosis DNA in tissues have been variably successful ${ }^{87}$. Seven controlled studies, involving different antimycobacterial drugs, have been reported but their results are conflicting ${ }^{88.92}$. Clinical trials in $\mathrm{CD}$ are fraught with difficulties like definition of a homogenous group, the choice of drug(s), duration of therapy and interpretation of results. Lack of response does not exclude the possibility of mycobacteria initiating the disease and improvement in symptoms does not necesarily support the hypothesis ${ }^{91}$. The case for or against mycobacteria as a causative agent of $C D$ has not yet been closed.

Viruses that have been isolated in IBD are Cytomegalovirus, small RNA virus, and rotavirus or reovirus-like agents ${ }^{93}$. Lately morphological and epidemiological studies have implicated measles virus as a potential component cause in CD, particularly when exposure occurs in utero or early in life ${ }^{94.96}$. Exposure to a measles epidemic as a risk factor in $C D$ could not be confirmed in a large casecontrol study in the $\mathrm{UK}^{97}$. Increased prevalence of $\mathrm{CD}$ and $\mathrm{UC}$ was found in people who had received live measles vaccine compared to a non-vaccinated group, suggesting that measles virus may play a role in the development of $\mathrm{CD}$ and $\mathrm{UC}^{98}$.

\section{Dietary habits}

A high intake of refined sugar and starch, before as well as after diagnosis, is a remarkably consistent finding in patients with $\mathrm{CD}$, in contrast to patients with $U C$ who do not differ from controls in this respect ${ }^{99-103}$. There is no self-evident mechanism for the action of sugar to promote the development of $\mathrm{CD}$. In a casecontrol study by Järnerot sugar intake was only higher in cases after diagnosis of $\mathrm{CD}^{104}$. This finding suggests that it is a consequence of the symptoms rather than a 
cause of the disease.

Another consistent dietary finding in $\mathrm{CD}$ concerns the intake of fresh fruit: several case-control studies have found fresh fruit intake to be significantly reduced in $\mathrm{CD}$ patients ${ }^{105-107}$. In various studies the daily intake of dietary fibre is reported to be either increased or decreased ${ }^{87,97,108}$. Recently frequent consumption of fast food has been linked with $U C$ and $C D$ in a case-control study ${ }^{105}$. However, the number of exposed subjects in that study was small.

Fat consumption (quantitative and qualitative) is of interest in the light of pathophysiological hypothesis related to the inflammatory cascade in IBD, in which the arachidonic acid and cyclooxygenase mediated pathways are involved. An Italian case-control study showed that patients with $C D$, but not with $U C$, had a slightly lower intake of fat (total fat and the saturated fatty acid component) before the first disease manifestation compared to controls ${ }^{103}$. Analysing the results of dietary factors, one should realise that the pre-illness diet is of importance. Bearing in mind that in $\mathrm{CD}$ the lag between onset of symptoms and diagnosis sometimes can exceed five years, it is not surprising that the attempts to link specific dietary factors with the development of IBD have run into major difficulties.

\section{Early life influences}

Breast feeding in early life might reduce the risk of developing $U C$ and $C D$, as it stimulates growth and development of intestinal mucosa and may provide protection through increased levels of $\operatorname{IgA} A^{97,109-112}$. Results of case-control studies are controversial in this respect and, also here, one should realise the great risk of recall bias.

Perinatall infections in genetically predisposed individuals may alter the immune system, and result in clinically overt IBD later in life, after exposure to a yet undefined immunological event. In agreement with this are the findings of a Swedish case-control study showing a four-fold increased risk for IBD in children with a "health event" in the perinatal period ${ }^{95}$. These events included infections in mothers before and after delivery, and especially postnatal infections in the child, which were mainly of respiratory and gastrointestinal origin. Measles infection has been discussed in the previous paragraph.

\section{Occupation and social class}

Most, but not all, studlies report a higher incidence of IBD in people of higher socio-economic class ${ }^{97,106,113,114}$. Obviously referral bias is important in this respect and has to be ruled out if possible. IBD is generally acknowledged to be more common in urban populations, although the literature is conflicting on this point ${ }^{114}$. Transmission of infectious diseases, possibly related to IBD, occurs more often in overcrowded areas, but socio-economic factors may also play a role. It has been 
suggested by Sonnenberg, investigating the risk of IBD for different types of occupation, that work in the open air and involving physical activity is protective whereas work in air-conditioned, artificial conditions, with irregular shift work, increases the risk of $\mathrm{IBD}^{113}$.

\section{Psychosocial factors}

The belief that IBD is a psychosomatic disease dates back to the early 1950s. More recent studies have reached different conclusions. In $C D$ the prevalence of anxiety, passive dependency and depression was reported to be higher than in controls by some, but other investigators found little psychopathology ${ }^{115-118}$. One is not surprised by such findings in a chronic disease with so many uncertainties and repercussions on social life. UC patients do not show elevated levels of psychopathology ${ }^{119,120}$. Major stressful events, however, can initiate a relapse in UC, as was shown by Duffy et al. ${ }^{121}$. Stress-exposed subjects were more than twice likely to have a relapse within four to six months.

\section{Thrombogenic factors}

\section{a. Smoking and non-smoking}

During the past decade, smoking behaviour has been identified as a strong, perhaps the strongest, exogenous risk factor in IBD. In this context $U C$ and $C D$ seem to be opposites. Non-smoking is associated with $U^{122-128}$. Ex-smokers seem to be at even higher risk of developing UC than never-smokers, suggesting either a cessation of smoking due to very early symptoms of the disease or a brief induction time of the protective effect of smoking on $\mathrm{UC}^{129}$. A meta-analysis of selected studies demonstrated a dose-response pattern with a decreasing risk of UC with increasing former usage of cigarettes ${ }^{130}$. A case-control study showed that childhood exposure to passive smoking reduced the risk of UC, but not significantly ${ }^{131}$. In addition, smoking has been reported ats preventing pouchitis in patients with restorative colectomy for $\mathrm{UC}^{132}$. It has been suggested that the protective effect of smoking in UC is due to nicotine ${ }^{133}$. Clinical trials using transdermal or oral nicotine show variable results on disease activity in the acute stage, but no effect of smoking in maintaining remission ${ }^{134-136}$.

In contrast to UC, smoking appears to be dijectly associated with the development of $\mathrm{CD}^{126,130,137,138}$. This relationship is more evident for women than for men and not as strong as in $\mathrm{UC}^{124}$. No consistent dose-response relationship has been shown, but duration of smoking and childhood exposure to passive smoking both appear to be important determinants ${ }^{139}$.

Smoking behaviour is not only associated with the first outbreak of disease but also influences the clinical course of $\mathrm{UC}$ and $\mathrm{CD}$. The presence of a smoking history delays the onset of $\mathrm{UC}$, and in this group extensive inflammation is less frequent 
compared to patients with a non-smoking history ${ }^{\mathrm{J} 40-142}$. Studies using the number of hospitalizations and colectomy as a marker of disease activity report either a favourable effect of smoking or no relationship in $\mathrm{UC}^{143,144}$. In $\mathrm{CD}$, smokers have more symptoms and, after a surgical resection, the risks of clinical, endoscopic and surgical recurrence are increased in smokers compared with non-smokers ${ }^{145-147}$. One of the reasons for the observed change in male:female ratios in UC, which was once at disease with female dominance and now seems to have become a disease with a male dominance, is possibly related to the fact that men tend to give up smoking, while women start smoking ${ }^{148}$.

\section{b. Oral contraceptives}

Conflicting associations between the use of oral contraceptives and the development of IBD have been reported ${ }^{149}$-154. A recent meta-analysis of 16 selected studies found a modestly increased risk of developing $\mathrm{CD}$ in oral contraceptive users (RR: $1.44 ; 95 \% \mathrm{Cl}, 1.12-1.86$ ) but failed to demonstrate a significant association between oral contraceptive use and development of UC (RR: 1.29 ; $95 \%$ CI, $0.94-$ $1.77)^{155}$. A large population-based case-control study showed an increased risk for both diseases in women using oral contraceptives within six months before disease onset compared to never users ${ }^{156}$. Higher UC risk occurred among users of high oestrogen dose oral contraceptives, while $\mathrm{CD}$ risk was similar regardless of oestrogen potency.

\section{c. Hypothetical mechanisms of thrombogenic factors in IBD}

The oestrogen component of contraceptives is associated with an increased risk of thromboembolic disease, and risk appears to rise with increasing dose ${ }^{157}$. Persistent activation of coagulation in IBD has been shown ${ }^{158,159}$. In $C D$ vascular abnormalities are more pronounced than in UC. Wakefield et al. have proposed as a pathogenic mechanism for $\mathrm{CD}$ multifocal gastrointestinal infarctions mediated by a chronic mesenteric vasculitis ${ }^{160-162}$. The pro-coagulant effects of smoking, with subsequent vasoconstriction and infarction of the small bowel arteries, may be of importance in CD. Smoking in this context also may interact with other potentially disease-provoking factors like oral contraceptives ${ }^{161}$. The results of epidemiological studies on smoking and -to a somewhat lesser extent- of those on contraceptives are in favour of this hypothesis.

The potential mechanisms for the protective effect of smoking and the possible harmful effect of contraceptive use in the pathogenesis of UC are less clear. Smoking has a number of known effects on immune and inflammatory functions. Heavy smoking results in alterations in immunoregulatory $T$ cells, and there is also evidence that smoking increases colonic mucus production in vitro ${ }^{163.164}$. Smoking inhibits the release of leukotriene B4, thus reducing cell chemotaxis, and decreases the production of interleukin-1 from these cells, and in addition influences the 
function of circulating neutrophils ${ }^{165-167}$. Another possible mechanism is that smoking may protect by lowering the rectal blood flow in patients with $\mathrm{UC}^{168}$. Finally, an interesting theory poses that altered bile composition, by enhancing (smoking) or inhibiting (contraceptives) lhepatic P-450 enzyme, may decrease or increase UC incidence ${ }^{169}$.

\title{
Miscellaneous aetio-pathogenetic factors
}

\begin{abstract}
Allergy
A significant higher incidence of (atopic) eczema has been reported in patients with IBD or their families than in appropriate controls ${ }^{106}$. Atopic eczema is usually associated with a higher incidence of allergic rhinitis and asthma. There are many similarities between asthma and inflammatory bowel disease. Both inflammatory processes are characterised by spontaneous exacerbations and remissions, and similar inflammatory mediators contribute to their pathogenesis ${ }^{170}$. On the other hand the T-helper cell. population, of importance in the pathogenesis, in both diseases is clearly different. While in CD low levels of the anti-inflammatory Interleukins 4 and 5 are found, those Interleukins are high in asthma.
\end{abstract}

\section{Toothpaste}

Ingested materials, like talc and ingredients of toothpaste, can produce granulomatous lesions in the bowel resembling those in CD. So far the subject of toothpaste as a risk factor for CD gave rise to interesting epidemiological discussions, but has not been shown to be of real importance ${ }^{32,171 \times 173}$.

\section{Appendectomy}

Three case-control studies showed a strong negative relation between appendectomy and the development of UC ${ }^{82,106,174}$. The explanation for this inverse association is uncllear. Factors predisposing for appendicitis may protect against UC, or removal of the appendix may alter the immune response of the gut. One of these studies also showed a tendancy to a positive relation between appendectomy and $C \mathrm{D}^{\mathrm{k} 2}$. 


\section{Summary and conclusions}

What have epidemiological studies on IBD taught so far? Consistent findings are:

- A high incidence for both $C D$ and $U C$ in industrialized countries and an increase in these areas of the incidence of CD during the years 1960-1.980 followed by a plateau phase, and a more stable pattern in UC during the same period. A greater number of mild cases have probably been diagnosed recently. This also helps to explain the differences in severity and survival between community and referral centre groups.

- The male to female ratio is greater than one in $\mathrm{UC}$, and this is the opposite in CD.

- Mortality of IBD has decreased during the last decades. As young people are especially prone to develop IBD, most of those affected will have their disease for many years.

- In developing IBD genetical influences are of importance. However, epidemiological studies strongly point to possible interactions between genetically determined features and environmental or other factors. Of these exogenic factors smoking is the most consistent, being of negative influence in $\mathrm{CD}$ and protective in UC. Diet and oral contraceptives may influence disease expression, and perinatal events -like viral infections- may alter adult susceptibility.

The question remains open whether UC and CD are one disease entity. Similarities in the epidemiologic features of $U C$ and $C D$ support the idea of IBD as being one disease. Other findings suggest to divide UC and $C D$ further into subgroups: in $C D$ it has been suggested to that fibrostenotic, penetrating and inflammatory behaviour should be considered different disease entities; in UC, some groups consider ulcerative proctitis as a disease entity on its own, separating it from the proximally extending colitis. In therapeutical trials this approach has proved to be of importance and it is not inconceivable that in subgroups, as far as aetiopathogenetic mechanisms are concerned, different factors have to be looked for.

\section{Preconditions for epidemiological studies in IBD}

- Comparing disease rates between different areas and -within areas- at different time intervals can be helpful for our understanding of IBD.

- Cohort studies are gaining popularity and might also lead to valuable new insights. This is only possible if generally accepted disease definitions and comparable methods of case ascertainment are used. 
- In order to compare different studies, the incidence rates should be standardised for age and sex. Most valuable are prospective, community-based studies. The European Study on Inflammatory Bowel Disease can serve as an example.

- Population-controls should be used when studying risk factors. Single item studies are of doubtful value, and risk factors should be studied in connection with each other.

- Studying the role of possible risk factors and the effect of therapies in subgroups seems to be of interest. New genetic markers may help to differentiate between these subgroups. 


\section{References}

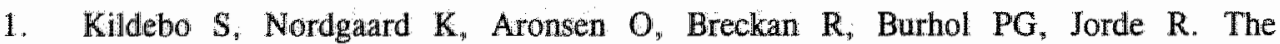
incidence of ulcerative colitis in Northern Norway from 1983 to 1986. The Northern Norwegian Gastroenterology Society. Scand J Gastroenterol 1990; 25:890-896.

2. Kildebo $\mathrm{S}$, Breckan $\mathrm{R}$, Nordgaard $\mathrm{K}$, Burhol $\mathrm{PG}$, Jorde $\mathrm{R}$. The incidence of Crohn's disease in northern Norway from 1983 to 1986. Northern Norway Gastroenterology Society. Scand J Gastroenterol 1989; 24:1265-1270.

3. Murkholm $\mathrm{P}$, Langholz $\mathrm{E}_{\text {, Nielsen }} \mathrm{OH}_{3}$ Kreiner $\mathrm{S}$, Binder $\mathrm{V}$. Incidence and prevalence of Crohn's disease in the county of Copenhagen, 1962-87: a sixfold increase in incidence. Scand J Gastroenterol 1992; 27:609-614.

4. Langholz $E$, Munkholm $P$, Nielsen $O H$, Kreiner $S$, Binder $V$. Incidence and prevalence of ulcerative colitis in Copenhagen county from 1962 to 1987 . Scand J Gastroenterol 1991; 26:1247-1256.

5. Stonnington CM, Phillips SF, Melton LJ3, Zinsmeister AR. Chronic ulcerative colitis: incidence and prevalence in a community. Gut $1987 ; 28: 402-409$.

6. Stowe SP, Redmond SR, Stormont MM, Shah AN, Chessin LN, Segal HL, et al. An epidemiologic study of inflammatory bowel disease in Rochester, New York. Hospital incidence. Gastroenterology 1990; 98:104-110.

7. Ekbom A, Helmick C, Zack M, Adami HO. The epidemiology of inflammatory bowel disease: a large, population-based study in Sweden. Gastroenterology 1991; 100:350-358.

8. Kyle J. Crohn's disease in the northeastern and northern Isles of Scotland: an epidemiological review. Gastroenterology 1992; 103:392-399.

9. Martinez Salmeron JF, Rodrigo $M$, de Teresa J, Nogueras F, Garcia Montero M, de Solla $\mathrm{C}$, et al. Epidemiology of inflammatory bowel disease in the Province of Granada, Spain: a retrospective study from 1979 to 1988 . Gut $1993 ; 34: 1207-1209$.

10. Tragnone A, Hanau C, Bazzocchi G, Lanfranchi GA. Epidemiological characteristics of inflammatory bowel disease in Bologna, Italy-incidence and risk factors. Digestion 1993; $54: 183-188$.

11. Vucelic B, Korac B, Sentic M, Milicic D, Hadzic N, Juresa V, et al. Ulcerative colitis in Zagreb, Yugoslavia: incidence and prevalence 1980-1989. Int J Epidemiol $1991 ; 20: 1043-1047$.

12. Cottone M, Cipolla C, Orlando A, Oliva L, Aiala R, Puleo A. Epidemiology of Crohn"s disease in Sicily: a hospital incidence study from 1987 to 1989 . "The Sicilian Study Group of Inflammatory Bowel Disease". Eur J Epidemiol 1991; $7: 636-640$.

13. Vucelic B, Korac B, Sentic M, Milicic D, Hadzic N, Juresa V, et al. Epidemiology of Crohn's disease in Zagreb, Yugoslavia: a ten-year prospective study. Int $J$ Epidemiol $1991 ; 20: 216-220$.

14. Ruiz V. Crohn's disease in Galicia, Spain. Scand J Gastroenterol Suppl 1989; 170:29-31. 
15. Manousos $\mathrm{ON}$, Triantaphyllidis I, Emmanoullidis $\mathrm{A}$, Papademitriou $\mathrm{C}$. Ulcerative colitis in Greece. Epidemiologic and clinical data. Scand $\mathrm{J}$ Gastroenterol Supp: $1989 ; 170: 25-26$.

16. Lee FI, Costello FT. Crohn's disease in Blackpool-incidence and prevalence 1968-80. Gut $1985 ; 26: 274-278$.

17. Mayberry JF: Crohn's disease in developing countries. Ital $\mathrm{J}$ Gastroenterol 1980; 12:324-326.

18. Mayberry JF, Mann R. Inflammatory bowel disease in rural sub-Saharan Africa: rarity of diagnosis in patients attending mission hospitals. Digestion 1989" 44:172-176.

19. Kurata JH, Kantor Fish S, Frankl H, Godby P, Vadheim CM. Crohn's disease: among ethnic groups in a large health maintenance organization. Gastroenterology $1992 ; 102: 1940-1948$.

20. Shivananda S, Mayberry JF. Epidemiology of inflammatory bowel disease. Inflammatory Bowel Disease Study Group, Royal Free Hospitall 1993; 9:560-565.

21. Calkins BM, Mendeloff AI. The epidemiology of idiopathic inflammatory bowel disease. In: Kirsner JB, Shorter RG, editors. Inflammatory Bowel Disease. 4th ed. Baltimore: Williams \& Wilkins 1995; 31-70.

22. Sonnenberg A, McCarty DJ, Jacobsen SJ. Geographic variation of inflammatory bowel disease within the United States. Gastroenterology $1991 ; 100: 143-149$.

23. Shivananda S, Lennard-Jones J, Logan R, Fear N, Price A, Carpenter L, Blankenstein van $\mathrm{M}$ and the EC-IBD Study Group. Indicence of inflammatory bowel disease across Europe: is there a difference between north and south? Results of the European collaborative study on inflammatory bowel disease (EC-IBD). Gut 1996; 39:690-697.

24. Thomas GA, Millar-Jones D, Rhodes J, Roberts GM, Williams GT, Mayberry JF. Incidence of Crohn's diseae in Cardiff over 60 years: 1986-1990 an update. Eur $\mathfrak{I}$ Gastroenterol Hepatol 1995; 7:401-406.

25. Sandler RS. Epidemiollogy of inflammatory bowel disease. In: Targan SR, Shanahan F, editors. Inflammatory bowel disease; from bench to bedside. Baltimore, Maryland: Williams \& Wilkins $1994 ; 5-32$.

26. Ekbom A Helmick C, Zack M, Adami HO. Ulcerative proctitis in central Sweden 1965-1983. A population-based epidemiological study. Dig Dis Sci 1991; 36:97-102.

27. Srivastava ED, Mayberry JF, Morris TJ, Smith PM, Williams GT, Roberts GM, ef al. Incidence of ulcerative colitis in Cardiff over 20 years: 1968-87. Gut 1992; 33:256-258.

28. Berner J, Kiaer T. Ulcerative colitis and Crohn's disease on the Faroe Islands 1964-83. A retrospective epidemiological survey. Scand J Gastroenterol 1986; $21: 188-192$.

29. Roin F, Roin J. Inflammatory bowel disease of the Faroe Islands, 1981-1988. A prospective epidemiologic study: primary report. Scand J Gastroenterol Suppl 1989; 170:44-46. 
30. Mendelloff AI. The epidemiology of chronic IBD. In: Järnerot G, editor. Inflammatory Bowel Disease. Malmo: Corona 1992; 15-35.

31. Burch RPJ, de Dombal FT, Watkinson G. Aetiology of ulcerative colitis.II. A new hypothesis. Gut 1969; 10:277-284.

32. Haug $K$, Schrumpf $E_{n}$ Halvorsen $J F$, Fluge $G$, Hamre $E$, Hamre $T$, et al. Epidemiology of Crohn's disease in western Norway. Study group of Inflammatory Bowel Disease in Western Norway. Scand J Gastroenterol 1989; 24:1271-1275.

33. Haug K, Schrumpf E, Barstad S, Fluge G, Halvorsen JF. Epidemiology of ulcerative collitis in western Norway. Scand J Gastroenterol 1988; 23:517-522.

34. Rhodes J, Rose JD. Crohn's disease in the elderly [editorial]. Br Med J Clin Res 1985; 291:1149-1150.

35. Devlin $\mathrm{HB}$, Datta $\mathrm{D}$, Dellipiana $\mathrm{AW}$. The incidence and prevalence of inflammatory bowel disease in North Tees Health District. World J Surg 1980; 4:183-193.

36. Binder V. Epidemiology, course and socio-economic influence of inflammatory bowel disease. Schweiz Med Wochenschr 1988; 118:738-742.

37. Rogers BHG, Clark LM, Kirsner JB. The epidemiology and demographic characteristics of inflammatory bowel disease: an analysis of a computerized file of 1400 patients. J Chron Dis $1971 ; 24: 743-773$.

38. Morson BC. Pathology of ulcerative colitis. In: Kirsner JB, Shorter RG, editors. Inflammatory bowel disease. Philadelphia: Lea \& Febiger 1980; 281-295.

39. Whitehead R. Pathology of Crohn's disease. In: Kirsner JB, Shorter RG, editors. Inflammatory bowel disease. Philadelphia: Lea \& Febiger 1980; 293-307.

40. Calkins BM, Mendeloff AI. Epidemiology of inflammatory bowel disease. Epidemiol Rev 1986; 8:60-91.

41. Calkins BM, Lilienfeld AM, Garland CF, Mendeloff AI. Trends in incidence rates of ulcerative colitis and Crohn's disease. Dig Dis Sci 1984; 29:913-920.

42. Mayberry JF, Rhodes J. An international study of mortality from inflammatory bowel disease. Digestion 1982; 244:73-78.

43. Qureshi H, Zuberi SJ, Banatwala N, Anwar A, Shamsi Z, Khan MN. Ulcerative colitis in Karachi. J Gastroenterol Hepatol 1989; 4:313-316.

44. Hendriksen $C$, Kreiner $S$, Binder $V$. Long term prognosis in ulcerative colitis based on results from a regional patient group from the county of Copenhagen. Gut 1985; 26:158-163.

45. Weterman IT, Biemond I, Pena AS. Mortality and causes of death in Crohn's disease. Review of 50 years' experience in Leiden University hospital. Gut 1990; 31:1387-1390.

46. Ekbom A, Hemlick CG, Zack M, Holmberg L, Adami HO. Survival and causes of death in patients with inflammatory bowel disease: a population-based study. Gastroenterology 1992; 103:954-960.

47. Weldon MJ, Maxwell JD. Lymphocyte and macrophage interleukin receptors in inflammatory bowel disease: a more selective target for therapy? Gut 1994; $35: 867-871$. 
48. Lochs $\mathrm{H}$. Consequences of aetiological hypotheses for the treatment of IBD. In. Schölmerich J, Kruis W, editors. IBD, pathophysiology as a basis of treatment. Dordrecht: Kluwer Academic Publishers 1993; 30-35.

49. Wright JP, Froggatt J, O'Keefe EA, Ackerman S, Watermeyer S, Louw J, et al. The epidemiology of inflammatory bowel disease in Cape Town 1980-1984. S Afr Med J 1986; 70:10-15.

50. Wright JP, Marks IN, Jameson C, Garisch JA, Burns DG, Kottler RE. Inflammatory bowel disease in Cape Town, 1975-1980. Part II. Crohn's disease. S Afr Med J 1983; 63:226-229.

51. Wright JP, Marks IN, Jameson C, Garisch JA, Burns DG, Kottler RE. Inflammatory bowel disease in Cape Town, 1975-1980. Part I. Ulcerative colitis. S Afr Med J 1983; 63:223-226.

52. Monk M, Mendeloff AI, Siegel CI, Lilienfeld AM. An epidemiological study of ulcerative colitis and regional enteritis among adults in Baltimore. Hospital incidence and prevalence 1960-1963. Gastroenterology 1967; 53:198-210.

53. Odes HS, Fraser D, Krawiec J. Incidence of idiopathic ulcerative colitis in Jewish population subgroups in the Beer Sheva region of Israel. Am J Gastroenterol 1987; $82: 854-858$.

54. Rozen P, Zonis J, Yekutiel P, Gilat T. Crohn's disease in the Jewish population of Tel-Aviv-Yafo. Gastroenterology 1979; 76:25-30.

55. Odes HS, Locker C, Neumann L, Zirkin HJ, Weizman Z, Sperber AD, et al. Epidemiology of Crohn's disease in southern Israel. Am J Gastroenterol 1994; 89:1859-1862.

56. Grossman A, Fireman Z, Lilos P, Novis B, Rozen P, Gilat T. Epidemiology of ulcerative colitis in the Jewish population of central Israel 1970-1980. Hepatogastroenterology 1989; 36:193-197.

57. Probert CS, Jayanthi V, Pinder D, Wicks AC, Mayberry JF. Epidemiological study of ulcerative proctocolitis in Indian migrants and the indigenous population of Leicestershire. Gut 1992; 33:687-693.

58. Jayanthi V, Probert CS, Pinder D, Wicks AC, Mayberry JF. Epidemiology of Crohn's disease in Indian migrants and the indigenous population in Leicestershire. Q J Med 1992; 82:125-138.

59. Jayanthi V, Probert CS, Pollock DJ, Baithun SI, Rampton DS, Mayberry JF. Low incidence of ulcerative colitis and proctitis in Bangladeshi migrants in Britain. Digestion 1992; 52:34-42.

60. Singer HC, Anderson JGD, Frischer H, Kirsner JB. Familial aspects of IBD. Clin Gastroenterol 1980; 9:271-277.

61. Yang HY, McElree C, Roth MP, Shanahan F, Targan SR, Rotter J. Familial empirical risks for inflammatory bowel disease: differences between Jews and non-Jews. Gut 1993; 34:517-524.

62. Roth MP, Petersen GM, McElree C, Feldman E, Rotter JI. Geographic origins of Jewish patients with inflammatory bowel disease. Gastroenterology 1989; 97:900-904. 
63. Tysk C, Riedesel H, Lindberg E, Panzini B, Podolsky D, Järnerot $G$. Colonic glycoproteins in monozygotic twins with inflammatiory bowel disease. Gastroenterology 1991; 100:419-423.

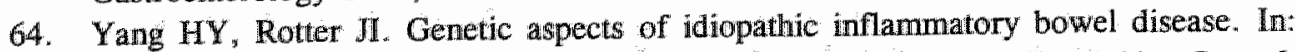
Kirsner JB, editor. Inflammatory bowel disease. 4th ed. Philadelphia: Lea \& Febiger 1993

65. Yang HY, Rotter $\mathrm{H}$. The genetics of inflanmatory bowel disease: genetic predisposition, disease markers, and genetic heterogeneity. In: Targan SR, Shanahan $\mathrm{F}$, editors. Inflanmatory bowel disease: from bench to bedside. 1st ed. Baltinore: Williams \& Wilkins 1994; 32-64.

66. Toyoda $\mathrm{H}_{3}$ Wang SI, Yang HY, Redford A, Magalong D, Tyan D, et al. Distinct associations of HLA class II genes with inflammatory bowel disease. Gastroenterology $1993 ; 104: 741-748$.

67. Oudkerk Pool M, Roca M, Reumaux D, Bouma G, Pena AS, Colombel JF, et al. The value of P-Anca as a serological marker for ulcerative colitis in different European regions. Eur J Gastroenterol Hepatol 1994; 6:399-403.

68. Shanahan F, Duerr RH, Rotter J, Yang HY, Sutherland LR, McElree C, et al. Neutrophil autoantibodies in ulcerative colitis: familial aggregation and genetic heterogeneity: Gastroenterology $1.992 ; 103: 456-461$.

69. Reumaux $\mathrm{D}$, Colombel $\mathrm{JF}_{*}$ Delecourt L, Noel LH, Cortot A, Duthilleul P. Anti-neutrophil cytoplasmic auto-antibodies (ANCA) in patients with ulcerative colitis (UC): influence of disease activity and familial study. Adv Exp Med Biol $1993 ; 336: 515-518$.

70. Duerr RH, Targan SR, Landers CJ, Sutherland LR, Shanahan F. Anti-neutrophil cytoplasmatic antibodies in ulcerative colitis. comparison with other colitides, diarrhoeal illness. Gastroenterology 1991; 100:1590-1596

71. Saxon A, Shanahan F, Landers C, Ganz T, Targan S. A distinct subset of anti-neutrophil cytoplasmatic antibodies is associated with inflammatory bowel disease. J Allergy Clin Inmunol 1990; 86:202-210.

72. Shanahan F, Landers $C_{y}$ Duerr RH, Targan SR. Neutrophil autoantibodies as disease markers for ulcerative colitis. Inmunol Res 1991; 10:479-484.

73. Seibold $F$, Klein R, Slametchika D, Weber $P$, Berg $P$, Gregor $M$. P-Anca in family members of patients with ulcerative colitis and PSC. Gastroenterology 1993; 104: A778.

74. Yang $\mathrm{P}$, Jämerot $\mathrm{G}$, Danielsson $\mathrm{D}$, Tysk $\mathrm{C}$, Lindberg E. P-Anca in monozygotic twins with inflammatory bowel disease. Gut 1995; 36:887-890.

75. Yang HY, Rotter II, Toyoda H, Landers C, Tyran D, McElree CK, et al. Ulcerative colitis: a genetically heterogeneous disorder defined by genetic (HLA class II) and subclinical (antineutrophil cytoplasmic antibodies) markers. I Clin Invest $1993 ; 92: 1080$-1084.

76. Harries AD, Baird A, Rhodes J, Mayberry JF. Has the rising incidence of Crohn's disease reached a plateau? BMJ 1982; $284: 235$.

77. Miller DS, Keighley A, Smith PG, Hughes AO, Langman MJ. Crohn's disease in Nottingham: a search for time-space clustering. Gut $1975 ; 16: 454-457$. 
78. Cave DR, Freedman LS. Seasonal variation in clinical presentation of Crohn"s disease and ulcerative colitis. Int J Epidemiol 1975; 4:317-320.

79. Tysk $C$, Järnerot $G$. Seasonal variation in exacerbations of ulcerative colitis. Scand J Gastroenterol 1993; 28:95-96.

80. Don BA, Goldacre MJ. Absence of seasonality in emergency hospital admissions for inflammatory bowel disease [letter]. Lancet 1984; 2:1156-1157.

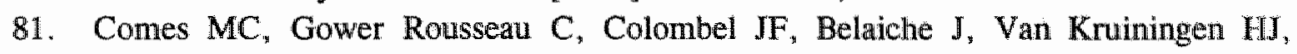
Nuttens MC, et al. Inflammatory bowel disease in married couples: 10 cases in Nord Pas de Calais region of France and Liege county of Belgium. Gut 1994; 35:1316-1318.

82. Gent AE, Hellier MD, Grace RH, Swarbrick ET, Coggon D. Inflammatory bowel disease and domestic hygiene in infancy. Lancet 1994; 343:766-767.

83. Sanderson IR, Hermon-Taylor J. Mycobacteriall disease of the gut: some impact from molecular biology. Gut 1992; 33:145-147.

84. Sanderson JD, Moss MT, Malik ZP, Tizard ML, Green EP, Hermon Taylor J. Polymerase chain reaction detects mycobacterium paratuberculosis in Crohn's disease tissue extracts. Gut 1991; 32:A572.

85. Burnham WR, Lennard-Jones JE. Mycobacterial disease as a possible cause of IBD. Lancet 1978; 2693-2696.

86. Chiodini RJ, Van Kruiningen HJ, Thayer WR, Coutu JA. Spheroblastic phase of mycobacteria isolated from patients with Crohn's disease. J Clin Microbiol 1986; 24:357-363.

87. Jewell DP. Pathogenesis of Crohn's disease: the environment revisited. Eur J Gastroenterol Hepatol 1995; 7:383-384.

88. Prantera C, Kohn A, Mangiarotti R, Andreoli A, Luzi C. Antimycobacterial therapy in Crohn's disease: results of a controlled, double-blind trial with a multiple antibiotic regimen. Am J Gastroenterol 1994; 89:513-518.

89. Graham DY, Al-Assi MT, Robinson M. Prolonged remission in Crohn's disease following therapy for mycobacterium Paratuberculosis. Gastroenterology 1995; 108:A826.

90. Afdhal NH, Long A, Lennon I, Crowe I, O'Donoghue DP. Controlled trial of antimycobacterial therapy in Crohn's disease. Clofazimine versus placebo. Dig Dis Sci 1991; 36:449-453.

91. Swift GL, Srivastawa ED, Stone R, Pullan RD, Rhodes J, Wilkinson S, et al. Controlled trial of anti-tuberculous chemotherapy for two years in Crohn's disease. Gut 1994; 35:363-368.

92. Schaffer JL, Hughes S, Linaker BD, Bakeft RD, Turnberg LA. Controlled trial of rifampicin and ethambutol in Crohn's disease. Gut 1984; 25:203-205.

93. Farmer GW, Vincent MM, Fucillo DA. Viral infection in ulcerative colitis and regional enteritis. Gastroenterology 1973; 65:8-18.

94. Ekbom A, Wakefield AJ, Zack M, Adami HO. Perinatal measles infection and subsequent Crohn's disease. Lancet 1994; 344:508-510. 
95. Ekbom A, Adami HO, Helmick CG, Jonzon A, Zack MM. Perinatal risk factors for inflammatory bowel disease: a case-control study. Am J Epidemiol 1990; 132:1111-1119.

96. Wakefield AJ, Pittilo RM, Sim R. Evidence of persistent measles virus infection in Crohn's disease. J Med Virol 1993; 39:345-353.

97. Thompson NP, Pounder RE, Wakefield AI. Perinatal and childhood risk factors for inflammatory bowel disease: a case-control study. Eur J Gastroenterol Hepatol $1995 ; 7: 385-395$

98. Thompson NP, Montgomery SM, Pounder RE, Wakefield AJ. Is measles vaccination a risk factor for inflammatory bowel disease? Lancet 1995; 345:1071-1074.

99. Thornton JR, Emmet PM, Heaton KW. Diet and Crohn's disease: characteristics of the pre-illness diet: BMJ 1979; 762-764.

100. Kasper H, Sommer H. Dietary fibre and nutrient intake in Crohn"s disease. Am J Clin Nutr 1979; 1898-1901.

101. Mayberry IF, Rhodes J. Increased sugar consumption in Crohn's disease. Digestion 1980; 323-326.

102. Thornton JR, Emmett PM, Heaton KW. Diet and ulcerative colitis. BMJ 1980; 293-294.

103. Tragnone A, Valpiani D, Miglio F, Elmi $G$, Bazzocchi $G$, Pipitone $E$, et all. Dietary habits as risk factors for inflammatory bowel disease. Eur J Gastroenterol Hepatol 1995; 47-51.

104. Järnerot $G$, Jarnmark I, Nilsson K. Sugar consumption in Crohn's disease, ulcerative collitis or irritable bowel disease. Scand J Gastroenterol 1983; 18:999-1002.

105. Persson PG, Ahlbom A, Hellers G. Diet and inflammatory bowel disease: a case-controll study. Epidemiology 1992; 3:47-52.

106. Gilat T, Hacohen D, Lilos P, Langman MJ. Childhood factors in ulcerative colitis and Crohn's disease. An international cooperative study. Scand J Gastroenterol 1987; 22:1009-1024.

107. Panza $\mathbb{E}$, Franchesi $S$, La Vecchia S, Paranzini F, Petrillo M, Decarli A, et al Dietary factors in the aetiology of inflammatory bowel disease. Ital J Gastroenterol 1987: 19:205-209.

108. Järnerot $G$. Dietary factors in inflammatory bowel disease. In: Järnerot $G$, Lennard Jones $\mathrm{NE}$, Truelove $\mathrm{SC}$, editors. Inflammatory bowel disease, Malmö: Corona Astra 1992; 53-60.

109. Koletzko S, Griffiths $A$, Corey $M$, Smith $C$, Sherman P. Infant feeding practices and ulcerative colitis in childhood. BMJ 1991; 302:1580-1581.

110. Koletzko $S$, Sherman $P$, Corey $M$, Griffiths A, Smith $C$. Role of infant feeding practices in development of Crohn's disease in childhood. BMJ 1989; 298: $1617-1618$.

111. Rigas A, Rigas B, Glassman M, Yen YY, Lan SJ, Petridou E, et al. Breast-feeding and maternal smoking in the etiology of Crohn"s disease and ulcerative colitis in childhood. Ann Epidemiol 1993; 3:387-392. 
112. Levine J. Exogenous factors in Crohn's disease. A critical review. J Clin Gastroenterol 1992; 14:216-226.

113. Sonnenberg A. Occupational distribution of inflammatory bowel disease among German employees. Gut 1990; 31:1037-1040.

114. Sandler RS, Golden AL. Epidemiology of Crohn's Disease. Clin Gastroenterol $1986 ; 8: 160-165$.

115. Whybrow PC, Kane FJ, Lipton MA. Regional ileitis and psychiatric disorder. Psychosom Med 1968; 30:209-221.

116. Cohn EM, Lederman II, Shore E. Regional enteritis and its relation to emotional dissorders. Am J Gastroenterol 1970; 54:378-387.

117. Goldberg D. A psychiatric study of patients with diseases of the small intestine. Gut $1970 ; 11: 459-465$.

118. Helzer JE, Chammas S, Norland CC, Stillings WA, Alpers DH. A study of the associaltion between Crohn's disease and psychiatirc illness. Gastroenterology 1984; 86:324-330.

119. Clouse RE, Alpers DH. The relationship of psychiatric disorder to gastrointestinal illness. Annu Rev Med 1986; 37:283-295.

120. Schwartz SP, Blanchard EB. Inflammatory bowel disease: a review of the psychological assessment and treatment literature. Ann Behav Med 1990; 12:95-105,

121. Duffy LC, Zielezny MA, Marshall JR, Weiser MM, Phillips JF, Byers TE, et al. Lag time between stress events and risk of recurrent episodes of inflammatory bowel disease. Epidemiology 1991; 2:141-145.

122. Jick $H$, Walker AM. Cigarette smoking and ulcerative colitis. N Engl J Med 1983; 308:261-263.

123. Boyko EJ, Koepsell TD, Perera DR, Inui TS. Risk of ulcerative colitis among former and current cigarette smokers. N Engl J Med 1987; 316:707-710.

124. Logan RF, Edmond M, Somerville KW, Langman MJ. Smoking and ulcerative colitis. Br Med J Clin Res 1984; 288:751-753.

125. Silverstein MD, Lashner BA, Hanauer SB. Cigarette smoking and ulcerative colitis: a case-control study. Mayo Clin Proc 1994; 69:425-429.

126. Persson $\mathrm{PG}$, Ahlbom A, Hellers G. Inflammatory bowel disease and tobacco smoke-a case-control study. Gut 1990; 31:1377-1381.

127. Lorusso D, Leo S, Misciagna $G$, Guerra V. Cigarette smoking and ulcerative colitis. A case control study. Hepatogastroenterology 1989; 36:202-204.

128. Harries AD, Baird A, Rhodes J. Non-smoking: A feature of ulcerative colitis. BMJ $1982 ; 284: 706$

129. Franchesi S, Panza E, La Vecchia C, Parazzini F, Decarli A, Bianchi Porro G. Nonspecific inflammatory bowel disease and smoking. Am J Epidemiol 1987; 125:445-452.

130. Calkins BM. A meta-analysis of the role of smoking in inflammatory bowel disease. Dig Dis Sci 1989; 34:1841-1854. 
131. Sandler RS, Sandler DP, McDonnell CW, Wurzelmann JI. Childhood exposure to environmental tobacco smoke and the risk of ulcerative colitis. Am J Epidemiol $1.992 ; 135: 603-608$.

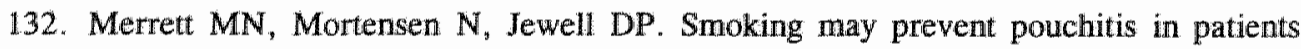
with restorative proctocolectomy for ulcerative colitis. Gastroenterology 1993; 104: A743.

133. Roberts CJ, Diggle R. Non smoking: a feature of ulcerative colitis. BMJ 1982; $285: 440$.

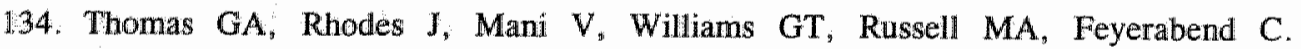
Transdermal nicotine as maintenance therapy for ulcerative colitis. $N$ Engl J Med $1995 ; 332: 988-92$.

135. Pullan RD, Rhodes J, Ganesh S, Mani V, Morris IS, Williams GT, et al. Transdermal nicotine for active ulcerative colitis. N Engl J Med 1994; 330:811-815.

136. Lashner BA, Hanauer SB, Silverstein MD. Testing nicotine gum for ulcerative colitis patients. Experience with single-patient trials. Dig Dis Sci 1990; 35:827-832.

137. Lindberg E, Tysk C, Andersson K, Järnerot G. Smoking and inflammatory bowel disease. A case control study. Gut $1988 ; 29: 352-357$.

138. Silverstein $\mathrm{MD}$, Lashner $\mathrm{BA}$, Hanauer $\mathrm{SB}_{3}$ Evans $\mathrm{AA}$, Kirsner JB. Cigarette smoking in Crohn's disease. Am J Gastroenterol 1989; 84:31-33.

139. Srivastava ED, Rhodes $\mathrm{J}$, Avramidis $\mathrm{P}$, Mayberry JF. Smoking and ulcerative colitis: a community study. Int J Colorectal Dis 1993; 8:71-74.

140. Motley RJ, Rhodes J, Kay $S_{*}$ Morris TJ. Late presentation of ulcerative colitis in ex-smokers. Int J Colorectal Dis 1988; 3:171-175.

141. Benoni C, Nilsson A. Smoking habits in patients with inflammatory bowel disease. A case- control study. Scand J Gastroenterol 1987; 22:1130-1136.

142. Samuelsson SM, Ekbom A, Zack M, Helmick CG, Adami HO. Risk factors for extensive ulcerative colitis and ulcerative proctitis: a population-based case-control study. Gut $1991 ; 32: 1526-1530$.

143. Benoni $C$, Nilsson A. Smoking habits in patients with inflammatory bowel disease. Scand J Gastroenterol 1984; 19:824-830.

144. Boyko EJ, Perera DR, Koepsell TD, Keane EM, Inui TS. Effects of cigarette smoking on the clinical course of ulcerative colitis. Scand J Gastroenterol 1988 ; 23:1147-1152.

145. Cottone M, Rosselli M, Orlando A, Oliva L, Puleo A, Cappello M, et al. Smoking habits and recurrence in Crohn's disease. Gastroenterology 1994; 106:643-648.

146. Sutherland LR, Rameharan S, Bryant H, Fick G. Effect of cigarette smoking on recurrence of Crohn"s disease. Gastroenterology 1990; 98:1123-1128.

147. Duffy LC, Zielezny MA, Marshall JR, Weiser MM, Byers TE, Phillips JF, et al. Cigarette smoking and risk of clinical relapse in patients with Crohn's disease. Am J Prev Med 1990; 6:161-166.

148. Tysk $\mathrm{C}$, Järnerot $\mathrm{G}$. Has smoking changed the epidemiology of ulcerative colitis? Scand J Gastroenterol 1992; 27:508-512.

149. Katschinski B, Fingerle D, Scherbaum B, Goebell $H$. Oral contraceptive use and cigarette smoking in Crohn's disease. Dig Dis Sci 1993; 38:1596-1600. 
150. Sandler RS; Wurzelmann Л, Lyles CM. Oral contraceptive use and the risk of inflammatory bowel disease. Epidemiology 1992; 3:374-378.

151. Lashner BA, Kane SV, Hanauer SB. Lack of association between oral contraceptive use and ulcerative colitis. Gastroenterology 1990; 99:1032-1036.

152. Logan RF, Kay CR. Oral contraception, smoking and inflanmatory bowel diseasefindings in the Royal College of General Practitioners Oral Contraception Study. Int J Epidemiol 1989; 18:105-107.

153. Lashner BA, Hanauer SB. The absence of an association between oral contraceptive use and ulcerative colitis in patients [letter]. Gastroenterology 1991; 100:1784

154. Lashner BA, Kane SV, Hanauer SB. Lack of association between oral contraceptive use and Crohn's disease: a community-based matched case-control study. Gastroenterology 1989; 97:1442-1447.

155. Godet PG, May GR, Sutherland LR. A meta-analysis of the role of contraceptive agents in inflammatory bowel disease. Gastroenterology 1994; 106:A689.

156. Boyko EJ, Theis MK, Vaughan TL, Nicol-Blades B. Increased risk of inflammatory bowel disease associated with oral contraceptive use. Am J Epidemiol 1994; 140:268-278.

157. Gerstman BB, Piper JM, Freiman JP, Tomita DK, Kennedy DL, Ferguson WJ, et al. Oral contraceptive oestrogen and progestin potencies and the incidence of deep venous thromboembolism. Int J Epidemiol 1990; 19:931-936.

158. Hudson M, Hutton RA, Wakefield AJ, Sawyerr AM, Pounder RE. Evidence for activation of coagulation in Crohn's disease. Blood Coag Fibrin 1992; 3:773-778.

159. Vecchi M, Cattaneo $M$, de Franchis R, Mannuchi PM. Risk of thromboembolic complications in patients with inflammatory bowel disease. Study of hemostasis measurements. Int J Clin Lab Res 1991; 21:165-170.

160. Wakefield AJ, Dhillon AP, Rowles PM, Sawyerr AM, Pittilo RM, Lewis AAM, et al. Pathogenesis of Crohn's disease: multifocal gastrointestinal infarction. Lancet 1989; (2)1057-1062.

161. Wakefield AJ, Sawyerr AM, Hudson M, Dhillon AP, Pounder RE. Smoking, the oral contraceptive pill, and Crohn's disease. Dig Dis Sci 1991; 36:1147-1150.

162. Wakefield AJ, Sankey EA, Dhillon AP, Sawyerr AM, More L, Sim R, et al. Granulomatous vasculitis in Crohn's disease. Gastroenterology 1991; 100:1279-1287.

163. Miller B, Goldstein G, Murphy M, Ginns LC. Reversible alterations in immunoregulatory $\mathrm{T}$ cells in smoking; Analysis by monoclonal antibodies and flow cytometry. Chest $1982 ; 82: 526-529$.

164. Cope GF, Heatly RV, Kelleher JK. Smgking and colonic mucus in ulcerative colitis. BMJ 1986; 293:481.

165. Tardif $\mathrm{J}$, Borgeat $\mathrm{P}$, Laviolette $\mathrm{M}$. Imhibition of human alveolar macrophage production of leukotriene $\mathrm{B} 4$ by acute in vitro and in vivo exposure to tobacco smoke. Am J Resp Cell Mol Biol 1990; 2:155-161.

166. Yamaguchi E, Okazi N, Itoh A, Abe S, Kawakami Y, Okuyama H. Interleukin-1 production by alveolar macrophages is decreased in smokers. Am Rev Resp Dis $1989 ; 140: 397-402$. 
167. Noble RC, Penny BB. Comparison of leucocyte count and function in smoking and non-smoking young men. Infect Immun 1975; 12:550-555.

168. Srivastava ED, Barton JR, O'Mahony S, Phillips DI, Williams GT, Matthews $N$, et al. Smoking, humoral immunity, and ulcerative colitis. Gut 1991; 32:1016-1019.

169. Crotty B. Ulcerative colitis and xenobiotic metabolism. Lancet 1994; 343:35-38.

170. Rachmilewitz D. Inflammatory bowel disease: concept or puzzel. In: Meyer zum Büschenfelder KH, Paumgartner C, Schölmerich $J$, editors. Perspectives in gastroenterology, current facts and future trends. Munich: Urban \& Schwartzenberg 1995; 97-99.

171. Sullivan SN. Hypothesis revisited: toothpaste and the cause of Crohn's disease. Lancet 1990; 336:1096-1097.

172. Anonymous. Toothpaste and Crohn's disease [letter]. Lancet 1990; 336:1580-1582.

173. Anonymous. Toothpaste and Crohn's disease [letter]. Lancet 1990; 336:1382

174. Rutgeerts P, D'Haens G, Hiele M, Geboes $\mathrm{K}$, Vantrappen G. Appendectomy protects against ulcerative colitis. Gastroenterology 1994; 106:1251-1253.

175. Lindberg $\mathrm{E}$, Järnerot $\mathrm{G}$. The incidence of Crohn's disease is not decreasing in Sweden. Scand $J$ Gastroenterol $1991 ; 26: 495-500$.

176. Tysk C, Järnerot $G$. Ulcerative proctocolitis in Orebro, Sweden. A retrospective epidemiologic study, 1963-1987. Scand J Gastroenterol 1992; 27:945-950.

177. Lee FI, Nguyen-Van-Tam S. Prospective study of incidence of Crohn's disease in northwest England: no increase since the late 1970's. Eur J Gastroenterol Hepatoll $1994 ; 6: 27-31$.

178. Rose JD, Roberts GM, Williams G, Mayberry JF, Rhodes J. Cardiff Crohn's disease jubilee: the incidence over 50 years. Gut 1988; 29:346-351.

179. Shivananda S, Pena AS, Nap M, Weterman IT, Mayberry JF, Ruitenberg $\mathbb{E J}$, et all. Epidemiology of Crohn's disease in Regio Leiden, The Netherlands. A population study from 1979 to 1983. Gastroenterology 1987; 93:966-974.

180. Brown JS, Humphreys WG, Parks TG. Some clinical aspects of Crohn's disease in Northern Ireland: an aid to earlier diagnosis? J $\mathrm{R}$ Coll Gen Pract 1988; 38:549-551.

181. Russel MGVM, Brummer R, Limonard C, Dorant E, Stockbrugger R. Incidence and prevalence of inflammatory bowel disease in South Limburg, The Netherlands. Neth J Med 1994; $45:$ A32

182. Gower Rousseau C, Salomez JL, Dupas JL, Marti R, Nuttens MC, Votte A, et al. Incidence of inflammatory bowel disease in northern France (1988-1990). Gut 1994; $35: 1433-1438$.

183. Goebell H. Dirks E, Förster S, Strey B, Quebe-Fehling E. A prospective analysis of the incidence and prevalence of Crohn's disease in an urban population in Germany. Eur J Gastroenterol Hepatol 1994; 6:1039-1046.

184. Dirks E, Forster S, Thom M, Quebe Fehling E, Goebell H. [Prospective study of the incidence and prevalence of ulcerative colitis in a large urban population in Germany (western Ruhr area)] Prospektive Untersuchung von Inzidenz und Pravalenz der Colitis ulcerosa in einer Grossstadtbevolkerung in Deutschland (Westliches Ruhrgebiet). Z Gastroenterol 1994; 32:332-337. 
185. Trallori $G$, $D^{3}$ Albasio $G$, Palli $D$, Bardazzi $G$, Cipriani $F$, Frittelli $G$, at al. Epidemiology of inflammatory bowel disease over a 10-year period in Florence (1978-1987). Ital J Gastroenterol 1991; 23:559-563.

186. Delcore R, Eisenach JB, Payne KM, Bhatia P, Forster J. Risk of occult carcinomas in patients undergoing orthotopic liver transplantation for end-stage liver disease secondary to primary sclerosing cholangitis. Transplant Proc 1993; 25:1883-1884.

187. Baron TH, Truss $\mathrm{CD}$, Elson $\mathrm{CO}$. Low-dose oral methotrexate in refractory inflammatory bowel disease. Dig Dis Sci 1993; 38:1851-1856.

188. Tsianos $\mathrm{EV}$, Masalas $\mathrm{CN}$, Merkouropoulos $\mathrm{M}$, Dalekos $\mathrm{GN}$, Logan RF. Incidence of inflammatory bowel disease in north west Greece: rarity of Crohn's disease in an area where ulcerative colitis is common. Gut 1994; 35:369-372.

189. Odes HS, Fraser D, Krawiec J. Ulcerative colitis in the Jewish population of southern Israel 1961-1985: epidemiological and clinical study. Gut 1987; 28:1630-1636.

190. Gollop JH, Phillips SF, Melton LJ3, Zinsmeister AR. Epidemiologic aspects of Crohn's disease: a population-based study in Olmsted County, Minnesota, 1943-1982. Gut $1988 ; 29: 49-56$. 


\section{Chapter Ib}

\section{Introduction}

\section{Measuring quality of life in Inflammatory Bowel Disease}

MGVM Russel, DMFM van der Heijde, RW Stockbrügger 


\section{The impact of IBD}

Crohn's disease (CD) and ulcerative colitis (UC) are two chronic gastrointestinal diseases of unknown origin. The effectiveness of medical and surgical therapy remains limited. Few patients die as a result of their Inflammatory Bowel Disease (IBD). However, many patients pay frequent visits to their general practitioner and specialist. Some require recurrent hospitalizations for problems due to their intestinal disease. This might cause work absenteeism, as well as stress due to uncertainties about future health.

Until recently, measuring the impact of IBD was almost exclusively performed by measurement of clinical disease activity, using activity indices or endoscopic appearance in clinical trials ${ }^{1-4}$. Recent investigations show that measures of disease activity for IBD are insensitive and discrepant with patient perceptions of their health status ${ }^{5-7}$. Quality of life measures such as functional status and diseaserelated concerns correlate better with scores of well-being and health care utilisation than the physician's rating of disease activity".

Health-related quality of life (HRQOL), also called health status, is a global concept that incorporates the patients' perceptions, attributions, and daily level of function in response to an illness. HRQoL is influenced by social, cultural, psychological, and disease-related factors and differs from measurement of symptoms and signs in that evaluation includes psychosocial as well as disease-related factors ${ }^{5}$. Typical areas of HRQoL which are evaluated include well-being, pain and discomfort, body image, sexuality, ability to perform activities of daily living, participation in social or recreational activities, ability to work, to attend school and to engage in personal relationships ${ }^{9}$. Standardised instruments have been developed during the last decade to measure various aspects of HRQoL. Three main types of instruments include global assessments, generic instruments and disease-specific instruments (Table 1b.1).

\section{Global measures}

The simplest approach is to use a single question, for example: "How would you rate your general well-being?" The response can be rated on a scale such as "excellent-good-fair-below average-poor". The response provides a clinically relevant global measure that is a strong predictor of physician visits for patients with $\mathrm{IBD}^{7}$. The major disadvantage of a global measure is that it cannot identify the reasons for good or poor HRQoL. 
Table 1b.1 Types of HRQDL measures used in Inflarnmatory Bowel Disease

\begin{tabular}{|c|c|c|}
\hline HRQoL & Description & Comments \\
\hline \multirow[t]{3}{*}{ Global assessments } & Unidimensional & $\begin{array}{l}\text { Unable to identify factors leading to } \\
\text { positive /negative oucome }\end{array}$ \\
\hline & Example & \\
\hline & - "good", "fair", "poor" & \\
\hline \multirow[t]{4}{*}{ Generic measures } & Multidimensional. & $\begin{array}{l}\text { lnsensitive to subtle changes with } \\
\text { time }\end{array}$ \\
\hline & Examples & \\
\hline & - Sickness Impact Profile & \\
\hline & - Nottingham Health Profile & \\
\hline \multirow[t]{7}{*}{$\begin{array}{l}\text { Disease-specific } \\
\text { instruments }\end{array}$} & $\begin{array}{l}\text { Multidimensional } \\
\text { Disease specific }\end{array}$ & $\begin{array}{l}\text { Most sensitive to detect important } \\
\text { clinical changes }\end{array}$ \\
\hline & Examples & \\
\hline & - IBDQ & \\
\hline & - Cleveland Clinic Questionnaire & \\
\hline & - Rating Form of IBD Patients & \\
\hline & Concerns & \\
\hline & - UC/CD Health Status Scales & \\
\hline
\end{tabular}

\section{Generic measures}

Generic measures evaluate HRQoL independent of the specific features of the disease and permit comparisons among diseases, populations, or interventions. In contrast to global measures these are multidimensional instruments, incorporating several domains of experience and behaviour, such as perceptions of disease, or physical or psychological functioning ${ }^{10}$. There are two basic types of generic measures: utility measures and health profiles ${ }^{11-13}$.

Utility measures relate self-perception to a reference point. For example the "Time Trade-Off Technique" evaluates the patiegat's perception of existing health compared with death ${ }^{14}$. The score ranges from 0.0 (equal to death) to 1.0 (full health) and patients choose between living in the present health with all its problems and living a shorter life span but in perfect health. A utillity measure is, similar to global measures, more useful as an evaluative rather than a discriminative measure because the factors leading to the score are not known ${ }^{11}$. The Sickness Impact Profile (SIP) is an example of a commonly used health profile, which has been used to study QoL in $\mathrm{CD}$. Drossman showed that patients 
with IBD had on the overall scale a poorer HRQoL than a random sample of patients with obesity, but a better HRQoL than patients with rheumatoid arthritis, chronic obstructive pulmonary disease, or chronic back pain ${ }^{6}$. Psychological dysfunction appeared to be worse in patients with $C D$ than in those with ulcerative colitis (UC).

Generic measures of HRQoL focus on activities of daily living such as eating and bathing, and fail to emphasise health problems more relevant to the young population with IBD, such as the consequences of blood loss, loose stool or abdominal pain ${ }^{15}$. They may therefore be too insensitive to measure true changes in clinical trials employing a therapeutic intervention.

\section{Disease specific measures in IBD}

Disease specific questionnaires are multidimensional instruments composed of patient-generated problems, and are the most sensitive instruments for detecting change over time or after intervention ${ }^{9}$. They evaluate special states and concerns of patients having a particular disease. Four disease-specific questionnaires have recently developed to be used in IBD: "The Cleveland Clinic Questionnaire", "The Rating Form of IBD Patient Concerns", "The UC/CD Health Status Scale", and the "Inflammatory Bowel Disease Questionnaire (IBDQ)". The Cleveland Clinic Questionnaire evaluates activities of daily living rather than medical symptoms and the items successfully discriminated patients with milder and more severe disease ${ }^{16}$. The Rating Form of IBD Patient Concerns can help clinicians to easily obtain information about the most important worries and concerns of patients with $\mathrm{IBD}^{17}$. The UC/CD Health Status Scale was developed to discriminate mild from severe illness and has shown to be a stronger predictor of outcome than the $C D$ Activity
Index $x^{4.18}$.

The Inflammatory Bowel Disease Questionnaire (IBDQ), a disease-specific QoL questionnaire, was developed by Guyatt et al. at McMaster University in Canada to measure treatment effects in clinical trials. This well-validated questionnaire has also been used in the South Limburg IBD Registry. During the formulation of the IBDQ, patients as well as health care providers identified 150 problems experienced by patients with $\mathrm{CD}$ or $\mathrm{UC}$, which were ranked by the patients according to severity and frequency. The most notable problems were intestinal symptoms, systemic symptoms and emotional dysfunction, whereas social dysfunction appeared less disabling than the other categories. The final questionnaire contained 32 items within four dimensions (bowel, systemic, social and emotional). Responses were graded on a seven-point Likert scale from 7 (not a problem) through 1 (a very severe problem). The questionnaire is psychometrically sound and has been shown to be reproducible, stable, and responsive to change in 
an IBD population ${ }^{19}$.

\section{Validation of measurements}

All types of instruments need to be valid (measure what they are supposed to measure), reliable (give comparable result if measured repeatedly), discriminative (able to detect differences between groups of patients with different stages of diseases), and sensitive to change (able to measure change over time) ${ }^{11,20}$. Since psychosocial determinants are not accessible through laboratory tests, validation rests with the patient ${ }^{5}$. Only two European countries have English (the language being used in most HRQoL instruments in IBD) as their native language. For other countries to be able to set up or participate in international clinical trials, it is necessary to either use a validated translation of the instrument or to develop a new instrument. To use a questionnaire like the IBDQ in respondents with a native language other than English requires translation, back-translation, and reestablishing the validity and reliability within the new national context ${ }^{20}$.

\section{Conclusions}

Clinicians and investigators in the field of IBD have come to realise that diseaserelated biological measures such as laboratory findings, histopathology, endoscopic/radiological findings do not adequately reflect the health status of patients with $\mathrm{CD}$ and $\mathrm{UC}^{10}$. The evaluation of HRQoL can broaden our understanding of the impact of these disorders in a manner that cannot be accomplished through traditional methods. HRQoL is important for measuring the impact of chronic diseases. At present there are few well validated disease specific QoL instruments. Most HRQoL instruments are developed to be used in clinical trials, but it might be worthwhile to investigate their use in daily patient care and to study the influence of environmental factors on disease outcome. Their use beyond clinical trials and in countries with native languages other than English remains to be elucidated.

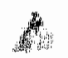




\section{References}

1. Harvey RF, Bradshaw JM. A simple index of Crohn's disease activity. The Lancet 1980; 8:514.

2. Hodgson $\mathrm{HJ}$, Bhatti $\mathrm{M}$. Assessment of disease activity in ulcerative colitis and Crohn's disease. Inflam Bow Dis 1995; 1:(2)117-134.

3. Camilleri $M$, Proana $M$. Advances in the assessment of disease activity in inflammatory bowel disease. Mayo Clin Proc 1989;64:800-807.

4. Best WR, Becktel JM, Singleton JW, Kern F, Jr. Development of a Crohn's disease activity index. National Cooperative Crohn's Disease Study. Gastroenterol 1976; $70.439-444$.

5. Garrett JW, Drossman DA. Health status in inflammatory bowel disease. Biological and behavioral considerations. Gastroenterol 1990; 99:90-96.

6. Drossman DA, Patrick DL, Mitchell CM, Zagami EA, Appelbaum MI. Healthrelated qualicy of life in inflammatory bowel disease. Functional status and patient worries and concerns. Dig Dis Sci 1989; 34:1379-1386.

7. Drossman DA, Leserman J, Mitchell CM, Li ZM, Zagami EA, Patrick DL. Health status and health care use in persons with inflammatory bowel disease. A national sample. Dig Dis Sci 1991; 36:1746-1755.

8. Drossman DA. Measuring quality of life in inflammatory bowel disease. Pharmacoeconomics 1994; 6 (6):578-580.

9. Irvine EJ. Measuring health-related quality of life in IBD. In: Tijtgat GNJ, Bartelsman JFWM, Deventer van SJH, editors. Inflammatory Bowell Diseases, Falk Symposium 85. Dordrecht, Boston, London: Kluwer Academic Publishers 1995; 319-333.

10. Drossman DA. Quality of Life issues in Crohn's disease. In: Prantera C, Korelitz B, editors. Crohn's disease. New York: Marcel Dekker 1996; 445-452.

11. Guyatt GH, Feeny DH, Patrick DL. Measuring health-related quality of life. Ann Intern Med 1993; 118:622-629.

12. Guyatt GH, Veldhuyzen Van Zanten SJ, Feeny DH, Patrick DL. Measuring quality of life in clinical trials: a taxonomy and review. Can Med Assoc J 1989; 140:1441-1448.

13. Patrick DL, Deyo RA. Generic and disease-specific measures in assessing health status and quatity of life. Med Care 1989; 27:S217-S232.

14. Torrance GW, Thomas WH, Sacket DL. A utility maximization model for evaluation of health care programs.

15. Irvine EJ. Quality of life measurement in inflammatory bowel disease. Scand J Gastroenterol Suppl 1993; 28:36-39.

16. Farmer RG, Easley KA, Farmer JM. Quality of life assessment by patients with inflammatory bowel disease. Cleve Clin J Med 1992; 59:35-42.

17. Drossman DA, Leserman J, Li ZM, Mitchell CM, Zagami EA, Patrick DL. The rating form of $\mathbb{L B D}$ patient concerns: a new measure of health status. Psychosom Med 1991; 53:701-712. 
18. Drossman DA, Li Z, Leserman J, Patrick DL. Ulcerative colitis and Crohn's disease health status scales for research and clinical practice. I Clin Gastroenterol 1992; 15:104-112.

19. Guyatt GH, Mitchell A, Irvine EJ, Singer J, Williams N, Goodacre R, et al. A new measure of health status for clinical trials in inflammatory bowel disease. Gastroenterol 1989; 96:804-810.

20. Streiner DL, Norman GR. Devising the items. In: Streiner DL, Norman GR, editors. Health measurement scales. A practical guide to their development. 2 nd ed. New York: Oxford University Press 1995; 15-27. 


\section{Chapter Ic}

\section{Introduction}

\section{Thesis outline and aims of the study}

MGVM Russel, DMFM van der Heijde, RW Stockbrügger 


\section{Thesis outline and aims of the study}

The present thesis reports the development of a population-based Inflammatory Bowel Disease Registry in South Limburg, The Netherlands (Chapter II). This Registry has enabled us to prospectively study the incidence of Inflammatory Bowel Disease (IBD) and to investigate genetic and environmental risk factors. The following aims are addressed in this thesis:

\section{Frequency of IBD in the study area}

- To prospectively investigate the incidence and the clinical features at presentation of patients with Inflammatory Bowel Disease living in South Limburg, The Netherlands (Chapter III)

- To assess the quality of the calculated incidence data, using the Registration Network of General Practitioners (RNH) as a reference (Chapter III).

\section{Genetic and environmental risk factors of IBD}

- To study familial aggregation of Inflammatory Bowel Disease in a well-defined selected group of the prevalent and incident patients registered at the IBD Registry South Limburg (Chapter IV).

- To study a possible association between 'modern life nutritional factors' and the risk to develop IBD in recently diagnosed patients using multiple logistic regression analysis to minimise confounding by other risk factors (Chapter $\mathbf{V}$ ).

- To further elucidate the role of appendectomy as a possible factor influencing the development of ulcerative colitis and in Crohn's disease, in a pairwise matched case-control study (Chapter VI).

- To define the role of smoking and disease characteristics at presentation and disease development during the first year of follow-up in a large cohort of incident European IBD patients (Chapter VII). To address this question, data of the European Collaborative Study on the incidence of IBD, a concerted action of twenty European Centres, have been used. Part of the patient data originate from IBD patients registered at the South Limburg IBD Registry who were diagnosed between October 1991 and October 1993.

The IBD patient questionnaire, a part of the South Limburg IBD Registry, was also developed to investigate Health Related Quality of Life (HRQOL) in IBD patients. The subject is introduced in Chapter Ib. In this thesis the results of two studies on quality of life are described, which had the following aims: 
- To validate the Dutch translation of the Inflammatory Bowel Disease Questionnaire (IBDQ), to be able to use this instrument in clinical trials in the Dutch-speaking IBD population (Chapter VIII).

- To investigate the usefulness of the validated Dutch IBDQ in studying the influence of risk factors on the course of disease. More specifically: to determine to what extent smoking influences HRQoL in IBD patients (Chapter $\mathbf{L X )}$.

The data that have been generated by the various studies are discussed in more detail and in the light of information from current literature in Chapter $\mathbf{X}$. 


\section{Chapter II}

\section{Data management of the South Limburg Inflammatory Bowel Disease Registry}

\section{'IBD South Limburg'}

MGVM Russel 


\section{Introduction}

Inflammatory Bowel Disease (IBD) is a summarising denominator for ulcerative colitis (UC) and Crohn's disease (CD). The cause of IBD is unknown. Most data on the clinical course and outcome of UC and $C D$ originate from referral centres with a special interest in IBD. After a period of progression during the sixties and seventies, the incidence of $C D$ in the Western world seems to have reached a plateau, and in the same time period the incidence rate for UC has stabilised in northern Europe and North America.

UC is primarily a mucosal disease involving the colon and rectum. It is characterised by abdominal cramps, rectal bleeding, diarrhoea, urgency, and systemic signs of inflammation. $\mathrm{CD}$, a transmural inflammation, can occur in every part of the gastrointestinal tract, but is mainly localised in the ileocolonic area. Signs of CD include narrowing and obstruction of the bowel, abscess and fistula formation, and sometimes perforation. Systemic problems involving the eyes, joints, skin, and hepatobiliary system are also associated with IBD.

There is no established cure for either disease and current therapy is supportive, immunosuppressive, and non-specific. Research on the cause(s) of IBD focuses on genetics, environment (including diet), circulatory factors and immunology.

Given this background of IBD, a population-based Inflammatory Bowel Disease Registry was established in 1991 in collaboration between the Departments of Gastroenterology / Hepatology and the MEMIC (Centre for Data and Information Management, University of Maastricht). The primary objective was to prospectively study the incidence of IBD and to investigate risk factors within a stable population in a large well-defined geographical and administrative area identified as South Limburg. Beyond this, the protocol of the study was also designed to study clinical features and quality of life in IBD. Secondary aims of the Registry were stimulation of the co-operation between clinicians in the field of gastroenterology and foundation of a study base for other clinically-orientated studies in IBD.

\section{Background area and population}

South Limburg is located in the south-east of The Netherlands and is a well-defined geographic entity, which bounds on Germany to the east and on Belgium to the south and west, while the northern border of the area is very narrow.

The region had an average population of 642.240 during the 1991-1994 period. The health care system in The Netherlands is regionally organised. In South Limburg there are six hospitals. Besides the University Hospital in Maastricht, the general district hospitals of Heerlen and Sittard, and three smaller associated 
hospitals (Geleen, Kerkrade and Brunssum) also participated in the study. IBD patients are normally referred to these hospitals for out- and in-patient care by about 300 general practitioners working in the area. To our knowledge, no patients with IBD living in the study area are treated in private practices, and only a small minority in hospitals outside the study area or abroad.

\section{Participation of clinicians, general practitioners, and patients}

During the preparatory period, clinicians treating IBD patients in the study area were visited by the main investigators and were asked on their opinion about the project and whether they were willing to actively participate in the study. Since most of the clinicians were enthusiastic about the basic idea, the next step was to visit the general practitioners. During the various discussions with representatives of the general practitioners, it became evident that it would almost be impossible to actively involve all general practitioners in the area. Hence it was decided to cooperate with the Registration Network of General Practices (RNH) in South Limburg instead. This registry contains files with most diagnoses, including IBD and it subgroups, of 47.850 patients $(7.5 \%$ ) of the total population living in the study area known to 35 general practitioners who have direct electronic connection with the RNH. Finally, as an important step, meetings with representatives of the Crohn's and colitis patient association were organised to discuss the usefulness of a regional IBD Registry.

\section{Development of the IBD Registry}

The second objective was to define a model of a successful IBD registry that included

a) a patient registry form (Appendix 1), which should be easy and quick to complete by specialists

b) a patient questionnaire (Appendix 2) that included detailed demographic characteristics, a family history of IBD, information on potential environmental risk factors, and instruments to measure quality of life and quality of care

c) a medical data form (Appendix 3) to record relevant medical data of the first six months after the first visit to the specialist

d) follow-up medical data forms to be used at the period after the first six months of IBD

e) follow-up patient questionnaires

f) a tentative data-entry system 
g) a clatabase (the 'Rolodex') as the only source of personal data such as name, address, and general practitioner of the participants etc., which should be capable of connecting the forms mentioned under a to e and of relating all forms with the purpose of knowing when to send out the different forms to patients and investigators of the study.

The MEMIC had a major role in developing the research structure and the patient data forms. All forms were validated in a selected group of IBD patients in collaboration with the Crohn's and Ulcerative Colitis Association in South Limburg. The IBD Registry was subsequently announced at the Dutch Person Registration Office and approval was given to collect patient data. All patients had to give informed consent before registration could take place. In the event that no informed consent was obtained, only non-traceable information was recorded to be able to study the incidence of IBD. Subsequently data entry of the patient registry form in the Rolodex was performed at the University Hospital of Maastricht after encoding of the patient data forms by the research assistant. Data entry of the encoded forms was then done at the MEMIC. To minimize mistakes, all forms were entered twice in the system by different data-entry employees. The registration of the first patient started on 1 October 1991.

\section{Registry Form}

All physicians and surgeons practising in the area and known to treat IBD patients were supplied with Registry forms. They were asked to report all new diagnosed (incident) patients with IBD and as many patients as possible with known IBD before the start of the Registration (prevalent group). Guidelines for the definition of the subgroups of IBD according to the criteria of Lennard-Jones and Truelove and Witts were enclosed in all registry forms. In addition to demographic data, the specialist was asked to complete four questions on the diagnosis and first complaints of the patient. The registry form is the only data file that contains fields which could specifically identify any patient. An unique IBD acquisition number is assigned to each record and used to link the data files. The patient has to sign that he or she had given informed consent to participate in the study on this form and the medical chart of the patient is marked with a sticker to indicate participation in
the study.

\section{Patient Questionnaire}

Within six months after registration all patients received the patient questionnaire. In case of non-response, the research assistant approached the patients by mail and as a second step by means of a phone call. 


\section{Medical Data Forms}

Senior medical students were trained by the investigator to complete the medical data forms and follow-up medical data forms of the IBD patients at the hospital of registration. After return, all forms were controlled by the main investigator and in case of doubt the treating physician was contacted to obtain reliable data. The diagnosis according to the opinion of the main investigator, also using the standardised criteria of disease definition, was added to the form.

\section{Database management}

Personal data of the patients are stored in a database ('Rolodex"), which links all the forms by the assignment of an IBD acquisition number to each patient. The 'Rolodex' automatically checks whether the patient has already been registered and whether the patient actually lives within the study area. After encoding of all the forms by the research assistant, data entry is performed at the MEMIC. Updates of the related forms are supplied to the investigators at intervals of circa 6 months. For privacy reasons, the access to the 'Rolodex' is restricted to the main investigator and the research assistant (Figure 2.1). This file is physically separated from the others to maximize the data confidentiality.

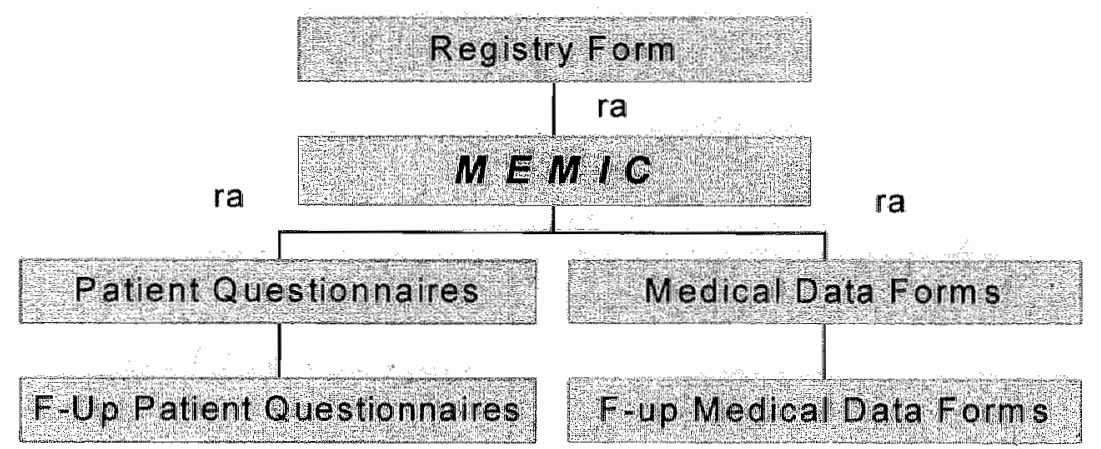

ra: research assistant

Figure 2.1 Data management of the South Limburg IBD registry

sto

\section{Control Population}

The third objective was to establish a population-based control group to be used in case-control studies when investigating risk factors. They were recruited in cooperation with the Registration Network Family Practices (RNH). Out of 47.750 registered patients at the $\mathrm{RNH}$, all living in the study area and without history of 
$\mathrm{IBD}$, a sample of 924 persons was selected, according to sex and age distribution of the IBD patients at January 1994 and with the restriction of having no IBD diagnosis. This group received a control questionnaire which lay-out and structure is similar to the patient questionnaire in May 1994. This group was also contacted by mail in the event of non-response.

\section{Basic results of the registration}

Until July 1996, a total number of 1567 patients were reportat to the study centre as having either UC $(n=750), C D(n=713)$ or indeurminate colitis $(n=104)$ according to the study criteria. Five patients reported with only basic data, because of refusal of the patient to participate in the study. Of this group of 1567 patients $592(38 \%)$ were newly-diagnosed, whereas the remaining were already known with IBD at the start of the registration. Figure 2.2 shows the distribution according to gender for the separate diagnostic subgroups of IBD. In contrast to UC and indeterminate colitis, in $\mathrm{CD}$ there was a preponderance for females. The number of patients registered during the first five years, divided into prospective and retrospective patients, is shown in Figure 2.3. The number of prospectively diagnosed patients is constant over the years. It has to be remembered that the rates were calculated at July 1996 resulting in low figures for this calendar year. In contrast the number of patients known with a diagnosis of IBD before October 1991 decreases over the years. The cumulative percentage of newly-diagnosed patients as were reported per participating hospital is illustrated in Figure $\mathbf{2 . 4}$.

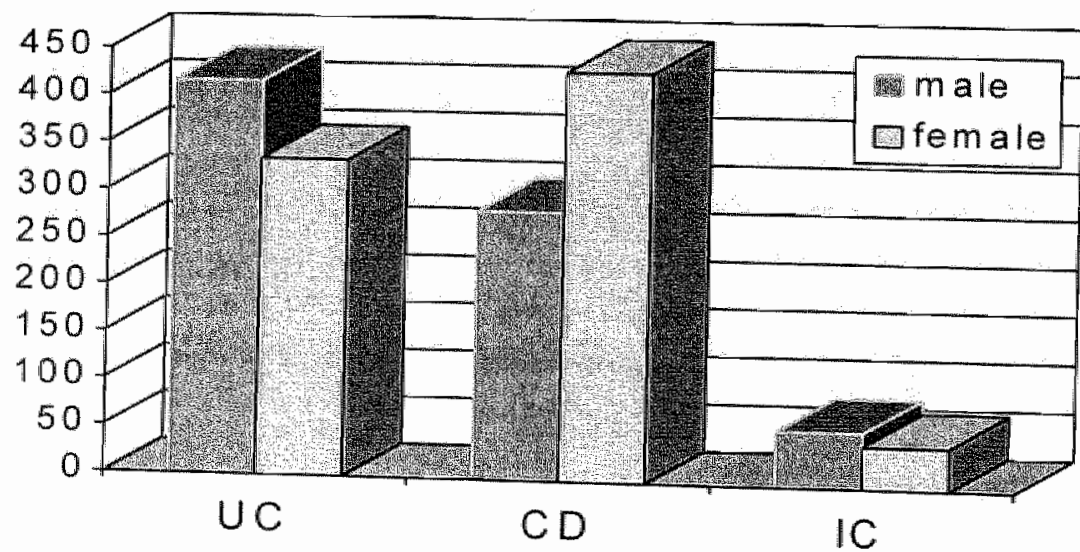

Figure 2.2 Number of registered IBD patients at July 1996 according to gender for the separate diagnostic subgroups of IBD at the moment of registration (UC: Ulcerative Colitis, CD:
Crohn's Disease. IC: Indeterminate Colitis) 


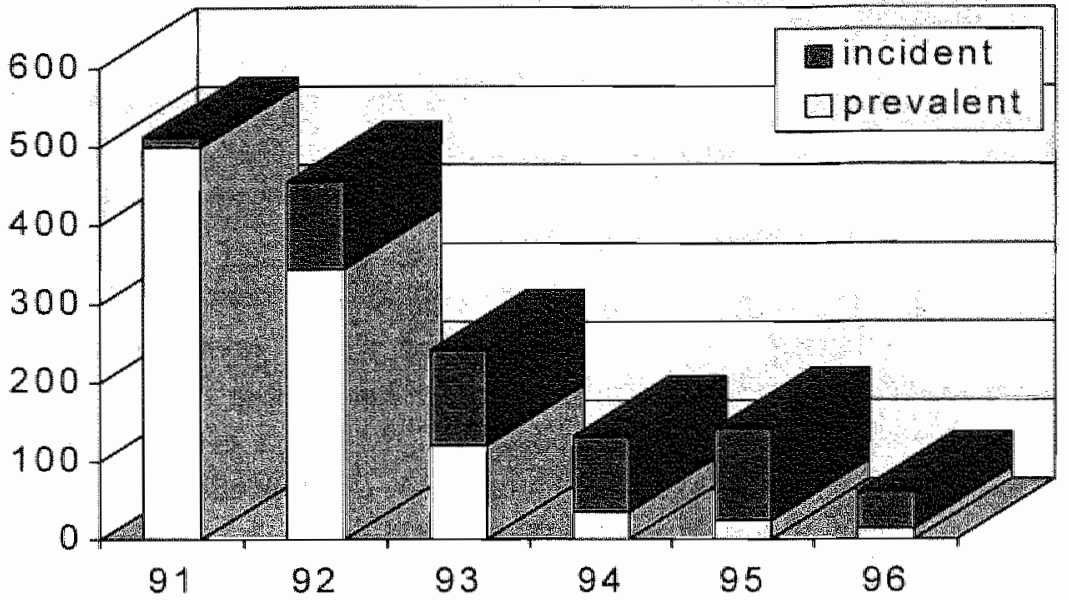

Figure 2.3 Number of IBD patients registered during the first five years, divided into prospective and retrospective registered patients

prospective cases

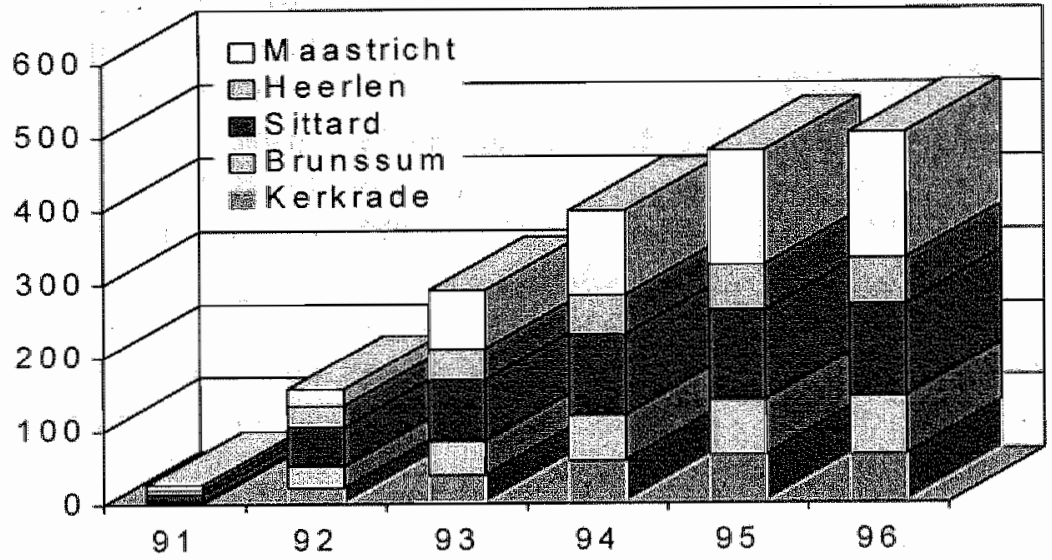

Figure 2.4 Cumulative percentage of IBD newly-diagnosed patients reporied per participating hospital

\section{4}

The response to the patient questionnaire in July 1996 was $93 \%$ (1452 out of 1567). At that time the data of the medical forms of 1218 patients $(78 \%)$ had been entered in the database at the MEMIC. In the control group the questionnaire was completed by 616 persons $(67 \%)$. 


\section{Scientific output}

The majority of the first analyses of the data of the South Limburg IBD Registry are reflected in this thesis, and have been published or submitted for publication in journals of Internal Medicine or Gastroenterology. The data also served for the European study on the incidence of IBD in the north and south of Europe, a multicentre prospective study during the period 1991 to 1993, including a large scale European follow-up study of this cohort which presently is underway. Furthermore the data are used in several spin-off studies that have originated from the main study such as "Osteoporosis and IBD", "Nutrition in IBD", "Coagulation and Fibrinolysis in IBD", and "Hepatobiliary Complications in IBD". The databases proved to be useful in patient recruitment for clinical trials, and finally it has been used to develop a multicentre protocol on quality of care in IBD.

\section{Conclusion}

The South Limburg IBD study was primarily set up to study the incidence of CD and UC and to study risk factors of IBD in a population-based design. This has prompted the development of a population-based Inflammatory Bowel Disease registry. Using an unique IBD identification number enabled us to link different databases whilst maintaining patient privacy. We have found that the design of the IBD registry and its related databases enabled us to manage the data accurately. So far the database has resulted in accurate incidence rates of both diseases in the study area, which can serve as guidelines for studies and planning of medical care. Risk factors could be addressed in a population-based study design. The secondary goal, validating and testing quality of life in $\mathrm{BBD}$, has also been successful. In the near future the registry has to prove its usefulness in the follow-up and long-term investigation of the incidence of IBD and in the spin-off trials. 


\section{References}

1. Metsemakers JFM, Höppener $\mathbb{P}$, Knottnerus JA, Kocken RJJ, Limonard CBG. Computerized health information in the Netherlands: a registration of family practices. Br J Gen Prac 1992; 42:102-106. 


\section{Chapter III}

\section{High incidence of Inflammatory Bowel Disease in The Netherlands: results of a prospective study}

MGVM Russel, E Dorant, A Volovics, R-JM Brummer, P Pop, JWM Muris, LP Bos, ChBG Limonard, RW Stockbrügger and the South Limburg IBD Study Group \% 


\begin{abstract}
Purpose: In order to gain recent epidemiological information about Inflammatory Bowel Disease (IBD) in The Netherlands, a prospective study over 4 years (1991-1995) was carried out.

Methods: The incidence of IBD and its subgroups was examined using standardised reports of newly-diagnosed patients. A separate study compared the IBD Registration and computerised diagnostic files of a subgroup of general practitioners with the aim of estimating completeness of case ascertainment.

Results: The following mean incidence rates (per 100.000 inhabitants and year) were found: 6.9 (95\% CI: 5.9-7.9) for Crohn's disease, 10.0 (95\% CI: 8.7-11.2) for ulcerative collitis - $23 \%$ of these with ulcerative proctitis - and 1.1 (95\% CI: 0.7-1.5) for indeterminate colitis. In the age category 20-29 years the incidence rate of Crohn's disease with small bowel involvement was higher in females than in males. In extended ulcerative colitis a malle preponderance was observed in the older age groups. Estimated case ascertainment was $100 \%$ in Crohn's disease, $80 \%$ in extended ulcerative colitis, but only $25 \%$ in ulcerative proctitis.
\end{abstract}

Conclusions: Compared to recent studies in neighbouring countries, the observed age and sex standardised incidence rates are high in the South of The Netherlands. Completeness of case ascertainment might have contributed to this observation; however, case ascertainment was low in ulcerative proctitis. In the study area, differences in age and sex standardised incidence rates, and in disease localisations, could be compatible with an influence of exogenic risk factors. 


\section{Introduction}

While the number of newly-diagnosed cases of Crohn's disease in Western Europe has increased since the $1950 \mathrm{~s}$, the incidence of ulcerative colitis has shown a more stable pattern ${ }^{1,2}$. In the United States and in Europe, Inflammatory Bowel Disease (IBD) appears to be more common in northern than in southern areas ${ }^{3,4}$. Differences in genetic background and variable exposure to exogenic risk factors have been mentioned as possible explanations for the inconsistent rates ${ }^{5}$. However, it should be kept in mind that comparison of incidence rates between areas is hazardous, since different methods of case ascertainment and variable diagnostic definitions have been used.

In The Netherlands, so far only one study has addressed the incidence of IBD. In 1987, a retrospective study from Leiden reported incidence rates regarding the period 1978-1981 6.7 . In order to gain more recent epidemiological information about inflammatory bowel disease in The Netherlands, we conducted a prospective study over 4 years between 1991 and 1994 in South Limburg.

\section{Methods}

\section{Background area and population}

South Limburg is located in the South East of The Netherlands and is a welldefined geographic entity, which bounds on Germany to the east and on Belgium to the south and west, while the northern border of the area is very narrow (Figure 3.1).

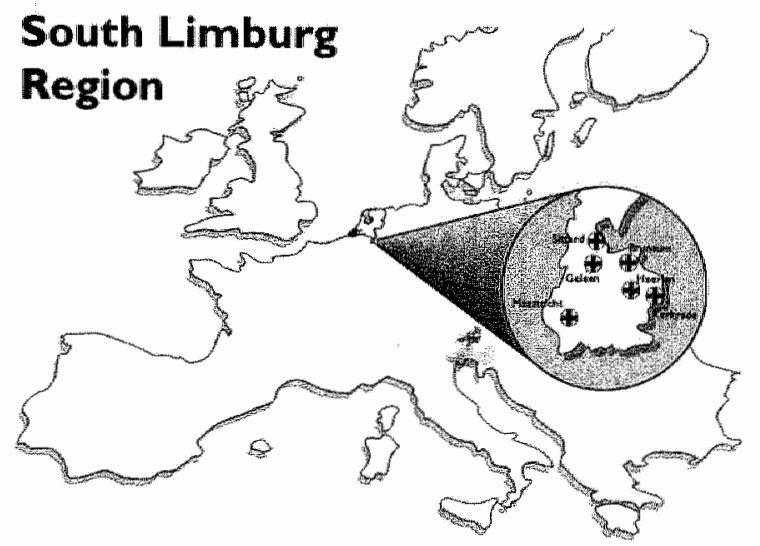

Figure 3.1 Study area South Limburg, a well-defined area situated in the south-east of The Netherlands 
The region had an average population of 642.240 during the 1991-1994 period. The exact number of persons, grouped by age and sex, for each of the years 19911994 was obtained from the Central Bureau of Statistics of The Netherlands (CBS; age structure Corop 39 (1991-1994); adapted by the Centre for Data and Information Management (MEMIC)).

The health care system in The Netherlands is regionally organised. In the South Limburg area there are six hospitals. Besides the University Hospital in Maastricht, the general district hospitals of Heerlen and Sittard, and three minor associated hospitals (Geleen, Kerkrade and Brunssum) participated in the study. IBD patients with degrees of disease severity ranging from very mild to severe are referred to these hospitals by about 300 general practitioners working in the area. To our knowledge, no patients with IBD living in the study area are treated in private practices, in hospitals outside the study area, or abroad.

\section{Disease definitions and disease location}

Cases of IBD were grouped into those with Crohn's disease (CD), ulcerative colitis (UC) or indeterminate colitis (IC). IBD was diagnosed, after exclusion of infections and other recognised causes of inflammation, on the basis of endoscopic and/or radiological evidence, supported -whenever possible- by mucosal biopsy and/or examination of a surgical specimen. The criteria of Lennard-Jones were applied in case definition for $\mathrm{CD}$, taking into account both macroscopic and microscopic features $^{8}$. UC was defined as continuous mucosal inflammation without granulomata, affecting the rectum and/or some or all of the colon in continuity with the rectum. The term "indeterminate colitis" was used for cases of IBD when, after careful investigation, the differential diagnosis between $C D$ and UC remained
uncertain.

Using all available medical information obtained during the first six months after diagnosis, localisation of the disease in the large and small bowel was carefully recorded. CD was subdivided into exclusive small bowel disease, exclusive colonic disease, and combined small and large bowel disease. UC was subdivided into ulcerative proctitis (UP) and extended ulcerative colitis (e-UC), depending on whether or not the disease extended proximal to the rectosigmoidal junction. In e-UC a further difference between left-sided colitis (inflammation up to, but not beyond, the splenic flexure) and pancolitis (inflammation beyond the splenic
flexure) was made.

\section{Case collection}

Gastroenterologists, physicians, surgeons and paediatricians working in the six hospitals were asked to participate in the study. Starting on 1 October 1991, these specialists reported information on their incident as well as prevalent IBD patients 
to the study centre on a short "first-report" form. Besides demographic data this form contained questions about the diagnosis according to the study criteria, the date of diagnosis and the duration of complaints. Patients were asked by their specialists to give written informed consent that further information might be obtained and recorded in a database. After six months comprehensive data from the medical record(s) of these patients were collected by specially trained senior medical students. The available medical information on the disease course during the first six months of all incident patients was subsequently examined by one of the authors (MR). In case of disagreement on the diagnostic classification of a case, the medical infornation was reviewed by a panel of two senior co-workers of the study (R-JB and RWS).

Methods to improve completeness of case ascertainment included searches of the computerised systems of the national pathology database PALGA ("Pathologisch Anatomisch Landelijk Geautomatiseerd Archief"), files of endoscopy units and hospital discharge databases ("Landelijke Medische Registratie") of the participating hospitals. Meetings with participating specialists known to treat IBD patients were held on a regular basis. In the present study, only data of newlydiagnosed (incident) cases living in the study area at the time of diagnosis are used for analysis.

Some of the data on 220 patients in the two-year period starting October 1991 have been included in the European Collaborative Study on Epidemiology of IBD ${ }^{9.10}$.

\section{Ascertainment of completeness of case collection}

To estimate the percentage of missing patients, a separate study was performed with the Registration Network of General Practitioners (RNH) in South Limburg as a reference ${ }^{10}$. This Register contains files with all diagnoses, including IBD and it subgroups, of 47.850 patients $(7.5 \%)$ of the total population of the study area known to 35 general practitioners practising in 13 group practices in the study area. Medical information was collected at the general practitioners' office of all patients with a diagnosis of IBD according to the information of the $\mathrm{RNH}$, who, while living in the study area and registered at the RNH in the study period, were unknown at the IBD Study Centre. Because of privacy reasons these patients were known to us only by initials, gender and date of birth. The same panel, as mentioned above, used this information for diagnostic classification into either nonIBD or CD, UC and IC.

\section{Analysis}

Age is reported as median (range). Data on disease manifestation are reported as percentages of patients with positive findings at either first presentation or during the first six months of presentation. The annual incidence rates were calculated 
Table 3.2 Anmul incidence rates (newly diagnosed cases per 100.000 inhabitants and year) of Crohn's diserse, ulcerative colitis, extended ulcerative colitis, ulcerative proctitis and indeterminate colitis during the study period

\begin{tabular}{lrrrrrr}
\hline & 1991 & 1992 & 1993 & 1994 & Mean 91-94 & \multicolumn{1}{c}{$(95 \% \mathrm{CI})$} \\
\hline Crohn's disease & 6.2 & 8.9 & 6.8 & 5.6 & 6.9 & $(5.9-7.9)$ \\
Ulcerative colltis & 10.0 & 12.8 & 9.2 & 7.9 & 10.0 & $(8.7-11.2)$ \\
- extended UC & 7.2 & 9.2 & 7.2 & 6.3 & 7.5 & $(6.4-8.5)$ \\
- ulcerative proctitis & 2.8 & 3.6 & 2.0 & 1.6 & 2.5 & $(1.9-3.1)$ \\
Indeterminate colitis & 1.2 & 1.1 & 0.8 & 1.1 & 1.1 & $(0.7-1.5)$ \\
\hline
\end{tabular}

\section{incidence}

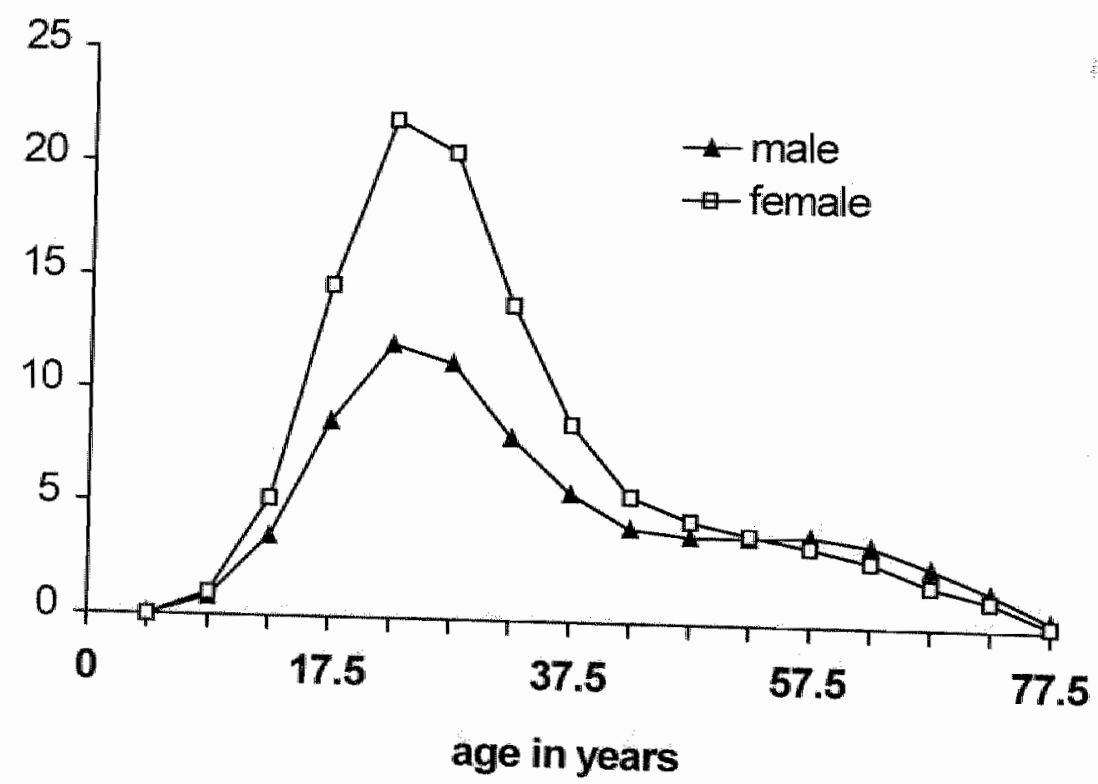
Figure 3.2 Mean annual incidence rates (per 100.000 and year) of Crohn's disease in different age groups
by gender. Every marker represents the mean value of a five years interval

In UC, males in the higher age strata (between 30 and 60 years), had a higher incidence rate than females, mostly caused by the groups of patients with left-sided colitis and pancolitis (Figure 3.3). Again the difference between sexes was not statistically significant when the three disease localisations were analyzed
separately. 


\section{incidence}

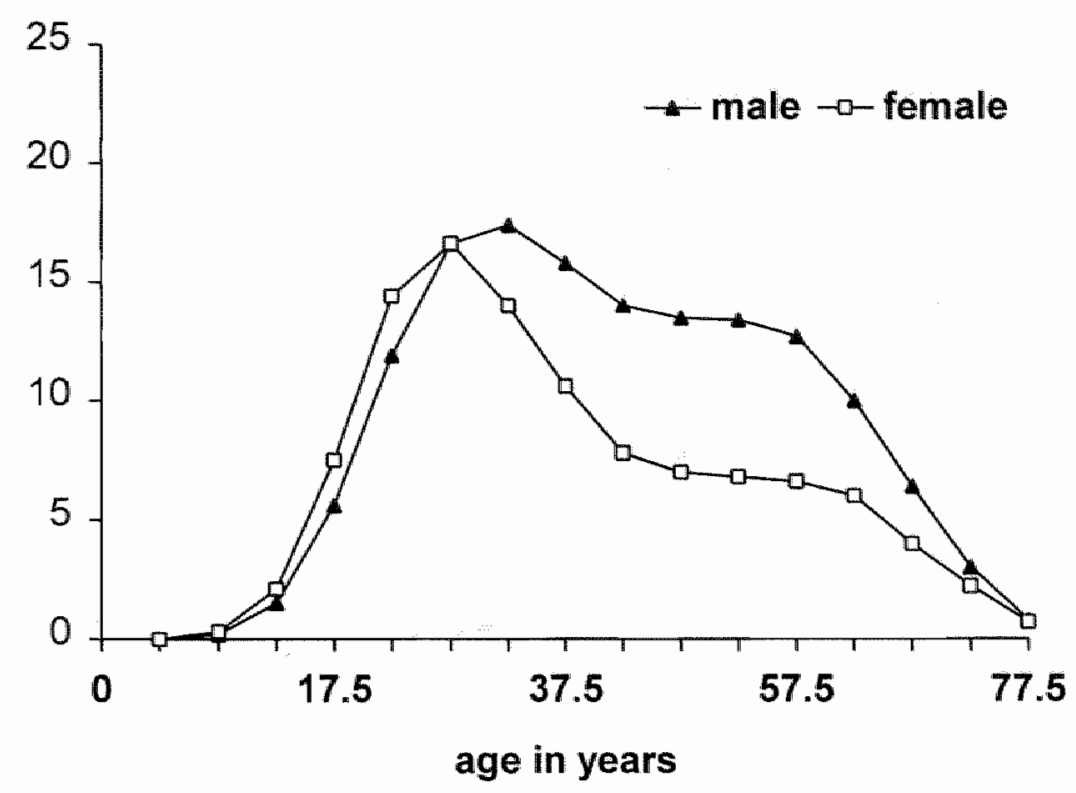

Figure 3.3 Mean annual incidence rates (per 100.000 and year) of ulcerative colitis in different age groups by gender. Every marker represents the mean value of a five years interval

\section{Completeness of case ascertainment}

During the first three years (1991-1993) of our registration, 39 new cases of IBD were diagnosed in the 13 general group practices (35 general practitioners) participating in the Registration Network of General Practitioners (RNH). Of those patients 18 were unknown at the IBD Registration. Verification of the exact date of diagnosis and of the diagnostic criteria as used in our study excluded 12 patients, resulting in 6 patients truly unknown to us: 5 with UC ( 3 of these with UP) and one with IC. Four of these patients were known to specialists in the study area but had not yet been reported. Patients with $C D$ were all known at the IBD Registration. In case that the general practitioners' registration would be defined as reference, the sensitivity of the IBD Registration for IBD would have been $78 \%$ $(21 / 21+6)$ (Table 3.3). 
Table 3.3 Sensitivity of the South Limburg IBD Registration defining the Registration Network General Practitioners (RNH) as a reference

\begin{tabular}{lccccc}
\hline & $\begin{array}{c}\text { CD } \\
\text { nr RNH }\end{array}$ & $\begin{array}{r}\text { e-UC } \\
\text { nr RNH }\end{array}$ & $\begin{array}{c}\text { UP } \\
\text { n RNH }\end{array}$ & $\begin{array}{c}\text { IC } \\
\text { n RNH }\end{array}$ & $\begin{array}{c}\text { all IBD } \\
\text { n R RNH }+\end{array}$ \\
\hline IBD Reg * & 11 & 8 & 1 & 1 & 21 \\
IBD Reg - & 0 & 2 & 3 & 1 & 6 \\
Sensitivity (\%) & 100 & 80 & 25 & 50 & 78 \\
\hline
\end{tabular}

(CD: Crohn's disease, e-UC: extended ulcerative colitis, UP: ulcerative proctitis, IC: indeterminate colitis, $\mathrm{nr}=$ number of patients, $+:$ known and $-:$ unkmown in database)

\section{Discussion}

The incidence rate of inflammatory bowel disease in the South Limburg area, as reported in this study, is high compared to the only available data reported for The Netherlands: in a retrospective study during the period 1978-1981 in the Leiden area, Shivananda and co-workers found incidence rates of 3.9 for $C D$ and 6.6 for $\mathrm{UC}^{6,7}$. As disease definitions in both studies are comparable, the higher rates of our study could either be explained by a more complete case ascertainment due to the prospective approach, or else by a real rise in incidence during the last 15 years. Finally, the difference could be due to a real higher incidence of IBD in our area. Both study populations might then differ because of the genetic background or because certain exogenic risk factors.

The age and sex specific incidence rates of IBD in South Limburg are also higher than in most of the 19 European centres participating in the European Collaborative Study on IBD during the study period October 1991-October 1993 ${ }^{10}$. Recently published incidence rates of IBD in Western European countries are given in Table 3.4, $4^{6,72-22}$. Compared to these studies the incidence rate of $C D$ in South Limburg is higher than of most other centres. Generally, the Scandinavian countries report a higher incidence of UC than was found in our study. Most striking is the high incidence of UC (10.0 per 100.00 and year) in our study compared to recently published figures of Northern France and the Ruhr area in Germany, geographically close to Maastricht, both reporting low rates (4.9 and 2.9 per 100.000 and year) ${ }^{12,14}$. Since all these recent studies have used the same or similar disease definitions and study design, the high incidence of IBD in South Limburg seems to be real. 
Table 3.4 Recently published incidence rates (per 100.000 inhabitants and year) of IBD in soine Western European countries

\begin{tabular}{lccc}
\hline Country, area, reference & Study period & \multicolumn{2}{c}{ Incidence per 100.000/year } \\
& & CD & UC \\
\hline France, Northern $^{11}$ & $1988-1990$ & 3.2 & 4.9 \\
Italy, Northern $^{12}$ & $1990-1993$ & 3.4 & 7.0 \\
Giermany, Ruhr area $^{13.14}$ & $1980-1984$ & 4.0 & 2.9 \\
Denmark, Copenhagen $^{15.16}$ & $1980-1987$ & 4.1 & 9.2 \\
The Netherlands, Leiden $^{6,7}$ & $1978-1981$ & 4.9 & 6.8 \\
Norway $^{17.18}$ & $1990-1993$ & 5.8 & 13.6 \\
Sweden, Uppsala (Urban) $^{19}$ & $1965-1983$ & 6.6 & 11.5 \\
UK, Cardiff $^{20.21}$ & $1981-1985$ & 8.3 & 7.2 \\
Present study (NL) $^{19}$ & $1990-1994$ & 6.9 & 10.0 \\
\hline
\end{tabular}

Fluctuations in the incidence rates during the four years of the registration were small and not significant. Incidence rates of the last study year (1994) are somewhat lower than those of the preceding years. The most probable explanations are a diagnostic delay (which also has been observed in other longitudinal studies) and a time lag between diagnosis and reporting the patient to the IBD Registration ${ }^{17}$.

Using the medical information on disease course and investigations during the first six months, half of the patients initially reported as IC could be either classified as $\mathrm{CD}$ or UC. The percentage of patients who remained classified as indeterminant colitis $(6 \%)$ was slightly lower than usually reported ${ }^{19.23}$. Making a diagnosis in patients with (possible) IBD can be difficult. The results on the median duration between onset of symptoms and diagnosis can be misleading. This is illustrated by the fact that $31 \%$ of the patients with $\mathrm{CD}$ and $18 \%$ of the patients with $\mathrm{UC}$ had complaints for more than a year before a diagnosis of IBD was made. Symptoms at first presentation might give a clue to the diagnosis, but are not specific to IBD and do not differentiate between UC and CD. Rectal bleeding at diagnosis was present in more than $90 \%$ in patients with UC. However, this symptom was also observed in $39 \%$ of the patients with $\mathrm{CD}$. While weight loss, tiredness and abdominal pain were more frequently reported in $\mathrm{CD}$, these symptoms were also reported in a substantial proportion of patients with UC.

The age and sex distribution in CD is similar to that observed in other recent studies, with a peak incidence at earlier age and higher incidence rates in females than in males ${ }^{12,14,16,20}$. The higher female incidence in the younger age groups might 
be compatible with a role for exogenic risk factors, for example oral contraceptive use and smoking, in the clinical expression of the disease. Another interesting observation is the male predominance in UC in the older age groups. Higher incidence rates in older males have been reported before by some authors but not by others and might, also here, reflect a different exposure to exogenic risk factors ${ }^{17,19,24}$. The frequently quoted "second peak" in older age categories was neither found in $C D$ nor in $U C$.

Only about half of the number of patients registered with $\mathrm{CD}$ and a quarter of the patients registered with UC were hospitalised during the first six months of their disease. This is low compared to the Ruhr area in Germany, where only $7.8 \%$ of patients with $\mathrm{CD}$ were diagnosed as outpatients, and urges the question of complete case ascertainment and comparability of incidence rates between different study areas ${ }^{14}$. The need for completeness of data in epidemiological studies of IBD is evident. Our results are based on patients seen by specialists at one of the six hospitals in the study area. Strictly speaking this may not be defined as a population-based study. It was our opinion, however, that most of the IBD patients would either be referred to an outpatient department or would have been hospitalised at some time during the first year after diagnosis. It has been suggested that questionnaires to general practitioners are essential to producing accurate estimation of disease incidence ${ }^{6}$. However, results in The Netherlands using questionnaires have been disappointing ${ }^{6}$. The present study used a computerised file of all diagnoses of a limited subgroup of general practitioners, participating in the Registration Network Family Practices to address this item ${ }^{9}$. Because of practical implications, it was impossible to involve all general practitioners working in the study area (more than 300 in number). The size of this subgroup is probably too small to make a valid estimation of completeness of case ascertainment, but the study suggests that most or all of the patients with $C D$, and most of the patients with e-UC are known at the IBD Registration. Case ascertainment of UP needs improvement.

In epidemiological studies of UC, patients with UP are classified in different ways $^{25}$. Some authors have excluded such cases from their studies, but most have included them and given the ratio of UP:UC $C^{17,26-31}$. Finally, some authors have grouped them with UC cases affecting part or all of the sigmoid colon ${ }^{32-34}$. Differences in time trends and certain other epidemiological characteristics (such as age and sex distribution) between UP and extensive UC suggest that UP is a specific disease, the aetiology of which may differ to some extent from that of extensive colitis ${ }^{25}$. The differences in UC incidence between various regions could be explained by the inclusion of milder cases, particularly UP, another reason to separate both entities ${ }^{35}$. The incidence rate of UP as found in our study, 2.5 per 
100.000 inhabitants and year, is lower than reported in most recently published studies $^{12,15,20,24,26,28-31}$. Swedish data would even suggest that at least $60 \%$ of the total UC cases actually are UP $\mathrm{UP}^{24,25}$.

In summary, our results suggest a high incidence of IBD in The South Limburg area of The Netherlands. Incidence rates are higher than previously reported in our country and also higher than published by centres of most surrounding countries. When comparing different studies on the incidence of $\mathrm{IBD}$, special attention has to be paid to the diagnostic criteria and the methods of case ascertainment used. Differences in age and sex adjusted incidence rates are possibly compatible with a role for exogenic risk factors. Continuation of studies with prospective and welldefining disease registrations of IBD might contribute to the understanding of the cause(s) of IBD. 


\section{References}

1. Sandler RS. Epidemiology of inflammatory bowel disease. In: Targan SR, Shanahan $F$, editors. Inflammatory bowel disease; from bench to bedside. Baltimore, Maryland: Williams \& Wilkins 1994; 5-32.

2. Bunder V. Epidemiology, course and socio-economic influence of inflammatory bowel disease. Schweiz Med Wochenschr 1988; 118:738-742.

3. Sonnenberg A, McCarty DJ, Jacobsen SJ. Geographic variation of inflammatory bowel disease within the United States. Gastroenterol 1991; 100:143-149.

4. Binder V. Progress in epidemiology, quality of life and life expectancy in IBD. In: Tijtgat GNJ, Bartelsman JFWM, Deventer van SJH, editors. Inflammatory Bowel Disease. Dordrecht, The Netherlands: Kluwer Academic Publishers 1995; 27-32.

5. Gilat T, Langman MJ, Rozen P. Environmental factors in inflammatory bowel disease. Front Gastrointes Res 1986; 11:158-176.

6. Shivananda S, Pena AS, Nap M, Weterman IT, Mayberry JF, Rnitenberg EJ, et al. Epidemiology of Crolhn's disease in Regio Leiden, The Netherlands. A population study from 1979 to 1983. Gastroenterol 1987; 93:966-974.

7. Shivananda S, Hordijk ML, Pena AS, Mayberry JF. Inflammatory bowel disease: one condition or two? Digestion 1987; 38:187-192.

8. Lennard-Jones JE. Classification of inflammatory bowel disease. Scand I Gastroenterol 1989; 24(suppl 170):2-6.

9. Shivananda $S$, Lennard-Jones J, Logan $R$, Fear $N$, Price A, Carpenter $\mathbb{L}$, Blankenstein van $\mathrm{M}$ and the BC-IBD Study Group. Indicence of inflammatory bowel disease across Europe: is there a difference between north and south? Results of the European collaborative studly on inflammatory bowel disease (EC-IBD). Gut 1996; 39:690-697.

10. Shivananda $S$, Mayberry JF. Epidemiology of inflammatory bowel disease. Inflammatory Bowel Disease Study Group, Royal Free Hospital 1993; 9:560-565.

11. Metsemakers JFM, Höppener P, Knottnerus JA, Kocken RJ, Limonard CBG. Computerized health information in the Netherlands: a registration of family practices. Br J Gen Prac 1992; 42:102-106.

12. Gower Rousseau C, Salomez JL, Dupas JL, Marti R, Nuttens MC, Votte A, et al. Incidence of inflammatory bowel disease in northern France (1988-1990). Gut 1994; 35:1433-1438.

13. Ranzi T, Bodini P, Zambelli A, Politi P, Lupinacci $G$, Campanini MC, et al. Epidemiological apects of inflammatory bowel disease in a north Italian population: a 4year prospective study. Eur J Gastroenterol Hepatol 1996; 8:(7)657 662 .

14. Goebell H, Dirks E, Förster S, Strey B, Quebe-Fehling E. A prospective analysis of the incidence and prevalence of Crohn's disease in an urban population in Germany. Eur J Gastroenterol Hepatol 1994; 6:1039-1045.

15. Dirks E, Forster S, Thom M, Quebe Fehling E, Goebell H. Prospective study of the incidence and prevalence of ulcerative colitis in a large urban population in Germany (western Ruhr area). Z Gastroenterol 1994; 32(6):332-337. 
16. Munkholm $P$, Langholz $E$, Nielsen $\mathrm{OH}$, Kreiner $S$, Binder $\mathrm{V}$. Incidence and prevalence of Crohn's disease in the county of Copenhagen, 1962-87: a sixfold increase in incidence. Scand J Gastroenterol 1992; 27:609-614.

17. Langholz E, Munkholm $\mathrm{P}$, Nielsen $\mathrm{OH}$, Kreiner $\mathrm{S}$, Binder $\mathrm{V}$. Incidence and prevalence of ulcerative colitis in Copenhagen county from 1962 to 1987. Scand J Gastroenterol 1991; 26:1247-1256.

18. Moum B, Vatn MH, Ekbom A, Aadland E, Fausa O, Lygren I, et al, Incidence of Crohn's disease in four counties in southeastern Norway, 1990-93. Scand J Gastroenterol 1996; 31:355-361.

19. Moum B, Vatn MH, Ekbom A, Aadland E, Fausa O, Lygren I, et al. Incidence of ulcerative colitis and indeterminate colitis in four counties of southeastern. Norway, 1990-93. Scand J Gastroenterol 1996; 31:362-366.

20. Ekbom A, Helmick C, Zack M, Adami HO. The epidemiology of inflammatory bowel disease: a large, population-based study in Sweden. Gastroenterol 1991; 100:350-358.

21. Srivastava ED, Mayberry JF, Morris TJ, Smith PM, Williams GT, Roberts GM, et al. Incidence of ulcerative colitis in Cardiff over 20 years: 1968-87. Gut 1992; 33:256-258.

22. Thomas GA, Millar-Jones D, Rhodes J, Roberts GM, Williams GT, Mayberry JF. Incidence of Crohn's diseae in Cardiff over 60 years: 1986-1990 an update. Eur J Gastroenterol Hepatol 1995; 7:401-406.

23. Stewenius J, Adnerhill I, Ekelund G, Floren CH, Fork FT, Janzon L, et al. Ulcerative colitis and indeterminate colitis in the city of Malmo, Sweden. A 25-year incidence study. Scand J Gastroenterol 1995; 30:38-43.

24. Tysk C, Järnerot G. Ulcerative proctocolitis in Orebro, Sweden. A retrospective epidemiologic study, 1963-1987. Scand J Gastroenterol 1992; 27:945-950.

25. Ekbom A, Helmick C, Zack M, Adami HO. Ulcerative proctitis in central Sweden 1965-1983. A population-based epidemiological study. Dig Dis Sci 1991; $36: 97-102$.

26. Berner J, Kiaer T. Ulcerative colitis and Crohn's disease on the Faroe Islands 196483. A retrospective epidemiological survey. Scand J Gastroenterol 1986; 21:188-192.

27. Binder $V$, Both $H$, Hansen PK, Hendriksen $C$, Kreiner $S$, Torp-Pedersen $K$. Incidence and prevalence of ulcerative colitis and Crohn's disease in the county of Copenhagen, 1962 to 1978 . Gastroenterol 1982; 83:563-568.

28. Devlin HB, Datta D, Dellipiana AW. The incidence and prevalence of inflammatory bowel disease in North Tees Health District. World J Surg 1980; 4:183-193.

29. Haug K, Schrumpf E, Barstad S, Fluge G, Halvorsen JF. Epidemiology of ulcerative colitis in western Norway. Scand J Gastroenterol 1988; 23:517-522.

30. Jacobsohn WZ, Levine $Y$. Incidence and prevalence of ulcerative colitis in the Jewish population of Jerusalem. Isr J Med Sci 1986; 22:559-563.

31. Stonnington CM, Phillips SF, Melton LJ3, Zinsmeister AR. Chronic ulcerative colitis: incidence and prevalence in a community. Gut 1987; 28:402-409. 
32. Morris $T$, Rhodes $J$. Incidence of ulcerative colitis in the Cardiff region 1968-1977. Gut 1984; 25:846-848.

33. Odles HS, Fraser D, Krawiec J. Ulcerative colitis in the Jewish population of southern Israel 1961-1985: epidemiological and clinical study. Gut 1987; $28: 1630-1636$.

34. Sinclair TS, Brunt PW, Mowat NAG. Nonspecific proctocolitis in northeastern Scotland a community study. Gastroenterol 1983; 85:1-11.

35. Calkins BM, Mendeloff AI. The epidemiology of idiopathic inflammatory bowel disease. In: Kirsner JB, Shorter RG, editors. Inflammatory Bowel Disease. 4th ed. Baltimore: Williams \& Wilkins 1995; 31-70. 


\section{Chapter IV}

Familial aggregation of Inflammatory Bowel Disease: a population-based study in South Limburg, The Netherlands

MGVM Russel, CJ Pastoor, KMW Janssen, CT van Deursen, JWM Muris, EHJ van Wijlick, RW Stockbrügger and the South Limburg IBD Study Group

Scand J Gastroenteral 1997 (accepted for publication) 
32. Morris $\mathrm{T}$, Rhodes $\mathrm{J}$. Incidence of ulcerative colitis in the Cardiff region 1968-1977. Gut $1984 ; 25: 846-848$.

33. Odes HS, Fraser D, Krawiec I. Ulcerative colitis in the Jewish population of southern Israel 1961-1985: epidemiological and clinical study. Gut 1987; 28: 1630-1636.

34. Sinclair TS, Brunt PW, Mowat NAG. Nonspecific proctocolitis in northeastern Scotland: a community study. Gastroenterol $1983 ; 85: 1-11$.

35. Calkins BM. Mendeloff AI. The epidemiology of idiopathic inflammatory bowel disease. In: Kirsner JB, Shorter RG, editors. Inflammatory Bowel Disease. 4th ed. Baltimore: Williams \& Wilkins 1995; 31-70. 


\section{Chapter IV}

\section{Familial aggregation of Inflammatory Bowel Disease: a population-based study in South Limburg, The Netherlands}

MGVM Russel, CJ Pastoor, KMW Janssen, CT van Deursen, JWM Muris, EHJ van Wijlick, RW Stockbrügger and the South Limburg IBD Study Group

Scand J Gastroenterol 1997 (accepted for publication) 


\begin{abstract}
Background: The aim of our study was to investigate the prevalence of Crohn's disease (CD) and ulcerative colitis (UC) in first-degree relatives of IBD patients, living in a welldefined area.

Methods: IBD patients known at the IBD Registration South Limburg as well as population-controls were asked about the occurrence of IBD in their first-degree relatives.
\end{abstract}

Results: IBD was reported and confirmed in 16 (out of 1554) relatives by 11 (out of 245) patients. Prevalence of IBD was highest for siblings (1.5\%) and children (1.3\%) while only $0.2 \%$ of the parents were affected with IBD. Among relatives of the control subjects, IBD was observed in $0.8 \%$ (vs. $4.5 \%$ in IBD patients), resulting in an odds ratio of $5.7(95 \% \mathrm{CI}: 2.0-16.7)$.

Conclusions: The observed risk of IBD for first-degree relatives of IBD patients was higher than in controls. However, the risk in our population is lower than has been reported by other centres, possibly caused by the population-based character of our study. 


\section{Introduction}

While the aetiology of inflammatory bowel disease is still unknown, there is ample evidence that Crohn's disease (CD) and ulcerative colitis (UC) are in part determined by genetic predisposition ${ }^{\mathrm{i}-6}$. This is suggested by studies on familial aggregation of IBD and the finding of a higher concordance rate in monozygotic than in dizygotic twins ${ }^{7.10}$. Several studies have shown an approximate thirtyfold increase in disease prevalence among siblings compared to the community-wide prevalence $^{11}$. The proportion of IBD patients with a positive family history varies considerably between case series, depending on the studied population, but is usually in the range of 10 to $20 \%$. The aim of the present study was to investigate family aggregation of IBD in a population-based cohort of persons with $\mathrm{CD}$ and $\mathrm{UC}$ residing in a geographical well-defined area and, secondly, to compare these findings with the occurrence of IBD in population-controls living in the study area.

\section{Materials and methods}

\section{Patients}

Cases were selected from the South Limburg IBD Registration, an ongoing study on the epidemiology of IBD in a well-defined geographic area in the south east of The Netherlands ${ }^{12}$. This study started in 1991 . The area has a population of close to 642.000 inhabitants. UC (including chronic proctitis) and CD were defined according to the criteria of Truelove \& Witts and Lennard-Jones ${ }^{13}$.

All incident and prevalent cases with UC and CD, registered at the South Limburg IBD Study Centre until June 1994, who were living in the cities of Maastricht or Brunssum at time of registration (during the 1991-1994 period), were eligible to be included in the present study. Maastricht, localisation of the university hospital, is the largest city of South Limburg and Brunssum is a smaller town which has a general district hospital (population size 118.102 and 30.139, respectively). Ethnic or racial minorities are rare in both cities, and the religion of most inhabitants is Roman Catholic.

Whenever two or more members of the same family were registered, only the member in whom $\mathrm{CD}$ or UC was first diagnosed was considered as a proband, while the others were regarded as relatives. 


\section{Information on family aggregation}

A basic questionnaire concerning number and sex of first-degree relatives (parents, siblings and children) and the presence or absence of a positive family history for IBD was applied either by a personal interview, by a telephone interview, or sent by mail. In case of a positive family history, an extended printed questionnaire was completed by the patients, including information on the relative marked as having IBD. Medical information of suspected first-degree relatives was requested and reviewed to verify a diagnosis of $\mathrm{IBD}$, according to the study criteria. Only relatives with sufficient medical information were included in the analyses. The number of relatives, prevalence of IBD among the relatives, and type of IBD were determined.

\section{Controls}

Controls were all living in the study area and had no history of IBD. They were recruited in co-operation with the Registration Network Family Practices (RNH), which is a reliable dynamic sampling frame of the Dutch general population ${ }^{14}$. Out of 47.750 registered patients at the RNH, a sample of 924 persons was randomly selected. This group received a questionnaire on IBD in their first-degree relatives, which was completed by 616 persons (52\% males, median age at time of the questionnaire 37 (13-81) years). Every control was asked about the occurrence of $\mathrm{CD}, \mathrm{UC}$ or chronic proctitis in either their parents, siblings or children. Because of privacy reasons, only date of birth and sex of the control population were known and verification of the diagnoses of the relatives of controls was not possible.

\section{Statistical analysis}

All statistical analyses were performed with SPSS package 6.0 for Windows and the Confidence Interval Analysis program (CIA) ${ }^{\text {is }}$. Descriptive statistics were provided as median, range and frequencies. Odds ratios (and $95 \%$ confidence intervals) were calculated. Prevalence of $\mathrm{UC}$ and $\mathrm{CD}$ among first-degree relatives was estimated by dividing the number of relatives with either disease by the number of first-degree relatives. 


\section{Results}

A total of 263 IBD patients, living in Maastricht or Brunssum, were registered until June 1994. Those patients who were deceased $(n=3)$, had moved out of the study area $(n=4)$, refused to collaborate $(n=2)$, or could not be traced by mail or tellephone $(n=1)$ were categorised and not included in the subsequent analysis. The same procedure was performed in one patient with $C D$ who was adopted to his family. Seven patients were regarded as relatives instead of probands, since a diagnosis of IBD in one of their first-degree relatives was made in advance, resulting in 245 patients who were included in the analysis (Table 4.1). In 167 patients a personal interview was performed, 37 were approached by a telephone interview, and 41 by a postal questionnaire and. Of those 132 were classified as CD (67\% females, median age 40 (16-81) years, median duration of disease 9 (1-41) years and 113 as UC ( $49 \%$ females, median age 46 (17-81) years, median duration of disease 7 (1-37) years).

Table 4.1 Eligible patients and response to the interview

\begin{tabular}{|c|c|c|}
\hline \multicolumn{3}{|l|}{ Eligible patients } \\
\hline Patients in South Limburg Registry & $1991-1994$ & 1171 \\
\hline Patients living in Maastricht or Brunssum & $1991-1994$ & 263 \\
\hline Patients not included & & $18(7 \%)$ \\
\hline Death & & 3 \\
\hline Refused & & 2 \\
\hline Moved away & & 4 \\
\hline Inability to contact & & 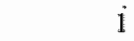 \\
\hline Adopted to family & & $\mathbb{1}$ \\
\hline Regarded as relative (instead of proband) & & 7 \\
\hline Complete responders & & $245(93 \%)$ \\
\hline Crohn's disease & & 132 \\
\hline Ulceratiwe colitis & & 113 \\
\hline
\end{tabular}

The family pedigrees of the 245 patients included a total of 1571 first-degree family members; sufficient information was available on 1554 (99\%) of them: 485 parents, 756 siblings and 313 children. A positive family history of IBD was reported by $22(9 \%)$ patients (probands), twenty of whom provided information on their relatives. Because some of the probands reported more than one relative, the subsequent analysis included a total of 28 relatives. Eight $(29 \%)$ were known at the South Limburg IBD Registration and had the disease confirmed from their medical records. Of the remaining 20 relatives, $8(29 \%)$ had disease confirmed from records of their general practitioners, in $9(32 \%)$ an IBD diagnosis according the 
study criteria could not be established and of three $(11 \%)$ relatives insufficient information for disease classification was available. A positive first-degree family history could be confirmed in 11 probands (4.5\%): 7 patients (5.3\%) with $\mathrm{CD}$ and 4 patients $(3.5 \%)$ with UC. Eight patients had one, one patient had two and two patients had three affected family members, resulting in 16 relatives with IBD among the 1554 first-degree relatives, a prevalence of $1.0 \%$. The highest prevalence was observed among siblings $(1.5 \%)$ and children $(1.3 \%)$, while only $0.2 \%$ of the parents were affected with IBD (Table 4.2). Disease concordance was observed in $88 \%$ : 9 cases with $C D$ and 1 with UC among relatives of patients with $\mathrm{CD}$, and 5 cases with $\mathrm{UC}$ and 1 with $\mathrm{CD}$ among relatives of patients with $\mathrm{UC}$.

Table 4.2

Prevalence of IBD among relatiwes of 245 IBD patients

\begin{tabular}{|c|c|c|c|c|c|c|c|c|}
\hline \multirow{2}{*}{ Relationship } & \multirow{2}{*}{$\begin{array}{c}\text { Total } \\
\mathbf{n} \\
1571\end{array}$} & \multirow{2}{*}{$\begin{array}{c}\begin{array}{c}\text { Sufficient } \\
\text { information } \\
\mathbf{n}\end{array} \\
1554\end{array}$} & \multicolumn{2}{|c|}{$\begin{array}{l}\text { Affected } \\
\text { with CD } \\
\text { n }(\%)\end{array}$} & \multicolumn{2}{|c|}{$\begin{array}{c}\text { Affected } \\
\text { with UC } \\
\text { n }(\%)\end{array}$} & \multicolumn{2}{|c|}{$\begin{array}{c}\text { Total affected } \\
\text { n }(\%)\end{array}$} \\
\hline & & & 10 & $(0.6)$ & 6 & $(0.4)$ & 16 & $(1.0)$ \\
\hline of UC patients & 775 & 768 & 1 & $(0.1)$ & 5 & $(0.7)$ & 6 & $(0.8)$ \\
\hline of $\mathrm{CD}$ patients & 796 & 786 & 9 & $(1.1)$ & 1 & $(0.1)$ & 10 & $(1.2)$ \\
\hline Parents & 490 & 485 & 1 & $(0.2)$ & 0 & & 1 & $(0.2)$ \\
\hline of UC patients & 226 & 223 & 0 & & 0 & & 0 & \\
\hline of $C D$ patients & 264 & 262 & 1 & $(0.4)$ & 0 & & 1 & $(0.4)$ \\
\hline Siblings & 766 & 756 & 8 & $(1.1)$ & 3 & $(0.4)$ & 11 & $(1.5)$ \\
\hline of UC patients & 392 & 388 & 1 & $(0.3)$ & 2 & $(0.5)$ & 3 & $(0.8)$ \\
\hline of $\mathrm{CD}$ patients & 374 & 368 & 7 & $(1.9)$ & 1 & $(0.3)$ & 8 & $(2.2)$ \\
\hline Offspring & 315 & 313 & 1 & $(0.3)$ & 3 & $(1.0)$ & 4 & (1.3) \\
\hline of UC patients & 157 & 157 & 0 & & 3 & $(11.9)$ & 3 & $(1.9)$ \\
\hline of CD patients & 158 & 156 & 1 & $(0.6)$ & 0 & & 1 & $(0.6)$ \\
\hline
\end{tabular}

Age at time of diagnoses was not significantly different in patients with and without a positive family history (median age 28 (15-66) years and 29 (10-80) years, respectively), and no difference was observed in the median age at time of enrolment (44 (19-71) years and 41 (16-81) years). In addition, no significant difference was found in duration of the disease (median duration 14 (2-37) years and 8 (1-41) years, respectively). 
Out of the 616 controls, five persons $(0.8 \%)$ reported a relative with IBD, all with $\mathrm{CD}$; three in a sibling, one in a child and one in a parent. It was not possible to verify diagnoses in the relatives of the controls, but regarding these patients as truly IBD, the odds ratio for positive family aggregation in IBD patients compared to controls would be 5.7 (95\% CI: $2.0-16.7), 4.5(1.2-17.0)$ in UC and 6.8 (2.1-21.9) in CD.

\section{Discussion}

In this study the main finding is a moderately high frequency of first-degree family members with IBD in a group of unselected IBD patients $(5.3 \%$ in CD and $3.5 \%$ in UC). Much effort has been made to obtain information on all first-degree rellatives, resulting in a $98 \%$ completeness. In studies with a lower response rate, it is conceivable that a lower rate of familial occurrence among persons not responding may have contributed to the higher rates of familial occurrence in those studied. Since all diagnoses had to be verified according to strict criteria, the reported prevalence of IBD in first-degree relatives of $1.0 \%$ is a minimum number. It was remarkable that, compared with the patients' opinion, a positive family history could only be confirmed in $57 \%$ of the relatives. This raises doubts as to the results of some previous studies, in which only questionnaires were used to obtain information on IBD diagnoses in relatives ${ }^{16}$. We did not include information on second-degree relatives, since it would have been difficult, if indeed possible, to check their medical diagnoses, which would have resulted in less reliable information.

Compared to other recent studies on familial aggregation of IBD, our results on the prevalence of IBD in relatives are lower than most (Table 4.3). Crude rates of up to $40 \%$ of family IBD history, as well as frequencies of IBD as high as $2 \%$ among siblings have been described, but these data probably grossly overestimate the real prevalence. The only Dutch study on familial incidence of CD by Weterman et al. ${ }^{6}$ was published in 1984 and reported a prevalence of $8 \%$ in a selected population visiting a referral hospital. Selection bias in the present study was minimised by including all prevalent IBD patients who were living in the well-defined catchment area and who were known at the outpatient clinfes of the six hospitals in the study area participating in the South Limburg IBD Registration.

As has been observed before, prevalence of IBD was higher in siblings and children compared to parents ${ }^{16-18}$. It is likely that many offspring of patients have not reached the age at which symptoms are manifested, and the risk to offspring is therefore probably underestimated by the majority of studies, including ours ${ }^{19}$. 
Since we had no information on the age of the 1544 relatives, it was impossible to calculate age- and sex- specific prevalence rates or to develop age-corrected empirical risks of $\mathrm{IBD}$, as was done by Yang et al ${ }^{20}$.

Table 4.3 Family history in first-degree relatives of patients with IBD

\begin{tabular}{|c|c|c|c|c|c|c|}
\hline $\begin{array}{c}\text { Disease } \\
\text { (number) }\end{array}$ & $\begin{array}{c}\text { Year of } \\
\text { Publlication }\end{array}$ & $\begin{array}{l}\text { \% positive } \\
\text { family } \\
\text { hulstory }\end{array}$ & $\begin{array}{l}\text { \% siblings } \\
\text { with IBD }\end{array}$ & $\begin{array}{l}\% \text { parents } \\
\text { with IBD }\end{array}$ & $\begin{array}{l}\% \text { offspring } \\
\text { with IBD }\end{array}$ & Study area \\
\hline $\mathrm{IBD}(838)$ & 1981 & 16.3 & 3.1 & 4.7 & - & Cleveland $^{27}$ \\
\hline $\mathrm{CD}(400)$ & 1984 & 8.0 & 1.9 & 1.5 & 0.6 & The Netherlands ${ }^{6}$ \\
\hline $\mathrm{IBD}(179)$ & 1986 & $22.0^{\circ}$ & 2.6 & 4.6 & 1.9 & Chicago $^{3}$ \\
\hline $\operatorname{IBD}(188)$ & 1989 & 17.6 & 5.2 & 2.9 & 2.5 & Los Angelles ${ }^{16}$ \\
\hline UC (504) & 1991 & 8.1 & $1.6^{*}$ & - & - & Copenhagen $^{21}$ \\
\hline $\mathrm{CD}(133)$ & 1991 & 5.3 & $1.2^{*}$ & - & - & Copenhagen ${ }^{21}$ \\
\hline UC (963) & 1987 & 5.7 & - & - & - & Stockholm ${ }^{22}$ \\
\hline CD(1048) & 1991 & 8.9 & - & - & - & Stockholm ${ }^{23}$ \\
\hline $\mathrm{CD}$ (157) & 1991 & 6.5 & 1.5 & 1.0 & 0 & Hadassa $a^{25}$ \\
\hline $\operatorname{IBD}(352)$ & 1992 & 9.9 & - & - & - & Pennsylvania ${ }^{2 \pi}$ \\
\hline $\operatorname{IBD}(652)$ & 1992 & 5.5 & 1.2 & 0.5 & 0.4 & Northern Italy ${ }^{18}$ \\
\hline$C D(433)$ & 1994 & 11.5 & 4.2 & 2.2 & 0.8 & Oxfordshire ${ }^{29}$ \\
\hline UC (113) & & 3.5 & 0.8 & 0 & 1.9 & Present study \\
\hline $\mathrm{CD}(132)$ & & 5.3 & 2.2 & 0.4 & 0.6 & Present study \\
\hline
\end{tabular}

The estimated odds ratio for a positive family aggregation in IBD patients compared to controls in our study was lower than reported by others ${ }^{21-23}$. Confirmation of the diagnoses in relatives of patients could only be made in about half of the cases. One has to realise that, in contrast to the cases, an IBD diagnosis as reported by the controls could not be verified because of privacy reasons, which may have resulted in this lower odds ratio.

UC incidence was higher than $C D$ among relatives of UC patients, and vice versa $C D$ among relatives with $C D$. However, as has been observed in previous studies, both diseases were also observed within the same families with a higher frequency than expected only by chance $e^{20,24}$. This could suggest either an aetiologic 
relationship or a misclassification of the disease. A positive family history was somewhat greater among relatives of probands with $C D$, but this difference was not as large as expected from the results of previous studies $5,11,18,20,22,23,25$.

The age of onset of IBD seems to be correlated with the severity of the disease ${ }^{24}$. IBD patients with early age of onset have been reported to have an increased positive family history compared to patient populations with a higher age of onset ${ }^{1,20,23,26}$. UC patients without positive family histories have been reported to be older than UC patients with a positive history. We were not able to confirm this last observation.

In summary this population-based study, including only patients and relatives after confirmation of an IBD diagnosis according to strict criteria, shows one of the lowest prevalence figures reported in first-degree family members. Therefore, in our area patients can be reassured that the risk for family members to develop IBD is relatively low. 


\section{References}

1. Farmer RG. Study of family history among patients with inflammatory bowel disease. Scand J Gastroenterol Suppl 1989; 170:64-65.

2. Korelitz BI. IBD in families, pregnancy, and childhood. Mt Sinai J Med 1983; $50: 181-186$.

3. Lashner BA, Evans AA, Kirsner JB, Hanawer SB. Prevalence and incidence of inflammatory bowel disease in family members. Gastroenterol $1986 ; 91: 1396-1400$.

4. Monsen U. Inflammatory bowell disease. An epidemiological and genetic study. Acta Chir Scand Suppl 1990; 559:1-42.

5. Probert CS, Jayanthi $V$, Hughes AO, Thompson JR, Wicks AC, Mayberry JF. Prevalence and family risk of ulcerative colitis and Crohn's disease: an epidemiological study among Europeans and south Asians in Leicestershire. Gut 1993; $34: 1547-1551$.

6. Weterman IT, Pena AS. Familial incidence of Crohn's disease in The Netherlands and a review of the literature. Gastroenterol $1984 ; 86: 449-452$.

7. Sofaer J. Crohn's disease: the genetic contribution. Gut 1993; 34:869-871.

8. Purmann J, Bertrams J, Borchard F, Cleveland S, Berges W, Strohmeyer G. Crohn's disease in four members of a family, two of whom are dizygotic twins. Hepatogastroenterology $1990 ; 37: 81-82$.

9. Tysk C, Lindberg E, Järnerot G, Floderus-Myhred B. Ulcerative colitis and Crohn's disease in an unselected population of monozygotic and dizygotic twins. A study of heritability and the influence of smoking. Gut 1988; 29:990-996.

10. Yang $\mathbf{P}$, Järnerot $G$, Danielsson $D$, Tysk C, Lindberg E. P-Anca in monozygotic twins with inflammatory bowel disease. Gut 1995; 36:887-890.

11. Fielding JF. The relative risk of inflammatory bowel disease among parents and siblings of Crohn's disease patients. J Clin Gastroenterol 1986; 8:655-657.

12. Russel MGVM, Brummer $R$, Limonard $C$, Dorant $E$, Stockbrugger $\mathbb{R}$. Incidence and prevalence of inflammatory bowel disease in South Limburg, The Netherlands. Neth J Med 1994; 45:A32

13. Lennard-Jones JE. Classification of inflammatory bowel disease. Scand J Gastroenterol 1989; 24(suppl 170):2-6.

14. Metsemakers JFM, Höppener P, Knottnerus JA, Kocken RJJ, Limonard CBG. Computerized health information in The Netherlands: a registration of family practices. Br J Gen Prac 1992; 42:102-106.

15. Morris JA, Gardner MJ. Calculating confidence intervals for relative risks, odds ratios, and standardised ratios and rates. In: Gardner $M J$, Altman $D G$, editors. Statistics with confidence-confidence intervals and statistical guidlines. London: BMJ 1989; 50-63.

16. Roth MP, Petersen GM, McElree C, Vadheim CM, Panish JF, Rotter JI. Familal recurrence risk estimates of inflammatory bowel disease in Ashkenazi Jews. Gastroenterol 1989; 96:1016-1020.

17. Satsangi J, Jewell DP, Rosenberg WM, Bell JI. Genetics of inflammatory bowel disease. Gut 1994; 35:696-700. 
18. Meucci G, Vecchi M, Torgano G, Arrigoni M, Prada A, Rocca F, et al. Familial aggregation of inflammatory bowel disease in northern Italy: a multicenter study. The Gruppo di Studio per le Malattie Infiammatorie Intestinali (IBD Study Group). Gastroenterol 1992; 103:514-519.

19. Shohat $T$, Vadheim CM, Rotter JI. Genetics. In: Gitnick G, editor. Inflammatory bowel disease. New York: Igaku-Shoin 1991; 53-86.

20. Yang HY, McElree C, Roth MP, Shanahan F, Targan SR, Rotter JI. Famillial empirical risks for inflammatory bowel disease: differences between Jews and nonJews. Gut 1993; 34:517-524.

21. Orholm M, Munkholm P, Langholz E, Nielsen OH, Sorensen IA, Binder V. Familial occurrence of inflammatory bowel disease. $N$ Engl I Med 1991; 324:84-88.

22. Monsen U, Brostrom O, Nordenvall B, Sorstad J, Hellers G. Prevalence of inflammatory bowel disease among relatives of patients with ulcerative colitis. Scand J Gastroenterol 1987; 22:214-218.

23. Monsen U, Bernell $O$, Johansson $C$, Hellers G. Prewalence of inflammatory bowel disease among relatives of patients with Crohn's disease. Scand J Gastroenterol $1991 ; 26: 302-306$.

24. Yang HY, Rotter JI. The genetics of inflammatory bowel disease: genetic predisposition, disease markers, and genetic heterogeneity. In: Targan SR, Shanahan F, editors. Inflammatory bowel disease: from bench to bedside. 1st ed. Baltimore: Williams \& Wilkins 1994; 32-64.

25. Zlotogora J, Zimmerman J, Rachmilewitz D. Prevalence of inflammatory bowel disease in family members of Jewish Crohn's disease patients in Israel. Dig Dis Sci $1991 ; 36: 471-475$.

26. Gilat $T$, Hacohen $D$, Lilos $P$, Langman $M J$. Childhood factors in ulcerative colitis and Crohn's disease. An international cooperative study. Scand J Gastroenterol 1987; 22:1009-1024.

27. Farmer RG, Michener WM, Sivak DS. Studies of family histories in inflammatory bowel disease. In: Pena AS, Weterman IT, Booth CC, Strober W, editors. Recent advances in Crohn's disease. The Hague: Martinus Nijhoff 1981; 213-218.

28. Reed JF, 3d, Calkins BM, Rosen $\mathrm{L}$. Concordance of familial characteristics in Crohn's disease and ulcerative colitis. Dis Colon Rectum 1992; 35:405-410.

29. Satsangi J, Rosenberg WM, Jewell DP. The prevalence of inflammatory bowel disease in relatives of patients with Crohn"s disease. Eur J Gastroenterol Hepatol $1994 ; 6: 413-416$. 


\section{Chapter V}

\section{"Modern life" in the epidemiology of Inflammatory Bowel Disease: a case-control study with special emphasis on nutritional factors}

MGVM Russel, LGJB Engels, JWM Muris, ChBG Limonard, A Volovics, R-JM Brummer, RW Stockbrügger 


\begin{abstract}
Background: The rising incidence of IBD since the Second World War coincides with profound changes of the dietary pattern. The aim of the study was to investigate the possible pathogenic role of some characteristic "modern life" dietary factors in IBD.

Methods: A case-control study was performed, studying risk factors in recently diagnosed cases, 290 with Crohn's disease and 398 with ulcerative colitis, compared to 616 population-controls. Smoking, age, gender, and education were taken into account by using logistic regression analysis.

Results: A positive association with cola drinks (OR: $2.2(95 \% \mathrm{CI}: 1.5-3.1)$ ), chewing gum (OR: $1.5(95 \% \mathrm{CI}: 1.1-2.1)$ ), and chocolate (OR: $2.5(95 \% \mathrm{CI}: 1.8-3.5)$ ) and a negative association with citrus fruit consumption (OR: $0.5(95 \% \mathrm{CI}: 0.3-0.7)$ ) and the development of Crohn's disease was found. Consumption of cola drinks (OR: 1.6 (95\% CI: 1.1-2.3)) and chocolate consumption (OR. 2.5 (95\% CL 1.8-3.5)) was positively associated with developing ulcerative colitis. There was a negative association between the intake of citrus fruits (OR: $0.5(95 \% \mathrm{CI}: 0.4-0.8)$ ) and 'having a toy pet' for a period longer than five years (OR: 0.6 (95\% CI: 0.4-0.9)) and developing the disorder. Moreover was negatively associated with developing ulcerative colitis. No association with the frequency of tooth brushing and developing IBD was found.
\end{abstract}

Conclusions: All the nutritional items mentioned may be true risk factors, or they just might be the expression of a modern life-style also involving other risk factors for the development of IBD which at the present are still unknown. 


\section{Introduction}

In the Western world an increase in the incidence of ulcerative colitis (UC) started in the early 1950 s and has continued fairly stable for the last 25 years. In Crohn's disease $(\mathrm{CD})$, the most rapid increase in frequency occurred during the period $1965-80$, reaching a plateau in recent years ${ }^{1-4}$.

At present the cause(s) of $\mathrm{CD}$ and UC are unknown. However, there are strong arguments to suggest that, in addition to a genetic predisposition, environmental risk factors are important in the pathogenesis of Inflammatory Bowel Disease $(\mathrm{IBD})^{5,6}$. In the industrialized world, the rising incidence of IBD during the last half century coincides with profound changes in environmental factors, especially the dietary pattern. This has led us to investigate the possible pathogenic role of some characteristic "modern life" dietary factors in UC and CD in a case-control study of recently diagnosed patients.

\section{Patients and methods}

\section{Cases}

All cases studied were non-hospitalized at the time of the investigation and had varying degrees of disease activity. They are participating in the South Limburg Epidemiological Study on Inflammatory Bowel Disease (IBD), an ongoing project on epidemiology, pathogenesis, and clinical course of IBD in the south-east of The Netherlands ${ }^{7}$. The study area has a population of about 642.000 inhabitants, and medical care to IBD patients is provided mainly by specialists working at six hospitals (one university hospital, two general district hospitals, and three local hospitals). Since October 1991, prevalent as well as incident cases of IBD have been reported by the specialists to the IBD study centre. All patients received a mailed questionnaire within a period of six months after they had given informed consent for data collection. Medical data were subsequently collected from the medical records.

The criteria of Lennard-Jones were applied in case definition for CD and those of Truelove \& Witts for $\mathrm{UC}^{8}$.

Using all the available medical information ohtained during the first six months after diagnosis, location of the disease in the lirge and small bowel was carefully recorded. CD was subdivided into exclusive small bowel disease, exclusive colonic disease, and combined small and large bowel disease. UC was subdivided into ulcerative proctitis (UP) and extended ulcerative colitis (e-UC), depending on whether or not the disease extended proximal to the rectosigmoidal junction. In e-UC a further difference between left-sided colitis (inflammation up to, but not 
beyond, the splenic flexure) and pancolitis (inflammation beyond the splenic flexure) was made. Patients with a diagnosis of indeterminate colitis $(n=104$ of a total of 1567) were excluded from subsequent data analysis.

Patients with $\mathrm{CD}$ or UC who had been reported during the period from October 1991 to July 1996 were eligible for the present study. In order to reduce confounding by recall bias, only cases whose complaints had started within a maximum of five years before receiving the questionnaire were included in the analysis.

\section{Controls}

Controls were all living in the study area and had no history of IBD. They were recruited in co-operation with the Registration Network Family Practices (RNH), which is a reliable dynamic sampling frame of the Dutch general population'. Out of 47.750 registered patients at the $\mathrm{RNH}$, a sample of 924 persons was randomly selected. This group received the questionnaire in May 1994.

\section{Questionnaire}

The questionnaire included detailed questions on the average consumption of selected nutrients during the five years before the first symptoms of IBD in patients, and during the period $1985-1990$ in controls. In order to investigate a possible change in the consumption pattern, we asked both groups to report their current consumption pattern as well. The specific nutrients selected for the questionnaire were: daily number of cups of coffee (with or without sugar) and tea (with or without sugar); weekly consumption of cola drinks, orange juice, citrus fruits, chocolate, sweets, and chewing gum (three categories: "none or one", "between 2-5 times", "more than 5 times weekly"); and weekly intake of portions of fish, and preserved food consumption. Cigarette smoking behavior was recorded for the retrospective and the current period (yes/no and the extent to which patients/controls smoked cigarettes (1-9, 10-19, >19 cigarettes per day)). Patients were also asked whether they had stopped smoking before the first complaints, Whereas controls were asked whether they had stopped smoking before 1987. Women were questioned on oral contraceptive use (ever used). The level of education was scored in three categories: elementary school and lower professional training only, high school for at least four years, and university. Furthermore information on breastfeeding (yes/no), use of an artificial nipple as an infant for more than two years (yes/no), and the habit of sleeping with a toy pet during a period longer than five years (yes/no) was also recorded. Finally, questions on 
dental care characteristics were asked (denture (yes/no), fillings (yes/no), and the frequency of teeth brushing during both periods).

\section{Statistical analysis}

Descriptive statistics are provided as median with 25 and 75 percentiles in brackets and frequencies with percentages in brackets. The entire group of controls was used for both series of cases. The odds ratios (OR) with corresponding $95 \%$ confidence intervals $(95 \% \mathrm{Cl})$ were estimated by multiple logistic regression analysis with dummy variables indicating the different categories of potential confounders. Four separate analyses were performed: consumption before complaints and present consumption in $\mathrm{CD}$ and in $\mathrm{UC}$ respectively. Age at time of the questionnaire, gender, education, smoking, and oral contraceptive use were all taken into account in the equation. All statistical analyses were performed with the SPSS package 6.0 for Windows. P-values less than 0.05 were considered as being statistically significant.

\section{Results}

Between October 1991 and July 1996, a total number of 1463 patients were reported to the study centre with a diagnosis of either UC or $\mathrm{CD}$ according to the study criteria. After a maximum of two reminders $1355(93 \%)$ cases of IBD (687 patients with UC and 668 patients with $\mathrm{CD}$ ) responded to the questionnaire. Of this group of 1355 patients $417(31 \%)$ were newly-diagnosed whereas the others were already known with IBD before the start of the registration. A total of $688(51 \%)$ patients (290 with CD and 398 with UC), reporting the first complaints within 5 years from receiving the questionnaire, were subsequently selected for the present study. Mapping of disease location was available of $248(86 \%)$ patients with CD and of $342(86 \%)$ patients with UC. In the control group the questionnaire was completed by 616 persons $(67 \%)$, who were all included in the analysis. The demographic characteristics of both groups are presented in Table 5.1.

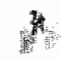




\begin{tabular}{|c|c|c|c|}
\hline & controlls & Crohn's dissease & ulcerative colitis \\
\hline Nunnter & 616 & 290 & 398 \\
\hline $\begin{array}{l}\text { Agge at first complaints / } \\
\text { in } 1987^{* *} \text { (controls) }\end{array}$ & $30(22-44)$ & $27(21-38)$ & $36(27-51)$ \\
\hline * Age at diagnosis & - & $28(21-38)$ & $36(27.51)$ \\
\hline *Age at questionnaire & $37(29-51)$ & $29(24-40)$ & $39(30-54)$ \\
\hline Gender (\% fenale) & 48 & 57 & 43 \\
\hline \multicolumn{4}{|l|}{ Eudiucational level } \\
\hline low $(\%)$ & 30 & 39 & 32 \\
\hline middle (\%) & 38 & 35 & 43 \\
\hline high (\%) & 32 & 26 & 25 \\
\hline \multicolumn{4}{|l|}{ Disease location } \\
\hline small bowel onty $\operatorname{ar}(\%)$ & & $71(25)$ & \\
\hline large bowel only $\operatorname{nr}(\%)$ & & $37(13)$ & \\
\hline small and large bowel $\operatorname{mr}(\%)$ & & $149(48)$ & \\
\hline proctivis nr(喿) & & & 61 (15) \\
\hline left-sided colitis $\operatorname{mr}(\%)$ & & & $177(45)$ \\
\hline pancolitis nr(\%) & & & $104(26)$ \\
\hline
\end{tabular}

* median (25-75 percentiles)

* 1987 in controls replaces the year of first complaints in cases

\section{Smoking and oral contraceptive use}

Accurate data on smoking history and present status were available in $99 \%$ of the patient group and $97 \%$ of the control population. The estimated odds ratios were derived from the multiple logistic regression analyses and are shown in Table 5.2. Compared to controls, $\mathrm{CD}$ patients were more likely to be smokers before the first complaints of IBD and also after the diagnosis had been made at the time of the questionnaire. The risk of developing UC was highest in patients who had stopped smoking before the first complaints, but never-smokers also had a higher risk of developing the disease. At the time of the questionnaire UC patients were less likely to smoke than controls.

No significant difference was observed between controls and patients with either disease concerning the use of oral contraceptives. 


\begin{tabular}{|c|c|c|c|c|c|}
\hline & $\begin{array}{c}\text { controls } \\
\%\end{array}$ & $\begin{array}{l}\text { Crohn's } \\
\text { disease \% }\end{array}$ & $\begin{array}{c}\text { OR } \\
\left(95 \% \mathrm{CI}^{*}\right.\end{array}$ & $\begin{array}{l}\text { ulcerative } \\
\text { colitis \% }\end{array}$ & $\begin{array}{c}\text { OR } \\
\left(95 \% \mathrm{Cl}^{*}\right.\end{array}$ \\
\hline $\begin{array}{l}\text { Non-smokers at first } \\
\text { complaints / in } 1987^{* *}\end{array}$ & 41 & 36 & & 39 & \\
\hline $\begin{array}{l}\text { Smokers at first } \\
\text { complaints / in } 1987^{* *}\end{array}$ & 41 & 50 & $1.5(1.0-2,2)$ & 21 & $0.4(0.3-0.6)$ \\
\hline $\begin{array}{l}\text { Ex-smokers at first } \\
\text { complaints / in } 1987^{4 *}\end{array}$ & 18 & 14 & $1.4(0.8-2.3)$ & 39 & $2.4(1.6-3.5)$ \\
\hline $\begin{array}{l}\text { Present smokers } \\
\text { (questionnaire) }\end{array}$ & 32 & 46 & $1.6(1.2-2.3)$ & 15 & $0.3(0.2-0.4)$ \\
\hline $\begin{array}{l}\text { Oral contraceptive } \\
\text { use ever (\% of females) }\end{array}$ & 81 & 86 & $1.2(0.4-3.1)$ & 82 & $1.2(0.6 \mathrm{~m} 2.4)$ \\
\hline
\end{tabular}

* Logistic regression estimated odds ratios, adjusted for age, gender and educational level

* 1987 in controls replaces the year of first complaints in cases.

The significant finding of the selected nutrional items are presented in Table $\mathbf{5 . 3}$ for $\mathrm{CD}$ and in Table $\mathbf{5 . 4}$ for UC.

\section{Selected nutritional items before complaints}

A positive association of the consumption of chocolate, cola drinks, and chewing gum, and a negative association of the consumption of citrus fruits before the first complaints was found with $\mathrm{CD}$ (Table 5.3). After dividing the group into nonsmokers (including ex-smokers) and smokers before the first complaints, the odds ratios changed slightly: in non-smokers the odds ratios to develop $C D$ were for chocolate $3.2(95 \% \mathrm{CI}: 1.9-5.4)$, for cola drinks $2.5(95 \% \mathrm{CI}: 1.4-4.3)$, for chewing gum $1.7(95 \% \mathrm{CI}: 1.0-3.0)$, and citrus fruits $0.7(95 \% \mathrm{Cl}: 0.4-1.2)$. The corresponding odds ratios in smokers at first complaints were: chocolate $2.0(95 \%$ CI: $1.2-3.4)$, cola drinks 2.0 (95\% CI: $1.2-3.4)$, chewing gum $1.2(95 \% \mathrm{CI}: 0.7-$ 2.1 ), and citrus fruits $0.7(95 \% \mathrm{CI}: 0.5-1.2)$ respectively.

As shown in Table 5.4, the consumption of cola drinks and chocolate consumption was positively associated with developing $\mathrm{UC}^{7}$ There was a negative association between the intake of citrus fruits and developing the disorder. Moreover 'having a toy pet' for a period longer than five years was negatively associated with developing UC. In the group of non-smokers at the time of first complaints the odds ratios of developing UC were for chocolate $3.0(95 \% \mathrm{CI}: 1.9-4.4)$, for cola drinks 1.8 (95\% CI: $1.1-2.7)$, for citrus fruits $0.7(95 \% \mathrm{CI}: 0.5-1.1)$, and for 
"having a toy pet" $0.5(95 \%$ CI: $0.3-0.8)$. The corresponding odds ratios in smokers at first complaints were: chocolate 1.5 (95\% CI: 0.9-2.9), cola drinks 1.7 (95\% Cl: $0.8-3.2)$, citrus fruits $1.0(95 \% \mathrm{CI}: 0.5-2.0)$, and having a toy pet 1.2 (95\% CI: $0.6-2.4)$ respectively

\section{Selected nutritional items at the time of the questionnaire}

To investigate whether the consumption pattern of the selected items had changed over time, we also asked the patients to report their current intake. In $C D$ (Table 5.3) the association with chocolate and chewing gum was no longer observed, whereas cola drinks were still significantly more often reported by patients, although the calculated odds ratio was lower than before the first symptoms $1.4(95 \% \mathrm{CI}: 1.0-2.0)$. The negative association with citrus fruits at the time of the questionnaire 0.4 (95\% CI: $0.2-0.5$ )) was comparable with the findings of the period before the first complaints. Coffee (with or without sugar) was consumed less often at the time of the questionnaire, and, on the other hand, tea with sugar more frequently.

At the time of the questionnaire, three nutrinal items were significantly associated with having UC (Table 5.4): a positive association for chocolate consumption 1.8 (95\% CI: 1.3-2.4), and a negative association for both citrus fruits intake and coffee (with or without sugar) drinking.

\section{Disease location and risk factors}

In $84 \%$ of the patients with $\mathrm{CD}$ adequate mapping of disease location was available. With respect to disease location, the positive association between consumption of cola drinks, chocolate and chewing gum before first complaints was highest in isolated small bowel disease with odds ratios of $3.2(95 \% \mathrm{Cr}: 1.4-$ 7.6), 3.3 (95\% Cl: $1.4-7.5$ ), and 2.2 (95\% CI: 0.9-5.2) respectively. The negative association with citrus fruits was only significant in patients with isolated colonic disease: 0.4 (95\% CI: $0.2-0.7)$. A remarkably strong association between stopping smoking before complaints and isolated colonic disease was observed with an odds ratio of 3.1 (95\% CI: 1.4-6.9).

In UC, where adequate mapping was also available in $84 \%$ of the patients, the positive association with chocolate consumption before the first complaints was observed in all subgroups with comparable odds ratios, whereas the positive association with cola drinks, and the negative association with citrus fruits and 'having a toy pet' longer than five years was only significant in the largest subgroup with left-sided colitis. Finally, a positive association was observed in the pancolitis group with breastfeeding 2.0 (95\% CI: 1.0-3.9). 


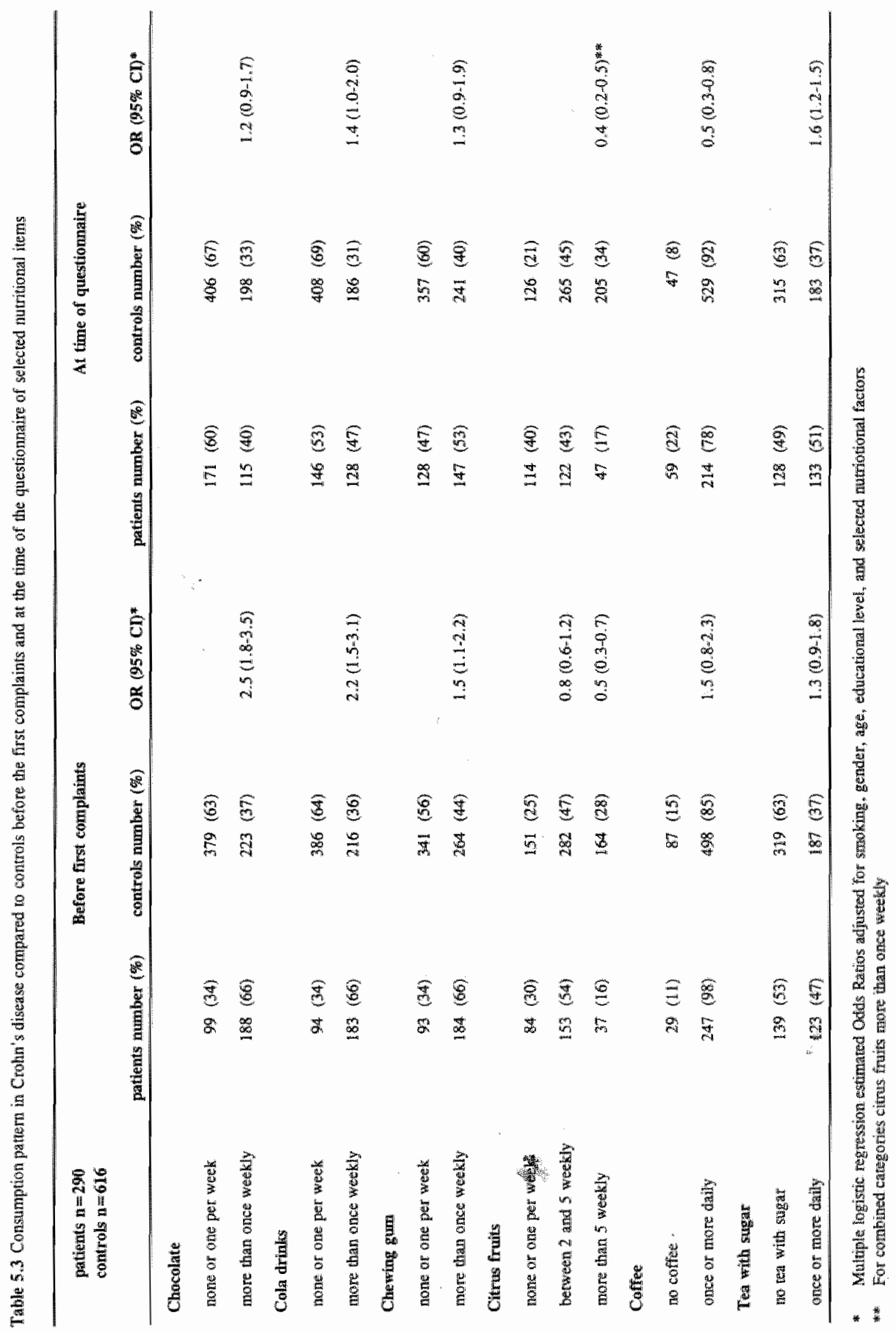




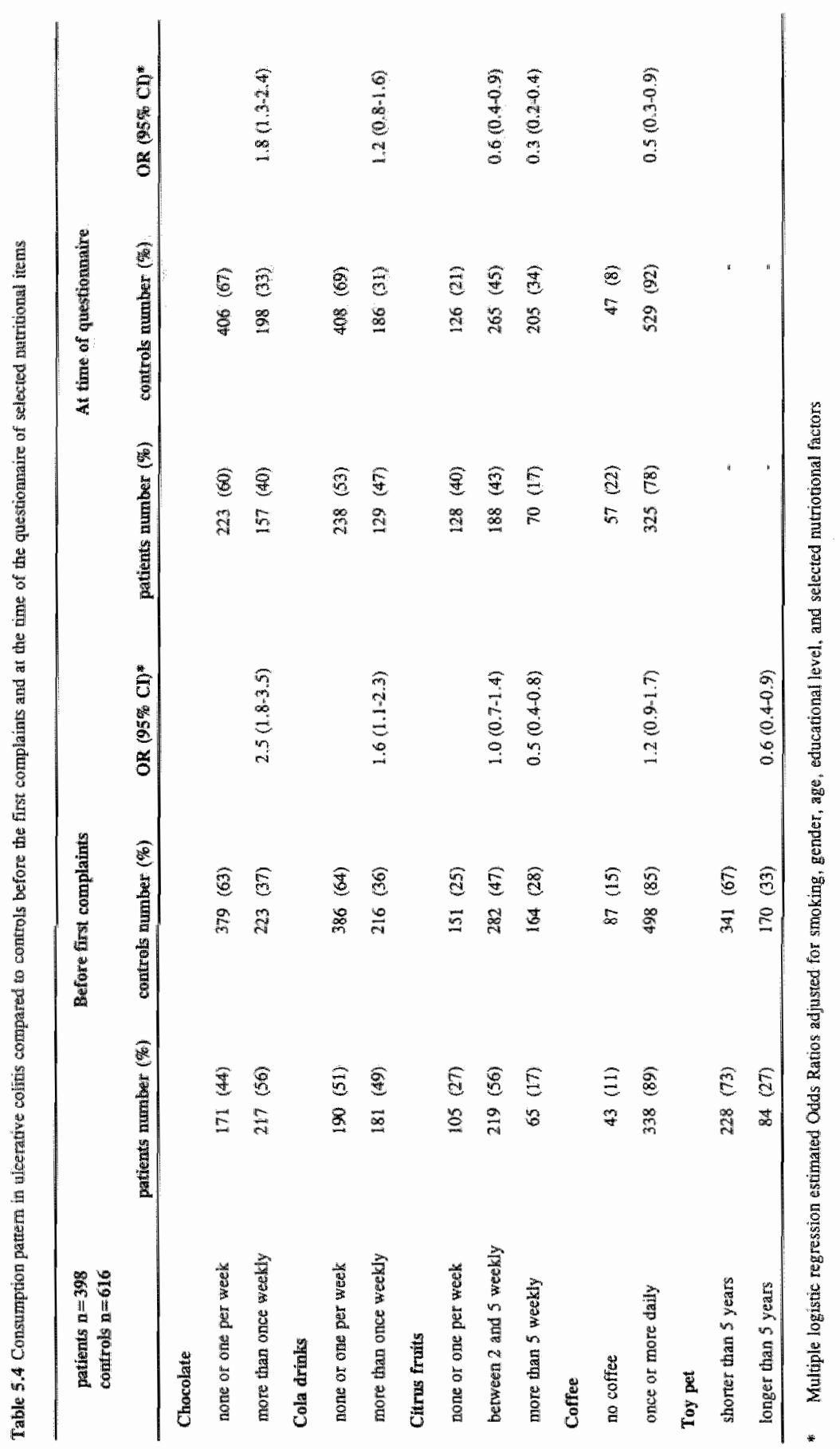




\section{Non-significant findings}

Oral contraceptive use, breastfeeding, and the use of an artificial nipple were not associated with the development of IBD, as were the consumption of fish, preserved food consumption, the daily number of cups of coffee and, orange juice, and sweets. None of the dental care characteristics addressed in our survey was significantly associated with developing either CD or UC.

\section{Discussion}

There is no doubt that in the Western world nutritional. habits have changed over the past decades. In the same period the incidence of $\mathrm{CD}$ and UC have increased. Food is a major factor affecting the intestinal environment, and the considerable change in dietary habits may explain why IBD has become more frequent. To investigate nutrition as a possible risk factor for the development of IBD, some typical modern life nutritional items were selected for the present study.

The major finding of the present study was a greater risk for $C D$ among those with a high consumption of chocolate, chewing gum, and cola drinks, whereas a decreased risk was observed with a high intake of citrus fruits. Except for chewing gum, the consumption of these food items was also associated with the development of UC.

What is the common denominator of the selected nutritional items implicated? In Europe, the consumption of chocolate, cola drinks and chewing gum has steadily increased since the Second World War, and might be regarded as a typical modern life-style living habit. Overall, the intake of citrus fruits also has increased during the same period. However, a relatively low intake of citrus fruits might correspond to a life style based on concentrated carbohydrates and fat. In line with this view, the group of Persson et al. has reported a positive association with fast food consumption and $\mathrm{IBD}^{10}$. The authors stated that eating fast-food probably defined a life-style rather than the consumption of specific foods and drinks. An interesting study from Japan, examining the correlation between the rise of the incidence of $\mathrm{CD}$ and parallel changes of dietary habits, showed that the rapidly rising incidence of $\mathrm{CD}$ in that country was strongly correlated with increased dietary fat intake ${ }^{11}$. In the opinion of the authors, the composition of the fat intake, high in (n-6) fatty acids and relatively low in $(\mathrm{n}-3)$ fatty acids, was of importance with regard to the pathogenetic mechanism. This interesting finding has yet to be confirmed by other studies.

Chocolate, cola drinks and chewing gum all share a high sugar content. Previous studies have consistently found strong positive associations between sweetened foods and $\mathrm{IBD}^{12-19}$. This might be interpreted as a consequence of the disease rather 
than a factor in its pathogenesis. Refuned sugar is rapidly absorbed in the small intestine and has no bulking effect. Patients may increase the consumption of sugar at an early stage of the disease in an attempt to compensate for loss of energy or weight. However, a causal relationship between long-term increased consumption of refined sugar and the pathogenesis of $C D$ could be explained by a change in the intestinal bacterial flora, potentially leading to intestinal mucosal damage ${ }^{i 4}$.

A decreased consumption of fruit, as was found in our study concerning citrus fruits, has inconsistently been reported in $\mathrm{IBD}^{14,20-22}$. Also here it can be argued that before diagnosis patients with IBD modified their diet in an effort to overcome symptoms of subacute obstruction, weight loss and loose stool ${ }^{23}$. Therefore it is of great importance to investigate the pre-illness diet. This was the reason for asking the patients to provide information on the consumption pattern before the first complaints of their bowel disease.

In an effort to reduce recall bias, only newly and recently diagnosed patients were included, limiting the dietary recall period to five years and taking as a cut-off limit the start of complaints according to the patient's view rather than the date of diagnosis. Both retrospective and current dietary questionning are likely to cause some misclassification with regard to food consumption during the relevant period of time in the past ${ }^{24}$. The so called "rumination bias" (cases doing more efforts to remember past habits than controls, leading to differential misclassification) is difficult to rule out in studies investigating dietary habits before symptom onset. Whereas we have no reason to believe that patients would over-report their dietary intake in comparison with controls in the present study, it remains difficult to prove the absence of over-reporting of consumption in cases compared to controls. To gain more knowledge on the direction of possible changes in the consumption pattern, we have recorded the dietary habits at the time before the first complaints as well as the present consumption pattern. The present intake of chocolate, cola drinks and use of chewing gum in patients changed with regard to that of controls. However, also at the latter time point a higher intake was still noted in the patient group.

As has been consistently reported before, smoking was positively associated with CD, whereas non-smoking and stopping smoking both were associated with UC. Smoking as a possible confounder was adjusted for by using multiple logistic regression as was done with age, gender and educational status ${ }^{25-29}$. In a second analysis, we investigated the odds ratios in never-smokers and in the group who smoked or had smoked separately, leading to basically the same results. Others have found that smoking and increased sugar intake are separate but also interactive risk factors in $\mathrm{CD}^{17}$.

No significant differences were found concerning the use of oral contraceptives, another factor reported to be associated with $\mathrm{IBD}^{30}$.

A negative association with coffee consumption at time of the questionnaire was 
observed in both $C D$ and $U C$ and a positive association with sugared tea in $C D$. These findings were only observed after the diagnosis of IBD and should probably be regarded as consequences of the disease rather than factors in the pathogenesis of IBD. A negative association with coffee consumption has been reported before, but other studies have shown no marked different association between cases and controls and even a positive association has been reported $d^{10,14,22,31-33}$.

A striking finding was a decreased risk of UC in patients having had a toy pet for a period longer than five years. Based on the small number of exposed subjects, the significance of this result might be explained by a minimal differential misclassification. However, we have no reason to believe that only the cases have underreported this peculiar item. Originally, this item was included in the questionnaire to investigate a possible (positive) association with $\mathrm{CD}$ in the view of increased ingestion of foreign material, which hypothetically might lead to the formation of granulomas in the bowel ${ }^{34}$. However, in this study having a toy pet longer than five years as a child appeared to be less frequent in non-smokers who subsequently developed UC. It might be speculated that smoking is a substitute for having a toy pet at child age, but we realize that we enter a vague area of explanation.

In the present study cases were identified occurring in a well-defined population. A random sample from the same population was selected as controls. This is in contrast to most case-control studies investigating diet in IBD, which have used patients with other diagnoses as controls (hospital controls) ${ }^{35}$. Hospital controls are mostly diseased people, and the chance exists that their disease is associated with the exposure under study, in which case they do not constitute an appropriate control series. Since age and gender of the controls were not perfectly matched in the design of the present study, we adjusted in the analysis for both as well as for educational status.

To elucidate whether risks were related to a specific disease location, subgroup analysis also under this aspect was performed. In this calculation the number of patients included in each analysis is low, resulting in wider confidence intervals and possibly masking true associations. The highest odds ratios for chocolate, cola drinks, and chewing gum were observed in small bowel $C D$, which corrobarates the findings of Persson et al. concerning the intake of sucrose in this subgroup ${ }^{10}$. A remarkable finding was the positive association of stopping smoking and Crohn's colitis, supporting the hypothesis that smoking protects the colon from inflammation in both subgroups of $\mathrm{IBD}^{27}$.

Because of the previously reported positive association with refined sugar consumption and $\mathrm{CD}$, we included some questions on dental care in the questionnaire. The higher consumption of sugar, if present at all, seemed not to have caused more frequent use of dentures or dental prostheses by patients than by controls. Secondly, the interesting and much debated hypothesis on the relation 
between the use of toothpaste and $C D$, as reported by Sullivan, was investigated ${ }^{36-38}$. No association was found between the presence of $\mathrm{CD}$ concerning the frequency of teeth brushing either before the first complaints or after the diagnosis had been made.

In summary, in this case-control study some distinct nutritional factors were found to be associated with IBD: the consumption of colla drinks, chocolate and chewing gum were all positively associated with the development of $\mathrm{CD}$ and the former two also with the development of $\mathrm{UC}$ in comparison with the controls. The investigated items with high odds ratios reflect a different consumption pattern preceding the rise in incidence of $C D$ and $U C$. A decreased use of citrus fruits was found to be a risk factor in the development of IBD. All the nutritional items mentioned may be true risk factors, or they might merely be the expression of a modern life-style also involving other risk factors for the development of IBD which at the present are still unknown. An ongoing study, restricted to newly-diagnosed IBD patients, pairwise matched with controls, will, we hope, provide more insight into the relevance of the findings presented ${ }^{39}$. 


\section{References}

1. Srivastava ED, Mayberry JF, Morris TJ, Smith PM, Williams GT, Roberts GM, et al. Incidence of ulcerative colitis in Cardiff over 20 years: 1968-87. Gut 1992; $33.256-258$.

2. Langholz E, Munkholm $\mathrm{P}$, Nielsen $\mathrm{OH}$, Kreiner $\mathrm{S}$, Binder $\mathrm{V}$. Incidence and prevalence of ulcerative colitis in Copenhagen county from 1962 to 1987 . Scand J Gastroenterol 1991; 26:1247-1256.

3. Calkins BM, Lilienfeld AM, Garland CF, Mendeloff AI. Trends in incidence rates of ulcerative colitis and Crohn's disease. Dig Dis Sci 1984; 29:913-920.

4. Gillat T. Incidence of inflammatory bowel disease: going up or down? Gastroenterol $1983 ; 85: 196-197$.

5. Jewell DP. Pathogenesis of Crohn's disease: the environment revisited. Eur J Gastroenterol Hepatol 1995; 7:383-384.

6. Levine J, Exogenous factors in Crohn's disease. A critical review. J Clin Gastroenterol 1992; 14:216-226.

7. Russel MGVM, Brummer R, Limonard C, Dorant E, Stockbrügger RW. Incidence and prevalence of inflammatory bowel disease in South Limburg, The Netherlands. Neth J Med 1994; 45:A32

8. Lennard-Jones JE. Classification of inflammatory bowel disease. Scand J Gastroenterol 1989; 24(suppl 170):2-6.

9. Metsemakers JFM, Höppener P, Knottnerus JA, Kocken RJJ, Limonard CBG. Computerized health information in the Netherlands: a registration of family practices. Br J Gen Prac 1992; 42:102-106.

10. Persson PG, Ahlbom A, Hellers G. Diet and inflammatory bowel disease: a casecontrol study. Epidemiology $1992 ; 3: 47-52$.

11. Shoda $\mathbb{R}$, Matsueda $K$, Shigeru $Y$, Umeda $N$. Epidemiologic analysis of Crohn disease in Japan: increased dietary intake of $n-6$ polyunsturated fatty acids and animal protein relates to the increased incidence of Crohn disease in Japan. Am J

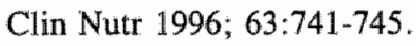

12. Sonnenberg A. Geographic and temporal variations of sugar and margarine consumption in relation to Crohn's disease. Digestion 1988; 41:161-171.

13. Mayberry JF, Rhodes J. Epidemiological aspects of Crohn's disease: a review of the literature. Gut 1984; 25:886-899.

14. Martini GA, Brandes JW. Increased consumption of refined sugar in patients with Crohn's disease. Klin Wochenschr 1976; 54:367-371.

15. James A. Breakfast and Crohn's disease. Br Med J 1977; 1:943-945.

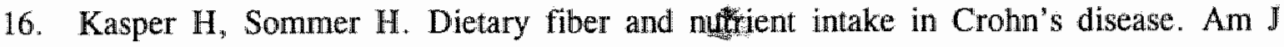
Clin Nutr 1979; 32:1898-1901.

17. Katschinski B, Logan RF, Edmond M, Langman MJ. Smoking and sugar intake are separate but interactive risk factors in Crohn's disease. Gut 1988; 29:1202-1206.

18. Beattie RM, Walker Smith JA. Treatment of active Crohn's disease by exclusion diet. J Pediatr Gastroenterol Nutr 1994; 19:135-136. 
19. Mayberry JF, Rhodes I. Increased sugar consumption in Crohn's disease. Digestion $1980 ; 323-326$.

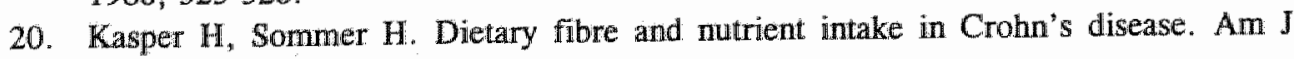
Clin Nutr 1979; 1898-1901.

21. Thornton JR, Emmet PM, Heaton KW. Diet and Crohn"s disease: characteristics of the pre-illness diet. Br Med I 1979; 762-764.

22. Panza E, Franchesi $S$, La Vecchia $S$, Parranzini $F$, Petrillo $M$, Decarli $A$, et al. Dietary factors in the aetiology of inflammatory bowel disease. Ital I Gastroenterol $1987 ; 19: 205-209$.

23. O'Morain C, Tobin A, Suzuki $Y$, O'Rjordan T. Risk factors in inflammatory bowel disease. Scand J Gastroenterol Supp1 1989; 170:58-60.

24. Persson $P G$, Ahlbom A, Norell SE. Retrospective versus original information on diet: implications for epidemiological studies. Int J Epidemiol 1990; 19:343-348.

25. Forbes A. Smoking and inflammatory bowel disease. Eur $\mathfrak{J}$ Gastroenterol Hepatol $1996 ; 8: 761-763$.

26. Järnerot $G$, Lindberg $E$, Tysk $C$. Smoking and inflammatory bowel disease. Gastroenterol Hepatol 1995; 18:507-509.

27. Benoni C. Lifestyle issues in inflammatory bowel disease - smoking. Can $J$ Gastroenterol 1994; 8:(7)422-427.

28. Osborne MJ, Stansby G. Smoking and chronic inflammatory bowel disease. J R Soc Health 1994; 114:317-319.

29. Silverstein MD, Lashner BA, Hanauer SB. Cigarette smoking and ulcerative colitis: a case-control study. Mayo Clin Proc 1994; 69:425-429.

30. Godet $P G$, May GR, Sutherland LR. Meta-analysis of the role of oral contraceptive agents in inflanmatory bowel disease. Gut 1995; 37:668-673.

31. Boyko EJ, Perera DR, Koepsell TD, Keane EM, Inui TS. Coffee and alcohol use and the risk of ulcerative colitis. Am J Gastroenterol 1989; 84:530-534.

32. Gilat $T$, Hacohen $D$, Lilos P, Langman MJ. Childhood factors in ulcerative colitis and Crohn"s disease. An international co-operative study. Scand J Gastroenterol 1987; $22: 1009-1024$.

33. Mayberry JF, Rhodes J, Allan RN, Newcombe RG, Regan GM, Chamberlain LM, et al. Diet in Crohn's disease: two studies of current and previous habits in newly diagnosed patients. Dig Dis Sci 1981; 26:444-448.

34. Levine, J. Exogenous factors in Crohn's disease. A critical review. J Clin Gastroenterol 1992;14(3):216-226.

35. Persson PG, Hellers G. Crohn's disease and ulcerative colitis. A review of dietary studies with emphasis on methodologic aspects. Scand J Gastroenterol 1987; 22:385-389.

36. Sullivan SN. Hypothesis revisited: toothpaste and the cause of Crohn's disease. Lancet 1990; 336: 1096-1097. map ethiology.

37. Anonymous. Toothpaste and Crohn's disease [letter]. Lancet 1990; 336:1580-1582.

38. Anonymous. "Toothpaste and Crohn's disease [letter]. Lancet 1990; 336:1382 
39. Geerling B, Brummer R-J, Stockbrügger R.W. Decreased trace ellement status in patients with inflammatory bowel disease. 5th United European Gastroenterology Week, Paris, November 2-6 1996; 1996;39(Suppl 3):A234. 


\section{Chapter VI}

\section{Appendectomy and the risk of developing ulcerative colitis or Crohn's disease: results of a large case-control study}

MGVM Russel, E Dorant, R-JM Brummer, MA van de Kruijs, JWM Muris, JM Bergers, J Goedhard, RW Stockbrügger, and the South Limburg IBD Study Group 


\begin{abstract}
Background/Aims: "To elucidate the role of appendectomy in Inflammatory Bowel Disease (IBD) a case-control study was performed in a well-defined population.

Methods: Seven years" prevalent and 3.5 years" incident cases with IBD, registered in South Limburg, The Netherlands, were separately studied. Controls were age- and sexmatched subjects from the same population.

Results: In 232 prevalent ulcerative colitis (UC) cases the risk of developing UC was significantly lower after previous appendectomy (OR: $0.36(95 \% \mathrm{Cl}: \quad 0.15-0.80)$ ); subgroup analysis found a protective effect only in pancolitis (OR: $0.2(95 \% \mathrm{CI}: 0.02$ $0.7)$ ). In 208 patients with Crohn's Disease (CD) the odds ratio was not significantly increased, but a positive association with appendectomy was observed in ileocoecal disease. A significant larger proportion of appendectomies was performed close to the time of diagnosis. Smoking was not a confounding factor. No statistically significant associations were observed in incident IBD patients. Prevalent and uncident patients taken together resulted in odds ratios of $0.44(95 \% \mathrm{CI}: 0.24-0.78)$ in $\mathrm{UC}$ and $1.65(95 \% \mathrm{CI}$ : $0.96-2.91$ ) in $\mathrm{CD}$.
\end{abstract}

Conclusions: An overall protective role of appendectomy for UC was observed; however, this was only significant in the prevalent patient group. The observations in CD suggest that appendectomy in some cases was due to still undiagnosed CD. The fact that sex- and age- matched population-controls were used in this study may contribute to a less pronounced association between appendectomy and UC than recently reported by others. 


\section{Introduction}

The aetiology of ulcerative colitis (UC) and Crohn's disease (CD) is unknown. There is evidence for an intense and prolonged local mucosal immune response, associated with recruitment and activation of lymphocytes and macrophages ${ }^{1}$. The factor(s) triggering this response is (are) presently unknown, but there are strong indications that inflammatory bowel disease (IBD) should be regarded as a multifactorial disease, involving an interaction between genetic and environmental factors, that give rise to an inadequate immunological response ${ }^{2,3}$.

Recently the role of appendectomy in the pathogenesis of IBD has been discussed. At present, four fully published studies have shown a negative association between appendectomy and $\mathrm{UC}^{4-7}$. The biological explanation for this association is unclear. Factors predisposing for appendicitis may protect against UC, or removal of the appendix may alter the immune response of the gut, making the development of UC less likely.

The relationship between appendectomy and $C D$ was investigated in three of the studies $^{4-6}$. In two studies a positive correlation between appendectomy and CD was observed, but no data were given on the time interval between the surgical procedure and IBD diagnosis ${ }^{4,5}$.

Patient as well as control selection has varied widely in the preceding studies. To further elucidate the suggested relations between appendectomy and the development of IBD, a case-control study was carried out in The Netherlands. To evaluate whether the results depend on the prevalence or incidence status of the cases, we separately analyzed the data of prevalent cases as well as of a group of newly-diagnosed incident patients with either UC or CD.

\section{Patients and methods}

Patients all lived in the South Limburg area, located in the south-east of The Netherlands, and were diagnosed as having either UC or CD according to the definitions of Truelove \& Witts and Lennard-Jones ${ }^{8}$. On January 1 1991; the region had a population of 638.781 . There are six hospitals (five general district hospitals and one university hospital) situated in the study area. From October 1991 onwards, specialists working in these hospitals were asked to report all their patients with inflammatory bowel disease to the South Limburg IBD Study Centre, as part of an ongoing study on the prevalence and incidence of IBD in this area.

In the present study, two analyses were performed: the first of all prevalent patients until January 1 1991, who were diagnosed since January 1984 and the second of a group of incident cases with UC and CD registered at the IBD Study Centre from January 1991 until November 1994, who had been diagnosed between 
January 1991 and September 1994. The overall odds ratios in combined prevalent and incident patients with $\mathrm{UC}$ and $\mathrm{CD}$ were subsequently calculated. After the written informed consent of the patients had been obtained, additional medical data on disease characteristics and localization of inflammation were collected from the medical charts and subsequently the diagnoses were verified according to the study criteria by a panel of senior gastroenterologists.

The controls were all living in the study area and had no history of IBD. They were recruited in cooperation with the Registration Network Family Practices (RNH), which is a reliable dynamic sampling frame of the Dutch general population. Out of 47.750 registered persons at the $\mathrm{RNH}$, a sample of 936 persons, with no record of having IBD, were randomly selected.

Complementary data were obtained by a postal questionnaire. In this questionnaire the patients and controls were asked about their smoking status and whether an appendectomy had been performed, and -if so- at what date. When it was not evident whether the appendectomy had been performed before or after the diagnosis of IBD was made, the patients were approached for more detailed information by a second questionnaire or by telephone.

Subsequently, for both analyses, two matched control groups were established, one for UC and the other for $\mathrm{CD}$, by randomly drawing, via a computerized matching program, one control of the same sex and age ( \pm 2 years) for each case.

Since the aim of our study was to investigate the relation between appendectomy and risk of $\mathrm{IBD}$, we ignored any appendectomy in a case performed after the diagnosis of IBD, as well as appendectomies in controls after the date of IBD diagnosis of the matched case.

\section{Statistics}

Statistical analyses were performed with SPSS package 6.0 for Windows and the Confidence Interval Analysis program (CIA $)^{10}$. Descriptive statistics are provided as median, range and frequencies. Odds ratios (and the $95 \%$ confidence interval) were calculated in a pairwise-matched analysis. Smoking was controlled for by logistic regression analysis. In both patient groups a Trend Test was used to compare intervals between appendectomy and IBD diagnosis, and the occurrence of an appendectomy in each disease localization was compared by the MantelHaenszel $\chi^{2}$ method. P-values less than or equal to 0.05 were considered as statistically significant. 


\section{Results}

The response rate of registered IBD cases to the questionnaire in the prevalent group was $90 \%$, resulting in 441 patients (out of 490 ) with IBD according to the chosen diagnostic criteria. Of those, 232 patients were classified as UC and 209 patients as $\mathrm{CD}$. In the control group the response rate was $64 \%$, resulting in 602 (out of 936) persons. Matches were found for all cases, except for one patient with CD.

The response rate of IBD cases to the questionnaire of the incident patients was $89 \%$, resulting in 328 patients (out of 368 ) with UC $(n=191)$ or $C D(n=137)$, respectively. Also here, matched controls were found for all UC patients and for all but one of the $\mathrm{CD}$ patients. Overall, a second questionnaire was send to 105 patients and 3 were approached by phone. Patient characteristics of both groups and of the matched controls are illustrated in Table 6.1.

Table 6.1.

Patient characteristics of ulcerative colitis (UC) and Crohn's disease (CD) cases and their respective controls after the matching procedure in the prevalent and incident patients with IBD

\begin{tabular}{|c|c|c|c|c|}
\hline & $\mathbf{U C}$ & UC-Controls & CD & CD-Controls \\
\hline & \multicolumn{4}{|c|}{ PREVALENT CASES AND MATCHED CONTROLS } \\
\hline Number & 232 & 232 & 208 & 208 \\
\hline Sex (\% males) & 56 & 56 & 43 & 43 \\
\hline Median Age (range) & $40(17-80)$ & $42(18-81)$ & $32(14-77)$ & $34(15-75)$ \\
\hline Current smokers & 14 & 33 & 49 & 35 \\
\hline \multirow{2}{*}{$\begin{array}{l}\text { Number of patients with } \\
\text { appendectomy (\%) }\end{array}$} & $9(4)$ & $25(11)$ & $27(13)$ & $16(8)$ \\
\hline & \multicolumn{4}{|c|}{ INCIDENT CASES AND MATCHED CONTROLS } \\
\hline Number & 191 & $\mathbb{1 9}$ & 136 & 136 \\
\hline Sex (\% males) & 57 & 57 & 42 & 42 \\
\hline Median Age (range) & $38(14-81)$ & $39(15-81)$ & $30(13-79)$ & $31(13-78)$ \\
\hline$\%$ Current smokers & 17 & 30 & 44 & 30 \\
\hline $\begin{array}{l}\text { Number of patients with } \\
\text { appendectomy (\%) }\end{array}$ & $12(6)$ & $19(10)$ & $12(9)$ & $8(6)$ \\
\hline
\end{tabular}

As to the prevalent patient group, the frequency of appendectomies in UC was $4 \%$ compared to $11 \%$ in the control group. In CD, appendectomy before IBD diagnosis had been carried out in $13 \%$ compared to $8 \%$ in the control group. When only 
incident cases were analyzed, the difference between cases and controls concerning the frequency of appendectomy were smaller for both disease entities (Table 6.1).

Pairwise matched analysis resulted in odds ratios of $0.36(95 \% \mathrm{CI}: 0.15-0.80)$ in UC and $1.7395 \% \mathrm{CI}: 0.88-3.52$ ) in $\mathrm{CD}$ in the prevalent group, compatible with a protective effect of appendectomy in UC and the opposite trend in CD. When only incident cases were analyzed, the odds ratios were slightly different: $0.56(95 \% \mathrm{CI}$ : $0.22-1.35)$ in UC and $1.50(95 \% \mathrm{CI}: 0.56-4.23)$ in $\mathrm{CD}$, both not significant (Table 6.2). In the combined group of prevalent and incident patients a protective effect was observed in UC (odds ratio: 0.44 (95\% CI: $0.24-0.78$ )), whereas no significant difference in appendectomy rate between cases and controls was found in $\mathrm{CD}$ (odds ratio 1.65 (95\% CI: 0.96-2.91)).

Table 6.2 Pairwise matched analysis of appendectomy status in ulcerative colitis and Crohn's disease, subdivided into prevalent and incident patients, both with their sex and age-inatched controls

\begin{tabular}{lccccc}
\hline & \multicolumn{1}{c}{ Case / control exposure status" } & Odds ratio (95\% CI) \\
\hline & \multicolumn{6}{c}{ ULCERATIVE COLITIS } \\
& $\mathrm{P}-/ \mathrm{C}-$ & $\mathrm{P}+/ \mathrm{C}-$ & $\mathrm{P}-/ \mathrm{C}+\quad \mathrm{P}+/ \mathrm{C}+$ \\
prevalent cases & 198 & 9 & 25 & 0 & $0.36(0.15-0.80)$ \\
incident cases & 163 & 9 & 16 & 3 & $0.56(0.22-1.35)$ \\
total group & 361 & 18 & 41 & 3 & $0.44(0.24-0.78)$
\end{tabular}

\section{CROHN'S DISEASE}

P. $/ \mathrm{C}-\mathrm{P}+/ \mathrm{C}-\mathrm{P}-/ \mathrm{C}+\mathrm{P}+1 \mathrm{C}+$

$\begin{array}{llllll}\text { prevalent cases } & 166 & 26 & 15 & 1 & 1.73(0.89-3.52) \\ \text { incident cases } & 116 & 12 & 8 & 0 & 1.50(0.56-4.23) \\ \text { total group } & 282 & 38 & 23 & 1 & 1.65(0.96-2.91)\end{array}$

\footnotetext{
Exposure status: P-: patients without appendectomy; P.t: patients with appendectomy;

$\mathrm{C}$-: controls without appendactomy; $\mathrm{C}+$ : controls with appendectomy
}

The interval between appendectomy and time of IBD diagnosis in cases, and the interval between appendectomy of a control and date of IBD diagnosis of the matched in both groups is shown in Table 6.3. When comparing CD cases with 
matched controls, the procedure was carried out significantly more often close to the $C D$ diagnosis in the prevalent group $(p<0.05)$. This was not so in prevalent UC cases compared to controls, nor in incident patient with both diagnoses.

Except in one patient with $U C$ and 9 patients with $C D$, review of the medical data of the patients allowed full classification of disease extent of all patients. A risk analysis per stratum did not show any significant differences in appendectomy rate in the incident patients (Table 6.4). In prevalent UC patients with pancolitis appendectomy was negatively associated with colitis (odds ratio: 0.2 (95\% CI: 0.02-0.7), whereas a non-significant trend in the same direction was found in proctitis and left-sided colitis. A significant positive association between appendectomy and $\mathrm{CD}$ was observed in prevalent patients with combined small and large bowel disease (odds ratio: 4.2 (95\% CI: 1.4-17.3). When the prevalent and incident groups were analyzed together, the results in the subgroups according to disease localization were basically the same as those in the prevalent groups of UC and $\mathrm{CD}$.

Table 6.3 Interval between appendectomy and date of diagnosis in appendectomy positive patients of prevalent and incident patients with ulcerative colitis (UC) and Crohn's disease (CD), both with their sex-and age- matched conirols

\begin{tabular}{cccccc}
\hline $\begin{array}{c}\text { Years before IBD } \\
\text { diagnosis }\end{array}$ & $\begin{array}{c}\text { UC Patients } \\
\text { number }\end{array}$ & $\begin{array}{c}\text { UC Controls } \\
\text { number }\end{array}$ & $\begin{array}{c}\text { CD Patients } \\
\text { number }\end{array}$ & $\begin{array}{c}\text { CD Controls } \\
\text { number }\end{array}$ \\
\hline & & & PREVALENT CASES AND MATCHED CONIROLS & \\
$0-1$ & years & 0 & 0 & 5 & 0 \\
$2-5$ & years & 0 & 0 & 5 & 0 \\
$>5$ & years & 9 & 25 & 17 & 16 \\
$0-1$ & years & 0 & 0 & 2 & 0 \\
$2-5$ & years & 2 & 0 & 1 & 0 \\
$>5$ & years & 10 & 19 & 9 & 8 \\
\hline
\end{tabular}

\section{Smoking}

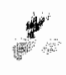

Current cigarette smoking was observed less frequently in UC (14\% smokers in the prevalent and $17 \%$ in the incident group) and more frequently in $\mathrm{CD}$ ( $49 \%$ and $44 \%$ smokers, respectively) compared to the control groups (between $30 \%$ and $35 \%$ smokers in the four control groups). In UC the odds ratio of current smoking 
in patients compared to controls was 0.32 (95\% CI: $0.20-0.52$ ) in the prevalent and 0.47 (95\% CI: $0.29-0.76$ ) in incident patients. In CD the comparable odds ratios were 1.89 (95\% CI: 1.27-2.81) in prevalent and $1.86(95 \% \mathrm{CI}: 1.12-3.06)$ in incident patients. Controlling for smoking status did not significantly change the odds ratios for appendectomy as a risk factor in both diseases and in both study groups.

\section{Discussion}

In the present study appendectomy was not as uncommon in patients with $\mathrm{UC}$ as could be expected in view of the results of four preceding case-control studies. With regard to prevalent patients in this study, the odds ratio of the matched analysis pointed towards a protective role of the procedure against UC. A significant association was only found in patients with pancolitis, however, the numbers in the subgroups are probably too small to allow a stratified risk analysis. In the incident patients with UC the difference between patients and controls was not significant.

Basically the same phenomenon, but in the opposite direction, was seen in CD patients: the odds ratio in the prevalent cases was higher than the odds ratio in the incident patients, although, both failed to reach statistical significance. Subgroup analysis however revealed a statistically significant positive association between $C D$ and appendectomy in the prevalent group with combined small and large bowel $\mathrm{CD}$. A substantial part of appendectomies in $\mathrm{CD}$ cases was performed relatively close to the date of diagnosis, which could mean that some of these patients were operated on because of bowel complaints related to $\mathrm{CD}$ still undiagnosed at that moment. The observation that mainly combined small and large bowell $C D$ (including ileocoecal location) was associated with appendectomy, also supports this view.

Gilat et al., studying childhood factors in relation to inflammatory bowel disease, were the first to report a negative association between appendectomy and UC and a positive association in CD patients ${ }^{4}$. This observation was confirmed for UC, but not for CD, by a case control study in the United Kingdom ${ }^{5}$. The issue of appendectomy as a protective factor in UC has been specifically addressed in two recent studies, both reporting a significant negative association ${ }^{6,7}$.

The negative association between appendectomy and UC in the present study is less pronounced than reported before (as illustrated in Table 6.5) and was not significant in the incident group under study. How can this difference be explained? Many factors have to be taken into account in case-control studies: the choice of cases, the diagnostic classification, selection of controls, the matching procedure, bias and confounding might all influence the results. 


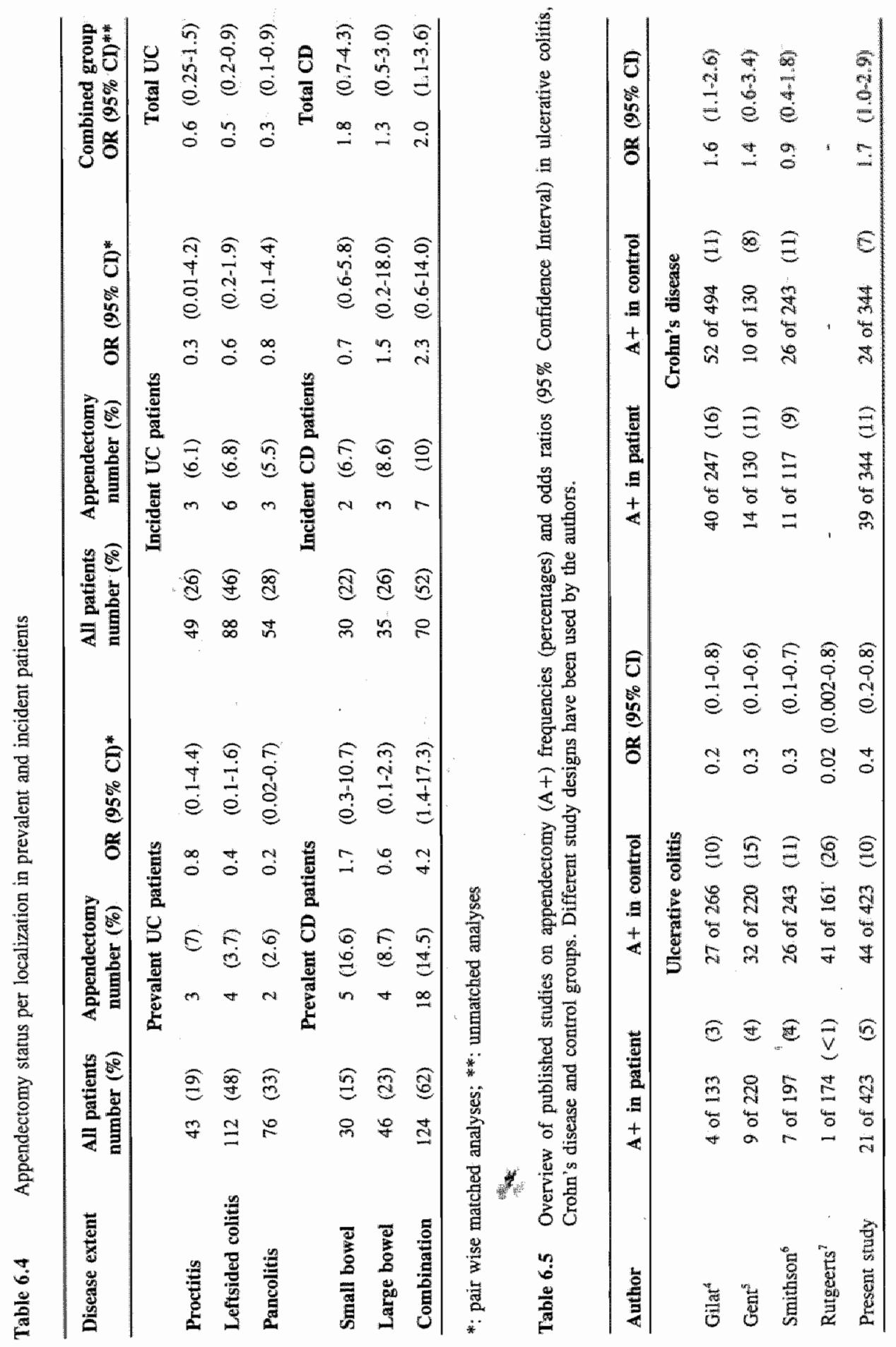


Cases in the present study consisted of all registered IBD patients diagnosed berween 1984 and 1994 in South Limburg who had completed a patient questionnaire in a very high percentage. Some of the previous studies, mainly using patients attending the outpatient department of -sometimes- tertiary referralhospitals, probably included a higher number of more severe cases. A recent study on the completeness of the South Limburg Register on incidence of IBD suggested a completeness of $80 \%$ in extensive UC and $100 \%$ in $\mathrm{CD}$, while patients with proctitis were more frequently underreported (accepted for publication Dis Colon and Rectum).

The different results between the prevalent and incident groups analyzed in the present study are possibly due to a selection bias. To be registered as a prevalent patient, cases diagnosed before 1991 had to attend the outpatient department of one of the six participating hospitals after the start of the study in 1991 for one reason or the other. This may underestimate the number of silent cases. Selection will therefore be higher in the prevalent group than in the incident group of patients. Moreover, it cannot be excluded from our data that a time trend in appendectomy rate is responsible for the differences between both groups. However, data on the frequency of appendectomies in The Netherlands during the study period are not in favor of the latter hypothesis (Source: SIG, Information Centre for Health Care, The Netherlands). Finally, one cannot formally exclude a false negative finding due to an insufficiently powered observation, since the number of patients in the incident groups was somewhat less than prevalent cases.

Another difference between the present and other studies is the choice of controls. Three basic tenets of comparability underlie attempts to minimize bias in control selection: the principles of study base, deconfounding and comparable accuracy ${ }^{11}$. In the present study controls were recruited from persons registered at the general practitioners' offices of the Registration Network Family Practices (RNH) ${ }^{9}$. In The Netherlands almost everyone, regardless of the presence of any illness, is registered with a general practitioner. The $\mathrm{RNH}$ is a reliable dynamic sampling frame of the Dutch general population'. In this way cases and controls are representative of the same study base (the set of persons in which diseased subjects become cases) ${ }^{\mathrm{i} 2}$.

As is illustrated in Table 6.5, the preceding studies, all using hospitall controls, report a higher frequency of appendectomies in the control group compared to the present study. One might argue that, in general, hospital controls have earlier access to the hospital than population-controls. Abdominal complaints in such a group might result more frequently in a visit to the hospital. In some of the members of this group this might lead to surgery of the -healthy or inflamedappendix.

Furthermore, in our study, controls were age- and sex-matched and pairwise analyzed, in contrast to the controls used in three of the former studies ${ }^{4,6,7}$. The 
exposure status (appendectomy or not) was measured according to information gathered by a mailed questionnaire. Recall bias cannot be excluded, but few arguments for a difference in recalling surgery of the appendix seems to be present. Cases and controls were pairwise matched for age and sex, in contrast to the Belgian study in which controls were older than cases, possibly overstating a presumed protective effect?. Furthermore, it could not be excluded that many of the appendectomies in controls were performed after the patients' age of disease onset $^{13}$. To be able to recognize a protective or a risk factor, it is evident that the reference procedure has to be performed before diagnosis. This was the reason for us to ignore appendectomy in cases if performed after TBD diagnosis and in controls where it was performed after IBD diagnosis of the paired case.

Confounding by smoking, the only factor consistently associated with UC (negatively) and $\mathrm{CD}$ (positively), was ruled out in the present study, but not in all four preceding studies ${ }^{14-17}$. We cannot be sure, however, that other confounding factors might explain our results.

To associate a factor with the occurrence of a disease, a biological hypothesis is needed. In UC the equilibrium between T-helper and T-suppressor cells is shifted in favor of the T-helper cells. A suggested biological explanation for appendectomy to protect against development of UC is that removal of the appendix, a T-helper cell organ, might change the balance in favor of $\mathrm{T}$-suppressor cells and thus prevent the inappropriate immune response ${ }^{7}$. However, it remains difficult to perceive why removal of a relatively small quantity of gut-associated lymphoid tissue should have such a profound effect ${ }^{13}$.

In conclusion, this is the first study also investigating the relationship between appendectomy and the risk of IBD in incident patients. Overall, a protective role of appendectomy was found in $\mathrm{UC}$, which reached significance in the prevalent group, whereas a trend towards the same direction was observed in the incident cases with this disease. In $C D$ the trendwise positive association with the operation could almost totally be explained by the number of appendectomies performed close to the time of diagnosis of IBD, suggesting that surgery was due to still undiagnosed $\mathrm{CD}$. The significant association in the subgroup of patients with ileocoecal disease is also in favour of this hypothesis. 


\section{References}

1. Weldon MJ, Maxwell JD. Lymphocyte and macrophage interleukin receptors in inflammatory bowel disease: a more selective target for therapy? Gut 1994; $35: 867-871$.

2. Calkins BM, Mendeloff AI. Epidemiology of inflammatory bowel disease: Epidemial Rev 1986; 8:60-91.

3. Jewell DP. Pathogenesis of Crohn's disease: the environment revisited. Eur I Gastroenterol Hepatol 1995; 7:383-384.

4. Gilat T, Hacohen D, Lilos P, Langman MJ. Childhood factors in ulcerative colitis and Crohn's disease. An international cooperative study. Scand $J$ Gastroenterol $1987 ; 22: 1009-1024$.

5. Gent AE, Hellier MD, Grace RH, Swarbrick ET, Coggon D. Inflammatory bowel disease and domestic hygiene in infancy. Lancet 1994; 343:766-767.

6. Smithson JE, Rayford-Smith G, Jewell GP. Appendectomy and tonsillectomy in patients with inflammatory bowel disease. J Clin Gastroenterol 1995; 21:(4)283-286.

7. Rutgeerts $P$, D'Haens $G$, Hielle $M$, Geboes $K$, Vantrappen $G$. Appendectomy protects against ulcerative colitis. Gastroenterol 1994; 106:1251-1253.

8. Lennard-Jones JE. Classification of inflammatory bowel disease. Scand $J$ Gastroenterol $1989 ; 24$ (suppl 170):2-6.

9. Metsemakers JFM, Höppener P, Knottnerus JA, Kocken RJJ, Limonard CBG. Computerized health information in the Netherlands: a registration of family practices. Br J Gen Prac 1992; 42:102-106.

10. Morris JA, Gardner MJ. Calculating confidence intervals for relative risks, odds ratios, and standardised ratios and rates. In: Gardner MJ, Altman DG, editors. Statistics with confidence-confidence intervals and statistical guidlines. London: BMJ 1989; 50-63.

11. Wacholder $\mathrm{S}$, McLaughin $\mathrm{JK}_{\mathrm{K}}$, Silverman DT, Mandel JS. Selection of controls in case-control studies. Am J Epidemiol 1992; 135:(9)1019-1027.

12. Miettinen OS. The "case-control" study: valid selection of subjects. J Chron Dis $1985 ; 38: 543-548$.

13. Logan RF. Appendectomy and ulcerative colitis: what connection? Gastroenterol 1994; 106:1382-1384.

14. Calkins BM. A meta-analysis of the role of smoking in inflammatory bowel disease. Dig Dis Sci 1989; 34:1841-1854.

15. Logan RF, Edmond M, Somerville KW, Langman MJ. Smoking and ulcerative colitis. Br Med J Clin Res 1984; 288:751-753.

16. Silverstein MD, Lashner BA, Hanauer SB. Cigarette smoking and ulcerative colitis: a case-control study. Mayo Clin Proc 1994; 69:425-429.

17. Silverstein MD, Lashner BA, Hanauer SB, Evans AA, Kirsner JB. Cigarette smoking in Crohn's disease. Am J Gastroenterol 1989; 84:31-33. 


\section{Chapter VII}

\section{Inflammatory Bowel Disease: Is}

there any relationship between smoking status and disease presentation? Results of the European collaborative study on Inflammatory Bowel Disease

MGVM Russel, A Volovics, EJ Schoon, EHJ v Wijlick, RF Logan, S Shivananda, RW Stockbrügger, and the European Collaborative IBD Study Group 


\begin{abstract}
Background: Smoking is associated with Crohn's disease and non-smoking with ulcerative colitis; however, no data have been published on Inflammatory Bowel Disease characteristics at presentation in relation to smoking status.
\end{abstract}

Objective: To compare clinical features at diagnosis and during the first year of followup in smokers and non-smokers amongst newly-diagnosed patients with IBD across Europe.

Design: Prospective study.

Setting: 19 centres across Europe.

Patients: 457 newly-diagnosed patients with Crohn's disease and 930 with ulcerative colitis with complete mapping of disease location.

Measurements: Disease characteristics as well as smoking habits were recorded by the treating physician on a standardized proforma at diagnosis, and treatment characteristics after one year of follow-up. Logistic regression analysis was applied to investigate clinical variables depending on smoking status.

Results: Weight loss occurred significantly more often in smoking patients with Crohn's disease as well as in smokers with ulcerative colitis $(p<0.02)$, and diarrhoea was more frequent in smoking Crohn's disease patients compared to non-smoking $(p<0.01)$. Abdominal pain was reported less often in "ex-smokers" with ulcerative colitis $(p<0.04)$. Smoking patients with Crohn's disease had less frequent colonic involvement $(p<0.01)$, and were more often prescribed immunosuppressive medication $(p<0.02)$.

Conclusion: Smoking seems to protect the colon from inflammation and is associated with a negative disease development in Crohn's disease. The association between weight loss and smoking in both diseases is probably due to a general effect of smoking. The reported relationship between smoking and the course of Crohn"s disease is a strong argument for eneouraging patients to give up smoking. 


\section{Introduction}

During the past decade smoking habits have been identified as strong risk factors in Inflammatory Bowel Disease (IBD), cigarette smoking being associated with the development of Crohn's disease (CD) and non-smoking or, perhaps more exactly, stopping smoking with ulcerative colitis (UC) ${ }^{1-10}$. Furthermore, in CD smoking is associated with an impaired prognosis and a reduced quality of life ${ }^{11-14}$. In active UC treatment with nicotine improves disease activity, suggesting a beneficial effect of smoking ${ }^{15-19}$. However, no data have been published on differences between smokers and non-smokers at time of diagnosis of IBD.

The aim of the present study was to compare clinical features at diagnosis in smokers and non-smokers in a large inception cohort of newly-diagnosed patients with IBD across Europe. Secondly, as markers of the disease course, the rate of surgical resections and the frequency of immunosuppressive medication use were compared in both groups.

\section{Patients and Methods}

Demographic and medical data of the patients included in the EC-IBD study were used in the present analysis. This prospective study, a concerted action of twenty European centers (appendix), investigated primarily the incidence of IBD in the North and South of Europe during the period 1991-1993. Beyond this, the protocol of the study was also designed to study clinical features and putative risk factors for IBD. The methods and results of the main study have recently been reported in detail ${ }^{20}$.

A uniform proforma was used by all centers and completed for each patient when the diagnosis was first made. One year later a follow-up form was completed giving additional information and any change in diagnosis. Besides medical data at presentation and at the one-year follow-up, findings such as age at diagnosis, gender, disease location, extraintestinal manifestations, smoking behavior, oral contraceptive use, and family history of IBD at diagnosis were recorded. As only a small minority of the patients were pipe or cigar smokers, it was decided to examine cigarette smoking only. This variable was divided into "non-smokers", "current smokers" and "ex-smokers" at time of diagnosis. Since data on smoking behavior were not available from Amiens (North-West France), patient data of this centre were excluded from the present analysis $(n=123$ of a total of 2201).

\section{Disease definition}

IBD was diagnosed, after exclusion of infections and other recognized causes of 
inflammation, on the basis of endoscopic and/or radiological evidence, supported -whenever possible- by mucosal biopsy and/or examination of a surgical specimen. The criteria of Lennard-Jones were applied in case definition for $\mathrm{CD}$, taking into account both macroscopic and microscopic features ${ }^{21}$. UC was defined as continuous mucosal inflammation without gramulomata, affecting the rectum without or with some or all of the colon in continuity with the rectum. Using all avallable medical information obtained around the time of diagnosis, location of the disease in the large and small bowel was carefully recorded. CD was subdivided into small bowel disease only, colonic disease only, and combined small and large bowel disease (also including small bowel plus coecal involvement). UC was subdivided into ulcerative proctitis (endoscopic extension distal to the rectosigmoidal junction), left-sided colitis (inflammation up to, but not beyond, the splenic flexure) and pancolitis (inflammation beyond the splenic flexure). $C D$ patients were excluded when no investigation of the small bowel and the collon had. been performed, as were UC patients without mapping of the colon beyond the splenic flexure. The definite diagnosis after one year of follow-up was used in the present analysis.

\section{Statistics}

Most data are presented as number of patients with percentages in brackets. Age is given as median and range. The variable smoking was divided into "neversmokers", "ex-smokers" and "smokers" at time of diagnosis. Smoking habits between UC and CD were compared using the chi-square test. Logistic regression analysis was used to investigate a possible association between clinical features and smoking. Clinical features studied were: disease location, weight loss, diarrhoea, abdominal pain, extraintestinal diseases, perianal disease at diagnosis, and -as markers of the disease course- immunosuppressive drug use and surgical intervention during the first year after diagnosis. To minimize confounding, the variables oral contraceptive use, positive family history of IBD, age at diagnosis, and gender were also taken into account in the analysis. The continuous variable age at diagnosis was divided into three categories: "below 25 ", "between 25 and $60 "$ ", and "above 60 years". Data analysis was performed with the SPSS package 6.0 for Windows and the S-Plus data analysis package. P-values less than 0.05 were considered as statistically significant.

\section{Results}

Data were available of 630 incident patients with $C D$ and 1317 incident patients with UC distributed over 19 participating centers. Of the patients with $C D$ 
complete mapping of the colon and the small bowel had been performed in 457 (73\%) and of those with UC the full colon (beyond the splenic flexure) was examined in $930(71 \%)$ patients. The demographic characteristics of the patients with complete disease mapping are shown in Table 7.1.

Table 7.1 Demographic characteristics of the patients

\begin{tabular}{|c|c|c|}
\hline & Crohn's disease & Ulcerative colitis \\
\hline All patients & 457 & 930 \\
\hline Females number $(\%)$ & $239 \quad(52)$ & 414 (44) \\
\hline Age at diagnosis (median and range) & $30 \quad(15-84)$ & $(15-89)$ \\
\hline "Current smokers" & $48 \%$ & $16 \%$ \\
\hline "Ex-smokers" & $11 \% \%^{*}$ & $34 \%$ \\
\hline "Never-smokers" & $41 \% \%^{*}$ & $50 \%$ \\
\hline Family history of IBD & $5 \%$ & $4 \%$ \\
\hline \multirow[t]{3}{*}{ Disease location number (\%) } & $130 \quad$ (28) colon only & $345 \quad$ (37) proctitis \\
\hline & 123 (27) small bowel only & 318 (34) left-sided \\
\hline & 204 (45) combination & 267 (29) pancolitis \\
\hline
\end{tabular}

* Chi-square derived p walues

Differences between Crohn's disease and ulcerative colitis: $\mathrm{p}<0.001$

\section{Smoking behavior in $\mathrm{CD}$ and $\mathrm{UC}$}

Data on cigarette smoking were available for $98 \%$ patients with $\mathrm{CD}$ and for $97 \%$ patients with UC. Cigarette smoking at time of diagnosis was noted more frequently in $\mathrm{CD}(48 \%)$ than in UC $(16 \%)(\mathrm{p}<0.001)$. On the other hand, the percentage of "ex-smokers" was higher in UC (34\%) than in CD (11\%) $(p<0.001)$; furthermore, the interval between stopping smoking and diagnosis of IBD was shorter in UC than in CD: $50 \%$ and $15 \%$ respectively had given up smoking within five years before diagnosis $(p<0.01)$.

\section{Smoking and disease location}

As shown in Table 7.2 significantly more "current smokers" than "non-smokers" or "ex-smokers" with $C D$ had small bowef involvement $(p<0.001)$. Logistic regression analysis showed no effect of oral contraceptive use, a positive family history, age at diagnosis or gender on disease location. No effect modification was observed between these variables and the effect of smoking on disease location. Corrected for smoking status and the other variables, small bowel involvement was 
more often observed in females $(p<0.016)$ and in younger persons $(p<0.026)$. In UC, no association between smoking and disease location in the colon was found. However, pancolitis was observed more often in males $(p<0.001)$ and in the oldest and youngest age category $(p<0.001)$.

Talble 7.2 Disease location at presentation according to smoking status

\begin{tabular}{|c|c|c|c|}
\hline Crolin's disease & $\begin{array}{l}\text { Current-smakers } \\
\text { nr }(\%)\end{array}$ & $\begin{array}{c}\text { Never-smokers } \\
\text { nr }(\%)\end{array}$ & $\begin{array}{c}\text { Ex-smokers } \\
\text { nr }(\%)\end{array}$ \\
\hline colon only & $45(35)$ & $64(50)^{*}$ & $18(14)$ \\
\hline small bowel onily & $67(55)$ & $38(31)$ & $14(11)$ \\
\hline combination & $103(47)$ & $80 \quad(40)$ & $18 \quad(9)$ \\
\hline Ulcerative collitis & $\begin{array}{l}\text { Current-smokers } \\
\text { nr (\%) }\end{array}$ & $\begin{array}{c}\text { Never-smokers } \\
\operatorname{nr}(\%)\end{array}$ & $\begin{array}{c}\text { Ex-smokers } \\
\text { nr }(\%)\end{array}$ \\
\hline proctitis & $50(14)$ & $171(50)$ & 113 (33) \\
\hline left-sided colitis & $50(16)$ & $151(47)$ & $107 \quad(34)$ \\
\hline pancolitis & $50(19)$ & $128 \quad(48)$ & $85 \quad(32)$ \\
\hline
\end{tabular}

Logistic regression derived p-value adjusted for age, gender, family history, and cinical variables. Difference between current smokers and non-or ex-smokers:* $* 0.001$

\section{Smoking and other clinical features at diagnosis}

Clinical characteristics at diagnosis and during the first year of disease are shown in Table 7.3. Weight loss was observed significantly more often in "current smokers" both in $\mathrm{CD}(\mathrm{p}<0.017)$ as well as in UC $(\mathrm{p}<0.001)$. Whereas no significant difference depending on smoking status was found in the frequency of diarrhoea in UC, "current-smokers" with CD more often reported frequent stools $(\mathrm{p}<0.004)$. Abdominal pain was reported less often in "ex-smokers" with UC $(\mathrm{p}<0.04)$.

\section{Smoking and disease course during the first year}

Steroids or other immunosuppressives (azathioprine, mercaptopurine, cyclosporin) were prescribed significantly more often in smoking $\mathrm{CD}$ patients than in nonsmoking $(p<0.02)$. This difference was not found in UC. No difference in the frequency of operation or bowel resection depending on smoking status was found in either disease group. 
Table 7.3 Symptoms and elinical findings at diagnosis and variables related to the course of disease during the first year depending on smoking status

\begin{tabular}{|c|c|c|c|c|c|c|}
\hline \multirow[b]{4}{*}{ Weight loss (>5kgr) } & \multicolumn{4}{|c|}{ Crohn's disease } & \multirow{3}{*}{\multicolumn{2}{|c|}{$\begin{array}{c}\text { ulcerative colitis } \\
\text { Non-smokers } \\
\text { (Ex-smokers) } \\
\text { \% positive }\end{array}$}} \\
\hline & \multirow{3}{*}{$\begin{array}{c}\text { Sinokers } \\
\text { \% positive } \\
31^{1}\end{array}$} & \multirow{2}{*}{\multicolumn{2}{|c|}{$\begin{array}{c}\text { Non-smokers } \\
\text { (Ex-smokers) } \\
\text { of positive }\end{array}$}} & \multirow{3}{*}{$\begin{array}{c}\text { Smokers } \\
\text { \% positive } \\
22^{2}\end{array}$} & & \\
\hline & & & & & & \\
\hline & & 18 & (13) & & 9 & (13) \\
\hline Diarrhoea ( $>5$ times per day) & $59^{3}$ & 45 & (51) & 60 & 56 & (58) \\
\hline Abdominal pain & 61 & 53 & (62) & 28 & 25 & $\left(20^{4}\right)$ \\
\hline Extraintestinal manifestations & 14 & 15 & (14) & 6 & 8 & (8) \\
\hline (Peri) anal disease & 14 & 17 & (26) & 4 & 2 & (3) \\
\hline Sterold/immuunsuppressive use & $66^{5}$ & 57 & (\$7) & 52 & 56 & (\$4) \\
\hline Surgical resection & 19 & 17 & (22) & 3 & 3 & (3) \\
\hline
\end{tabular}

Logistic regression derived p-values adjusted for age, gender, farmily history, clinical variables and disease location.

Differences between "current-smokers" and "non-smokers" or "ex-smokers":

${ }^{1} \mathrm{p}<0.017 ;{ }^{2} \mathrm{p}<0.001:{ }^{3} \mathrm{p}<0.004 ;{ }^{4} \mathrm{p}<0.04$.

Difference between "current-smokers" or "non-smokers" and "ex-smokers":

${ }^{5} \mathrm{p}<0.02$.

\section{Discussion}

The differential association between smoking and the two subtypes of Inflammatory Bowel Disease is well established ${ }^{1-8}$. We were interested in elucidating whether smoking behavior also influences clinical features of IBD at the time of diagnosis and during the first year of follow-up; evidence of a causal relationship between smoking and IBD would be further strengthened if the habit would influence the extension of inflammation, clinical symptoms and signs at presentation, and the course of disease ${ }^{22}$.

In the present study smokers with $\mathrm{CD}$ had more often small bowel involvement at diagnosis than never-smokers or ex-smokers with this disease. No difference in disease location depending on smoking statush was observed in UC. To reduce confounding, factors possibly related to characteristics of disease location and to smoking such as gender, age at presentation, oral contraceptive use, and a positive family history of IBD were controlled for by logistic regression analysis. The role of oral contraceptives is an example of a possible interactive risk factor combined 
with smoking in $\mathrm{CD}$, the suggested common mechanism being multifocal gastrointestinal infarction ${ }^{23,24}$. In our study no interaction between smoking and oral contraceptives was observed.

Age at presentation was taken into account, since it might be related to life-time tobacco use in smokers, and gender because of different smoking habits in males and females. Independent of smoking status both age and gender were found to be associated with disease location in UC: males, and persons above 60 years and younger than 25 years, presented more often with a pancolitis. The reason for this observation is not clear, but it is in line with recent reports on the incidence of UC in Norway and in The Netherlands ${ }^{25.26}$.

Seven studies have, mostly in a side-track, addressed the topic of disease location in prevalent groups of smokers and non-smokers with $C D^{11,12,27-31}$. In three studies a positive association between smoking and small bowel involvement was observed, whereas the other four did not find any association. The present study -the first investigating clinical features at diagnosis of $I B D$ - supports the concept that nonsmoking is preferentially associated with colonic disease, and smoking with small bowel involvement ${ }^{22}$. The finding of opposite smoking habits in $\mathrm{CD}$ and $\mathrm{UC}$ raises the possibility that smoking may be associated with distribution of inflammation. Does smoking protect the colonic mucosa from inflammation? Or, elaborating a little further on this concept: are smoking habits an important determinant for differential expression of IBD in genetically similarly predisposed subjects ${ }^{3}$ ?

The mechanisms by which smoking may be protective in UC and deleterious for CD remain unknown. Smoking increases colonic mucus production which is reduced in UC and decreases intestinal permeability: mechanisms possibly leading to protection of smoking against (ulcerative) colitis, as both factors could limit the exposure to harmful exogenous agents ${ }^{32-34}$. Furthermore, cigarette smoking has several known effects on immune and inflammatory functions: for example it decreases the helper/suppressor $\mathrm{T}$-cell ratio and reduces tissue levels of prostaglandin $\mathrm{E}$ and leukotriene $\mathrm{B} 4^{35-40}$. For $\mathrm{CD}$ Wakefield et al. have proposed as a pathogenic mechanism multifocal gastrointestinal infarction mediated by a chronic mesenteric vasculitis ${ }^{24,41,42}$. The pro-coagulant effects of smoking could enforce this mechanism in CD. It can also be hypothesized that the richly blood-supplied small. intestine is more susceptible to smoking induced vasospasm and thrombosis than the more inert large bowel.

The fraction of patients with abdominal pain, diarrhoea and weight loss was higher in smoking patients with CD than in "non-smokers" or "ex-smokers" "After correcting for the other variables, such as disease location, only diarrhoea and weight loss was reported significantly more often in smokers with $C D$, suggesting more active disease at diagnosis. Surprisingly the latter observation was also found. 
in UC. A possible mechanism to explain weight loss in smokers with either disease is enhancement of satiety following meal consumption by smoking, acting via increase of brain serotonin release $e^{43-45}$. This may lead to reduced food consumption in patients, who are already in a stressed catabolic state because of active (bowel) inflammation. We cannot explain the association between ex-smoking and reduced abdominal pain as was found in the present study.

No difference between both groups was observed concerning the presence of anal problems or extraintestinal disease at diagnosis. A higher rate of perianal disease in smoking patients with $\mathrm{CD}$ has inconsistently been reported ${ }^{11,12,29}$. Since studies finding a higher frequency of (peri)anal disease in smokers all concern prevalent patients, these results are difficult to compare with the incident population described in the present study. Another explanation for not finding a difference could be that the fraction of patients with (peri)anal disease at the time of diagnosis was not large enough.

Disease outcome depending on smoking status, as measured by the variables surgical intervention and use of immunosuppressive medication, was not different in UC. This is in line with the findings of two previous studies on this subject, but not with the protective effect of smoking on colonic resection as reported by Boyko et al. ${ }^{28,46,47}$. Benoni et al, as well as Holdstock et al. concluded that it was difficult to interpret the effect of current smoking in their studies because of the low number of smoking UC patients ${ }^{27,28}$. Since the number of patients in the present study, including the number of non-smokers, is much higher than in the former reports, this is probably not an important issue. It has to be remembered, however, that we have so far only studied the course during the first year after diagnosis, which period might be too short to obtain a difference.

Treatment with nicotine patches has shown favourable results in active UC, but there is no case for nicotine in maintenance of remission ${ }^{15-17}$. The evidence in favor of smoking (as opposed to nicotine alone) is insufficient to warrant its recommendation to UC patients, given the potentially fatal consequences of smoking on other biological structures ${ }^{39}$.

Whereas no higher resection rate in $\mathrm{CD}$ was observed in smokers, immunosuppressive medication was prescribed significantly more often in smokers than in non-smokers in the present study. The difference was small, but has been reported previously and suggests a worse prognosis in smokers with $C^{1.11-13}$. In the report of Cosnes et al smoking $\mathrm{CD}$ patients required more steroids and other immunosuppressive drugs, and resection rates were higher in smoking patients who were not using immunosuppressive medication ${ }^{12}$. The authors concluded that immunosuppressives neutralized the influence of smoking on surgical rates. In his comment on this article, Cottone remarked that the authors did not account for 
disease extension, which could be of importance in predicting surgical recurrence ${ }^{48}$. Furthermore, in the majority of the above-mentioned publications selected populations were studied, possibly causing bias by excluding a group of patients with inactive disease. The statistically different results, as were observed in the present study, still have to prove their clinical relevance. The results of the ongoing follow-up study of the European inception cohort of incident IBD patients will hopefully provide more insight in the topic of long-term disease outcome in both subgroups of IBD.

In summary, the course of disease, as measured by the use of steroids and immunosuppressive medication, was less favourable in smoking $\mathrm{CD}$ patients. Besides other harmful effects of eigarette smoking in general, the latter finding is a reason to strongly discourage smoking in patients with $C D$. In this study there was no evidence that smokers with UC do better. Smoking habits also determine some clinical aspects of IBD at diagnosis, such as weight loss and diarrhoea. In CD smoking affects disease location: non-smoking being associated with colonic disease. The finding of more colonic disease in non-smoking $C D$ patients, and the positive association between non-smoking and UC might be due to a common mechanism of smoking protecting the colon from inflammation. 


\section{References}

1. Sutherland LR, Ramcharan S, Bryant H, Fick G. Effect of cigarette smoking on recurrence of Crohn's disease. Gastroenterol 1990; 98:1123-1128.

2. Logan RF, Edmond $\mathrm{M}$, Somerville $\mathrm{KW}$, Langman MJ. Smoking and ulcerative colitis. Br Med J Clin Res 1984; 288:751-753.

3. Somerville KW, Logan RF, Edmond M, Langman MJ. Smoking and Crohn's disease. Br Med J 1984; 289:954-956.

4. Järnerot G, Lindberg E, Tysk C. Smoking and inflammatory bowel disease. Gastroenterol Hepatol 1995; 18:507-509.

5. Silverstein MD, Lashner BA, Hanauer SB. Cigarette smoking and ulcerative colitis: a case-control study. Mayo Clin Proc 1994; 69:425-429.

6. Persson PG, Ahlbom A, Hellers G. Inflammatory bowel disease and tobacco smoke-a case-control study. Gut 1990; 31:1377-1381.

7. Silverstein MD, Lashner BA, Hanauer SB, Evans AA, Kirsner JB. Cigarette smoking in Crohn's disease. Am J Gastroenterol 1989; 84:31-33.

8. Lindberg E, Tysk C, Andersson K, Järnerot G. Smoking and inflammatory bowel disease. A case control study. Gut 1988; 29:352-357.

9. Boyko EJ, Koepsell TD, Perera DR, Inui TS. Risk of ulcerative colitis among former and current cigarette smokers. N Engl J Med 1987; 316:707-710.

10. Motley RJ, Rhodes J, Ford GA, Wilkinson SP, Chesner IM, Asquith P, et al. Time relationships between cessation of smoking and onset of ulcerative colitis. Digestion $1987 ; 37: 125-127$.

11. Breuer-Katschinsky B, Holländer N, Goebell $\mathrm{H}$. Effect of cigarette smoking on the course of Crohn's disease. Eur J Gastroenterol Hepatol 1996; 8:225-228.

12. Cosnes J, Carbonnel F, Beaugerie L, Le Quintrec $Y$, Gendre JP. Effects of cigarette smoking on the long-term course of Crohn's disease. Gastroentera! 1996; 110:424-431.

13. Cottone M, Rosselli M, Orlando A, Oliva L, Puleo A, Cappello M, et al. Smoking habits and recurrence in Crohn's disease. Gastroenterol 1994; 106:643-648.

14. Russel MGVM, Nieman FH, Bergers JMM, Stockbrügger RW, "South Limburg IBD Study Group". Smoking and qualitiy of life in patients with inflammatory bowel disease. Eur J Gastroenterol Hepatol 1996; 8:1075-1081.

15. Sandborn WJ, Tremaine WJ, Offord KP, Lawson GM, Petersson BG, Steiner BL. A randomized, double-blind, placebo-controlled trial of transdermal nicotine for mildly to moderately active ulcerative colitis. Gastroenterol 1996; 110: A1008.

16. Thomas GA, Rhodes J, Mani V, Williams GT, Russell MA, Feyerabend C. Transdermal nicotine as maintenance therapy for ulcerative colitis. $N$ Engl $J$ Med $1995 ; 332: 988-92$.

17. Pullan RD, Rhodes J, Ganesh S, Mani V, Morris JS, Williams GT, et al. Transdermal nicotine for active ulcerative colitis. N Engl J Med 1994; 330:811-815.

18. Lashner $\mathrm{BA}$, Hanauer SB, Silverstein MD. Testing nicotine gum for ulcerative colitis patients. Experience with single-patient trials. Dig Dis Sci 1990; 35:827-832. 
19. Rhodes J, Thomas G. Nicotine treatment in ulcerative colitis. Current staus. Drugs 1995; 49: $157-160$.

20. Shiwananda $S$, Lennard-Jones $J E$, Logan $R F$, Fear $N$, Price $P$, Carpenter $L$, et al. Incidence of inflammatory bowel disease across Europe: is there a difference between North and South? Results of the European collaborative study on inflammatory bowel disease (EC-IBD). Gut 1996; 39: 690-697.

21. Lennard-Jones JE. Classification of inflammatory bowel disease. Scand J Gastroenterol 1989; 24(suppl 170):2-6.

22. Benoni C. Lifestylle issues in inflammatory bowel disease-smoking. Can J Gastroenterol $1994 ; 8:(7) 422-427$.

23. Wakefield $A J$, Sawyerr $\mathrm{AM}_{\text {, Hudson }} \mathrm{M}$, Dhillon $\mathrm{AP}$, Pounder RE. Smoking, the oral contraceptive pill, and Crohn's disease. Dig Dis Sci 1991; 36:1147-1150.

24. Wakefield AJ, Sawyerr AM, Dhillon AP, Pittilo RM, Rowles PM, Lewis AAM, et al. Pathogenesis of Crohn's disease: multifocal gastrointestinal infarction. Lancet 1989; (2)1057-1062.

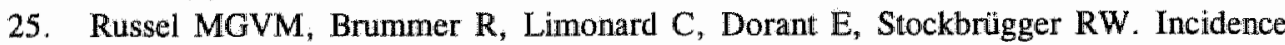
and prevalence of inflammatory bowel disease in South Limburg, The Netherlands. Neth J Med 1994; 45:A32

26. Moum B, Vatn MH, Ekbom A, Aadland $\mathrm{E}$, Fausa O, Lygren I, et al. Incidence of ulcerative colitis and indeterminate colitis in four counties of southeastern Norway, 1990-93. Scand J Gastroenterol 1996; 31:362-366.

27. Benoni $\mathrm{C}$, Nilsson A. Smoking habits in patients with inflammatory bowel disease. A case- control study. Scand J Gastroenterol 1987; 22:1130-1136.

28. Holdstock G, Savage D, Harman M, Wright R. Should patients with inflammatory bowel disease smoke? Br Med J 1984; $288: 362$.

29. Lindberg E, Järnerot G, Huitfeldt B. Smoking in Crohn's disease: effect on localisation and clinical course. Gut 1992; 33:779-782.

30. Wright JP. Factors influencing first relapse in patients with Crohn's disease. I Clin Gastroenterol 1992; 15:12-16.

31. Musso A, Sostegni $R$, Astegiano $M$, Rocca $G$, Fiorentini MT, Pera A, et all. Smoking and clinical course of Crohn's disease: an adverse effect? Gastroentero] 1995; 108:A882

32. Cope GF, Heatley RV. Cigarette smoking and intestinal defences. Gut 1992; 33:721-723.

33. Prytz H, Benoni C, Tagesson C. Does smoking tighten the gut? Scand I Gastroenterol 1989; 24:1084-1088.

34. Cope GF, Heatly RV, Kelleher JK. Smoking and colonic mucus in ulcerative colitis. Br Med J 1986: 293:481

35. Peptic Ulcer epidemiology. Lifestyle issues in inflammatory bowel disease-smoking. Can J Gastroenterol 1994; 8:(7)422-427.

36. Van Dijk JP, Madretsma GS, Keuskamp ZJ, Zijlstra FJ. Nicotine inhibits cytokine synthesis by mouse colonic mucosa. Eur J Pharmacol 1995; 278:R11-2.

37. Zijlstra FJ, Srivastava ED, Rhodes $M$, van Dijk AP, Fogg F, Samson HJ, et al. Effect of nicotine on rectal mucus and mucosal eicosanoids. Gut 1994; 35:247-251. 
38. Barton IR, Riad MA, Gaze MN, Maran AG, Ferguson A. Mucosal immunodeficiency in smokers, and in patients with epithelial head and neck tumours. Gut 1990; 31:378-382.

39. Forbes A. Smoking and inflammatory bowel disease. Eur J Gastroenterol Hepatol 1996: 8:761-763.

40. Tardif J, Borgeat P, Laviolette M. Inhibition of human alveolar macrophage production of leukotriene B4 by acute in vitro and in vivo exposure to tobacco smoke. Am J Resp Cell Mol Biol 1990; 2:155-161.

41. Wakefield AJ, Sankey EA, Dhillon AP, Sawyerr AM, More $L$, Sim R, et al. Granulomatous vasculitis in Crohn's disease. Gastroenterol 1991; 100:1279-1287.

42. Hudson M, Piasecki C, Wakefield AJ, Sankey EA, Dhillon AP, Osborne M, et al. A vascular hypersensitivity model of acute multifocal gastrointestinal infarction. Dig Dis Sci 1994; 39:534-539.

43. Perkins KA, Epstein LH, Fonte C, Mitchell SL, Grobe JE. Gender, dietary restraint, and smoking's influence on hunger and the reinforcing value of food. Physiol Behav 1995; 57:(4)675-680.

44. Perkins KA, Mitchell SL, Epstein LH. Physiological and subjective responses to food cues as a function of smoking abstinence and dietary restraint. Physiol Behav 1995; 58:(2)373-378.

45. Wurtman RJ, Wurtman JJ, Brain serotonin, carbohydrate-craving, obesity and depression. Obes Res 1995; 3 (Supp1 4): 477S-480S.

46. Benoni C, Nilsson A. Smoking habits in patients with inflammatory bowel disease. Scand J Gastroenterol 1984; 19:824-830.

47. Boyko EJ, Perera DR, Koepsell TD, Keane EM, Inui TS. Effects of cigarette smoking on the clinical course of ulcerative colitis. Scand J Gastroenterol 1988; 23:1147-1152.

48. Cottone $\mathrm{M}$, Rosselli $\mathrm{M}$, Casa A. Smoking,azathioprine, and clinical course in Crohn's disease. Gastroenterol 1996; 110:1161. 


\section{Chapter VIII}

Validation of the Dutch translation of the Inflammatory Bowel Disease Questionnaire (IBDQ): A health-related quality of life questionnaire in Inflammatory Bowel Disease

MGVM Russel, CJ Pastoor, S Brandon, J Rijken, LGJB Engels, DMFM vd Heijde, RW Stockbrügger

Digestion 1997 (accepted for publication) 


\begin{abstract}
Health-related quality of life assessment can benefit several groups involved with health care. The aim of our study was to assess construct validity, reliability, discriminant ability and sensitivity to change of the Dutch translation of the Inflammatory Bowel Disease Questionnaire (IBDQ), a disease-specific quality of life questionnaire. A group of 120 IBD patients completed the IBDQ and two Visual Analogue Scales concerning general well-being and bowel function twice. Fifty-two patients also completed the ShortForm 36 twice. Disease activity was assessed once. Correlations between the IBDQ scores and the global assessments were reasonably high and the IBDQ was shown to be discriminative. High intraclass correlation coefficients between both measurements of the IBDQ were observed in patients who reported no change in bowel complaints. In contrast, significant differences were found between both moments in patients who reported change. The Dutch IBDQ proved to be valid, discriminative and reliable.
\end{abstract}




\section{Introduction}

Physiologic measures of diseases often correlate poorly with functional capacity and well-being and are therefore of limited interest to patients ${ }^{1}$. Health-related quality of life (HRQoL) assessment is important for measuring the impact of chronic disease on a patient's state of general well-being ${ }^{1,2}$. HRQoL differs from disease measurement in that evaluation includes psychosocial as well as diseaserelated factors. Since psychosocial determinants are not accessible through laboratory tests, validation rests with the patient ${ }^{3}$.

Self-administered or interviewer-administered questionnaires can be used to measure cross-sectional differences in quality of life between patients or longitudinal changes in the same patient during a period of time. While generic questionnaires provide a summary of health-related quality of life, disease-specific questionnaires focus on problems associated with unique disease states or patient groups. Both type of instruments need to be valid (measure what they are suppose to measure), reliable (give comparable results if measured repeatedly), have discriminant power (are able to discriminate between patients with various disease severity), and sensitive to change (able to measure change over time) ${ }^{1,4}$. For Crohn's disease (CD) and ulcerative colitis (UC) there are a few specific instruments available ${ }^{5-11}$. The Inflammatory Bowel Disease Questionnaire (IBDQ), developed by Guyatt and Irvine, has been shown to be valid and reliable in a clinical setting 12,13 .

To use a questionnaire like the IBDQ in respondents with a native language other than English requires translation, back-translation, adaptation, and re-establishing the validity and reliability within the new national context $t^{4}$. The aim of our study was to investigate the various aspects of validity of the Dutch translation of the IBDQ.

\section{Methods}

\section{Questionnaires}

The original IBDQ was developed to measure disease-specific quality of life in clinical trials involving patients with $\mathrm{IBD}^{12}$. Tुwis self-administered questionnaire, regarding the patient's situation of the preceding two weeks; contains 32 questions grouped into four health dimensions: bowel symptoms (10 items), systemic symptoms ( 5 items), social function ( 5 items), and emotional function (12 items). Responses are graded on a 7 -point Likert scale in which " 1 " represents a very 
severe problem and " 7 " represents no problem at all.

A sequence of two steps was followed during the translation of the IBDQ. The first step involved the translation into Dutch by a panel of two physicians familiar with inflammatory bowel disease, followed by back-translation of the IBDQ by an official bilingual (English-Dutch) translator. Secondly, the back-translation was compared with the original IBDQ and differences between these two versions were looked upon by the panel, which consisted of a researcher in the field of IBD and two gastroenterologists (CP, RS, MR). Changes were made until agreement was found. This Dutch version of the IBDQ was pre-tested in a small group of patients with IBD and proved to be understandable and easy to complete. Completion of the IBDQ took between 15 and 25 minutes.

In patients with $C D$, disease activity was assessed by the Harvey Bradshaw Index $(\mathrm{HBI})^{14}$. In patients with UC it was determined by an index (UCI) described by Levenstein, including four symptoms: haematochezia or passage of mucus, the presence or absence of watery stools; tenemus; and number of dailly bowel movements ${ }^{15}$.

Visual analogue scales (VAS) were used to assess the degree of bowel function and the state of general well-being experienced by the patients themselves. The VAS consisted of a vertical line with at both ends a statement, in which the bottom represented the worst and the top of the line the best possible situation. A crossline was added to mark the middle. Scores were calculated as percentages of the scale, $0 \%$ indicating the least favourable health state to $100 \%$ indicating the most favourable health state.

Health-related quality of life was also assessed by a Dutch translation of the nondisease-specific 36-item Short Form Health Survey (SF-36). Translation was carried out as part of a International Quality-of-Life Assessment Project ${ }^{16}$. The SF-36 includes multi-item scales, measuring eight general health concepts: physical functioning; role limitations due to physical health problems; bodily pain; general health perception; vitality; social functioning; role limitations due to emotional problems; and mental health ${ }^{17,18}$. To make a comparison with the IBDQ dimensional scores possible, the eight SF-36 concepts were converted into four dimensions corresponding to the IBDQ dimensions: bowel symptoms, systemic symptoms, social function and emotional function. In this conversion the concept bodily pain represents bowel symptoms; the two concepts general health perception and vitality represent systemic symptoms; the concepts physical function, role limitations due to physical health problems, and social functioning of the SF-36 were combined to allow a comparison with the social function dimension of the 
IBDQ; and, finally, role limitations due to emotional problems and mental health were joined to be compared with the dimension emotional function of the IBDQ.

\section{Patients}

One hundred and thirty-six patients who were diagnosed as having $\mathrm{CD}$ or $\mathrm{UC}$ were invited to participate in the study. The criteria of Lennard-Jones were applied in case definition for $\mathrm{CD}$ and those of Truelove and Witts for UC, including only patients with extended colitis (inflammation beyond the rectosigmoidall junction) ${ }^{19}$. Patients with an illeostomy were excluded. While the majority of the patients were recruited from the outpatients' clinic, some were hospitalised at the time of initial enrolment $(n=13)$.

Participants were asked to complete the IBDQ twice, at an interval of four to six weeks. In addition, they were asked to mark their degree of bowel function and general well-being on the VAS at both assessments. At the second assessment each patient responded to a so called "transition question" concerning bowel complaints; the patients were asked whether their bowel complaints were better, worse or the same as four weeks before.

A subgroup of 52 patients ( $C D n=32, U C n=20$ ) of the 136 patients, also completed the Short Form 36 (SF-36) at both moments. In this subgroup, also the $\mathrm{HBI}$ for $\mathrm{CD}$ or the $\mathrm{UCI}$ for $\mathrm{UC}$ was assessed by a gastroenterologist at the time of inclusion.

Of the 136 patients who were asked to participate in this study, 6 patients $(4.4 \%)$ refused to take part, 5 patients $(3.7 \%)$ were excluded during the study because only the furst questionnaire was returned and 5 patients $(3.7 \%)$ were excluded because of an ileostomy. This resulted in 120 participants, 71 with $\mathrm{CD}$ and 49 with UC. Although patients were asked to complete all 32 questions, in some cases one or more items were missing. For that reason, IBDQ dimensional scores were not calculated as sum scores, as in the original description of the IBDQ, but as mean values provided that at most one item per dimension was missing ${ }^{2}$.

Demographic characteristics of the study population are shown in Table 8.1. The main reason for refusal was old age. Patients who took part in the study received standard medical care during the course of the study. 
Table 8.1 Demographic characteristics of the suidy population

\begin{tabular}{lcc}
\hline & Crohn"s disease & Ulcerative colitis \\
\hline Total number of patients & 71 & 49 \\
Female patients & 41 & 24 \\
Hospititlised & 9 & 4 \\
Duration of IBD (years) & 8.1 & 5.6 \\
Bowel resection & 19 & 1 \\
Age median (range) & $36(15-73)$ & $43(16-80)$ \\
\hline
\end{tabular}

\section{Statistical analysis}

\section{Descriptive statistics}

All statistical analyses were performed with SPSS package 6.0 for Windows. Descriptive statistics for the patient groups were provided as mean, median, range and frequencies. To determine whether the value of the questionnaire might differ in patients with $C D$ and with UC, construct validity, reliability, and sensitivity to change were analyzed separately for those two diagnoses. T-tests were two-sided, and $p$-values less than or equal to 0.05 were considered as statistically significant.

\section{Construct validity}

Validity examines whether the instrument measures the phenomenon of interest. One approach is the so-called construct validity, which relates scores to a hypothesis or concept. Ideally it is determined by comparison against a gold standard. If no gold standard is available for thealth-related quality of life, it is advised to use 'proxy measures' for comparison. In this study the proxy measures included disease activity indices (HBI and $\mathrm{UCD}$ ) and global assessments (VAS and SF-36). Pearson correlation coefficients were calculated to express the relationships between the above assessments and the four dimensional scores of the IBDQ.

\section{Discriminant ability}

The discriminant ability of an instrument is the ability to distinguish between groups of interests. In this study the patients were divided into two groups: patients with no or minor bowel complaints and patients with considerable bowel complaints. The VAS scores concerning bowel function as well as the disease activity indices were used to separate the groups. VAS scores less than $55 \%$, HBI scores higher than 6 , and UCI scores higher than 3 were considered "considerable bowel complaints'. To investigate whether the IBDQ was able to discriminate 
between the two groups with no or minor and with considerable bowel complaints, the Mann-Whitney U test was used.

\section{Reliability}

The reliability of a measure relates to the degree of agreement between two sets of measurements. Repeated measures ANOVA were carried out to assess mean differences in scores and to calculate intraclass correlation coefficients (ICC) between scores at both moments of measurements. For each dimension ICC shows the proportion of total variability accounted for by the variability among persons ${ }^{20}$. In other words, ICC assesses not only the strength of correlation, but also whether the slope and intercept vary from those expected with replicate measures. Reliability analysis was only carried out in patients who reported no change following the transition question on bowel complaints completed at the second measurement moment.

\section{Sensitivity to change}

Sensitivity to change of a measure refers to the ability to detect any clinically important change over time, even if it seems small ${ }^{21}$. In our study sensitivity to change was estimated by a paired t-test between the results of two moments in patients who were identified as feeling better or worse according to the transition question concerning change of bowel complaints. Changes in scores were computed as second assessment minus first assessment, so that positive changes indicated improvement, whereas negative changes indicated deterioration.

\section{Results}

\section{Construct validity}

Pearson correlation coefficients were calculated for each diagnosis separately. As illustrated in Table 8.2, most of the correlations between the disease activity indices and the IBDQ dimensional scores were moderately high $(-0.39$ to -0.72$)$. In patients with UC, the IBDQ dimension social function as well as systemic symptoms showed a lower correlation with the indices than in patients with $\mathrm{CD}$.

Correlation coefficients between the VAS concerning general well-being and the IBDQ dimensional scores varied between 0.54 and 0.70 . The VAS for bowel function and IBDQ dimensional scores correlated best $(0.68-0.71)$ in patients with CD. 
Table 8.2 Construct validity of the $\mathbb{B B D Q}$ : correlation coefficients between the four IBDQ dimensional scores and proxy measures of quality of life in IBD: disease actiwity indices, Visual Analogue Scales (VAS) for general well-being and for bowel function, and the dimensional scores of the Short-Form 36

\begin{tabular}{lcccc}
\hline $\begin{array}{l}\text { rBDQ } \\
\text { Dimensions }\end{array}$ & $\begin{array}{c}\text { Disease } \\
\text { activity index }\end{array}$ & $\begin{array}{c}\text { VAs general } \\
\text { Well-being }\end{array}$ & $\begin{array}{c}\text { VAS bowel } \\
\text { function }\end{array}$ & $\begin{array}{c}\text { Short-Form } \\
\mathbf{3 6}\end{array}$ \\
\hline $\begin{array}{l}\text { Crohm's disease } \\
\text { bowel symptoms }\end{array}$ & -0.61 & 0.61 & 0.69 & 0.78 \\
systemic symptoms & -0.70 & 0.64 & 0.68 & 0.83 \\
social function & -0.49 & 0.65 & 0.68 & 0.90 \\
emotional function & -0.55 & 0.65 & 0.71 & 0.91 \\
Ulcerative colitis & & & & \\
bowel symptoms & -0.72 & 0.54 & 0.54 & 0.69 \\
systemic symptoms & -0.48 & 0.70 & 0.46 & 0.89 \\
social function & -0.39 & 0.55 & 0.40 & 0.50 \\
emotional function & -0.52 & 0.58 & 0.45 & 0.84 \\
\hline
\end{tabular}

- Harvey Bradshaw Index (HBI) for patients with CD and Levenstein index for patients with UC

Regarding the SF-36, correlation coefficients with the IBDQ dimensional scores were high and similar for both diagnoses. The only exception was observed in the social function dimension in patients with $U C$, which showed a lower correlation than the other dimensional scores.

\section{Discriminant ability}

According to the VAS on bowel function 42 patients were classified as having considerable bowel complaints and 78 patients as having no or minor bowel complaints. The Mann-Whitney $U$ test showed a statistical significant difference between the two groups for all four dimensional scores of the IBDQ. For a subgroup of 52 patients disease activity scores were available. Twenty of these patients were classified as having considerable bowel complaints and 32 as having minor complaints according to the disease activity scores. Again there was a significant difference $(p<0.001)$ for all four dimensional scores of the IBDQ between both groups of patients (Mann-Whitney U test). 


\section{Reliability}

According to the transition question regarding bowel complaints, 75 patients (CD $n=48$ and $U C n=27$ ) remained stable during the course of the study. Table 8.3 illustrates the reliability outcomes for each diagnosis separately. Intraclass correlation coefficients were high for all IBDQ dimensional scores, with a range from 0.75 to 0.93 . None of the differences between baseline scores and follow-up scores was statistically significant.

Table 8.3 Reliability of the IBDQ: agreement between two sets of measturements, expressed by the intraclass correlation coeficients (ICC) between the IBDQ dimensional scores in patients who reported no change in bowel complaints at two assessments with an intervall of four to six weeks

\begin{tabular}{lccccc}
\hline $\begin{array}{l}\text { IBDQ } \\
\text { Dimensions }\end{array}$ & $\begin{array}{c}\text { Number of } \\
\text { pairs }\end{array}$ & $\begin{array}{c}\text { Baseline } \\
\text { mean }\end{array}$ & $\begin{array}{c}\text { Follow-up } \\
\text { mean }\end{array}$ & $\begin{array}{c}\text { Difference } \\
\text { mean }\end{array}$ & ICC \\
\hline $\begin{array}{l}\text { Crohn's disease } \\
\text { bowel symptoms }\end{array}$ & 48 & 5.52 & 5.53 & 0.01 & 0.93 \\
$\begin{array}{l}\text { systemic symptoms } \\
\text { social function }\end{array}$ & 48 & 5.22 & 5.15 & 0.07 & 0.75 \\
emotional function & 45 & 5.93 & 5.94 & 0.01 & 0.78 \\
Ulceivative colitis & 46 & 5.47 & 5.51 & 0.04 & 0.88 \\
bowel symptoms & 27 & & & & 0.06 \\
systemic symptoms & 27 & 5.72 & 5.78 & 0.06 & 0.87 \\
social function & 23 & 5.09 & 5.30 & 0.21 & 0.91 \\
emotional function & 27 & 6.06 & 6.25 & 0.19 & 0.78 \\
\hline
\end{tabular}

\section{Sensitivity to change}

Response to the transition question at the second assessment resulted in 35 patients reporting improvement in bowel complaints and 10 patients reporting deterioration. The number of patients who deteriorated was too small to allow separate analysis. For this reason, the sign of the difference score in every such patient was reversed. All 45 patients who reported change in bowel complaints were included in the analysis for each diagnosis separately $(C D n=22$ and $U C n=23)$. The results of the paired t-tests are shown in Figures 8.1 and 8.2. Statistically significant differences between baseline and follow-up in all dimenstonal scores were found in patients with $\mathrm{CD}$. In patients with $\mathrm{UC}$, only IBDQ bowel sympton scores were significantly different between both assessments. 


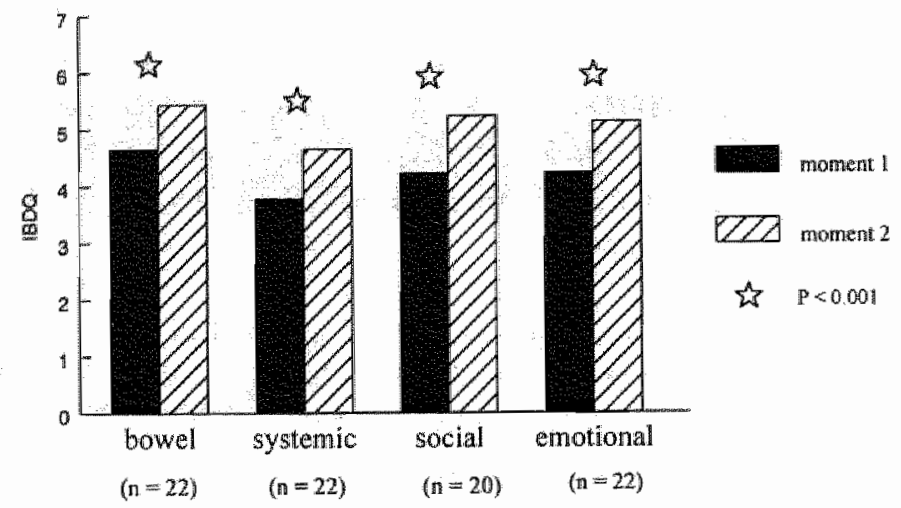

Figure 8.1 Sensitivity to change of the IBDQ: IBDQ dimensional scores in patients with Crohn's disease who -according to the transition question- reported change in bowel complaints at two assessments with an interval of 4-6 weeks

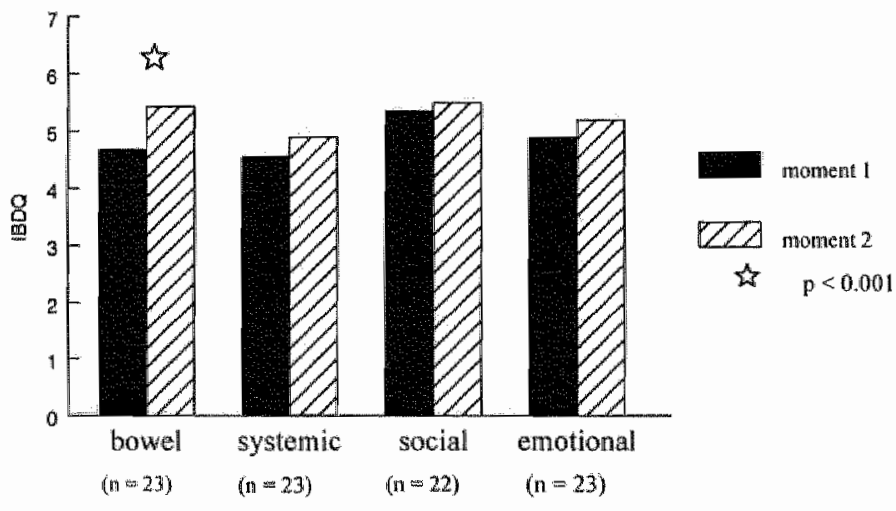

Figure 8.2 Sensitiwity to change of the IBDQ: IBDQ dimensional scores in patients with ulcerative colitis who -according to the transition question- reported change in bowel complaints at two assessments with an interval of 4-6 weeks

\section{Discussion}

Health-related quality of life (HRQOL) measurement is becoming an important issue in both clinical trials and surveys concerning $\mathrm{IBD}^{13.22}$. Only two European countries have English as their first language, the language used in most HRQOL 
instruments in IBD. For the other countries, to be able to set up or to participate in international clinical trials, it is necessary to either use a validated translation of the instrument or to develop a new instrument.

The first step in developing a translated instrument concerns aspects concerning translation procedures. In the present study we used the method of translation, back-translation followed by assessing the final version by means of the judgement of a panel of physicians familiar with IBD.

Theoretically, translation and back-translation have to be performed by official bilingual translators. In our study, the translation of the original IBDQ was done by two clinicians familliar with IBD, followed by back translation by an official bilingual translator. Another approach is to involve, instead of back-translation, a lay panel to comment on the translated questionnaire with the purpose of commenting on, or changing the translated questionnaire, provided that the original meaning is maintained ${ }^{23}$. The suitability of the content for the new country has to be tested in later stages of the adaptation procedure.

In addition to the important aspects concerning translation of an existing HRQoL instrument, validation requires repeating the process of reassessing construct validity, reliability, and sensitivity to change of the new instrument $t^{4}$. In the present study the performance of the IBDQ, using a Dutch translation, was investigated in patients with $\mathrm{CD}$ and UC, the two disease entities for which the original IBDQ was developed and validated ${ }^{12}$. As in the Canadian study patients with an ileostomy were excluded, because certain items of the IBDQ are not applicable to them.

As shown in detail in this study, measurement of the construct validity of the Dutch $I B D Q$, using four proxy measures, was good for both disorders. A higher correlation between the Dutch IBDQ and the SF-36 (a generic health-status questionnaire) was observed than between the Dutch IBDQ and global instruments of disease activity or disease perception (HBI, UCI, VAS). The bowel and systemic symptoms dimensions correlated better with the HBI and UCI than the dimensions of social and emotional function. It has to be mentioned here, however, that the IBDQ questions concerning social and emotional dimensions almost all refer to impairment as a result of bowel dysfunction. For this reason correlations of social and emotional function could be compared to disease activity scales, only taking somatic function into account.

The IBDQ was able to distinguish between a group of patients with considerable bowel complaints and a group with no or minor complaints. Patients were separated using the patients' disease perception (VAS concerning bowel function) as well as the physicians' view on disease activity (HBI and UCI). In both cases 
highly significant differences in IBDQ dimensional scores between the two groups of patients were found.

The Dutch IBDQ was shown to be reliable: patients with $C D$ as well as with UC who reported no change in bowel complaints between two time points had comparable scores in all dimensions at both moments, reflected by high ICC values.

Measurement of the sensitivity to change, in the context of the present study, is arguable and is fraught with problems ${ }^{24}$. It has been disputed whether patients are able to compare their state of well-being between two moments with a transition question $^{25}$. Probably the best way to assess the sensitivity to change of an instrument is by performing a randomised clinical trial ${ }^{24}$. However, before using an instrument in a randomised clinical trial, one needs to know if the new instrument is able to detect small and clinical relevant changes over time. An alternative, therefore, is to examine sensitivity to change against an external criterion such as the view of the patient who reports that a change has occurred ${ }^{26}$. This was the reason for using a transition question concerning bowel complaints to separate stable patients from those who reported change. The transition question was able to discriminate between the group of unstable patients and those who remained stable, according to the SF-36, as well as the VAS on general well-being, and the VAS on bowel dysfunction (data not shown).

In patients with $C D$ who reported change according to the transition question, all four dimensions of the IBDQ showed significant differences between the two moments. Concerning UC, only the dimension bowel symptoms was significantly different. This might reflect a difference between $C D$ and $U C . C D$ in general is more characterised by systemic complaints than UC, and probably also results in more severe social and emotional impairment. In addition, a few more patients with CD were hospitalised at the time of enrolment, therefore more improvement in these patients would be expected. Finally, patients with UC had higher IBDQ dimensional scores at the first assessment, so the possibility of improving scores at the second assessment was less in this patient group.

In contrast to the original Canadian IBDQ, a postal questionnaire was used in the present study. As a consequence of this approach, some questionnaires with missing items were returned. To be able to include most patients, mean scores were calculated for each dimension in the analysis, providing that at most one question per dimension was not completed. Mainly in the social function dimension more than one item was missing, resulting in a decreased amount of paired measurements, as can be observed in Table 8.3. The analysis showed that mostly 
the items concerning daily work and/or sexual habits were missing. In everyday practice, the problem of missing items is well known, and the Dutch IBDQ proved to be valid under the prerequisite mentioned.

Recently de Boer et al. reported their results on validation and cross-cultural adaptation of an into Dutch translated $I B D Q^{27}$. Their main conclusion was that the IBDQ proved to be a reliable and valid measure of quality of life in inflammatory bowel disease. To be able to compare results with other international studies we used, in contrast to de Boer et al., the seven point Likert scale, as was applied in the original IBDQ. Secondly, we used mean scores for each dimension, allowing patients to miss one question in each dimension. While the former study, using the IBDQ once in all patients, focused on reliability, we approached the patients twice to be able to investigate reproducibility and sensitivity to change. Both studies prove that the IBDQ can be validly used in a different culture, with a different language.

In conclusion, the Dutch IBDQ appeared to be easy to use when studying quality of life in patients with IBD. The instrument was shown to be valid and reliable. As far as can be concluded from our data, sensitivity to change was good in all dimensional scores in $C D$, and for bowel symptoms in UC. Further assessments of sensitivity to change, sometimes referred to as responsiveness, have to be obtained in clinical trials. This item is addressed at this moment in an ongoing clinical trial in patients with $C D$ in remission (Crohn Remission Trial). The IBDQ can be used in the Dutch-speaking IBD population, and our results suggests that it will be feasible to use translations of the IBDQ in non-English-speaking countries. The present study can serve as a guideline in evaluating translated versions of the original IBDQ (Table 8.4).

Table 8.4 Guideline for translating and validating a questionnaire

Translation / back-translation or lay panel

Construct validity

comparison with proxy measurements (Pearson cortelation)

Discriminant ability

comparison of two groups of patients (Mann-Whitney $U$ test for independent samples)

Reliabillity

iwo measurements 4-6 weeks apart (intraclass correlation coefficient between two moments in stable patienis)

Sensitivity to change

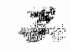

during clinical trial or two measuirements 4-6 weeks apart (significant difference between two moments in patients with a change in disease activity) 


\section{References}

1. Guyatt GH, Feeny DH, Patrick DL: Measuring health-related quality of life. Ann Intern Med 1993; 118:622-629.

2. Drossman DA, Leserman J, Mitchell CM, Li ZM, Zagami EA, Patrick DL: Health status and health care use in persons with inflammatory bowel disease. A national sample. Dig Dis Sci 1991; 36:1746-1755.

3. Garrett JW, Drossman DA: Health status in inflammatory bowel disease. Biological and behavioral considerations. Gastroenterology 1990; 99:90-96.

4. Streiner DL, Norman GR: Devising the items. In: Streiner DL, Norman GR (eds): Health measurement scales. A practical quide to their development. New York, Oxford University Press 1995; 15-27.

5. Binder V: Prognosis and quality of life in patients with ulcerative colitis and Crohn's disease. Int Disabil Stud 1988; 10:172-174.

6. Drossman DA: Measuring quality of life in inflammatory bowel disease. Pharmacoeconomics 1994; 6(6):578-580.

7. Farmer RG, Easley KA, Farmer JM: Quality of life assessment by patients with inflammatory bowel disease. Cleve Clin J Med 1992; 59:35-42.

8. Hellers G: A new quality of life questionnaire for patients with inflammatory bowel disease. Cleve Clin J Med 1995; 59:(1)56-57.

9. Irvine EJ: Quality of life measurement in inflammatory bowel disease. Scand $J$ Gastroenterol Suppl 1993; 199:36-39.

10. Moody GA, Mayberry JF: Quality of life: its assessment in gastroenterology. Eur J Gastroenterol Hepatol 1992; 4:1025-1030.

11. Drossman DA: Psychosocial factors in ulcerative colitis and Crohn's disease. In: Kirsmer JB, Shorter RG (eds): Inflammatory Bowel Disease. Baltimore, Williams \& Wilkins $1995 ; 492-513$.

12. Guyatt $G H$, Mitchell $A_{*}$ Irvine $E J$, Singer J, Williams $N$, Goodacre R, Tompkins C: A new measure of health status for clinical trials in inflammatory bowel disease. Gastroenterology 1989; 96:804-810.

13. Irvine EJ, Feagan B, Rochon J, Archambault A, Fedorak RN, Groll A, Kinnear D, Saibil F, McDonald JWD: Quality of life: a valid and reliable measure of therapeutic efficacy in the treatment of inflammatory bowel disease. Canadian Crohn's Relapse Prevention Trial Study Growp. Gastroenterology 1994; 106:287-296.

14. Harvey RF, Bradshaw JM: A simple index of Crohn's disease activity. The Lancet $1980 ; 8: 514$

15. Levenstein S, Prantera C, Varvo V, Scribano ML, Berto E, Andreoli A, Luzi C: Psychological stress and disease activity in ulcerative colitis: a multidimensional cross-sectional study. Am J Gastroenterol 1994; 89:1219-1225.

16. Tulder van MW, Aaronson NK, Bruning PF: The quality of life of long-term survivors of Hodgkin's disease. Annals of Oncology 1994; 5:153-158.

17. Ware JE, Sherbourne CD: The MOS 36-item Short-Form Health Survey (SF-36) $\mathbb{1}$. Conceptual framework and item selection. Medical Care 1992; 30:(6)473-481. 
18. McHorney CA, Ware JE, Lu R, Sherbourne CD: The MOS 36-item Short-Form Health Survey (SF-36): III. Test of data quality, scaling assumptions, and reliability across diverse patient groups. Medical Care 1994; 32:(1)40-66.

19. Lennard-Jones JE: Classification of inflammatory bowel disease. Scand J Gastroenterol Suppl 1989; 24:2-6.

20. Deyo RA, Diehr P, Patrick DL: Reproducibility and responsiveness of health status measures. Statistics and strategies for evaluation. Control Clin Trials 1991; $12: 142 S-158 S$.

21. Bulpitt $\mathrm{CJ}$, Fletcher $\mathrm{AE}$ : The measurement of quality of life in hypertensive patients: a practical approach. Br J Clin Pharmacol 1990; 30:353-364.

22. Mitchell A, Guyatt $G$, Singer $J$, Irvine $E J$, Goodacre $R$, Tompkins $C$, Williams $N$, Wagner F: Quality of life in patients with inflammatory bowel disease. $J$ Clin Gastroenterol 1988; 10:306-310.

23. Castellino $\mathrm{F}$, Rosina $\mathrm{F}$, Bansi DS, Bauducci M, Touscoz GA, Giorda L, Borghesio E, Bessone MP, Astegiano M, Musso A, Maina AM, Mattalia A, Bonino $F$, Fleming KA, Chapman RW, Verme G, Pera A: Anti-neutrophil cytoplasmatic antibodies in inflammatory bowel disease: do they recognise different subsets of a heterogeneous disease? Eur J Gastroenterol Hepatol 1995; 7:(9)859-864.

24. Streiner DL, Norman GR: Measuring change. In: Streiner DL, Norman GR (eds): Heath measurement scales. A practical quide to their development. New York., Oxford University Press 1995; 163-180.

25. Fitzpatrick $R$, Ziebland $S$, Jenkinson $C$, Mowat $A$ : Transition questions to assess outcomes in rheumatoid arthritis. Brit Journ Rheum 1993; 32:807-811.

26. Fitzpatrick R, Fletcher A, Gore S, Jones D, Spiegelhalter D, Cox D: Quality of life measures in health care. I: Applications and issues in assessment. BMJ 1992; 305:1074-1077.

27. de Boer AGEM, Wijker W, Bartelsman JFW, de Haes HCJM: Inflammatory Bowel Disease Questionnaire: cross-cultural adaptation and further validation. Eur $\mathbb{I}$ Gastroenterol Hepatol 1995; 7:1043-1050. 


\section{Chapter IX}

\section{Cigarette smoking and quality of life in patients with Inflammatory Bowel Disease}

MG Russel, FH Nieman, JM Bergers, RW Stockbrügger and the South Limburg IBD Study Group

Eur J Gastroenterol hepatol 1996; 8:1075-1081 


\begin{abstract}
Objective: Smoking has been reported as influencing disease activity in inflammatory bowel disease. The aim of our study was to elucidate the relationship between smoking and aspects of disease-specific quality of life in inflammatory bowel disease.
\end{abstract}

Design: Cross-sectional study.

Methods: In 1105 prevalent patients with inflammatory bowel disease, diagnosed according to the criteria of Lennard-Jones and Truelove \& Witts, disease-specific quality of life was investigated using the Inflammatory Bowel Disease Questionnaire (IBDQ).

Results: In Crohn's disease, smoking females reported a lower quality of life than nonsmoking females (all four dimensions of the IBDQ). Using an explanatory model of relationships between the four dimensions for the analysis, it became evident that smoking is associated with more bowel symptoms in young Crohn's disease females, with more emotional dysfunction in all Crohn's disease females, and with more systemic symptoms in all three diagnostic groups with marked bowel symptoms. Moderately smoking male ulcerative colitis patients reported fewer bowel complaints compared to non-smoking male ulcerative colitis patients.

Conclusion: There is a relationship between smoking and disease specific quality of life in both ulcerative colitis and Crohn's disease. The hypothesis is presented that a part of the observed differences in the studied quality of life dimensions with respect to age, sex and disease group are related to concomitant oral contraceptive use. 


\section{Introduction}

Although the aetiology of Inflammatory Bowel Diseases (IBD) remains obscure, there is now abundant evidence that cigarette smoking is a risk factor in Crohn's disease (CD) and non-smoking in ulcerative colitis (UC) ${ }^{1-12}$. Furthermore, smoking may influence disease activity in IBD. In $\mathrm{CD}$ a positive relationship between smoking, symptoms and recurrence has been reported, while in UC therapy with nicotine patches reduces disease activity in the acute stage ${ }^{13-16}$.

Assessment of disease activity is known to be difficult in $\mathrm{IBD}^{17,18}$. Investigating the role of exogenic factors on disease activity or the outcome of medical interventions, it might be of great importance also to take into consideration the patients" evaluation of the quality of life.

The purpose of the study here described was to elucidate the relationship between cigarette smoking and different aspects of disease-specific quality of life in UC and $\mathrm{CD}$. The specific hypothesis under investigation was that, due to bowel and systemic complaints, smokers experience a lower quality of life compared to nonsmokers in $C D$, while the opposite is found in $U C$.

\section{Methods}

\section{Patients}

All 1105 patients studied were non-hospitalised at time of the investigation and had varying degrees of disease activity. They are participating in the South Limburg Epidemiological Study on IBD, an ongoing project on epidemiology, pathogenesis, and clinical course of IBD in the south-east of The Netherlands ${ }^{19}$. The study area has a population of about 640.000 inhabitants, and medical care to IBD patients is provided mainly by specialists working at six hospitals (one university hospital, two general district hospitals, and three local hospitals). Since October 1991 IBD patients, prevalent as well as incident cases, have been reported by their treating specialist to the IBD study centre. Cases that had been reported during the period from October 1991 through November 1994 formed the basis of the study population. All patients had given informed consent for data collection. Medical data were subsequently collected from the medical records and data on smoking and quality of life were assessed by a postal questionnaire. The criteria of LennardJones were applied in case definition for $C D^{2}$ and those of Truelove \& Witts for $\mathrm{UC}^{20}$. The group of UC patients was further subdivided into patients with disease limited to the rectum, ulcerative proctitis (UP), and into patients with mucosal inflammation beyond the rectosigmoidal junction, extended ulcerative colitis 
performed and Cronbach's alpha for internal consistency was calculated ${ }^{24.25}$. Given the explanatory model between the four dimensions, causal relations were supposed to be present so that four separate factor analyses had to be performed using principal-axis-factoring as analysing technique. Results are shown in Table 9.1: all dimensions were unidimensional; as factor loadings were "high" $(>0.4)$ and "second factors" could be neglected. Reliability coefficients turned out to be sufficiently high, so the additive scale construction in the first part turned out to be legitimate. Subsequently analysis of covariance (Ancova) was used for data analysis. Age was considered as a covariate, 'smoking cigarettes' and the intensity of smoking, gender and diagnosis group were the factors. Following the causal order hypothesized in Figure 9.1, for instance in analysing systemic symptoms as a dependent variable, 'bowel symptoms' was used as an extra covariate. Using stepwise backward elimination as a guiding line to test all types of interactions between factors themselves and between factors and covariates, the best fitting model was searched which could reproduce the observed scores most efficiently. A p-value belonging to F-ratios of 0.05 was considered to be statistically significant. All data analysis was made using SPSS-pc programs (Dos /5.0 and Windows /6.0).

\section{Results}

\section{Actual smoking habits}

Current cigarette smoking was reported more frequently in $\mathrm{CD}(45 \%)$ than in e-UC $(17 \%)$ or UP $(10 \%)$. Correcting for age (below or above 45 years) and gender this difference between $C D$ on the one side and $e-U C$ and UP on the other was statistically significant in females of any age $(p<0.0001)$ and in males above 45 years $(p<0.0001)$, but not in males younger than 45 years $(p=0.20)$. Male e-UC patients above 45 years, were significantly less often smokers than male UP patients above 45 years $(p<0.0001)$. No difference between e-UC and UP was observed in females or male patients under 45 years $(p=0.51)$. The average number of cigarettes smoked each day, as reported by the patients in the various groups, is illustrated in Figure 9.2.

\section{Smoking status and IBDQ}

The mean scores, standard deviations and numbers of patients of the four dimensions and the total IBDQ score in e-UC and $C D$ are given in the Figures $\mathbf{9 . 3}$ and 9.4. Data are given by gender and separately for smoking and non-smoking patients. In e-UC and UP (data not shown) no difference between smokers and non-smokers in the mean scores of the total IBDQ score and of the four dimensions was observed. In CD the mean total IBDQ score as well as the mean scores of the 
Table 9.1 Factor-analytic results and results of the reliability analysis for the four dimensions ("factors") within the IBDQ. The ifems are reproduced as a shortening of the original IBDQ 2 .

\begin{tabular}{|c|c|c|c|}
\hline Bowel symptoms & Factor loading & Systemic synptoms & Factor loading \\
\hline Abdominal cramps & 0.820 & Fatigue and tiredness & 0.839 \\
\hline Abdominal pain & 0.795 & Generally unwell & 0.831 \\
\hline Abdominal bloating & 0.677 & Energy & 0.788 \\
\hline Frequency of defecation & 0.629 & Keeping awake & 0.540 \\
\hline Loose bowels & 0.568 & Getting the desired weight & 0.394 \\
\hline Accidental soiling & 0.560 & & \\
\hline Tenesmus & 0.547 & & \\
\hline Large amounts of gas & 0.519 & & \\
\hline Rectal bleeding & 0.472 & & \\
\hline Eigenvalue & $3.59(39.8 \%)$ & Eigenvalue & $2.46(49.2 \%)$ \\
\hline Cronbach's alpha & 0.85 & Crombach's alpha & 0.81 \\
\hline Eimotional function & Factor loading & Social impairment & Factor loading \\
\hline Feeling depressed & 0.817 & Cancel an engagement & 0.807 \\
\hline Feeling tearful & 0.801 & Problems with sports activity & 0.698 \\
\hline Feeling irritable & 0.795 & Unable to attend work & 0.682 \\
\hline Feeling happy & 0.776 & Avoid events, washroom & 0.674 \\
\hline Feeling frustated & 0.752 & Limited sexual activity & 0.571 \\
\hline Feeling relaxed & 0.736 & & \\
\hline Feeling embarrassed & 0.712 & & \\
\hline Worries, complications & 0.709 & & \\
\hline Feeling angry & 0.667 & & \\
\hline Lack of understanding & 0.573 & & \\
\hline Fear of no washroom & 0.499 & & $\therefore$ \\
\hline Fear of needing surgery & 0.497 & & \\
\hline Eigenvalue & $5.96(49.6 \%)$ & Eigenvalue & $2.38(47.4 \%)$ \\
\hline Cronbach's alpha & 0.92 & Cronbach "s alpha & 0.82 \\
\hline
\end{tabular}

Note: High factor loadings mean a high correlation of a varable with the factor" the Eigenvalues express the total amount of variance explained by the factor; Crohnbach's alpha reflects internal consistency of the factor 
performed and Cronbach's alpha for internal consistency was calculated ${ }^{24,25}$. Given the explanatory model between the four dimensions, causal relations were supposed to be present so that four separate factor analyses had to be performed using principal-axis-factoring as analysing technique. Results are shown in Table 9.1: all dimensions were unidimensional, as factor loadings were "high" $(>0.4)$ and "second factors" could be neglected. Reliability coefficients turned out to be sufficiently high, so the additive scale construction in the first part turned out to be legitimate. Subsequently analysis of covariance (Ancova) was used for data analysis. Age was considered as a covariate, 'smoking cigarettes' and the intensity of smoking, gender and diagnosis group were the factors. Following the causal order hypothesized in Figure 9.1, for instance in analysing systemic symptoms as a dependent variable, 'bowel symptoms' was used as an extra covariate. Using stepwise backward elimination as a guiding line to test all types of interactions between factors themselves and between factors and covariates, the best fitting model was searched which could reproduce the observed scores most efficiently. A p-value belonging to F-ratios of 0.05 was considered to be statistically significant. All data analysis was made using SPSS-pc programs (Dos /5.0 and Windows /6.0).

\section{Results}

\section{Actual smoking habits}

Current cigarette smoking was reported more frequently in CD (45\%) than in e-UC $(17 \%)$ or UP (10\%). Correcting for age (below or above 45 years) and gender this difference between $\mathrm{CD}$ on the one side and $\mathrm{e}-\mathrm{UC}$ and UP on the other was statistically significant in females of any age $(p<0.0001)$ and in males above 45 years $(p<0.0001)$, but not in males younger than 45 years $(p=0.20)$. Male e-UC patients above 45 years, were significantly less often smokers than male UP patients above 45 years $(\mathrm{p}<0.0001)$. No difference between e-UC and UP was observed in females or male patients under 45 years $(p=0.51)$. The average number of cigarettes smoked each day, as reported by the patients in the various groups, is illustrated in Figure 9.2.

\section{Smoking status and IBDQ}

The mean scores, standard deviations and numbers of patients of the four dimensions and the total IBDQ score in e-UC and CD are given in the Figures 9.3 and 9.4. Data are given by gender and separately for smoking and non-smoking patients. In e-UC and UP (data not shown) no difference between smokers and non-smokers in the mean scores of the total IBDQ score and of the four dimensions was observed. In CD the mean total IBDQ score as well as the mean scores of the 
Table 9.1 Factor-analytic results and results of the reliability analysis for the four dimensions ("factors") within the IRDQ. The items are reproduced as a shortening of the original $1 \mathrm{BDQ}$.

\begin{tabular}{|c|c|c|c|}
\hline Bowel symptoms & Factor loading & Systemic symptons & Fuctor loading. \\
\hline Abdominal cramps & 0.820 & Faligue and tiredness & 0.839 \\
\hline Abdominal pain & 0.795 & Generally unwell & 0.831 \\
\hline Abdominal blloating & 0.677 & Energy & 0.788 \\
\hline Frequency of defecation & 0.629 & Keeping awake & 0.540 \\
\hline Loose bowels & 0.568 & Getting the desired weight & 0.394 \\
\hline Accidental soiling & 0.560 & & \\
\hline Tenesmus & 0.547 & & \\
\hline Large amounts of gas. & 0.519 & & \\
\hline Rectal bleeding & 0.472 & & \\
\hline Eigenvalue & $3.59(39.8 \%)$ & Eigenvalue & $2.46(49.2 \%)$ \\
\hline Crombach's alpha & 0.85 & Cronbach's alpha & 0.81 \\
\hline Emotional function & Factor loading & Social impairment & Factor loading \\
\hline Feeling depressed & 0.817 & Cancel an engagement: & 0.807 \\
\hline Feeling tearful & 0.801 & Problems with sports activity & 0.698 \\
\hline Feeling irritable & 0.795 & Unable to attend work & 0.682 \\
\hline Feeling happy & 0.776 & Avoid events, washroom & 0.674 \\
\hline Feeling frustated & 0.752 & Limited sexual activity & 0.571 \\
\hline Feeling relaxed & 0.736 & & \\
\hline Feeling embarrassed & 0.712 & & \\
\hline Worries, complications & 0.709 & & \\
\hline Feeling angry & 0.667 & & \\
\hline Lack of understanding & 0.573 & & \\
\hline Fear of no washroom & 0.499 & & 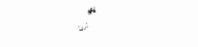 \\
\hline Fear of needing surgery & 0.497 & & \\
\hline Eigenvalue & $5.96(49.6 \%)$ & Eigenwalue & $2.38(47.4 \%)$ \\
\hline Crombach 's alpha & 0.92 & Cronbach's alpha & 0.82 \\
\hline
\end{tabular}

Note: High factor loadings mean a high correlation of a variabile with the factor; the Eigenvalues express the total amount of variance explained by the factor; Crohnbach's alpha reflects internal consistency of the factor 
four dimensions were significantly lower in smokers. After further subdivision by gender these differences were due to significant differences in females only.

\section{Explanatory model}

In this second part only the significant findings will be given following data analysis with the explanatory model, in which the four IBDQ dimensions are treated as dependent variables and age, gender, smoking habit, and diagnosis as predictors (ANCOVA).
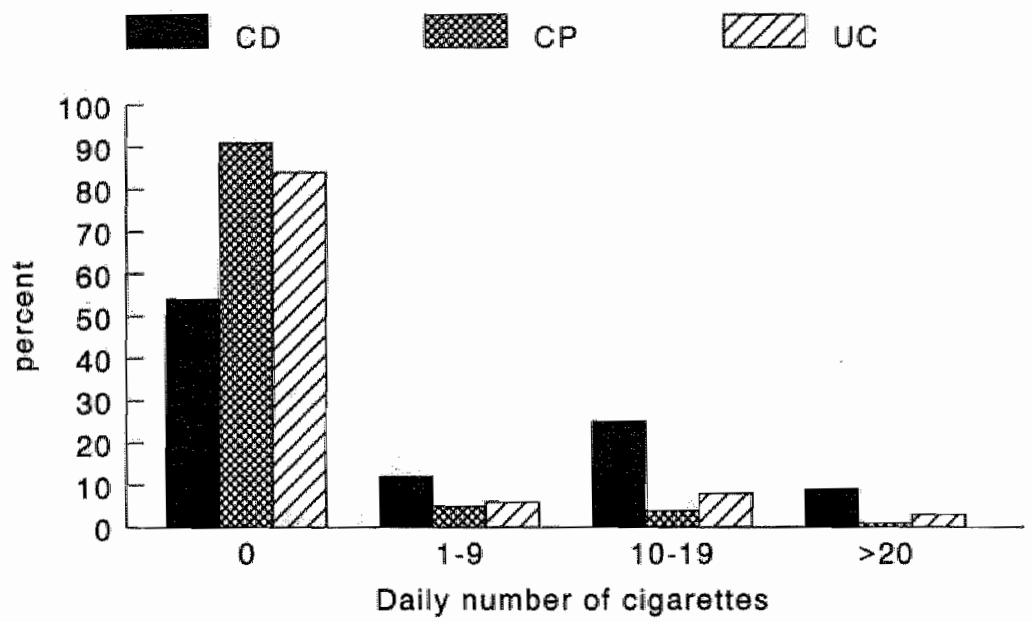

Figure 9.2 Actual smoking behaviour of the study population

\section{Bowel symptoms}

Smoking male e-UC patients had a significantly higher (better) mean score concerning bowel symptoms than non-smoking male e-UC patients $(p<0.04)$. Controlled for the number of cigarettes smoked daily, the significance was true only in patients smoking $1-9$ cigarettes/day $(6.2 \%$ of the patients; $p<0.006)$. In female e-UC patients and in patients with UP (of both genders) no difference was found in bowel symptoms between smokers and non-smokers.

In contrast, smoking female $\mathrm{CD}$ patients, but only those under the age of 45 years, had a lower (worse) mean score of bowel symptoms than non-smoking female $C D$ patients in this age group $(\mathrm{p}<0.001 ; \mathrm{n}=238)$. Above the age of 44 years no difference was found between smoking and non-smoking female $\mathrm{CD}$ patients $(p=0.896 ; n=75)$. 


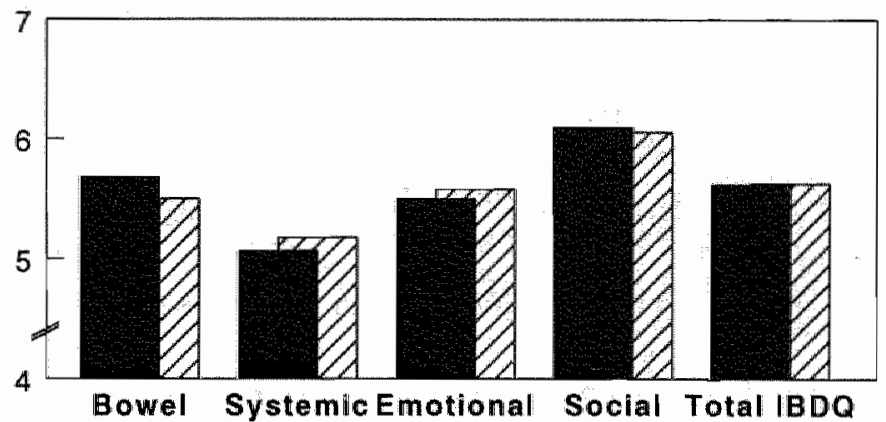

\begin{tabular}{|c|c|c|c|c|c|c|c|c|c|c|c|}
\hline \multicolumn{2}{|c|}{ HBDQ Dimension } & \multirow{2}{*}{$\begin{array}{l}\text { Giowel } \\
\text { mean }(50) \\
59 *(1.10)\end{array}$} & \multirow{2}{*}{$-\frac{\mathrm{nr}}{42}$} & \multirow{2}{*}{$\begin{array}{l}\text { Systemic } \\
\text { meata (sd) }\end{array}$} & \multirow{2}{*}{$\frac{\mathrm{mr}}{28}$} & \multirow{2}{*}{$\begin{array}{l}\text { Emotionat } \\
\text { mean (bet) } \\
5.70(1.04)\end{array}$} & \multirow{2}{*}{$\frac{\mathrm{nr}^{r}}{43}$} & \multirow{2}{*}{$\frac{\begin{array}{l}\text { Social } \\
\text { meann (sd) }\end{array}}{6.19(1.26)}$} & \multirow{2}{*}{$\frac{\mathrm{gar}}{42}$} & \multirow{2}{*}{$\frac{\begin{array}{c}\text { Total storio } \\
\text { mexin (sui) }\end{array}}{5.75(1.07)}$} & \multirow{2}{*}{$\frac{\mathrm{mr}}{40}$} \\
\hline Stmokefs & malie & & & & & & & & & & \\
\hline & female & $5.291(1.37)$ & 28 & $4.75(1.35)$ & 30 & $5.20(1.23)$ & 29 & $5.96(1.20)$ & 28 & $5.40(1.08)$ & 25 \\
\hline \multirow[t]{2}{*}{ Nan Shrokers } & male & $5.53(1.23)$ & 202 & $5.28(1.21)$ & 204 & $5.60(1.09)$ & 197 & $6.07(1.30)$ & 194 & $5.680 .98)$ & 179 \\
\hline & [emaje: & $5.46(1.22)$ & 145 & $5.04(1.18)$ & 150 & $5.55(1.10)$ & 147 & $6.05(1.35)$ & 142 & $5.58(0.99)$ & 132 \\
\hline
\end{tabular}

Figure 9.3 Four dimensions and total score of the $\mathrm{BBDQ}$ in e-UC according to smoking status (top), supplemented with more detailed data involving gender, standard deviation (sd), and number of patients (nr) at the bottom

\section{Smokers

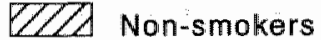

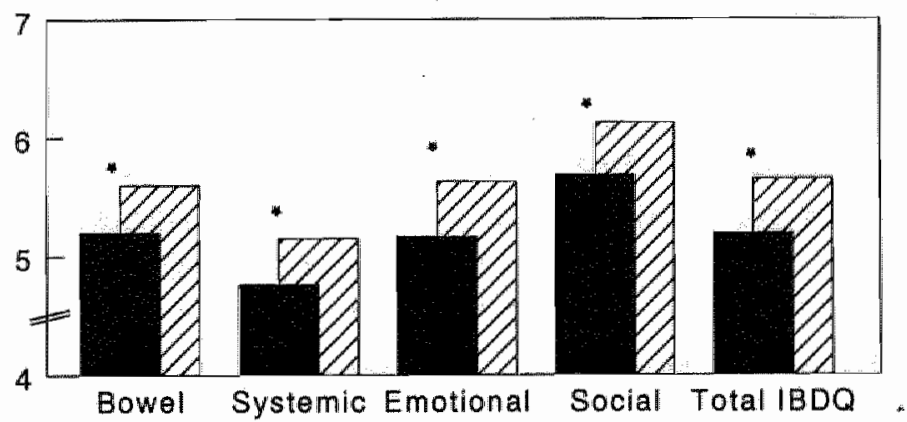

\begin{tabular}{|c|c|c|c|c|c|c|c|c|c|c|c|c|}
\hline \multicolumn{2}{|c|}{ MBDQ Dimensfioti } & \multirow{2}{*}{$\begin{array}{l}\text { Howel } \\
\text { mean (5d) }\end{array}$} & \multirow{2}{*}{$\frac{\text { or }}{39}$} & \multicolumn{2}{|c|}{$\begin{array}{l}\text { Systenilc } \\
\text { mean (fd) }\end{array}$} & \multirow{2}{*}{$\frac{\mathrm{Aur}}{80}$} & \multirow{2}{*}{$\begin{array}{l}\begin{array}{l}\text { Emational } \\
\text { mean (sd) }\end{array} \\
5.51(1.05)\end{array}$} & \multirow{2}{*}{$\frac{\mathrm{nr}}{7 y}$} & \multirow{2}{*}{$\frac{\text { Sodial }}{5.86(1.13)}$} & \multirow{2}{*}{$\frac{\mathrm{mr}}{78}$} & \multirow{2}{*}{$\begin{array}{l}\text { Total sicore } \\
\text { methin (5d) } \\
5.50(0.96)\end{array}$} & \multirow{2}{*}{$\frac{n \mathbf{r}}{\eta_{2}}$} \\
\hline Srnokers. & miale & & & 4.98 & $(1.27)$ & & & & & & & \\
\hline & femaite & $5.07(1.13)$ & 159 & 4.65 & $(1,27)$ & $1.5:$ & $4.99(1.21)$ & 159 & $5.58(1.52)$ & 150 & $5.03(1.17)$ & 14.4 \\
\hline \multirow[t]{2}{*}{ Nan Smoversts } & male & $5.68(0,2)$ & $\$ 26$ & 5.30 & $(1.03)$ & 127 & 5.70 (ppos) & 120 & $6.13(1.07)$ & 120 & $5.72(0.84)$ & 110 \\
\hline & femple & $5.54(0.97)$ & :15* & $5.03^{*}$ & $(1.13)$ & 156 & $5.57 \%(100)$ & $15 i$ & $6.12 *(0.991$ & 148 & $5.60 \%(0.88)$ & 137 \\
\hline
\end{tabular}

Figure 9.4 Four dimensions and total score of the IBDQ in Crohn's disease according to smoking status (top), supplemented with more detailed data involving gender, standard deviation (sd), and number of patients (nr) at the bottom 


\section{Systemic symptoms}

In the "systemic symptoms" dimension smoking males with either e-UC or UP reported a lower (worse) mean score than non-smoking male e-UC $(p<0.05)$ or UP $(\mathrm{p}<0.0008)$ patients. If only patients with a relatively low mean bowel symptom score $(<=5)$ were included, male smokers in all three diseases had lower (worse) scores regarding systemic symptoms compared to male non-smokers (e-UC: $p<0.019, \mathrm{CD}: \mathrm{p}<0.028, \mathrm{UP}<0.025$ ). No difference in systemic symptoms was observed between smoking and non-smoking females. Independent of the smoking status, $\mathrm{CD}$ females with a low (worse) mean bowel score reported generally more systemic symptoms than females with a high score $(p<0.006)$.

\section{Emotional and social function}

Concerning the dimension "emotional function", smoking $C D$ females reported lower mean emotional function scores compared to non-smoking females with $C D$ $(p<0.001)$. Smoking had no relationship to social functioning in either of the three disease groups.

\section{Discussion}

In this study we report the relationship between current smoking behaviour and disease-specific quality of life in patients with IBD, as defined by the inflammatory bowel disease questionnaire. In a first -conventional statistical- analysis smoking patients with $C D$ had a lower total quality of life score than non-smokers, consistent with our original hypothesis. This difference was found concerning all four dimensions of the IBDQ, but was only significant in females. The conventional analysis did not confirm our hypothesis in patients with e-UC and UP. To elucidate the relationship between smoking and quality of life in IBD in more detail a relational model between the four dimensions was developed. The main results of this second analysis were that in $\mathrm{CD}$ smoking is strongly associated with more bowel symptoms in females under the age of 45 , while in e-UC male smokers reported fewer bowel symptoms. Additionally, in all three disease groups, male smokers with marked bowel symptoms reported more systemic symptoms than non-smokers. Finally, female smoking $\mathrm{CD}$ patients more frequently reported emotional dysfunction, while no relationship between smoking and social function was observed.

Smoking clearly is an important variable in IBD and is associated with an increased risk of developing $\mathrm{CD}$ and a decreased risk of developing e-UC'. The important observations of Cottone et al suggest that there is a negative effect of smoking on 
disease activity in $\mathrm{CD}$. They showed that after surgery for $\mathrm{CD}$ the risks of clinical, endoscopic and surgical recurrence were all increased in smokers compared to nonsmokers $^{26}$. A number of other studies also showed a positive, dose-dependent, association between smoking and disease activity in $\mathrm{CD}^{27-29}$. It has been suggested that microvascular inflammation and thrombosis may contribute to the pathogenesis of $\mathrm{CD}^{30}$. Independent risk factors for thrombosis, like smoking and oral contraceptive use, could aggravate microvascular damage and enhance disease activity $^{31}$. In UC smoking possibly has a favourable effect on active disease, which may act via nicotine ${ }^{32}$. A placebo controlled trial on disease activity in UC using nicotine patches has recently been published. In the acute stage nicotine reduced symptoms and endoscopic inflammation ${ }^{15}$. However, as was shown by the same group, nicotine did not diminish the number of exacerbations in quiescent $\mathrm{UC}^{33}$. As was expected patients with $C D$ in the present study were more frequently active smokers than those with UC. There was an exception, however, in the group of males under the age of 45 years, in whom no significant difference in smoking habits was found between $\mathrm{CD}$ and $\mathrm{UC}$.

In IBD, quality of life measurement has become popular during recent years and several instruments have been developed ${ }^{34-38}$. For the present study the IBDQ was used in a survey to measure the patients" -disease-specific- quality of life in a cross-sectional way. Originally, the IBDQ had been developed for repeated use in clinical trials. The original article analyzes four dimensions: bowel and systemic symptoms, and emotional and social function ${ }^{21}$. As was reported earlier by Mitchell, our study showed that those four concepts are not independent factors. By constructing an explanation model one hypothesizes interdependencies between the four different dimensions of the IBDQ. Our model assumes that bowel symptoms influence systemic symptoms and that both bowel symptoms and systemic symptoms have influence on emotional and social function (Figure 9.1). Using the predictors diagnosis, smoking behaviour, age, and gender, the four dimensions were analyzed by analysis of covariance. In this way it is possible to assess the empirical relations between the predictors and each of the interdependent dimensions of the IBDQ. One might argue that all relations between the four dimensions are reciprocal, for instance by assuming that besides bowel symptoms influencing emotional function the latter dimension may also affect the former ${ }^{39,40}$. However, many of the items of the IBDQ measuring emotional function are clearly phrased as specific consequences of the general cause of bowel symptoms. Thus it is not very plausible to argue that the IBDg dimensions will all be mutually dependent on each other. The patients in the present study, all outpatients, seemed in general to have a relatively high quality of life, which is expressed by high mean scores in the four dimensions of the IBDQ compared to previous studies using this instrument ${ }^{21,23}$. Most of the observed differences are small, although statistically 
significant, and the question remains open whether the differences are of clinical significance. Smoking seems to act differently in patients with high disease activity compared to patients with low disease activity. This was seen in the dimension "systemic symptoms" in CD. Only in patients with moderate or severe bowel symptoms was a difference between smokers and non-smokers found, the former having more systemic symptoms. The observed differences in CD between smokers and non-smokers in the dimensions emotional and social function, where lower mean scores were observed in smokers, could almost fully be explained by the effects of bowel and systemic symptoms on those dimensions. The only significant relationship was found in female $C D$ patients, where smoking was associated with lower scores for emotional function.

It has been reported that females in general report a lower quality of life than men $^{4342}$. In our study smoking $\mathrm{CD}$ females under the age of 45 reported the worst quality of life in the dimension "bowel symptoms". Oral contraceptive use as a risk factor has been studied in both $\mathrm{CD}$ and UC ${ }^{45-48}$. Results are conflicting, but there is a tendency towards a positive association in both diseases. One might speculate that smoking and oral contraceptive use interact and both influence the outcome of the quality of life scores in the different subgroups (younger versus older and male versus female) of patients. To our knowledge there is no literature available concerning the influence of oral contraceptive use on clinical symptoms in IBD. Since we did not have reliable data on oral contraceptive use at the time of the questionnaire, it was not possible to further examine a possible additive effect.

This study adds a new dimension to quality of life studies in IBD. In addition to using the IBDQ as an instrument in clinical trials, it appeared possible to investigate the effect of a specific risk factor on disease-specific quality of life. The reported negative relationships between smoking and quality of life are strong arguments to encourage patients with IBD to give up smoking. The only exception was formed by bowel symptoms in mildly smoking male UC patients. In spite of this last finding, realising other harmful effects of smoking on health, we feel that also this group should be advised to stop smoking. The important finding that smoking is associated with more bowel symptoms in females with CD under 45 years of age is possibly associated with concurrent contraceptive use. Further studies are necessary to analyze the relationships between smoking and oral contraceptive use, disease activity, and quality of life in IBD. To investigate these relationships and to study the effects of cessation to smoke on quality of life in IBD, a follow-up case-control study involving incident patients is in progress. 


\section{References}

1. Harries AD, Baird A, Rhodes J, Mayberry JF: Has the rising incidence of Crohn's disease reached a plateau? BMJ $1982 ; 284: 235$

2. Jick $\mathrm{H}$, Walker AM: Cigarette smoking and ulcerative colitis. $N$ Engl J Med 1983; 308:261-263.

3. Boyko EJ, Koepsell TD, Perera DR, Inui TS: Risk of ulcerative colitis anong former and current cigarette smokers. N Engl I Med 1987; 316:707-710.

4. Logan RF, Edmond M, Somerville KW, Langman MJ: Smoking and ulcerative colitis. Br Med J Clin Res 1984; 288:751-753.

5. Silverstein MD, Lashner BA, Hanawer SB: Cigarette smoking and ulcerative colitis: a case-control study. Mayo Clin Proc 1994; 69:425-429.

6. Persson PG, Ahlbom A, Hellers $G_{. "}$ Inflammatory bowel disease and tobacco smoke-a case-control study. Gut 1990; 31:1377-1381.

7. Lorusso D, Leo S, Misciagna G, Guerra V: Cigarette smoking and ulcerative colitis. A case control study. Hepatogastroenterology 1989; 36:202-204.

8. Harries AD, Baird A, Rhodes J. Non-smoking: A feature of ulcerative colitis. BMJ $1982 ; 284: 706$

9. Calkins BM: A meta-analysis of the role of smoking in inflammatory bowel disease. Dig Dis Sci 1989; 34:1841-1854.

10. Lindberg E, Tysk C, Andersson K, Järnerot G: Smoking and inflammatory bowel disease. A case control study. Gut 1988; 29:352-357.

11. Katschinski B: Rauchen und Ovulationshemmer bei entzundlichen Darmerkrankungen. Med Klin 1993; 88 Suppl 1:5-8.

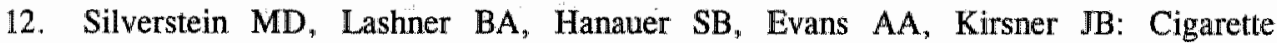
smoking in Crohn's disease. Am J Gastroenterol 1989; 84:31-33.

13. Rhodes $J$, Thomas GA: Smoking: good or bad for inflammatory bowel disease?: Gastroenterology 1994: 106:807-810.

14. Cottone M, Rosselli M, Orlando A, Oliva L, Puleo A, Cappello M, et al.: Smoking habits and recurrence in Crohn's disease. Gastroenterology 1994; 106:643-648.

15. Pullan RD, Rhodes J, Ganesh S, Mani V, Morris JS, Williarns GT, et al.: Transdermal nicotine for active ulcerative colitis. N Engl J Med 1994; 330:811-815.

16. Lashner BA, Hanauer SB, Silverstein MD: Testing nicotine gum for ulcerative colitis patients. Experience with single-patient trials. Dig Dis Sci 1990; 35:827-832.

17. Camilleri $M$, Proana $M$ : Advances in the assessment of disease activity in inflammatory bowel disease. Mayo Clin Proc 1989; 64:800-807.

18. Hodgson $H J$, Bhatti $M$ : Assessment of disease activity in ulcerative colitis and Crohn's disease. Inflammatory Bowel Disease 1995; 1:(2)117-134.

19. Russel MGVM, Brummer $\mathrm{R}$, Limonard $\mathrm{C}$, Dorant $\mathrm{E}$, Stockbrigger $\mathrm{R}$ : Incidence and prevalence of inflammatory bowel disease in South Limburg, The Netherlands. Neth J Med 1994; 45:A32

20. Lennard-Jones JE: Classification of inflammatory bowel disease. Scand J Gastroenterol 1989; 24(suppl 170):2-6. 
21. Guyatt $G$, Mitchell $A$, Irvine $E$, Singer $J$, Williams $\mathbb{N}$, Goodacre $\mathbb{R}$, et al.: $A$ new measure of health status for clinical trials in inflammatory bowel disease. Gastroenterology 1989; 96:804-810.

22. Russel MGVM, Brandon S, Engels $\mathbf{L}$, Rijken J, Stockbrügger RW, "South Limburg IBD Study Group": Validation of the Dutch translation of the "Inflammatory Bowel Disease Questionnaire". Gut 1995; 37:A179 Abstract.

23. Mitchell A, Guyatt $G$, Singer J, Irvine EJ, Goodacre $R$, Tompkins $C$, et al: Quality of life in patients with inflammatory bowel disease. I Clin Gastroenterol 1988; 10:306-310.

24. Streiner DL, Norman GR: Selecting the items. In: Health measurement scales; a practical guide to their development and use. Edited by Streiner DL and Norman GR. Oxford: Oxford Medical Publications 1989; 39-53.

25. Kline P: A general description of factor analysis. In: An easy guide to factor analysis. Edited by Kline P. London: Routledge 1994; 1-13.

26. Cottone $\mathrm{M}$, Rosselli $\mathrm{M}$, Orlando A, Lorenzo O, Puleo A, Cappello $\mathrm{M}$, et al.: Smoking habits and recurrence in Crohn's disease. Gastroenterology 1994; 106:643648.

27. Kurata JH, Kantor Fish S, Frankl H, Godby $\mathrm{P}$, Vadheim CM: Crohn's disease among ethnic groups in a large health maintenance organisation. Gastroenterology $1992 ; 102: 1940-1948$.

28. Duffy LC, Zielezny MA, Marshall JR, Weiser MM, Byers TE, Phillips JF, et al.: Cigarette smoking and risk of clinical relapse in patients with Crohn"s disease. Am J Prev Med 1990; 6:161-166.

29. Lindberg $\mathbb{E}$, Järnerot $G$, Huitfeldt $B$ : Smoking in Crohn's disease: effect on localisation and clinical course. Gut 1992; 33:779-782.

30. Wakefield AJ, Dhillon AP, Rowles PM, Sawyerr AM, Pittilo RM, Lew is AAM, et al.: Pathogenesis of Crohn's disease: multifocal gastrointestinal infarction. Lancet $1989 ;(2): 1057-1062$.

31. Wakefield AJ, Sawyerr AM, Hudson M, Dhillon AP, Pounder RE: Smoking, the oral contraceptive pill, and Crohn's disease. Dig Dis Sci 1991; 36:1147-1150.

32. Boyko EJ, Perera DR, Koepsell TD, Keane EM, Inui TS: Effects of cigarette smoking on the clinical course of ulcerative colitis. Scand J Gastroenterol 1988; 23:1147-1152.

33. Thomas GA, Rhodes J, Mani V, Williams GT, Russell MA, Feyerabend $C$ : Transdermal nicotine as maintenance therapy for ulcerative colitis. $N$ Engl J Med $1995 ; 332: 988-92$.

34. Irvine EJ: Quality of Life-measurement in inflammatory bowel disease. Scand J Gastroenterol Suppl 1993; 199:36-39.

35. Kunsebeck HW, Korber J, Freyberger $H$ : Quality of life in patients with inflammatory bowel disease. Psychother Psychosom 1990; 54:110-116.

36. Binder V: Prognosis and quality of life in patients with ulcerative colitis and Crohn's disease. Int Disabill Stud 1988; 10:172-174. 
37. Drossman DA, Patrick DL, Mitchell CM, Zagami EA, Appelbaum MI: Health-related quality of life in inflammatory bowel disease. Functional status and patient worries and concerns. Dig Dis Sci 1989; 34:1379-1386.

38. Farmer RG, Easley KA, Farmer JM: Quality of life assessment by patients with inflammatory bowel disease. Cleve Clin J Med 1992; 59:35-42.

39. Duffy LC, Zielezny MA, Marshall JR, Weiser MM, Phillips JF, Byers TE, et al.: Lag time between stress events and risk of recurrent episodes of inflammatory bowel disease. Epidemiology 1991; 2:141-145.

40. Ramchandani D, Schindler B, Katz J: Evolving concepts of psychopathology in inflammatory bowel disease. Implications for treatment. Med Clin North Am 1994; 78:1321-1330.

41. Wenger NK: Quality of life issues in hypertension: consequences of diagnosis and considerations in management. Am Heart J 1988; 116:628-632.

42. Vandenburg MJ, Evans SJW, Kelly BJ, Bradshaw F, Currie WJC, Cooper WJD: Factors affecting the reporting of symptoms by hypertensive patients. $\mathrm{Br} \mathrm{J}$ Clin Pharmacol 1984; 10:189-195.

43. Katschinski B, Fingerle D, Scherbaum B, Goebell H: Oral contraceptive use and cigarette smoking in Crohn's disease. Dig Dis Sci 1993; 38:1596-1600.

44. Sandler RS, Wurzelmann JI, Lyles CM: Oral contraceptive use and the risk of inflammatory bowel disease. Epidemiology $1992 ; 3: 374-378$.

45. Logan RF, Kay CR: Oral contraception, smoking and inflammatory bowel diseasefindings in the Royal College of General Practitioners Oral Contraception Study. Int J Epidemiol 1989; 18:105-107.

46. Boyko EJ, Theis MK, Vaughan TL, Nicol Blades B: Increased risk of inflammatory bowel disease associated with oral contraceptive use. Am I Epidemiol 1994; 140:268-278.

47. Lashner BA, Hanauer SB: The absence of an association between oral contraceptive use and ulcerative colitis in patients [letter]. Gastroenterology $1991 ; 100 ; 1,784$

48. Godet PG, May GR, Sutherland LR: Meta-analysis of the role of contraceptive agents in inflammatory bowel disease. Gut $1995 ; 37: 668-673$. 


\section{Chapter X}

\section{General discussion}

(4) 


\section{General discussion}

\section{Introduction}

The ultimate purpose of clinical epidemiology is to provide important clues as to the nature of diseases and to recognize preventable risk factors ${ }^{1}$. The comparison between diseased and non-diseased populations allows the epidemiologist to determine those features requiring further investigation. Epidemiological studies of Inflammatory Bowel Disease (IBD) were first published in the 1950's and 1960 ' $\mathrm{s}^{2-7}$. In spite of there being many studies, we still know relatively little about the epidemiology of IBD.

Most data on the clinical manifestation, disease course and outcome of IBD originate from referral centres with special interest in IBD. The bias introduced by studying only the referred cases is obvious.

\section{Incidence of IBD}

After a period of progression during the sixties and seventies, the incidence of Crohn's disease (CD) in the Western world seems to have reached a plateau at a level of around 6 per 100.000 inhabitants per year in most industrialised areas. In the same time, the incidence rate for ulcerative colitis (UC) has stabilised in northern Europe and North America. Differences in geographical distribution and, particularly, changes over time within one area may provide insights into possible etiologic factors. Comparing incidence rates between different areas, and to a lesser degree also within areas, can be misleading and several problems have to be faced. Besides the fact that it is important to recognise these problems when studying incidence rates, they also apply to investigations of risk factors and of clinical outcome.

First of all the researcher is confronted with the problem of diagnosis. The bowel has only a limited capacity of response to differing etiologic agents, such as microbial and parasitic infections or ischemia. The diagnostic facilities needed to differentiate various forms of the non-specific IBD from specific bowel disorders are not equally distributed over the world and observer variation concerning diagnostic techniques like endoscopy, histology, and barium enemas is considerable'. Several diagnostic classification criteria are used at present, which may lead to incomparable results ${ }^{8.9}$. In the studies presented in this thesis the criteria developed by Lennard-Jones have been used because of their practical features and their adequacy to distinguish IBD from non-IBD. A second reason for us to apply the Lennard-Jones criteria was the participation in a large-scale European study, in which these criteria are employed by all centers ${ }^{10}$.

Then there is the problem of case ascertainment: different case finding methods 
have been used. Some studies are population-based and others are mainly or exclusively based on hospitalised patients. Investigators also must be aware of the referral pattern for IBD at the venue of a study, which might cause referral bias leading to underestimation of the incidence rate. Until recently, only few centres have prospectively collected cases, which in fact is a 'conditio sine qua non' for investigating incidence rates. According to Ekbom, it is questionable whether more retrospective studies done in a traditional way, counting heads for short periods in areas without a prior assessment of the incidence, will yield any additional information ${ }^{11}$.

To be able to compare different studies, the incidence rates should be standardised for age- and sex. A further problem is that of population size, characterisation and geographic definition of the study area. Compared to most other gastrointestinal diseases the occurrence of IBD is rare and much larger populations are needed to accumulate adequate numbers of IBD patients. According to Calkins, a rule of thumb for IBD studies is about 250.000 persons for studies lasting several years ${ }^{12}$.

During the past five years several prospective studies, using the same disease classification and employing comparable case ascertainment protocols, have been initiated by the EC-IBD study ${ }^{13-17}$. The study on the incidence of IBD in the South Limburg area, as is described in Chapter III, prospectively collected cases living in a well-defined geographical and administrative area. In - and out - patients with IBD were reported by specialists working in the area and completeness of the data was estimated in a second study using the computerised diagnostic system of the Registration Network Family Practitioners ${ }^{18}$. It appeared that of the selected subgroup known at the RNH, all patients with $\mathrm{CD}, 80 \%$ of the patients with extended ulcerative colitis, but only $25 \%$ of the patients with proctitis were known to the IBD registry. This proves the importance of quality control of data.

The incidence rate (per 100.000 inhabitants and year) of IBD in the South Limburg area (6.9 for $\mathrm{CD}, 10.0$ for $\mathrm{UC}$ and 1.1 for indeterminate colitis) is high compared to the only available data reported for The Netherlands. In a retrospective study during the period 1978-1981 in the Leiden area, Shivananda and co-workers found incidence rates of 3.9 for $\mathrm{CD}$ and 6.6 for $\mathrm{UC}^{19,20}$. As disease definitions in both studies are comparable, the higher rates of our study could either be explained by a more complete case ascertainment due to the prospective approach, or else by a real rise in incidence in the last 15 years. Finally, the difference could simply be due to a higher incidence of IBD in our ayea compared to Leiden; both study populations might differ in genetic background and / or environmental risk factors. The incidence rate of IBD in South Limburg was also higher than in most of the 19 European centres participating in the European Collaborative Study on IBD during the study period October 1991 - October $1993^{13}$. Continuation of the assessment of 
the frequency of $\mathrm{BBD}$ in our study area might prove to be important in studying the pathogenesis of IBD.

\section{Risk factors of IBD}

Investigating risk factors in IBD confronts the researcher with almost all the problems that have been mentioned in the previous paragraph. Beyond these, some other factors have to be taken into account. Because of the low incidence of IBD, the preferred research design is the case - control approach. The nature of this design requires patients and controls to recall factors before some previous event (like the moment of first complaints). This introduces the concept of bias, defined by Sackett et al. as any systematic deviation of an observation from the true (clinical) state ${ }^{21}$. Bias distorts reality and influences the validity of a study negatively. The deviation can shift the measure of association, such as the relative risk in cohort studies and the odds ratio in case - control studies, towards zero, and away from zero, and bias can even switch the effect parameter. The concept bias can be divided into three major groups: selection bias, information bias, and confounding ${ }^{22}$. Since most sources of bias are introduced in the design and execution stage of the research, they can no longer be controlled for in the analysis of the results. In most epidemiological studies in IBD relatively little attention is given to the selection of an adequate control population. The importance of choosing comparable controls, meaning that selection - and information - bias is avoided, will be further discussed in this chapter in the light of the studies described in this thesis.

The pathogenesis of $\mathrm{CD}$ and $\mathrm{UC}$ probably involves an interaction between genetic and environmental factors. The present thesis focuses on three (groups of risk factors in the development of IBD: genetic factors, "modern life" factors (including oral contraceptive use and smoking), and appendectomy.

\section{Familial aggregation of IBD, the role of genetics}

In Chapter IV the familial aggregation of IBD in South Limburg, a measure for the role of genetic factors in the pathogenesis of $\mathrm{IBD}$, is described. The first analysis of the patient questionnaire concerning $\mathbb{I B D}$ occurring in family members showed that inconsistent answers were provided by the patients. It was therefore decided to disregard these data and to perform a new study in a selected welldefined population, who were all interviewed by their doctor. In case of a positive family history of IBD, family members and their general physicians were approached by the researchers to be able to confirm the diagnosis. IBD was reported and confirmed in 16 (out of 1554) first-degree relatives by 11 (out of 245) patients. Prevalence of IBD was highest for siblings $(1.5 \%)$ and children $(1.3 \%)$ 
whereas only $0.2 \%$ of the parents were affected by IBD. Among relatives of the control subjects, IBD was observed in $0.8 \%$ (vs. $4.5 \%$ in IBD patients), resulting in an odds ratio of 5.7 (95\% CI: 2.0-16.7).

Compared to other studies on familial aggregation of IBD, our figures on the prevalence of IBD in relatives are lower than most others. Crude rates of up to $40 \%$ of family IBD history, as well as frequencies of IBD as high as $2 \%$ among siblings have been described, but these reports are largely from referral practices, which raises the issue of selection bias. Referral centers usually deal with more seriously ill subjects who may have more family members affected than less seriously ill. A second concern is whether the reports of relatives with IBD are confirmed by inquiry of the relatives themselves or by reviewing the medical records. It was remarkable that, compared with the patients" opinion, a positive family history could only be confirmed in $57 \%$ of the relatives in our study. Reports of positive family histories based on diagnoses confirmed by an objective method have ranged from 1 to $8 \% \%^{23-25}$. Remarkably, our data on the prevalence of IBD in family members are rather consistent with the large, well-designed, population-based study from Copenhagen ${ }^{26}$. The only Dutch study on familial incidence of $C D$ by Weterman et al. was published in 1984 and reported a prevalence of $8 \%$ in a selected population attending a referral hospital ${ }^{27}$.

As has been observed, prevalence of IBD was higher in siblings and children compared to parents ${ }^{16-18}$. It is likely that many offspring of patients have not reached the age at which symptoms become manifest, and the risk to offspring is therefore probably underestimated by the majority of studies, including ours. Since we had no information on the age of all the 1544 relatives, it was impossible to calculate age- and sex- specific prevalence rates or to develop age-corrected empirical risks of IBD, as was done by Yang et $\mathrm{al}^{28}$.

Other evidence for a genetic component in developing IBD comes from twin studies. In a study from Sweden, there was a high concordance rate for monozygotic twins for CD (58.3\%), whereas a concordance for UC could be demonstrated for only $6 \%$ of the pairs ${ }^{29}$. The elegance of that study lies not only in the large number of pairs that could be studied, but also in the adjustment for known environmental risk factors, such as smoking. Smoking was significantly related to risk in the same fashion as has been noted elsewhere but when control for this factor was made, neither the genetic nor the smoking factor were sufficient to account for risk. Thus other etiologic rigk variables are strongly implicated. However, it has to be realised that, for $C D$ in particular, the coefficient of heritability calculated from concordance rates in twin pairs is greater than that for insulin-dependent diabetes, asthma, or schizophrenia ${ }^{29}$. 
Recently, progress has also been made in studies on chromosomal markers. Linkage studies, determining whether marker alleles are inherited together with the disease of interest, point to a role for the najor histocompatibility complex (MHC) class II genes in UC, but not in $C D^{30}$. These data prowide strong evidence for genetic heterogenity in IBD. Whereas genes of the MHC are implicated as important inherited determinants of UC, in CD important susceptibility genes are likely to exist outside the HLA region. Hugot et al. described recently how, using microsatellites and affected sib-pair analysis, a susceptibility locus for $\mathrm{CD}$ could be mapped to chromosome $16^{31}$. The near future might bring important breakthroughs on the genetic background of IBD.

\section{Environmental risk factors: 'modern life' as a risk factor?}

There is no doubt that in the Western world nutritional habits have changed over the past decades. In the same time the incidence of CD and UC have increased to a great extent $t^{9235}$. Food is a major factor affecting the intestinal environment, and the considerable change in dietary habits may explain why IBD has become common. To assess the impact of dietary compounds on disease outcome, researchers are faced with methodological difficulties because the exposure is most often assessed after the diagnosis of disease and the information, therefore, has to be assembled retrospectively. Differential misclassification, the frequency of errors in reporting the exposure level being dependent on having the disease or not, results in over-estimating or under-estimating of effects ${ }^{22}$. When investigating nutritional risk factors, it is important to recognize and to rule out this kind of error in the design of a study.

In the literature, consumption of refined sugar before or after diagnosis has repeatedly been implicated as a risk factor in $C D$, and in a few studies also as a risk factor in UC ${ }^{6-41}$. The increased consumption of sugar could, however, be a secondary phenomenon ${ }^{42}$. Moreover, smoking is positively associated with sugar consumption and any analytical study should take that into account ${ }^{\mathrm{t1}}$. Cornllakes and fast food have been implicated as risk factors, as has exposure to dietary yeast in $\mathrm{CD}$. Antibodies to bakers" yeast have been reported among patients with $\mathrm{CD}$ but not with UC or other gastrointestinal disorders ${ }^{43}$. Margarine has been proposed as a risk factor, mainly because the introduction of margarine to the Western world paralleled the beginning of the increase of $\mathrm{CD}$ However, the variations in the dietary intake of margarine was not responsible for the geographical and temporal patterns of CD in an extensive ecological study by Sonnenberg ${ }^{44}$.

In an effort to elucidate the impact of some specific 'modern life' nutritional factors as risk factors to develop IBD, a case-control study was performed in the South Limburg area. The results of this study are presented in Chapter $\mathbf{V}$. 
Smoking and oral contraceptives were taken into account in the multivariate analysis, as were age, gender and educational class. The major findings of the study were a greater risk for $\mathrm{CD}$ among those with a high consumption of chocolate, chewing gum, and cola drinks, and a decreased risk with a high intake of citrus fruits. Except for chewing gum, the consumption of these food items was in a parralel way associated with the development of UC. The highest odds ratios were observed in small bowel $C D$, which confirms the findings of Persson et al. concerning the intake of sucrose in this subgroup ${ }^{45}$. The investigated items with high OR all share a high sugar content and possibly reflect the changed consumption pattern preceding the rise in incidence of $C D$ and UC. A decreased use of citrus fruits, as has been reported before, was also found to be a risk factor in developing $\mathrm{IBD}^{46,47}$. In our view it might be possible that a modern life-style, equal to frequent fast-food 'dining' as reported by Persson, rather than the intake of a specific nutrient is related to the increased occurrence of IBD. An ongoing study, restricted to newly-diagnosed IBD patients, pairwise matched to controls, will provide more insight into the relevance of the presented findings.

The higher consumption of sugar, if present at all, seemed not to have caused more frequent dentures or dental prostheses in patients than in controls in the setting of our study. Secondly, the interesting and much debated hypothesis on a positive relation between teeth brushing and $\mathrm{CD}$, as reported by Sullivan, could be investigated ${ }^{48}$. No association was found between the presence of $C D$ concerning the frequency of teeth brushing before the first complaints or after the diagnosis had been made.

A striking finding was a decreased risk of UC in non-smokers who had had a toy pet for a period longer than five years. Based on few exposed subjects, the significance of this result might be explained by a minimal differential misclassification. In trying to explain this finding, it might be hypothesized that smoking is a substitute for having a toy-pet in childhood.

A remarkable finding was the positive association between stopping smoking and Crohn's colitis, supporting the hypothesis that smoking protects the colon from inflammation ${ }^{49}$. The consistently reported issue of smoking as a risk factor in CD and stopping smoking as a risk factor in UC was confirmed in our study. Oral contraceptive use, in some studies regarded as a risk factor in CD and to a lesser extent also in UC, was not significantly associated with the development of IBD. Here has to be remarked that we have analyzed the use of oral contraceptives at any time period, since data on temporal use appeared to be collected inadequately, which might have masked a true association. A potential mechanism for the role of oral contraceptive use and CD could be similar to that proposed for smoking, that is, multifocal gastrointestinal infarction mediated by chronic mesenteric 
vasculitis ${ }^{50.51}$. Literature on the role of oral contraceptive use in the pathogenesis of IBD remains inconsistent at this moment, and both smoking and oral contraceptive use should probably regarded as promoters and not as initiators of $\mathrm{CD}^{11}$.

\section{Does Appendectomy protect against the development of UC?}

It is ten years ago since Gilat et al., in an international study of childhood factors in IBD, noted the rarity of appendectomies in patients with UC compared to their control population ${ }^{52}$. The authors had no explanation for their findings and until 1994 there were no further reports on this peculiar observation. The group of Rutgeerts, apparently unaware of this publication, then confirmed this finding and even suggested that removal of the appendix might be a useful procedure since the relative risk of developing UC with an intact appendix exceeds the protection associated with smoking ${ }^{33}$. This study gave rise to some other investigations on the subject, all confirming the negative association between appendectomy and UC ${ }^{54.59}$. The material of the IBD registry South Limburg appeared appropriate to investigate this interesting association, avoiding some of the possible sources of bias which in our view had been present in the studies published so far (Chapter VI). Incident and prevalent patients with IBD were studied separately. Whereas a small protective role of appendectomy was found in the prevalent group in UC, only a trend was observed in the incident cases with this disease. Subgroup analysis only found a significant association in patients with a pancolitis. No significant association was found between appendectomy and the development of $\mathrm{CD}$. Subgroup analysis, however, revealed a significant positive association in the prevalent group with combined small and large bowel CD. A substantial number of appendectomies in $\mathrm{CD}$ cases were performed relatively close to the date of diagnosis, which could mean that some of these patients were operated on because of bowel complaints related to $\mathrm{CD}$ still undiagnosed at that moment. The observation that mainly combined small and large bowel $\mathrm{CD}$ (including the ileocoecal location) was associated with appendectomy also supports this view.

Another difference between the South Limburg study and the other studies is the choice of controls. Controls were recruited from persons registered at the general practitioners' offices of the Registration Network Family Practices (RNH) ${ }^{18}$. The RNH is a reliable dynamic sampling frame of the Dutch general population ${ }^{18}$. In this way cases and controls are representative of the same study base (the set of persons in which diseased subjects become cases), a precondition when studying risk factors in a case-control design ${ }^{60}$. The preceding studies, all using hospital controls, report a higher frequency of appendectomies in the control group compared to the South Limburg study. One can argue that, in general, hospital controls have earlier access to the hospital than population-controls. Abdominal complaints in such a group might result more frequently in a visit to the hospital. 
In some of the members of this group this might lead to surgery of the -either healthy or inflamed-appendix. Furthermore, in our study, controls were age- and sex-matched and pairwise analyzed, in contrast to the controls used in three of the previous studies ${ }^{52,53,61}$. The exposure status (appendectomy or not) was measured according to information gathered by a mailed questionnaire. Recall bias cannot be excluded, but few arguments for a difference in recalling surgery of the appendix seem to be present. Cases and controls were pairwise matched for age and sex, in contrast to the Belgian study in which controls were older than cases, possibly overstating a presumed protective effect ${ }^{53}$. Furthermore, it could not be excluded that many of the appendectomies in controls were performed after the patients" age of disease onset ${ }^{54}$. The different results between the prevalent and incident groups analyzed in the South Limburg study are possibly due to a selection bias.

The basis of the relationship between appendectomy and UC remains unclear. In a recent comment on the subject the group of Rutgeerts suggests that appendectomy may protect against the development of UC. As a biological explanation they offer that the characteristics of the lymphoid tissue system of the appendix could predispose to colonic inflammation and that the removal of the appendix would suppress this activity ${ }^{56}$. In an interesting comment in the section 'controversies in IBD' of the same issue of 'Inflammatory Bowel Disease' Marion et al. reject this interpretation. They speculate that factors that predispose an individual to develop UC lower the risk of suppurative appendicitis, referring to confounding ${ }^{57}$. In summary, there is probably a negative association between appendectomy and UC, but the association is mainly evident for more severe cases with extended disease. The mechanism remains unknown and we need to know more about the role of the appendix in the gut immune system before accepting the hypothesis of a protective effect of appendectomy ${ }^{62}$. There is no proof that appendectomy is a risk factor in CD.

\section{Smoking and disease characteristics}

At present, smoking is the only widely accepted environmental risk factor in $C D$, as is non-smoking or, more precisely, stopping smoking in UC $\mathrm{UC}^{41,49,63 \mathrm{fm} / 5}$. Smoking may also influence disease activity in $\mathrm{IBD}^{76-82}$. Seven studies have, mostly in a sidetrack, addressed the topic of disease location in prevalent groups of smokers and non-smokers with $\mathrm{CD}^{22,76,78,83-86}$. In three studies a positive association between smoking and small bowel involvement was observed, whereas the other four did not find any association. A higher rate of perlanal disease in smoking patients with $\mathrm{CD}$ has inconsistently been reported ${ }^{76,83,85}$. Furthermore, in $\mathrm{CD}$ smoking is associated with an impaired prognosis $\mathrm{s}^{76,81,83}$.

In active UC treatment with nicotine improves disease activity, suggesting a 
beneficial effect of smoking ${ }^{79,80.87-89}$. However, no data have been published on differences in clinical manifestation between smokers and non-smokers at time of diagnosis of IBD. In Chapter VII the results from the analyses of data of the European Collaborative Study on $\mathbb{I B D}$ are presented regarding clinical features at diagnosis in smokers and non-smokers in a large inception cohort of newlydiagnosed patients with IBD across Europe. We were interested in determining whether smoking behavior also influences clinical features of IBD at the time of diagnosis and during the first year of follow-up; evidence of a causal relationship between smoking and IBD would be further strengthened if the habit would influence the extension of inflammation, clinical symptoms and signs at presentation, and the course of disease ${ }^{49}$.

The course of disease, measured by the use of steroids and other immunosuppressive medication, was less favourable in smoking $C D$ patients. There was no evidence that smokers with UC did better than non-smokers. Smoking habits also determined some clinical aspects of IBD at diagnosis, such as weight loss and diarrhoea. In CD smoking affected disease location: non-smoking was associated with colonic disease. The finding of more colonic disease in nonsmoking $C D$ patients, and the positive association between non-smoking and UC might be due to a common mechanism of smoking protecting the colon from inflammation.

The statistically different results, as were observed in the present study, still have to prove their clinical relevance. The results of the ongoing follow-up study of the European inception cohort of incident IBD patients will hopefully provide more insight in the topic of long-term disease outcome in both subgroups of IBD. Although it is not (yet) proven, it is likely that cessation of smoking will lead to lower incidence rates for $\mathrm{CD}$, lower rates of recurrence, and less severe complications ${ }^{90}$.

\section{Health related quality of life in IBD}

One of the more interesting aspects of the history of $\mathrm{CD}$ and $\mathrm{UC}$ is the change in thought from psychological issues as being causative to their being a consequence of the recurrent intestinal (and extraintestinal) symptoms. Unfortunately, outdated stereotypical characterisations of the personalities of patients with IBD are still heard among the lay public and are mentioned by therapists, who are entrusted with counselling these patients ${ }^{91}$. As a result of this change of thought, psychological issues have recently been included in the assessment of disease activity.

The number of disease activity indices in IBD is considerable and during the past 
decade also several Health-Related Quality of Life (HRQoL) indices have been developed for application in IBD. Physiologic measures of disease often correlate poorly with functional capacity and well-being and are therefore of limited interest to patients ${ }^{92}$. Health-related quality of life (HRQoL) assessment might be important for measuring the impact of chronic disease on a patient's state of general wellbeing ${ }^{92.93}$. So far there are oniy limited data from studies using validated instruments. An example of a disease-specific HRQoL instrument is the 32-item Inflammatory Bowel Disease Questionnaire (IBDQ), which was developed and validated by Guyat et al. at McMaster University in Canada ${ }^{94}$. HRQoL was assessed by Irvine et al. using the IBDQ during a 18-month trial of low-dose cyclosporin in patients with stable $\mathrm{CD}^{95}$. The IBDQ total score and fourdimensional subscores (bowel, systemic, social, and emotional) correlated well with the Crohn's Disease Activity Index (CDAI), but gave more consistent scores than the CDAI in stable patients. In 171 patients who deteriorated during the study, the IBDQ significantly decreased, whilst it was remaining stable in 134 patients who did well. A subgroup of patients requiring surgery experienced more impairment of social function than patients who had flare-ups but did not require surgery, suggesting that perhaps non-disease related features such as personality might lead to surgery in some patients ${ }^{96}$.

The choice of a HRQoL instrument usually depends on the interests and needs of the clinician and investigator. An instrument that can differentiate between persons or groups in terms of a better and worse HRQOL is said to be discriminative. For a discriminative instrument reliability (that is the condition when the variability between patients is greater than the variability within a single patient) is most important. For an evaluative measure responsiveness (that is the ability to detect change) is most important ${ }^{97}$. The disease specific HRQoL instruments that are available for IBD are summarised in Chapter Ic. In the patient questionnaire of the South Limburg IBD registry we have chosen to include the IBDQ, since this instrument was at that moment, in our view, the best validated instrument. To use a questionnaire like the $\mathbb{B B D Q}$ in respondents with a native language other than English requires translation, back-translation, and re-establishing the yalidity and reliability within the new national context ${ }^{98}$. The results of this procedure concerning the IBDQ translated into Dutch are described in Chapter VIII. The instrument was shown to be valid and reliable. As far as can be concluded from our data, sensitivity to change was good in all dimensional scores in $\mathrm{CD}$, and for bowel symptoms in UC. In contrast to the original Canadian IBDQ, a selfadministered form was used in our study. As a consequence of this approach, some questionnaires were returned with missing items. To be able to include the majority of patients, mean scores were calculated for each dimension in the analysis, providing that at most one question per dimension was not completed. The analysis 
showed that mostly the items concerning daily work and/or sexual habits were missing. In everyday practice, the problem of missing items is well known, and the Dutch IBDQ proved to be valid under the prerequisite mentioned.

Recently de Boer et al. reported their results on validation and cross-cultural adaptation of an IBDQ translated into Dutch ${ }^{99}$. Their main conclusion was that the IBDQ proved to be a reliable and valid measure of quality of life in Inflammatory bowel disease. To be able to compare results with other international studies we used, in contrast to de Boer et al., the seven point Likert scale, as was applied in the original IBDQ. Whereas the former study, using the IBDQ once in all patients, focused on reliability, we approached the patients twice to be able to investigate reproducibility and sensitivity to change. Both studies prove that the IBDQ can be validly used in a different culture, with a different language.

Recently the main outcomes of HRQOL research in IBD were reviewed by Drossman $^{97}$. He concluded that:

- for most ambulatory patients, HRQoL is generally good

- functional impairment is greater in the psychological and social dimensions than in the physical dimensions

- Patients with CD have greater impairment in HRQoL than those with UC

- There is a strong correlation between disease severity and HRQoL impairment

- Disease-related worries and concerns are associated with psychological distress and poor function, so reduction in these concerns through education and counselling may improve HRQoL

- HRQOL measures correlate better with general well-being than with the physician's rating of disease activity

- For UC, colectomy, regardless of surgical repair, is associated with improved HRQoL, reduced worries about disease, and there was no worsening of body image concerns ${ }^{100-102}$.

In an interesting retrospective study using the Sickness Impact Scale (SIP) and the Dutch IBDQ in operated patients with CD, A. Kok and P. Soeters have shown that ileocoecal resection improved HRQoL (unpublished manuscript). They found a high correlation between both instruments, and it appeared that the IBDQ was easier to use and less time consuming in this patient group than the SIP.

The possible relation between smoking and the course of disease in $\mathrm{CD}$ and $\mathrm{UC}$ has already been discussed. In Chapter $\mathbf{I X}$ the results of our study on the relationship between cigarette smoking and different aspects of disease-specific quality of life in $U C$ and $C D$ are described. The specific hypothesis under 
investigation was that, due to bowel and systemic complaints, smokers experience a lower quality of life compared to non-smokers in $C D$, whilst the opposite is found in UC. In general, a negative relationship between smoking and quality of life was found. The only exception was formed by bowel symptoms in moderately smoking male UC patients. The important finding that smoking was most strongly associated with more bowel symptoms in females with $C D$ under 45 years of age, is possibly associated with concurrent contraceptive use. Further studies are necessary to analyse the interrelationships between smoking and oral contraceptive use, disease activity, and quality of life in IBD. The reported negative relationships between smoking and quality of life are once more strong arguments to encourage patients with IBD to give up smoking. However, in the personal experience of the author, although it appears easy to convince patients of the benefits of giving up the habit, it remains difficult to really stop. It might be worthwhile to set up a detoxification program for patients with $\mathrm{CD}$, who probably have even more advantages from non* smoking than the rest of the population. 


\section{References}

1. Calkins BM, Mendeloff AI. The epidemiology of idiopathic inflammatory bowel disease. In: Kirsner $\mathbf{I B}_{\text {, Shorter }} \mathbf{R G}_{*}$ editors. Inflammatory Bowel Disease. 4th ed. Baltimore: Williams \& Wilkins 1995; 31-70.

2. Houghton EAW, Naish IM. Familial ulcerative colitis and regional ileitis. Gastroenterologia 1958; 89:65-74.

3. Melrose $\mathbf{A G}$. The geographic incidence of chronic ulcerative colitis in Britain. Gastroenterol 1955:89:1055.

4. Uvstedt H.J. Ulcerative colitis: A study of all cases discharged from Norvwegian hospital in the ten year period 1945-55. In: Pemberton $J$, Willard H, editors. Recent studies in Epidemiology. Oxford Press, 1958.

5. Acheson ED. The distribution of ulcerative colitis and regional enteritis in United States veterans with particular reference to the Jewish religion. Gut 1960;1:291

6. Evans $J G$, Acheson ED. An epidemiological study of ulcerative colitis and regional enteritis in the Oxford area. Gut 1965; 6:311.

7. Iversen 1, Bonnevie $O$, Anthonison P, Riis $P$. An epidemiological model of ulcerative colitis. Scand J Gastroenterol 1968; 3:432.

8. Myren J, Bouchier IA, Watkinson G, Softley A, Clamp SE, de Dombal FT. The OMGE multinational inflammatory bowel disease survey 1976-1986. A further report on 3175 cases. Scand J Gastroenterol Suppl 1988; 144:11-19.

9. Calkins BM, Lilienfeld AM, Garland CF, Mendeloff AI. Trends in incidence rates of ulcerative colitis and Crohn's disease. Dig Dis Sci 1984; 29:913-920.

10. Lennard-Jones JE. Classification of inflammatory bowel disease. Sicand J Gastroenterol 1989; 24(suppl 170):2-6.

11. Ekbom A. Epidemiology of Crohn's disease. In: Prantera C, Korelitz B, editors. Crohn's disease. New York: Marcel Dekker 1996; 57-79.

12. Calkins BM, Mendeloff AI. Epidemiology of inflammatory bowel disease. Epidemiol Rev $1986 ; 8: 60-91$.

13. Shivananda $S$, Lennard-yones IE, Logan RF, Fear $N$, Price $P$, Carpenter $L$, et al. Incidence of inflammatory bowel disease across Europe: is there a difference between North and South? Results of the European collaborative study on inflammatory bowel disease (EC-IBD). Gut 1996; 39:(5) 690-697.

14. Manousos $\mathrm{ON}$, Koutroubakis $I_{3}$ Potamianos $S$, Roussomoustakaki $M$, Gourtsonyiannis N, Vlachonikolis IG. A prospective epidemiologic study of Crohn's disease in Heraklion, Crete. Incidence over a 5-year period. Scand J Gastroenterol 1996; 1996:(31)599-603.

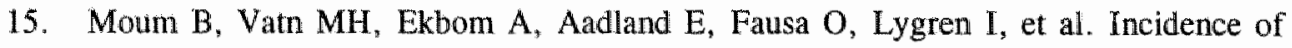
Crohn's disease in four counties in southeastern Norway, 199093. Scand J Gastroenterol 1996; 31:355-361.

16. Moum B, Vatn MH, Ekbom A, Aadland E, Fausa O, Lygren I, et al. Incidence of ulcerative colitis and indeterminate colitis in four counties of southeastern Norway, 1990-93. Scand J Gastroenterol 1996; 31:362-366. 
17. Ranzi $T$, Bodini $P$, Zambelli $A$, Politi $P$, Lupinacci $G$, Campanini MC, et al. Epidemiological apects of inflammatory bowel disease in a north Italian population: a 4-year prospective study. Eur J Gastroenterol Hepatol 1996; 8:(7)657-662.

18. Metsemakers JFM, Höppener P, Knotmerus JA, Kocken RJJ, Limonard CBG. Computerized health information in The Netherlands: a registration of family practices. Br J Gen Prac 1992; 42:102-106.

19. Shivananda S, Pena AS, Nap M, Weterman IT, Mayberry JF, Ruitenberg EJ, et all. Epidemiology of Crohn's disease in Regio Leiden, The Netheriands. A population study from 1979 to 1983 . Gastroenteroll 1987; 93:966-974.

20. Shivananda S, Hordijk ML, Pena AS, Mayberry JF. Inflammatory bowel disease: one condition or two? Digestion 1987; 38:187-192.

21. Sackett DL, Haynes RB, Guyatt GH, Tugwell P. The clinical examination. In: Sackett DL, Haynes RB, Guyatt GH, Tugwell P, editors. Clinical epidemiology; a basic science for clinical medicine. 2nd ed. Toronto,Boston: Little, Brown and Company 1991; 19-51.

22. Bouter LM, Dongen van MCJM. Vertekende resultaten. In: Bouter LM, Dongen van MCJM, editors. Epidemiologisch onderzoek; opzet en interpretatie. 2nd ed. Houten, Antwerpen: Bohn, Stafleu, van Loghum 1991; 158-214.

23. Farmer RG. Study of family history among patients with inflammatory bowel disease. Scand J Gastroenterol Suppl 1989; 170:64-65.

24. Lashner BA, Evans AA, Kirsner JB, Hanauer SB. Prevalence and incidence of inflammatory bowel disease in familly members. Gastroenterol 1986; 91:1396 1400.

25. Monsen U. Inflammatory bowel disease. An epidemiological and genetic study. Acta Chir Scand Suppl 1990; 559:1-42.

26. Orholm $M$, Munkholm $P$, Langholz $E$, Nielsen $O H$, Sorensen IA, Binder V. Familial occurrence of inflammatory bowel disease. N Engl J Med 1991; 324:84 88.

27. Weterman IT, Pena AS. Familial incidence of Crohn's disease in The Netherlands and a review of the literature. Gastroenterol 1984; 86:449-452.

28. Yang HY, McElree C, Roth MP, Shanahan F, Targan SR, Rotter JI. Familiall empirical risks for inflammatory bowel disease: differences between Jews and nonJews. Gut $1993 ; 34: 517-524$.

29. Tysk C, Lindberg E, Järnerot G, Floderus-Myhred B. Ulcerative colitis and Crohn"s disease in an unselected population of monozygotic and dizygotic twins. A study of heritability and the influence of smoking. Gut 1988; 29:990-996.

30. Satsangi J, Welsh KI, Brunce $\mathrm{M}$, Julier C, Farrant IM, Bell J, et al. Contribution of genes of the major histocompatibility complex to susceptibility and disease phenotype in inflammatory bowel disease. Lancet 1996; 347:1212-1217.

31. Hugot JP, Laurent Puig $\mathbb{P}$, Gower Rousseau C, Olson JM, Lee IC, Beaugerie L, et al. Mapping of a susceptibility locus for Crahth's disease on chromosome 16. Nature 1996; 379:821-823.

32. Srivastava ED, Mayberry JF, Morris TJ, Smith PM, Williams GT, Roberts GM, et al. Incidence of ulcerative colitis in Cardiff over 20 years: 1968-87. Gut 1992; $33: 256-258$. 
33. Langholz $E$, Munkholm $P$, Nielsen $O H$, Kreiner $S$, Binder V. Incidlence and prevalence of ulcerative colitis in Copenhagen county from 1962 to 1987 . Scand J Gastroenterol $1991 ; 26: 1247-1256$.

34. Gilat T. Incidence of inflammatory bowel disease: going up or down? Gastroenterol 1983; $85: 196-197$.

35. Harries $A D$, Baird $A$, Rhodes $\mathbb{J}$, Mayberry $J F$. Has the rising incidence of Crohn's disease reached a plateau? BMJ $1982 ; 284: 235$

36. Mayberry JF, Rhodes J. Epidemiological aspects of Crohn's disease: a review of the literature. Gut $1984,25: 886-899$.

37. Martini GA, Brandes JW. Increased consumption of refined sugar in patients with Crohn's disease. Klin Wochenschr 1976; 54:367-37\%.

38. James A. Breakfast and Crohn's disease. Br Med J 1977; 1:943-945.

39. Kasper H, Sommer H. Dietary fibre and nutrient intake in Crohn's disease. Am J Clin Nutr 1979; 1898-1901.

40. Mayberry JF, Rhodes $J$. Increased sugar consumption in Crohn's disease. Digestion $1980 ; 323-326$.

41. Katschinski B, Logan RF, Edmond M, Langman MJ. Smoking and sugar intake are separate but interactive risk factors in Crohn's disease. Gut 1988; 29:1202-1206.

42. Järnerot $G$, Jarnmark. $I$, Nilsson $K$. Sugar consumption in Crohn's disease, ulcerative colitis or irritable bowel disease. Scand J Gastroenterol 1983; 18:9991002.

43. Main $J$, McKenzie H, Yeaman GR. Antibodies to Saccharomyces cerevisiae (bakers' yeast) in Crohn's disease. Br Med J 1988; 297:1105-1106.

44. Sonnenberg A. Geographic and temporal variations of sugar and margarine consumption in relation to Crohn's disease. Digestion 1988; 41:161-171.

45. Persson PG, Ahlbom A, Hellers G. Diet and inflammatory bowel disease: a casecontrol study. Epidemiology 1992; 3:47-52.

46. Thornton JR, Emmet PM, Heaton KW. Diet and Crohn's disease: characteristics of the pre-illness diet. Br Med J 1979; 762-764.

47. Thornton JR, Emmett PM, Heaton KW. Diet and ulcerative colitis. Br Med J 1980; 293-294.

48. Sullivan SN. Hypothesis revisited: toothpaste and the cause of Crohn's disease. Lancet 1990; 336:1096-1097.

49. Benoni $C$. Lifestyle issues in inflammatory bowel disease-smoking. Can J Gastroenterol 1994; 8:(7)422-427.

50. Wakefield AJ, Sawyerr AM, Fudson M, Dhillon AP, Pounder RE. Smoking, the oral contraceptive pill, and Crohn's disease. Dig Dis Sci 1991; 36:1147-1150.

51. Wakefield AJ, Sawyerr AM, Dhillon AP, Pittilo RM, Rowles PM, Lewis AAM, et al. Pathogenesis of Crohn's disease: multifocal gastrointestinal infarction. Lancet 1989; (2)1057-1062.

52. Gilat $T$, Hacohen $D$, Lilos $P$, Langman MJ. Childhood factors in ulcerative colitis and Crohn's disease. An international co-operative study. Scand J Gastroenterol $1987 ; 22 ; 1009-1024$. 
53. Rutgeerts $P, D^{\prime}$ Haens G, Hiele M, Geboes K, Vantrappen G. Appendectomy protects against ulcerative colitis. Gastroenterol 1994; 106:1251-1253.

54. Logan RF. Appendectomy and ulcerative colitis: what connection? Gastroenterol 1994; 106:1382-1384.

55. Smithson JE, Radford Smith G, Jewell GP. Appendectomy and tonsillectomy in patients with inflammatory bowel disease. J Clin Gastroenterol 1995; 21:283-286.

56. Peeters $P$, Rutgeerts $P$. The negative association between appendectony and ulcerative colitis reflects causal relationship. Inflam Bow Dis 1996; 2:214-216.

57. Marion JF, Bodian CA, Janowitz HD. The appendix and IBD: Appendectomy does not protect against ulcerative colitis. Inflam Bow Dis 1996; 2:217-221.

58. Russel MGVM, Dorant E, Brummer RM, van de Kruijs MA, Muris JW, Bergers J, et al. Appendectomy and the risk of developing ulcerative colitis or Crohn's disease: results of a large case-control study in The Netherlands. Gastroenterol 1996; submitted for publication.

59. Logan RF, Duggan AE, Usmansi $X$, Neal KR. Appendectomy, tonsillectomy and the risk of inflammatory bowel disease. Gut 1995; A25:T100.

60. Miettinen OS. The "case-control" study: valid selection of subjects. J Chron Dis $1985 ; 38: 543-548$.

61. Smithson JE, Rayford-Smith G, Jewell GP. Appendectomy and tonsillectomy in patients with inflammatory bowel disease. J Clin Gastroenterol 1995; 21:(4)283-286.

62. Banks PA, Present DH. The appendix and the colon: just how intimate is their relationship? Inflam Bow Dis 1996; 2:222.

63. Calkins BM. A meta-analysis of the role of smoking in inflammatory bowel disease. Dig Dis Sci 1989; 34:1841-1854.

64. Lindberg E, Tysk C, Andersson K, Järnerot G. Smoking and inflammatory bowel disease. A case control study. Gut 1988; 29:352-357.

65. Boyko EJ, Koepsell TD, Perera DR, Inui TS. Risk of ulcerative colitis among former and current cigarette smokers. N Engl J Med 1987; 316:707-710.

66. Silverstein MD, Lashner BA, Hanauer SB. Cigarette smoking and ulcerative colitis: a case-control study. Mayo Clin Proc 1994; 69:425-429.

67. Lorusso $D$, Leo $S$, Misciagna $G$, Guerra V. Cigarette smoking and ulcerative colitis. A case control study. Hepatogastroenterology 1989; 36:202-204.

68. Silverstein MD, Lashner BA, Hanauer SB, Evans AA, Kirsner JB. Cigarette smoking in Crohn's disease. Am J Gastroenterol 1989; 84:31-33.

69. Harries AD, Baird A, Rhodes J. Non-smoking: A feature of ulcerative colitis. Br Med J 1982; 284:706.

70. Roberts CJ, Diggle R. Non smoking: a feature of ulcerative colitis. $\mathrm{Br}$ Med J 1982; 285:440

71. Franchesi S, Panza E, La Vecchia C, Parazzini F, Decarli A, Bianchi Porro G. Nonspecific inflammatory bowel disease and smoking. Am J Epidemiol 1987, 125:445-452.

72. Benoni C, Nilsson A. Smoking habits in patients with inflammatory bowel disease. A case- control study. Scand J Gastroenterol 1987; 22:1130-1136. 
73. Jẩmerot G, Lindberg E, Tysk C. Smoking and inflammatory bowell disease. Gastroenterol Hepatol 1995; 18:507-509.

74. Tysk $C$, Jatrnerot $G$. Has smoking changed the epidemiology of ulcerative colitis? Scand J Gastroenterol 1992; $27: 508-512$.

75. Forbes A. Smoking and inflammatory bowel disease. Eur I Gastroenterol Hepatol $1996 ; 8: 761-763$.

76. Breuer-Katschinsky $B$, Hollander $N$, Goebell $\mathrm{H}$. Effect of cigarette smoking on the course of Crohn's disease. Eur J Gastroenterol Hepatol 1996; 8:225-228.

77. Cosnes J, Carbonnel F, Beaugerie L, Quintrec YL, Gendre JP. Effects of cigarette smoking on the long-term course of Crohn's disease. Gastroenterol 1996; 110:424431.

78. Musso A, Sostegni R, Astegiano M, Rocea G, Fiorentini MT, Pera A, et al. Smoking and clinical course of Crohn's disease: an adverse effect? Gastroenterol 1995; 108:A882.

79. Rhodes $J_{*}$ Thomas $G$. Nicotine treatment in ulcerative colitis. Current status. Drugs 1995; 49:157-160.

80. Thomas GA, Rhodes J, Mani V, Williams GT, Russell MA, Feyerabend C. Transdermal nicotine as maintenance therapy for ulcerative colitis. $\mathrm{N}$ Engl $J$ Med $1995 ; 332: 988-92$.

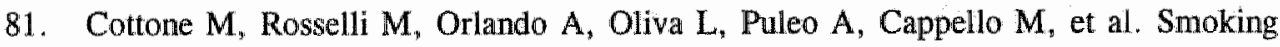
habits and recurrence in Crohn's disease. Gastroenterol 1994; 106:643-648.

82. Griffel L, Das KM. Nicotine and ulcerative colitis. Natl Med J India 1994; $7: 222-223$

83. Cosnes J, Carbonnel F, Beaugerie L, Le Quintrec Y, Gendre JP. Effects of cigarette smoking on the long-term course of Crohn's disease. Gastroenterol 1996; 110:424-431.

84. Holdstock $G$, Savage D, Harman M, Wright R. Should patients with inflammatory bowel disease smoke? Br Med J 1984; 288:362.

85. Lindberg E, Järnerot $\mathrm{G}$, Huitfeldt B. Smoking in Crohn's disease: effect on localisation and clinical course. Gut 1992; 33:779-782.

86. Wright JP. Factors influencing first relapse in patients with Crohn's disease. J Clin Gastroenterol 1992; 15:12-16.

87. Sandborn WJ, Tremaine WJ, Offord KP, Lawson GM, Petersson BG, Steiner BL. A randomized, double-blind, placebo-controlled trial of transdermal nicotine for mildly to moderately active ulcerative colitis. Gastroenterol 1996; 110:A1008.

88. Pullan RD, Rhodes I, Ganesh $S$, Mani $V$, Morris JS, Williams GT, et al. Transdermal nicotine for active ulcerative colitis. N Engl J Med 1994; 330:811-815.

89. Lashner BA, Hanauer SB, Silverstein MD. Testing nicotine gum for ulcerative colitis patients. Experience with single-patient trials. Dig Dis Sci 1990; 35:827-832.

90. Lasimer BA. Considerations of smoking in patients with Crohn's disease. In: Prantera C, Korelitz B, editors. Crohn's disaese. New York, Basel, Hong Kong: Marcel Dekker, 1996:81-92. 
91. Kirschner SK. Commentary on Quality of Life in Crohn's disease. In: Prantera C, Korelitz B, editors. Crohn's disease. New York, Basel, Hong Kong: Marcel Dekker, 1996:452-453.

92. Guyatt GH, Feeny DH, Patrick DL. Measuring health-related quality of life. Ann Intern Med 1993; 118:622-629.

93. Drossman DA, Leserman J, Mitchell CM, Li ZM, Zagami EA, Patrick DL. Health status and health care use in persons with inflammatory bowel disease. A national sample. Dig Dis Sci 1991; 36:1746-1755.

94. Guyatt G, Mitchell A, Irvine EJ, Singer J, Williams N, Goodacre R, et al. A new measure of health status for clinical trials in inflammatory bowel disease. Gastroenterol 1989; 96:804-810.

95. Irvine EJ, Feagan B, Rochon J, Archambault A, Fedorak RN, Groll A, et al. Quality of life: a valid and reliable measure of therapeutic efficacy in the treatment of inflammatory bowel disease. Canadian Crohn's Relapse Prevention Trial Study Group. Gastroenterol 1994; 106:287-296.

96. Irvine EJ. Activity scores and qualtiy of life indices in inflammatory bowel disease. Curr Opin Gastroenterol 1995; 11:331-336.

97. Drossman DA. Quality of Life issues in Crohn's disease. In: Prantera C, Korelitz B, editors. Crohn's disease. New York: Marcel Dekker, 1996:445-452.

98. Streiner DL, Norman GR. Measuring change. In: Streiner DL, Norman GR, editors. Heath measurement scales. A practical quide to their development. 2nd ed. New York: Oxford University Press, 1995:163-180.

99. de Boer AGEM, Wijker W, Bartelsman JFW, de Haes HCJM. Inflammatory Bowel Disease Questionnaire: cross-cultural adaptation and further validation. Eur J Gastroenterol Hepatol 1995; 7:1043-1050.

100. McLeod RS, Churchill DN, Lock AM, Vanderburgh S, Cohen Z. Quality of life of patients with ulcerative colitis preoperatively and postoperatively. Gastroenterol $1991 ; 101: 1307-1313$.

101. Tjandra JJ, Fazio VW, Church JM, Oakley JR, Milsom JW, Lavery IC. Similar functional results after restorative proctocolectony in patients with familial adenomatous polyposis and mucosal ulcerative colitis. Am J Surg 1993; 165:322-325.

102. Kohler LW, Pemberton JH, Zinsmeister AR, Kelly KA. Quality of life after proctocolectomy. A comparison of Brooke ileostomy, Kock pouch, and ileal pouchanal anastomosis. Gastroenterol 1991; 101:679-684. 


\section{Chapter XI}

\section{Summary and}

concluding remarks 


\section{Summary and concluding remarks}

The present thesis reports the development of a population-based Inflammatory Bowel Disease Registry in South Limburg, The Netherlands. The methods and basic results of this registry until June 1996 are presented in Chapter II.

The aims of the studies addressed in this thesis were: 1) to investigate the incidence of Inflammatory Bowel Disease (IBD) in a prospective way and 2) to study genetic and environmental risk factors in IBD; 3) to elucidate the effect of smoking on disease characteristics at presentation and disease development during the first year of follow-up and 4) to validate the Dutch translation of a Health Related Quality of Life Questionnaire (the Inflammatory Bowel Disease Questionnaire) which was subsequently used as a tool to investigate the influence of the risk factor smoking on the course of the disease.

In Chapter Ia a critical overview of the present epidemiological knowledge concerning IBD, focussing on incidence and risk factors, is presented. In summary, an increasing high incidence for both Crohn's disease (CD) and ulcerative colitis (UC) in industrialised countries is reported, reaching a plateau phase during the 1960 s and 1970s in UC and recently in CD. In developing countries the occurrence of IBD seems to be lower but growing after the implementation of a Western life style.

In developing IBD, genetical influences are of importance. However, epidemiological studies strongly point to possible interactions between genetically determined features and environmental factors. Of these environmental factors smoking is the most consistent, being of negative influence in $\mathrm{CD}$ and protective in UC. Diet and oral contraceptives may influence disease expression, and perinatal events -like viral infectionis- may alter adult susceptibility. Preconditions for epidemiological studies in IBD, in the view of the authors, are outlined. Most important in defining the role of risk factors is the use of a population-based registry and of population-controls. Furthermore, risk factors should be studied in connection with each other, and finally, investigating subgroups of IBD might prove to be worthwhile.

In Chapter Ib a review is presented on Health Related Quality of Life (HRQoL) in IBD. HRQoL is a global concept that incorporates the patients' perceptions, attributions, and daily level of functioning in response to an illness. Three main types of instruments including global assessments, generic instruments, and diseasespecific instruments are discussed. The evaluation of HRQoL is important for measuring the impact of chronic diseases and can broaden our understanding of the impact of these diseases in a manner that cannot be accomplished through traditional methods. 
The thesis outline and aims of the study are summarised in Chapter $1 \mathrm{c}$.

In Chapter III the incidence of IBD in South Limburg, The Netherlands, is reported using standardised reports of newly-diagnosed patients. During a four year study a mean standardized incidence rates (per 100.000 inhabitants and year) of 6.9 (95\% CI: 5.9-7.9) for CD, 10.0 (95\% CI: 8.7-11.2) for UC, and $1.1(95 \% \mathrm{CI}$ : 0.7-1.5) for indeterminate colitis were calculated. Estimated case ascertainment, using the database of the Registration Network Family Practices as a reference, was $100 \%$ for $C D, 80 \%$ for extended colitis, but only $25 \%$ in ulcerative proctitis. The results suggest a high incidence rate of IBD in The South Limburg area, which is higher than previously reported in The Netherlands and higher than published by centers in most surrounding countries.

To investigate the genetics of $\mathrm{CD}$ and $\mathrm{UC}$ a study on family aggregation of IBD in a subgroup of cases registered at the IBD South Limburg Registry was performed. The results of this study are presented in Chapter IV. The observed risk of IBD for first-degree relatives of IBD patients was higher than in controls. However, the risk in our population was lower than has been reported by most other centers investigating this subject, possibly as a result of the population-based character of our study. Furthermore, all diagnoses in first-degree relatives had to be verified according to strict criteria. It was remarkable that, compared to the patients" opinion, a positive family history could only be confirmed in $57 \%$ of the relatives. Prevalence of IBD was highest for siblings $(1.5 \%)$ and children $(1.3 \%)$ of index patients, whereas only $0.2 \%$ of the parents were affected with IBD. Strong disease concordance was found in both groups, and a positive history was somewhat greater among relatives of probands with $C D$ than among relatives of UC.

The results of a case-control study, investigating "modern life" in the epidemiology of IBD with special emphasis on nutritional factors, are presented in Chapter V. A total of 688 recently diagnosed patients, 290 with $\mathrm{CD}$ and 398 with UC, and 616 population-controls were selected for this study. Smoking, age, gender, and educational level were taken into account by using logistic regressionanalysis. As has been consistently reported before, smoking was positively associated with $\mathrm{CD}$, whereas non-smoking and stopping smoking both were associated with UC. No differences were found as far as the use of oral contraceptives was concerned.

A positive association with the consumption of cola drinks, chewing gum, and chocolate, and a negative influence with citrus fruit consumption and the development of $\mathrm{CD}$ was found. Consumption of cola drinks and chocolate were both positively associated with the development of $U C$, whereas, in $U C$, a negative association with citrus fruits and having a toy pet for a period longer than five years was observed. No associations with the frequency of tooth brushing and 
developing IBD was found. It is concluded that all nutritional items mentioned may either be true risk factors, or they might merely be the expression of a modern lifestyle also involving other causitive risk factors for the development of IBD which at present are still unknown.

To elucidate the role of appendectomy as a risk factor in IBD, a case-control study, using a pairwise matched design, was performed (Chapter VI). The risk of developing UC, in 232 prevalent UC patients, was significantly lower after previous appendectomy (OR: 0.36 ( $95 \% \mathrm{CI}: 0.15-0.80$ ); subgroup analysis found a protective effect only in pancolitis. In 208 patients with $\mathrm{CD}$ the odds ratios were not significantly different; however, a positive association was found in ileocoecal disease. A significantly larger proportion of appendectomies in CD was performed close to the time of diagnosis, suggesting that appendectomy in some cases was due to still undiagnosed CD. No significant associations were observed in incident IBD patients. The fact that sex- and age-matched population-controls were used in our study may contribute to a less pronounced association between appendectomy and UC than recently reported by others.

Smoking is associated with $\mathrm{CD}$ and non-smoking with $\mathrm{UC}$; however, so far no data have been published on IBD characteristics at presentation in relation to smoking status. In Chapter VII a prospective study is presented concerning clinical features at diagnosis and during the first year of follow-up in smokers and non-smokers amongst newly-diagnosed patients with IBD across Europe. The main findings were that weight loss occurred significantly more often in smoking patients with $\mathrm{CD}$ than in smokers with $U C$, and diarrhoea was more frequent in smoking $C D$ patients compared to non-smoking. The association between weight loss and smoking in both diseases is probably due to a general effect of smoking, acting via increase of brain serotonin release. Smoking $\mathrm{CD}$ patients had less frequent colonic involvement. Smoking seems to protect the colon, in both $C D$ and $U C$, from inflammation. The course of disease, as measured by the use of steroids and other immunosuppressive medication, was less favourable in smoking $C D$ patients, a reason to strongly discourage smoking in patients with $\mathrm{CD}$.

In Chapter VIII a study is described which had the aim of assessing the validity of the Dutch translation of the Inflammatory Bowel Disease Questionnaire (IBDQ), a disease-specific quality of life questionnaire. This self-administered questionnaire contains 32 questions grouped into four health dimensions: bowell symptoms, systemic symptoms, social function, and emotional function. The Dutch version of the IBDQ appeared to be easy to use and was shown to be valid, discriminative, and reliable. Sensitivity to change was good in all dimensional scores in $C D$, and for bowel symptoms in UC. The IBDQ can be used in the Dutch-speaking IBD 
population, and the results of this study suggest that it will be feasible to use translations of the IBDQ in non-English-speaking countries.

In Chapter IX a study is reported with the aim of elucidating the relationship between smoking and aspects of disease-specific quality of life in IBD. In 1105 patients disease-specific quality of life was investigated using the IBDQ. In $C D$, female smokers reported a lower quality of life than female non-smokers in all four dimensions of the IBDQ. Using an explanatory model of relationships between the four dimensions for the analysis, it became evident that smoking is associated with more bowel symptoms in young $C D$ females, with more emotional dysfunction in all $C D$ females, and with more systemic symptoms in all three diagnostic groups with marked bowel symptoms. Moderately smoking male UC patients reported fewer bowel complaints compared to non-smoking male UC patients. It is concluded that there is a relationship between smoking and disease-specific quality of life in both UC and CD. The hypothesis is presented that several of the differences observed in the quality of life studied dimensions with respect to age, sex and disease group are related to concomitant oral contraceptive use.

The general conslusion to be drawn from these studies is that a near-complete population-based registry of IBD patients in combination with population-based control groups is suitable for providing answers in widely diverse clinicopathological questions, including pathogenesis, clinical presentation, symptomatology, co-morbidity, and quality of life. Future studies employing this registry may deal with the impact of therapy and disease course, and the influence of health care mechanism in the long-term development of IBD. 


\section{Chapter XII}

\section{Samenvatting}




\section{Samenvatting}

Het proefschrift beschrijft de opzet van een 'Inflammatory Bowel Disease' (chronische inflammatoire darmziekten) registratie in Zuid Limburg. Dit is een registratie waarin gegevens van patiënten met de ziekte van Crohn (CD), aspecifieke colitis (IC) en colitis ulcerosa (UC), woonachtig in Zuid Limburg, worden opgenomen.

De volgende onderwerpen worden in dit proefschrift behandeld:

1 het op een prospectieve wijze vaststellen van de incidentie van chronische inflammatoire darmziekten (IBD)

2 het bestuderen van genetische en exogene risicofactoren bij IBD

3 het verschaffen van meer duidelijkheid over de rol van roken ten aanzien van de kenmerkende eigenschappen van de ziekte op het moment van de diagnose en gedurende het eerste jaar van de follow-up

4 het valideren van de Nederlandse vertaling van de Inflammatory Bowel Disease Questionnaire (IBDQ), een gezondheid gerelateerde kwaliteit-van-leven vragenlijst (HRQoL).

Deze vragenlijst werd vervolgens als meetinstrument gebruikt om de invloed van de risicofactor roken op het ziektebeloop van IBD te bestuderen.

Hoofdstuk I is een introductie van de onderwerpen die in het proefschrift worden behandeld.

In Hoofdstuk Ia wordt een kritisch overzicht van de huidige epidemiologische kennis van IBD gepresenteerd. Er worden stijgende incidentie cijfers voor zowel de ziekte van Crohn (CD) als voor colitis ulcerosa (UC) gerapporteerd in geïndustrialiseerde landen. Gedurende de jaren zestig en zeventig lijkt er in deze streken voor $\mathrm{UC}$ en meer recent ook voor $\mathrm{CD}$ een plateau te zijn bereikt. In zich ontwikkelende landen is de incidentie van IBD lager maar stijgende, mogelijk door aanname van een meer Westers georiënteerde levensstijl.

Bij het ontstaan van IBD spelen genetische invloeden een rol. Epidemiologisch onderzoek wijst er echter duidelijk op dat hiernaast ook interacties tussen genetische en omgevingsfactoren van belang zijn. Van deze omgevingsfactoren is roken het meest duidelijk. Roken is positief geassocieerd (risicofactor) met het ontwikkelen van $\mathrm{CD}$ en negatief geassocieerd (beschermende factor) met het ontwikkelen van UC. Voedingsfactoren en pilgebruik beïnvloeden mogelijk de ziekte expressie, en perinatale gebeurtenissen - zoals virale infecties - veranderen mogelijkerwijs de gevoeligheid voor IBD op volwassen leeftijd. Bij de bestudering van risicofactoren is het gebruik van zogenaamde populatie-controles en populatiegebaseerde registraties van patiënten het meest belangrijk. Tevens moeten 
mogelijke risicofactoren in relatie met elkaar worden bestudeerd, en lijkt het zinvol om subgroepen van IBD patiënten te onderscheiden.

In Hoofdstuk $\mathbf{~ b}$ wordt een samenvatting gegeven van het onderwerp kwaliteit-vanleven, 'Health Related Quality of Life' (HRQoL). Drie soorten meetinstrumenten (globale belasting, generische instrumenten en ziekte-specifieke instrumenten) worden besproken. De evaluatie van HRQoL kan het begrip voor de invloed van deze ziekten op het dagelijks leven verruimen.

De vraagstellingen en de opzet van het proefschrift worden in Hoofdstuk Ic beschreven.

De methodes van de opzet van de Zuid Limburgse IBD registratie en de basale resultaten hiervan worden aan de orde gesteld in Hoofdstuk II.

In Hoofdstuk III wordt verslag gedaan van het onderzoek naar de incidentie van IBD in Zuid Limburg, waarbij gebruik gemaakt werd van gestandaardiseerde rapportages van nieuw gediagnostiseerde patiënten in de regio. Gedurende een vier jaar durende prospectieve studie werden de volgende gemiddelde incidentie cijfers (per 100.000 inwoners en per jaar) met het bijbehorend $95 \%$ betrouwbaarheidsinterval berekend: $\mathrm{CD}: 6.9$ (95\% CI: 5.9-7.9); UC: 10.0 (95\% CI: 8.7-11.2) en indeterminate colitis: 1.1 (95\% CI: 0.7-1.5). De compleetheid van de registratie werd geschat aan de hand van onderzoek samen met het Registratienet Huisartspraktijken (RNH). Wanneer het RNH als referentie werd gebruikt bleek $100 \%$ van de patiënten met $\mathrm{CD}, 80 \%$ van de patiënten met UC, maar slechts $25 \%$ van de patiënten met een chronische proctitis bij de IBD registratie bekend te zijn. De resultaten van deze studie geven aan dat er een hoge incidentie van IBD bestaat in Zuid Limburg, hoger dan in het verleden voor Nederland werd gerapporteerd (Leiden en omgeving), en hoger dan in de meeste ons omringende landen.

Familiair voorkomen van IBD, als maat voor de genetische invloed bij het ontstaan van deze ziekten, in een subgroep van de patiënten van de IBD Registratie wordt beschreven in Hoofdstuk IV. Het risico op IBD voor eerste graads famillieleden (waaronder hier werd verstaan ouders, kinderen en broers/zussen) van IBD patiënten was groter dan bij controles. Het risico was echter minder groot dan door andere centra is gerapporteerd, mogelijk door het populatie-gebaseerde karakter van de Zuíd Limburgse studie. Daarnaast moesten alle IBD diagnoses van de familieleden voldoen aan dezelfde strikte criteria voor ziekteclassificatie als de index patiënten. Het bleek dat een positieverfamilie anamnese bij slechts $57 \%$ van de door de IBD patiënten opgegeven positieve familielleden kon worden bevestigd. De prevalentie was het hoogste voor broers/zussen $(1.5 \%)$ en kinderen $(1.3 \%)$, terwijl slechts $0.2 \%$ van de ouders IBD bleek te hebben. Er werd een sterke ziekteconcordantie gevonden voor zowel $\mathrm{CD}$ als $\mathrm{UC}$, en een positieve familie 
anamnese werd iets vaker geobserveerd bij CD dan bij UC.

"Moderin life' en de epidemiologie van IBD, met speciale aandacht voor voedingsfactoren, is de titel van Hoofdstuk $\mathbf{V}$. Voor deze studie werden 688 recent gediagnostiseerde IBD patiénten, 290 met CD en 398 met UC, en 616 populatiecontroles geselecteerd. Voor controle van mogelijk verstorende variabelen (roken, leeftijd, geslacht en opleidingsniveau) werd gebruik gemaakt van logistische regressie analyse. Zoals herhaaldelijk beschreven bleek roken positief geassocieerd te zijn met $\mathrm{CD}$ en zowel niet roken als het stoppen met roken met UC. Er werd geen verschil gevonden wat betreft het gebruik van de pil.

Er werd een positieve associatie tussen de consumptie van cola, kauwgum, en chocolade, en een negatieve invloed tussen de inname van citrus vruchten en CD gevonden. Consumptie van cola en chocolade waren beiden positief geassocieerd met UC, terwijl er een negatieve associatie werd geobserveerd tussen zowel consumptie van citrusvruchten als het langer dan vijf jaar hebben van een troeteldier en UC. Er werd geen verschil gevonden in de frequentie van tandenpoetsen of in het al dan niet hebben gehad van borstvoeding tussen patiënten en controles. Geconcludeerd werd dat alle bovengenoemde voedingsfactoren daadwerkelijke risicofactoren kunnen zijn, of misschien de uitdrukking zijn van een moderne levensstijl die ook andere oorzakelijke risicofactoren voor het ontwikkelen van IBD bevat.

Om meer duidelijkheid te verkrijgen over de rol van appendectomie als een mogelijke risicofactor voor IBD werd een paarsgewijs gematcht patiënt-controle onderzoek uitgevoerd (Hoofdstuk VI). In de prevalente groep bleek het risico op het ontstaan van UC significant lager te zijn na een voorafgaande appendectomie (OR: 0.36 (95\% CI: $0.15-0.80)$ ). Subgroep analyse liet echter alleen een negatieve associatie zien in de groep patiënten met een pancolitis. Bij de ziekte van Crohn werd geen significante associatie tussen appendectomie en het verkrijgen van de ziekte gevonden, hoewel subgroep analyse hier een positieve associatie tussen appendectomie en ileocoecale Crohn liet zien. Een significant groter deel van de blinde darm operaties bij de ziekte van Crohn bleek recent voor het vaststellen van de diagnose te hebben plaatsgevonden. Dit suggereert dat in een aantal gevallen de appendix werd verwijderd in verband met klachten die mogelijk verband hielden met een op dat moment nog niet gediagnostiseerde ziekte van Crohn. Bij de analyse van de incidente patiënten werd geen verschil gevonden in appendectomie frequentie ten opzichte van controles. Mogelijk dat het matchen op leeftijd en geslacht van patiënten en controles en de bron van controles een verklaring zijn voor het minder duidelijke effect van appendectomie op een eventuele latere ontwikkeling van UC in onze studie in vergelijking met eerdere studies op dit gebied. 
Roken is geassocieerd met het ontstaan van $\mathrm{CD}$ en niet roken of het stoppen met roken met het ontstaan van UC. Er zijn echter geen gegevens gepubliceerd over de kenmerkende eigenschappen van IBD op het moment van diagnose in relatie tot het rookgedrag. In Hoofdstuk VII wordt een prospectieve studie gepresenteerd die de klinische karakteristieken op het moment van diagnose en gedurende het eerste jaar van de follow-up beschrijft in rokers en niet-rokers met een nieuw gediagnostiseerde IBD in Europa. De belangrijkste bevindingen waren dat gewichtsverlies vaker voorkwam bij patienten met $C D$ en UC die rookten, en dat diarree vaker werd gezien bij patiènten met $C D$ die rookten in vergelijking met $C D$ patiënten die niet rookten. De associatie tussen gewichtsverlies en roken is waarschijnlijk vooral te wijten aan een algemeen effect van roken, gemedieerd via een verhoging van cerebrale serotonine afgifte. $C D$ patenten die rookten hadden minder frequent ziekte van het colon en het lijkt erop dat roken het colon beschermt tegen ontsteking, niet alleen in CD maar ook in UC. Het beloop van de ziekte, zoals gemeten middels het gebruik van steroiden en immunosuppressieve medicatie, was ongunstiger bij $\mathrm{CD}$ patiënten die rookten. Alweer een duidelijk argument om roken bij patiënten met deze ziekte sterk te ontmoedigen.

Hoofdstuk viil behandelt de validatie van de Nederlandse vertaling van de Inflammatory Bowel Disease Questionnaire (IBDQ), een ziekte-specifieke kwaliteitvan-leven vragenlijst. Deze vragenlijst bevat 32 vragen, gegroepeerd in vier dimensies: darmklachten, algemene symptomen, emotioneel functioneren en sociaal functioneren. De Nederlandse IBDQ bleek gemakkelijk te zijn in het gebruik en valide. Tevens was de Nederlandse IBDQ discriminatief en bij gelijkblijvende ziekteactiviteit stabiel. De gevoeligheid voor verandering van ziekteactiviteit was goed voor alle dimensies bij $C D$ en voor de dimensie darmklachten bij UC. De IBDQ kan gebruikt worden in een Nederlands sprekende IBD populatie, en de resultaten van onze studie suggereren dat het goed mogelijk is vertalingen van de IBDQ te valideren in andere niet-Engels sprekende landen.

In Hoofdstuk IX wordt een studie beschreven met als doel de relatie tussen roken en ziekte-specifieke aspecten van kwaliteit-van-leven in IBD te verhelderen. Kwaliteit-van-leven werd bij 1105 IBD patiënten onderzocht met behulp van de IBDQ. Het bleek dat vrouwelijke patiënten met $C D$ die rookten een lagere kwaliteit-van-leven rapporteerden dan vrouwen met $C D$ die niet rookten (voor alle vier de dimensies van de IBDQ). Wanneer de onderlinge relaties tussen de verschillende dimensies van kwaliteit-van-leven in ogenschouw werden genomen bleek dat roken geassocieerd was met mect darmklachten bij jonge vrouwen met $\mathrm{CD}$, en met meer systemische symptomen bij alle IBD patenten die ziekteactiviteit aangaven. Mannelijke UC patiënten, die matig rookten, rapporteerden minder darmklachten dan mannelijke UC patiënten die niet rookten. De conclusie van deze 
studie was dat er een relatie bestaat tussen roken en ziekte specifieke kwaliteit-vanleven in zowel UC als CD. De hypothese wordt vervolgens nader uitgewerkt dat een deel van de geobserveerde verschillen, in relatie tot leeftijd, geslacht en ziektecategorie, in de bestudeerde kwaliteit-van-leven dimensies gerelateerd zouden kunnen zijn aan het gelijktijdig gebruik van de pil.

De algemene conclusie van de in dit proefschrift beschreven studies is dat een populatie-gebaseerde IBD Registratie in combinatie met populatie-controles geschikt is om antwoorden te verschaffen op sterk uiteenlopende klinisch-pathologische vragen. Deze omvatten ondermeer vragen betreffende pathogenese, klinische presentatie, symptomatologie en kwaliteit-van-leven. Verdere studies, gebruik makend van deze registratie, kunnen mogelijk onderwerpen behandelen als de invloed van therapie en de invloed van kwaliteit van gezondheidszorg op het ziektebeloop bij IBD. 
Dankwoord

난 


\section{Dankwoord}

Het verrichten van regionaal klinisch-epidemiologisch onderzoek houdt uiteraard samenwerking met vele personen en instanties in. Het is praktisch gezien niet goed mogelijk om iedereen die bij mijn proefschrift betrokken is geweest bij name te noemen, vandaar dan ook: allemaal hartelijk bedankt voor jullie samenwerking, de lering en het plezier dat er was.

Enkele uitzonderingen wil ik maken. Allereerst mijn ouders, die mij de mogelijkheid hebben gegeven om in de positie te komen een dergelijk onderzoek te kunnen opstarten. Ik ben jullie beiden, ondermeer hiervoor, zeer dankbaar. Jullie hebben altijd veel belangstelling voor het onderzoek getoond en ik denk dat het manuscript van dit proefschrift het meest nauwkeurig door pappa is gelezen (en gecorrigeerd).

Hooggeleerde Stockbrügger, beste Reinhold, de oprichting van een Zuid Limburgse IBD Registratie was jouw idee, waarvoor je mij snel enthousiast hebt weten te maken. Jij bent de drijvende kracht achter dit proefschrift, en naast een duidelijke sturing heb je mij ook steeds de ruimte gegeven voor ontplooiing van persoonlijke initiatieven. Het is voor mij een grote eer om door jou te zijn opgeleid tot gastroenteroog en om jou als promotor te hebben.

Zeergeleerde Brummer, beste Robert-Jan, vanaf mijn eerste bezoek aan Reinhold was je erbij. Tijdens het onderzoek heb je me bijgestaan met raad en daad, waarvoor mijn hartelijke dank. Zeergeleerde Limonard, beste Charles, het MEMIC is cruciaal geweest bij de opzet en de voortgang van het onderzoek en het ziet ernaar uit dat deze rol in de toekomst voor de Zuid Limburgse en Europese IBD registratie alleen maar belangrijker zal gaan worden. De efficiënte en plezierige samenwerking met jou en alle medewerkers van het MEMIC, waarbij ik met name Jan Bergers, Ruud Schmeitz, Eric van Wijlick, Gregor Franssen, Jacqueline Khalifa, Anneke Partowihono, Gertie Wijnands en Marlène Kruyen will noemen, wordt door mij zeer gewaardeerd.

Prof Dr HFP Hillen, hoofd Vakgroep Interne Geneeskunde, bedank ik hartelijk voor zijn inzet voor de IBD Registratie Zuid Limburg.

De leden van de beoordelingscommissie, Prof dr JW Arends, Prof Dr PB Soeters, Prof Dr JA Knotnerus, Dr RW Logan en Prof Dr JBMJ Jansen bedank ik voor hun bereidwilligheid het manuscript te lezen en voor het geven van waardevolle adviezen.

Patiënt-controle onderzoek is onmogelijk zonder de medewerking van zowel patiënten als controles (sic!). Vanaf het moment van opzet van de IBD Registratie is de patiëntenvereniging Crohn en colitis ulcerosa Zuid Limburg actief betrokken geweest bij het onderzoek. De ideeên die mensen uit de vereniging en Ilse van Engelshoven in 1991 hebben aangedragen blijken wetenschappelijk gezien in 1997 veel waard te zijn: er zijn nu gegevens van meer dan 1600 patiënten over guality of life en quality of care verzameld. De verdere uitwerking hiervan zal ongetwijfêtd een proefschrift kunnen vullen. Het feit dat meer dan $90 \%$ van de benaderde patiènten een zeer uitgebreide enquête heeft geretourneerd, geeft de belangstelling en medewerking van de patiënten weer. De controles in ons onderzoek wijken voordelig af van die van de meeste centra in die zin dat het echt popullatie-gebaseerde controles zijn. Dit was mogelijk door samenwerking met het 
Registratienet Huisartspraktijken (RNH). Naast de huisartsen van het RNH in COROP 39 (Zuid Limburg), hebben met name Jean Muris en Job Metsemakers hierin veel energie gestoken.

De rol wan research assistent heb ik, na vele uurtjes achter de computer tijdens de nachtdienst, af kunnen staan aan een zeer professioneel team van Research Assistentes. Dit is denk ik een veelzijdige baan waarbij momenten van congres-organisatrice, dia- en poster- ontwerpster, begeleidster van medische studenten en data-entry, afgewisseld worden met de rol van onderzoekster, studiecoördinatrice en analiste. Achtereenvolgens is deze functie ingevuld door Ilse van Engelshoven, Wilke Ellenbroek, en momenteel door Martine van de Kruijs en Ingrid van der Eijk. Allen hartelijk bedankt voor jullie enthousiasme, veelzijdigheid, het steeds weer terugvinden van mijn paperassen en de gezelligheid. Zonder de hulp van vele studentes en studenten bij allerlei aspecten van IBD Zuid Limburg had dit proefschrift niet geschreven kunnen worden. Met name Ingrid Lousberg en Karin Janssen wil ik hier noemen. Ik ben ervan overtuigd dat bij de meeste van hen meer begrip voor chronische darmziekten, een zekere kennis van de ziekte IBD en van onderzoek in het algemeen is ontstaan.

Financiering van een project waarvan nog geen resultaten voorhanden zijn is moeizalam. Ik ben dan ook zeer erkentelijk voor de financiële steun van diverse farmaceutische bedrijven (Astra, Byk, Glaxo, Pharmacia, Tramedico, Yamamouchi), van de Universiteit Maastricht en zeker ook van het Development Fund van het academisch ziekenhuis Maastricht, bij wie ik de afgelopen twee jaar aangesteld was als wetenschappelijk onderzoeker.

IBD Zuid Limburg is destijds ondermeer opgestart om een verdere samenwerking tot stand te laten komen op het gebied van IBD en van de gastroenterologie in zijn algemeenheid binnen de regio Zuid Limburg. Dit is mijns inziens succesvol gebleken en ik ben zeer blij met de goede samenwerking tijdens dit project met vele collega's binnen de regio. Ik hoop dat deze samenwerking zich in de toekomst nog verder zal antwikkelen. Alle aanmelders van patiënten bij deze hartelijk bedankt. Het is mijn vaste overtuiging dat door klinisch-epidemiologisch onderzoek ook de kwaliteit wan zorg en hierdoor ook de kwaliteit van leven bij patiënten met IBD in Zuid Limburg zal verbeteren.

Binnen de vakgroep epidemiologie wan de Universiteit Maastricht ben ik vooral veel dank verschuldigd aan Elisabeth Dorant, wiens heldere visie en kritische geest steeds weer resulteerde in een verbeterde versie van het manuscript. Voor de hulp bij de vele, voor mij altijd weer ingewikkelde, statistische bewerkingen wil ik wooral Jan Bergers, Fred Nieman, Jos Thijsen, John Mullink en Alexander Volovics hartelijk danken.

Binnen de werkgroep gastroenterologie van ons ziekenhuis heb ik tijdens de periode van het onderzoek met veel plezier gewerkt. Dame en heren, bedankt voor jullie adviezen, medewerking en prettige werksfeer. Met name de samenwerking met Bertine Geerling, Claudia Pastoor, René Wouters, Ton Vrij en bovenal met mijn huidige kamergenoot en paranimf Eric Schoon is altijd zeer stimulerend en plezierig geweest. We zoudlen alleen eens wat vaker moeten fietsen! Ik ben ervan overtuigd dat jullie dissertatie, en ook die van Martine van de Kruijs en Ingrid van der Eijk, nog meer gestalte zullen geven aan IBD Zuid Limburg.

Gaby Scheepers, onze werkgroepsecretaresse, was altijd zeer behulpzaam en wist veel 
"storingen" te voorkomen, waardoor ik de gelegenheid kreeg om aan dil proefschiflt te werken. Tiny Wouters heeft de hoofdrol gespeeld in de laatste fase van dit proefschrift. Niet alleen het op tijd "drukklaar" krijgen van het manuscript, ook alles er ombeen en de manier waarop, hebben voor mij deze laatste maanden zeer plezierig en ontspannen gemaakt.

Lieve Liesbeth, we hadden er voor de aanvang van dit project al én, en gedurende de periode waarin het onderzoek zich heeft afgespeeld is ons gezin nog een stukje groter geworden. Je gezelligheid, je zonnige karakter, je "management of care and of good quality of life" in ons gezin zijn voor mij steeds het belangrijkste geweest gedurende de afgelopen zes jaar. Lieve schatten, beste kerel, het grote boek is af, kinderhouse mag weer op voll volume! 


\section{Curriculum Vitae}




\section{Curriculum Vitae}

Maurice GVM Russel

1958

1976

1976

1977

$1978-1986$

$1986-1987$

1987

1987 - $1992 \quad$ Opleiding interne geneeskunde

De Wever Ziekenhuis, Heerlen

Opleider: Dr FATh Lustermans

1992 - 1993 Vervolgopleiding interne geneeskunde

Academisch Ziekenhuis Maastricht

Opleider: Prof dr JA Flendrig $\dagger$

1993 - 1996 Opleiding gastroenteroloog

Academisch Ziekenhuis Maastricht

Opleider: Prof dr RW Stockbrügger

1996 - Werkzaam als gastroenteroloog

Academisch Ziekenhuis Maastricht

Hoofd: Prof dr RW Stockbrügger 
18 
Appendix 1 


\title{
EPIDEMIOLOGISCH ONDERZOEK \\ INFLAMMATOIRE DARMZIEKTEN
}

IN DE REGIO ZUID-LIMBURG

\author{
EC - IBD
}

\section{AANMELDING}

(door specialist)

na aanmelding

patiènten dossier markenen met stikker

Agemente instruktiex:

- Bif di onderoek zijn van belang de patiènten met als diagnose warschijulijke dan wel zekere chronisch inflummatoire

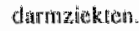

- "itot defe ziokten worden gerekend: Colihis Utcerosa, Chronische Proctitis, ziekte wan Crohn en Aspecifieke Colitis,

- Er wordt an onderscheid gernakt in:

- newwe patientem indier ben van deze diagnoses in de periode van a oklober 1991 tot I oknober 1995 gesteld wordt;

- belende pantienten: indien cern van deze diagnoses feeds woor 1 oktober 1991 gesteld werd.

Door u ara te mellen pattènten:

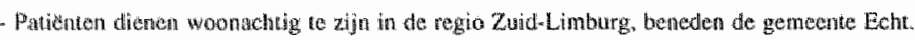

- Tjdelijke inwoners, zoals milituren, seizoenswerkers en tocristen worden witgestoten, studenten worden ingestoten.

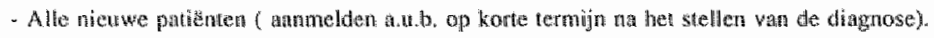

- Zoveel mogelik bekende patiantea die nomented bij u onder kontrole staan.

Ingevulde formulieren:

De ingevalde ammeldingsformulieren an b, bewaren op de poli , wat ze regelmatig zullen worden afgehaald. 
Woormanen:

Adres:

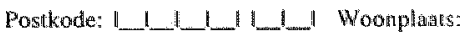

Crestacht:

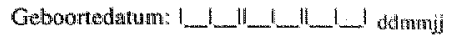

Naan hivisarts:

Invuldatum formulier:

\section{MEDISCH GEDEELTE}

(invullen door specialist)

1. a. Wat is de cerste bij deze patiënt gestelde 'IBD-diagnose'?

$\begin{array}{ll}1 \square \text { zeker - Colitis Ulcerosa } & 4 \square \text { zeker Morbus Crohn } \\ 2 \square \text { warsch Colitis Uhcerosa } & 50 \text { warsch. Morbus Crohn } \\ 3 \square \text { Claronische Proctits } & 6 \square \text { Aspecifieke Colitis }\end{array}$

b. Op welke datum werd deze diagnose gesteld: L_L___ I mmji

2. a. Datum cerste konsult;

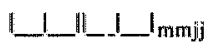

b. Dour van symptomen vớór ecrste kionsult:

3. Is patient nog bij ander relevant specialismo in bohandeling?
U nee

specialisme

○ ja, zoja: gemeente
4. Is de patiènt ooit geopereerd atan de triatus digutstivas?

0 newe

Q ja, zoja:

jair ziekenhuis gemeente

11911

1191_1

$11,1,1$
KODERTNGSGTDEELTE

(invulten door rolodexnmedewertien)

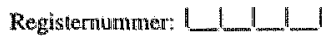

Registertimanneri: 1

Toestemming: $\square$ inee

a ja

Specoialist:

Speciallsme:

Ziekerthuis: 1_

Woonplatats: 1_L___ CB: kode

Geslacht: $\quad 1$

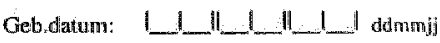

Huisarts: | I I I I

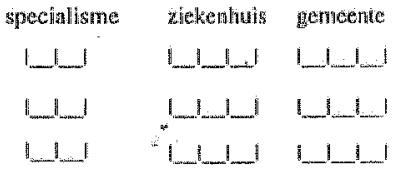

wiekenthis getmeente

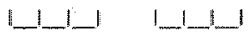

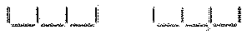

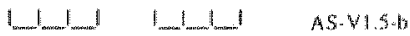




\section{TOESTEMMING VAN PATIENT}

Ik heb er geen bezwat tegen dat gegevens uit miln medisch dossier en aanvillende gegevens middels aan milj geriehte enquetes, losgekoppeld van mijn persoonsgegevens, worden geloruikt woor benedenbeschreven onderzoek. Ik weet dat ik ten alle tijde mijn medewerking kan staken en dat, indien ik dit aangeef, ook de bestaande gegevens betreffende mijn persoon uit de registratie zullen worden verwijderd.
Datum:
Naam:
Handtekening:

\section{INFORMATIE VOOR PATIËNT}

In 1991 gatat in Zuid-Limburg een onderzoek wan start met als onderwerp chronische ( $=$ langdurige) darmziekten, waartoe onder andere de ziekte var Crohn en Colitis Ulcerosa behoren. Het doel van het onderzoek is enerzijds zo exakt mogelijk het vơorkomen van deze ziekten en de kenmerken hiervan in Zuid-Limburg in kaart te brengen. Anderzijds is het de opzer door vervolgen van patiënten met langdurige darmziekten een beter inzicht in het beloop van deze ziekten te krijgen. Met deze informatie hopen wij meer medische kennis te vergaren, die gebruikt kan worden on inzicht te krijgen in de oorzaak, hel verloop en de behandeling.

Praktisch gezien komt het erop neer dat wij wan alle patiënten met een chronische darmziekte een aantal medische gegevens willen verzamejen uit de bestaande medische dossiers. Deze worden aangevuld met gegevens die aan de patient, via een schniftelijke enquete, worden gevraagd. Deze gegevens worden vervolgens losgekoppeld van de naam van de patiënt, zodat ze op anonieme basis vergeleken ktinnen worden.

Om dit onderzoek wardevol te laten zijn is het belangrijk dat veel, liefst alle, patiënten die in anmerking komen met het onderzoek meedoen. Derhalve vragen wij uw toestemming om op anonierre basis gegevens uit uw medisch dossier te registreren. Met nadrak wijzen wij erop dat er met deze gegevens uiterst vertrouwelijk zah worden omgegaan en dat zij alleen gebruikt zullen worden on de medische kennis ontrent oorzaak, verloop en behandeling te vergroten, Tevens vragen wij toestemming om middels een aan a gerichte enquete aanvillende gegevens te verkrijgen en via vervolg-enquetes in de loop der jaren de gegevens up to date te houden.

Met dank voor ww medewerking, natmens de werkgroep inflammatoire darmziekten Zuid-Limburg,

Prof. Dr. R.W. Stockbrigger

Gastroenteroloog

Acadenisch Ziekenhuis Maastricht
M.G.V.M. Russel

Internist in opleiding

De Wever Ziekenhuis /

Academisch Ziekenhuis Maastricht 


\section{KRTTERIA VOOR DE DEFINTTL VAN IBD BEHOREND BLI \\ EPIDEMIOLOGISCH ONDERZOEK INFLAMMATOIRE DARMZIEKTEN}

IN DE REGIO ZUID-LIMBURG

* Lennard-Jones JE.

Classification of Inflammatory Bowell Disense.

Scand J Gastroenterol 1989, 24(suppl 170):2*6.

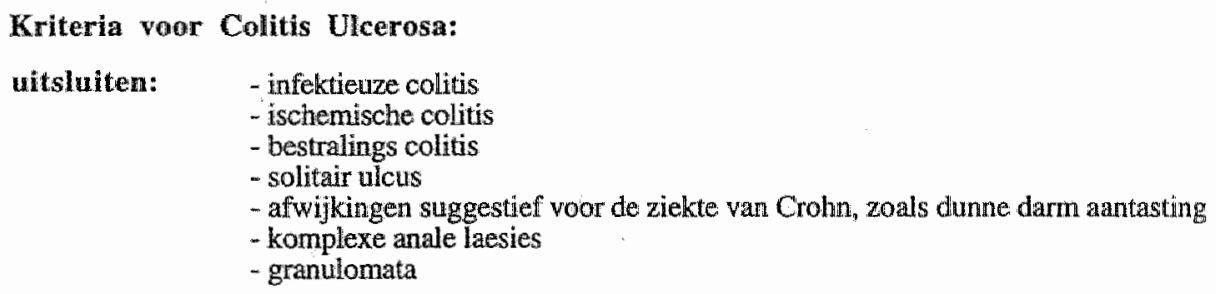

zeker: kontinu mucosale ontsteking zonder granulomata, én rectum aantasting (endoscopie) met een gedeelte van het gehele colon in kontinulteit met het rectum (endoscopie of röntgenonderzoek)

waarschijnlijk: symptomen wijzen op Colitis Ulcerosa, maar de kriteria zoals bij 'zeker' genoemd zijn (nog) niet aanwezig, omdat het onderzoek nog niet mogelijk of nog niet getheel afgerond is, of omdat de resultaten van het onderzoek (nog) niet goed interpreteerbaar zijn.

\section{Kriteria voor Chronische Proctitis:}

Als voor Calitis Ulcerosa, echter alleen aantasting van het rectum (ongeveer eerste $15 \mathrm{~cm}$ vanaf anus). 


\section{Kriteria voor ziekte van Crohn:}

\begin{tabular}{|c|c|c|c|c|c|}
\hline & & endoscopie / klingsch & rơntgen & biopt: & weetisel \\
\hline \multirow{2}{*}{ a) Mond tot antis: } & madagdammkanal & + & + & + & + \\
\hline & anus & 4 & & * & + \\
\hline \multirow{4}{*}{$\begin{array}{l}\text { b) Digkontiniti } \\
\text { c) Transmunata: }\end{array}$} & & + & + & $\phi^{+}$ & + \\
\hline & fissuner & & + & & + \\
\hline & abcess & + & + & & + \\
\hline & fistel & + & + & & + \\
\hline d) Fibrose: & stencase & + & + & & + \\
\hline e) Lymifald: & ulous & & & + & + \\
\hline & aggregaiat & & & + & + \\
\hline \multirow{2}{*}{\multicolumn{2}{|c|}{$\begin{array}{l}\text { f) Slijmretentid: } \\
\text { g) Granulloon }\end{array}$}} & & & + & to \\
\hline & & & & $(4$ & (†) \\
\hline \multicolumn{6}{|c|}{ 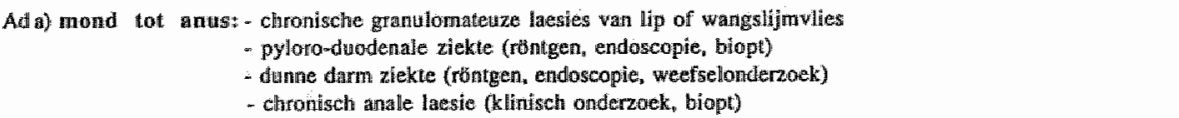 } \\
\hline b) distionttau: & \multicolumn{5}{|c|}{$\begin{array}{l}\text { - laesies gescheiden van elkaar door normale mucosa, "skip"-laesies of discrete ulcera } \\
\text { (röntgen, weefselonderzoek) }\end{array}$} \\
\hline c) trantsmurat: & \multicolumn{5}{|c|}{$\begin{array}{l}\text { - abces (klinisch, beeldvormend onderzoek) } \\
\text { - fistel (klimisch, rontgen, weef selonderzaek) }\end{array}$} \\
\hline d) ribrase: & \multicolumn{5}{|c|}{ - strictuur, eventueel multiple en asymetrisch (röntgen, endoscopie, werefselonderzoek) } \\
\hline e)lymifoind: & \multicolumn{5}{|c|}{ - biopt waarin klein aphteus ulcus of lymfoüde aggregaten } \\
\hline \multicolumn{6}{|c|}{ O) slijmretentie: - retentie van colon-siljm in biopt in nabijheid wan aktieve ontsteking (biopt, weefselonderzoek) } \\
\hline B) gramuloom: & \multicolumn{5}{|c|}{ - niet werkazend, niet door vreend lichaam } \\
\hline
\end{tabular}

uitsluiten: - infektieuze colitis (mikrobiologie, eventueel antilichamen tegen Yersinia)

- ischemische colitis

- bestralings colitis

- lymitoon/ carcinoom

zeker: $\quad$ volgens bovenstaand schema minstens +++ , of minstens $+(\oplus$

waarschijnlijk: symptomen wijzen op ziekte van Crohn, maar aan de kriteriă zoals bij 'zeker' gencend wordt (nog) niet woldaan, omdat het onderzoek nog niet mogelijk of nog niet geheel afgerond is, omdat de resultaten wan het onderzoek (nog) niet goed interpreteerbaar zijn of omdat te laag gescoord wordt.

\section{Kriteria voor Aspecifieke Colitis:}

Uitsluitkriteria woor Colitis Ulcerosa en ziekte van Crohn niet aanwezig.

Ondanks adequaat onderzoek (momenteel) geen keuze te maken tussen Colitis Ulcerosa en de ziekte van Crohn 
Appendix 2 
Naam:

Voorncinat

Adres:

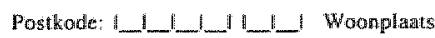

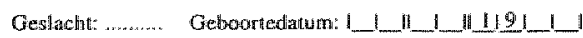

Haisgrts:

\section{wel invullen door patient}

Gatarne andtruisen dan wel invallem wat op a ran toepassing is. Bifloorbeeld:
4 bent geboren op 12 moant in 1962
U ben geboren in Nederkand.
1121013.1916121
(8) Nederand

\section{ALGEMEEN}

(tavelilen door pillicht)

\section{Invuldatum $1,1,1 / 1119$}

1. In welk land bent a geboren?

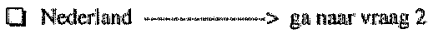

$\square$ ander land t. H.: .....................................................m.

2. In welke gemeente en provincie bent a geboren? genvente:

provincie:

3. In welk land is uw vader geboren?

D. Nedertand

D ander land i.w:

4. In walli land is ww moeder peboren?

Dij Nederlitind

$\square$ ander land t.w:

5. Welke nationaliteit(on) heeft a ma? (bij nuer don I mationaliteit deze noteren)

Q Nedeslind

D athders in wi:

\section{niet invulten door patient}

Registernumumer: 1_1_1

Registernummer" L_L___L

(alleen indien trgevild in IDENTT, GEDEEL TE)

Woonplats: I I I I CBS kode

Gestacht:

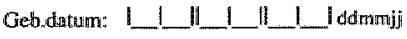

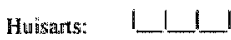

I I I I kodie geb land

L_L___ll___ I kode geb.gemneenthe

$1 \quad 1 \quad 1$ l kate gebland

L_L_L Kodtegebshand

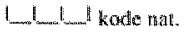

1 I I I l kowe nat. 


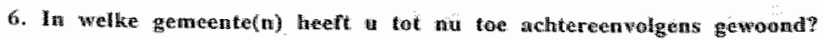

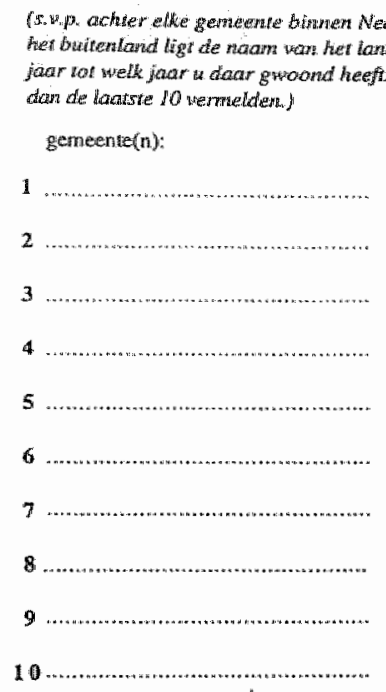

nivet invullen door patrent dan de bantre 10 wermeldern.

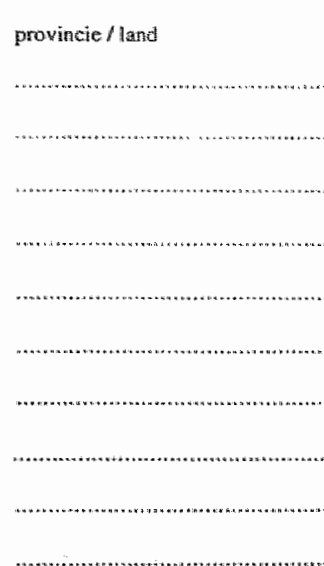

7. Hoe lang woonde in de regio Zuid-Limburg VOORDAT u darmklachten had?

Wanneer a tussendoor perioden buiten Zatd-Limburg woonde, deze nit wietellen. zuid-Limburg strekt zich wit over alle gernetenten BIENEDEN de gemeente Echt.

1 Gorter dan 1 jatar

20 tot en met 5 jaar

3 . langer dan 5 jaar

4. woon(de) alleen in Züd-Limburg gedurende mijn studie periode

50 woonde butten Zuid-Limburg

8. In welke gemeente(n) woonde u de laatste 5 jarren vóORDAT u darmkilachten liad?
germectinge:
provilacie:
gempintia:
pirowincite:
geneente:
provincle:

9. Wat is tw huidlge burgerlifke situat?
10 gehwnid of samen woncend
2. [0] ongethund
30 anescheiden
4. 1 wedumedwedumonat: 


\section{AMILLE}

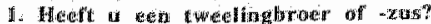

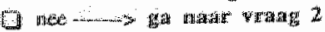

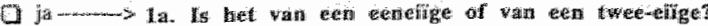

10 oneigy

20 mentgen

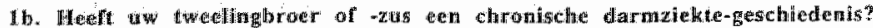

I nee

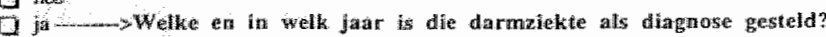

1.] ziefce van Crotari

$2 \square$ Colitis Ucerota

30 anders

40 whet niet

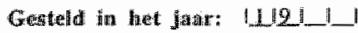

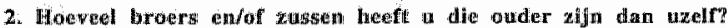
Arintal: 1_L

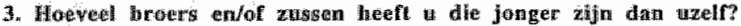

Aantal: $1 \quad 1$

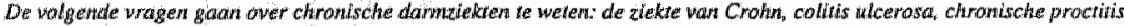

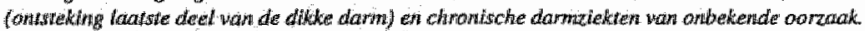

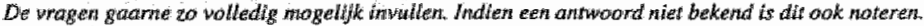

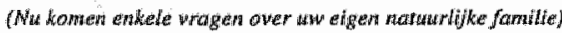

4. Kont chronische darmakekte voor in uw aigen (natuurlijke) familie?

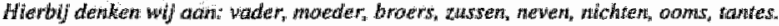

Dus do le en ze graads biloed we moratschapt.

$\square$ nee $\rightarrow$ ga nar wraag 5

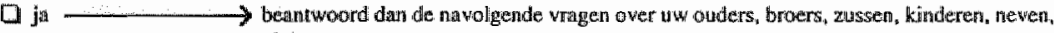
níchterni, owns en tantes:

4a. Heeft ww vader enfor moedter ecn chronische darmziekte (gehad)?

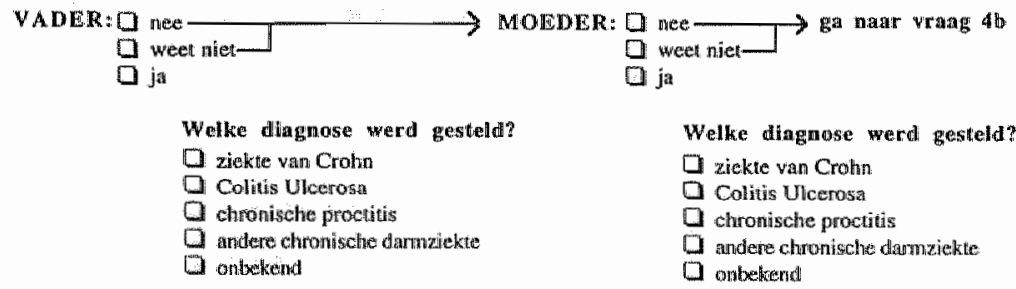

In welk Jom wherd die dingnose gesteld?

In welk joar werd dife dagnose gesteld?

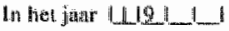

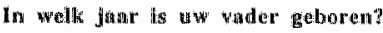

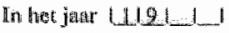

Iin ww water noge In leven?

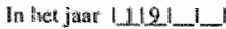

la: wellk jaar is uw moder metoren?

In het jarat 11 19.

lis thw moeder nog in leven?

ala nem

[1. nee

In welk jatar is hij gestorven?

In wellk jaar is zij gestorven?

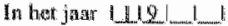




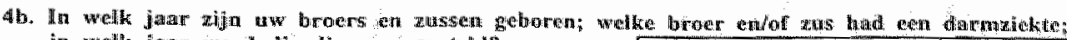

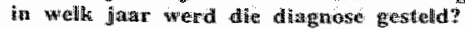

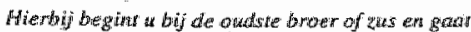

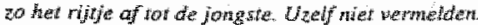

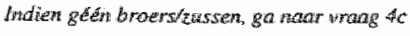

\begin{tabular}{|c|c|c|}
\hline eboren & nogs in & In \\
\hline
\end{tabular}

\begin{tabular}{|c|c|c|c|c|c|c|}
\hline de ondiste & 11011 & $\square$ & 0 & 1119111 & 1 & $11121 \quad 1$ \\
\hline de $2 x$ & $\| 191 \ldots$ & 1 & $\square$ & $1191-1$ & 1 & $1191 \quad 1$ \\
\hline we $3 \mathrm{e}$ & 1 U9 1 & 0 & II & 1191 & $i$ & 1191 \\
\hline$d e d e$ & $1191 \quad 1$ & ] & $D$ & LIS_L_ & 1 & $1191 \ldots$ \\
\hline de se & $1191 \quad 1$ & $\square$ & 0 & 1191 & 1. & $1121-1$ \\
\hline de 6 & $1191+1$ & $\square$ & Q & 11,91 & 1 & $1191 \quad 1$ \\
\hline oe $7 e$ & $1191 \quad 1$ & $\mathrm{a}$ & 0 & $1121 \ldots$ & 1 & 1191 \\
\hline dese & $11191 \mathrm{~J}$ & 0 & $\square$ & 10191 & 1 & $1,19,1$ \\
\hline dege & 1191 & 0 & Q] & $1191 \quad 1$ & 1 & 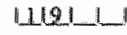 \\
\hline de $10 x$ & $11121<1$ & D & $\square$ & $\|109\|$ & 11 & 11191 \\
\hline
\end{tabular}

Nu koven enkele yrogen over us kimderen.

\section{KINDEREN:}

4c. Heeft ainderen?

0 mee $\rightarrow$ gat natar raag 5

$\square$ ja $\rightarrow$ Hoeweel? Fiendj her aamal overledten kinderen metellen.

\section{I lkinderent}

4d. In welk jaar zijn uw kinderen geboren" welk kind had cen darmziekte; in welk jaar werd die diagnose gesteld?

Hiarbij begint w bij ww oudste kind en gact to het rijije af tor de jongsie.

$$
\begin{aligned}
& \text { gatboriert! } \\
& \text { in liset jasp: }
\end{aligned}
$$

\begin{tabular}{|c|c|}
\hline then ouldste & 11191 \\
\hline het $2 e$ & $\mid 1 \| 91$ \\
\hline nell $3 e$ & $11121 \_1$ \\
\hline het 40 & 11121 \\
\hline thet $5 \mathrm{e}$ & 11211 \\
\hline het $6 \mathrm{e}$ & 11191 \\
\hline het $7 \mathrm{e}$ & 111911 \\
\hline het $8 \mathrm{~B}^{\mathrm{x}}$ & $1191 \ldots$ \\
\hline thet $9 \mathrm{e}$ & 1191 \\
\hline het the & 109 \\
\hline
\end{tabular}

\begin{tabular}{|c|c|}
\hline$\square$ & 11121 \\
\hline 0 & 111911 \\
\hline D & 11121 \\
\hline 0 & |U2___ \\
\hline$\square$ & 11912 \\
\hline$\square$ & 1121 \\
\hline 0 & U121 \\
\hline$\square$ & 1121 \\
\hline$\square$ & 10191 \\
\hline 1 & $11121 \ldots$ \\
\hline
\end{tabular}

$T=$ chronasetye procti tis

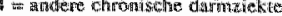

$\$=$ antakerad

a disyngese nuter

eld ary het jas

\begin{abstract}
11211
\end{abstract}
$121+1$

$121<1$

11

U2 I I I 


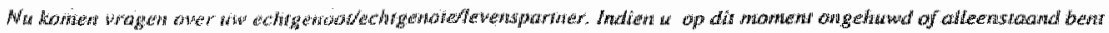

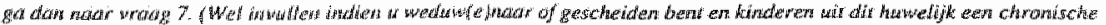

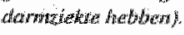

\section{ECHTG NOOOTECHTGENOTEULEVERSPATTNER:}

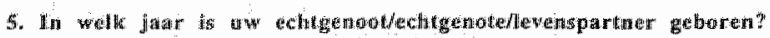

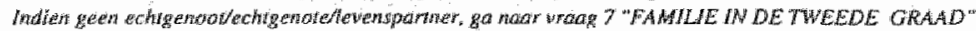

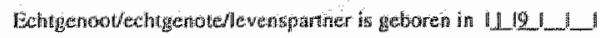

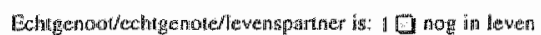

$$
2 \text { I owerleden } \rightarrow-\rightarrow \text { in he jatr }|1| 9 ! \text {, }
$$

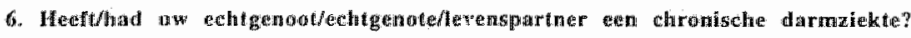

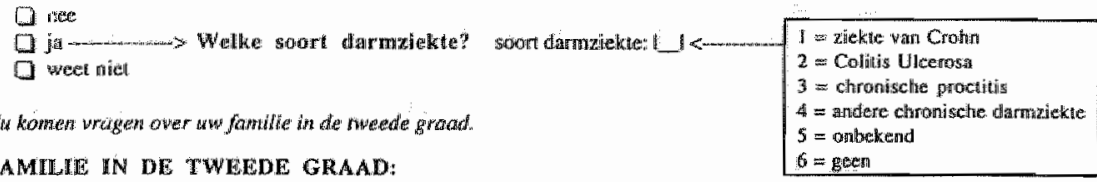

TAMILIIE WN DE TWEEDE GRAAD:

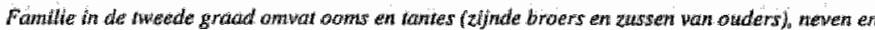

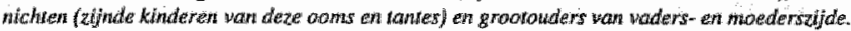

7. Heeft fumille in de 20 graad chronisiche darmaickte en zoja hoeveel onms, tantes, meven,

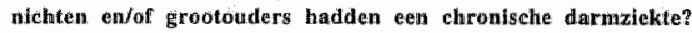

ar wise

[J ja [1] ween aniet Aramilekté(n)? Ooms er tanles:

zickte van Crohn
Colitis Uluerosn
chronische proctitis
andere chronische damraziekto
ongrekend

\begin{tabular}{|c|c|}
\hline \multirow[t]{5}{*}{ neven en nichten: } & zlekte van Crothn \\
\hline & Colitis Ulicerosa \\
\hline & chironhsche prottitig: \\
\hline & 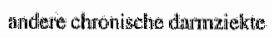 \\
\hline & onthekend \\
\hline \multirow[t]{5}{*}{ grool outhersi } & ziekte van Crohm \\
\hline & Colitis Ulcemosa \\
\hline & chron \\
\hline & andere chronische dannziekte \\
\hline & anbetkend \\
\hline
\end{tabular}

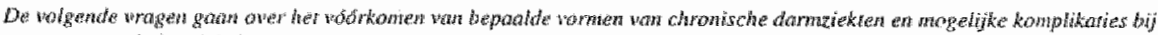

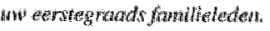




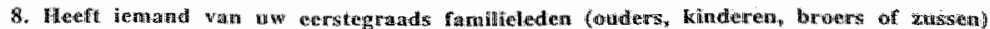
aud een thrombiosebenim doorigematat?

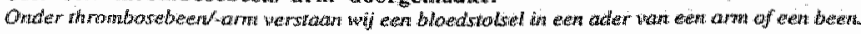

Dine

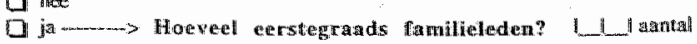

[1] weat rite

9. Heeft hemand van un eerstegraads lamilieleden (owders, Hituderen, broers wo zussen) ooli eter Hongerrbolie doorgemaakt?

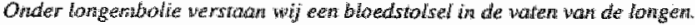

Di: nee

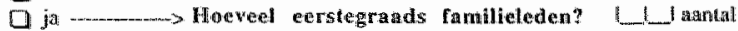

Dij wext riet.

10. Heef iemand wan us cerstegraads fambielleden (owders kinderco broers of zussen) owit een hartinfarct dowrgemagkt?

D. mest

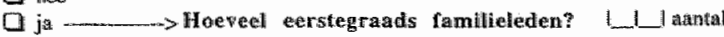

Di] weet niet

11. Heeft iemand wan uw eerstegraads famulieleden (oudors, kinderen, brocks or aussen) ooit een thersemintarct doorgemaknt?

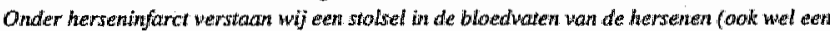

"hersen-attack", "CWA "of "TLA" genoemd)

Ane

in

a weet niest

$\rightarrow$ Hoeveel cerstegraadis familleleden? l_L_lantal

\section{VOEDING}

1. Heeft u zelf als baby borstvoeding gekregen?

10 mee

$20 \mathrm{ja}_{\mathrm{n}}$ korter dan 3 mstanden

30 ja, langer dan 3 matanden

$410 \mathrm{ja}$, weet riet thoellang

5 Q weel niet

2a. Wolgde $u$ in de jaren WÖBRDAT de darmklachtein ontstondien gedurende lamgere tijd een bepaald diect of hield $\mathrm{u}$ zich an een bepagld woedingspaitroon of een alliternatieve voedingsgewoonte?

Onoe

Q ja $\rightarrow$ mam $\rightarrow$ Welk van de angegeven voorbelden ts op u van toepassing?

(meerdere artwoordern mogelijk)

dil ex:

0. $\square$ werlopperkit dieel

020 dintestes mellutus (sulkerzicke)

030 a

04. Cholestenol beperk

050 sader dieet nl: wod da guspatroonn

On 0 Hindoestadns.

070 Kosher (joods)

08. Mosint all ther natieve yoedilngsgewoonte:

0 a mancobiotische voeding

$10 \square$ wegatial sich (strikt)

11 W wegetarisch (wel zuivelprodukien) ovet

120 anders al: 


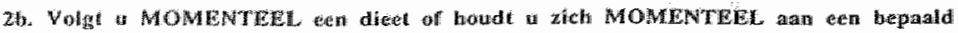

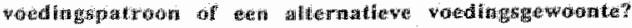

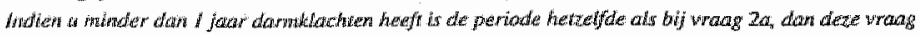

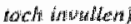

(i) mes

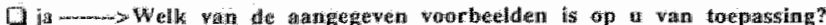

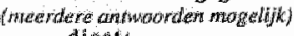
diles:

01 rid wetheperke diteet

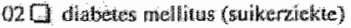

030 verelam diect

(04) 1 cholesterol bepertin

05 G ander dipel $\mathrm{nt}$. voed In

1060 Hindoestaning

07 Kosher (joods)

08D Moslim

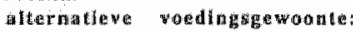

0917 macrobjotische woeding

100 vegetarisioh (strikt)

11. vegetisisch (wel zai welproduktent)

overtig:

$12 \mathrm{O}$ anders $\mathrm{nl}$ :

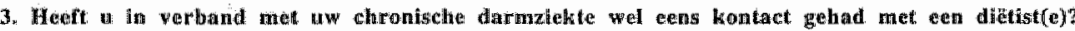

10 new

20 jais 1 or 2 keer

$3 \mathrm{Q} \mathrm{ja}_{\mathrm{i}}$ Yhiker dan 2 toer

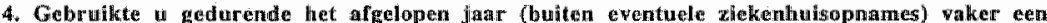

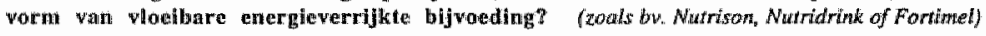

D nee

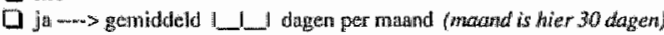

5. Heeft a op thet moment wianeer de chronisehe darmakick aktiever is cen duidelijk veranderd expatroon (hterdoor)?

Q nace

Q

20 hoveelheid düidetijl meer

3 lil samenstellirg delideligk anders

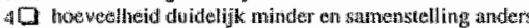

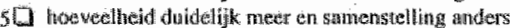

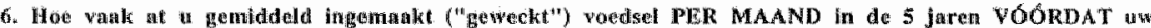

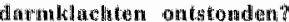
1. I lawer per mawind

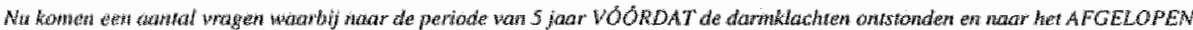

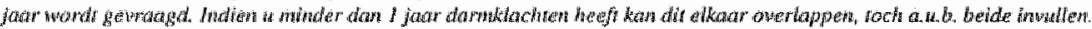

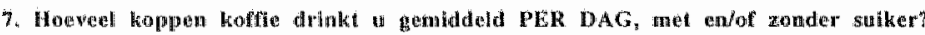

\begin{tabular}{|c|c|c|}
\hline & $\begin{array}{l}\text { in de } 5 \\
\text { Jaren } \\
\text { VOORDAT }\end{array}$ & $\begin{array}{l}\text { In het } \\
\text { AfGCOLOPEN } \\
\text { JaAl }\end{array}$ \\
\hline annal kogpen zonder stiker" per atag & $1+1$ & 1 \\
\hline 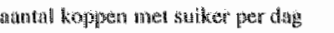 & 1 & $1 \ldots$ \\
\hline
\end{tabular}


8. Hoeved koppen thee drinkt gemiddeld PER DAG met of zonder suiker?

\begin{tabular}{|c|c|c|}
\hline 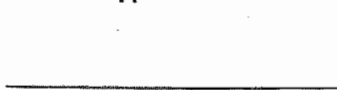 & $\begin{array}{l}\text { in de } 5 \\
\text { jaren } \\
\text { vóndat }\end{array}$ & $\begin{array}{l}\text { in het } \\
\text { AFGELOPEN } \\
\text { jaar }\end{array}$ \\
\hline aanital koppen zonder suiker per dag & $1-1$ & $1 \quad 1$ \\
\hline aantal koppen met suilker per dag. & L_ I & 111 \\
\hline
\end{tabular}

9. HOEVAAK at u in de 5 jaren VÓORDAT de darmkllachten begomnet ten wan de volgende soortien wils

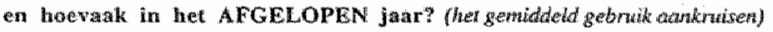

\begin{tabular}{|c|c|c|c|c|c|c|c|c|c|c|}
\hline \multirow[b]{2}{*}{ soort wis } & \multicolumn{5}{|c|}{$\begin{array}{l}\text { in de } 5 \text { jaren VÓólRDAT } \\
\text { gemiddeld gebruik: }\end{array}$} & \multicolumn{5}{|c|}{$\begin{array}{l}\text { in het AFGELOPEN jaar } \\
\text { gemiddeld gebritulk: }\end{array}$} \\
\hline & $\begin{array}{l}\text { Ix } \\
\text { per dag } \\
\text { of meer }\end{array}$ & $\begin{array}{l}5.6 \\
\text { keer } \\
\text { per } \\
\text { week }\end{array}$ & $\begin{array}{l}2 \cdot 4 \\
\text { keer } \\
\text { per } \\
\text { week }\end{array}$ & $\begin{array}{l}1 \\
\text { keer } \\
\text { per } \\
\text { weet }\end{array}$ & $\begin{array}{l}\text { minder dan } \\
1 \text { keer per } \\
\text { week }\end{array}$ & \begin{tabular}{|l}
$1 x$ \\
per ifigg \\
of meer
\end{tabular} & $\begin{array}{l}5.6 \\
\text { keer } \\
\text { per } \\
\text { week }\end{array}$ & $\begin{array}{l}2 \cdot 4 \\
\text { keer } \\
\text { ger } \\
\text { weok }\end{array}$ & $\begin{array}{l}\sharp \\
\text { keer } \\
\text { per } \\
\text { week }\end{array}$ & $\begin{array}{l}\text { minder dat } \\
\text { i keer par } \\
\text { watk }\end{array}$ \\
\hline \multirow{2}{*}{$\begin{array}{l}\text { totale } \\
\text { hoevedheid } \\
\text { is } \\
\end{array}$} & 1 & 2 & 3 & 4 & 5 & I & 2 & 3 & 4 & 5 \\
\hline & $\square$ & $\square$ & 0 & $\square$ & $\square$ & $\square$ & $\square$ & $\square$ & $\square$ & 口 \\
\hline $\begin{array}{l}\text { Warwan: } \\
\text { magere vis }\end{array}$ & $\square$ & $\square$ & $\square$ & $\square$ & $\square$ & $\square$ & $\square$ & $\square$ & $\square$ & $\square$ \\
\hline \multicolumn{11}{|c|}{ 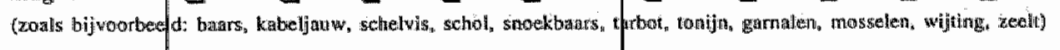 } \\
\hline $\begin{array}{l}\text { gemiddeld } \\
\text { vette vis } \\
\text { (zoals bijvoorbee }\end{array}$ & a: bot, br: & $\underset{\text { sem. }}{0}$ & $\underset{\text { ell, heilt }}{\square}$ & a karper & $\square$ & $\square$ & $\square$ & $\square$ & a & $\square$ \\
\hline vette vis & D. & 0 & a & $\square$ & $\square$ & $\square$ & $\square$ & $\square$ & $\square$ & $\square$ \\
\hline
\end{tabular}

10. Hoeveel gram van de verschillende soorten vis at $u$ ongeveer PER WEEK in de 5 jaar vÓORDAT de darmklachten begomnen en in het AFGELOPEN jaar?

(Een geniddelde portie schol of kabeljatow bedrangt angeveer 150 gram per keer)

\begin{tabular}{|c|c|c|}
\hline & $\begin{array}{l}\text { in de } 5 \text { jaren vóndDAT } \\
\text { boeveelheid per week: }\end{array}$ & $\begin{array}{l}\text { in thet AFGELOPEN jaar } \\
\text { hoeverilieid per week: }\end{array}$ \\
\hline $\begin{array}{l}\text { totale } \\
\text { hoeveelheid vis }\end{array}$ & 1111 I gram & L1. L I I gram \\
\hline $\begin{array}{l}\text { warkyan: } \\
\text { magere wis } \\
\text { Goals bijwoorbeld: baars }\end{array}$ & 1_Labeljaurw, schelvis, schol, snoekbr & 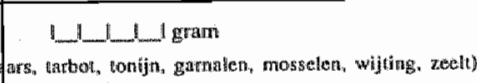 \\
\hline $\begin{array}{l}\text { geuniddeld valle wis } \\
\text { goats bijvoorbeald bot. }\end{array}$ & orisem, forel, heilboh, karper) & 1-1 L L gram \\
\hline velte wis & 1_L1_l_ gram & 1. \\
\hline
\end{tabular}

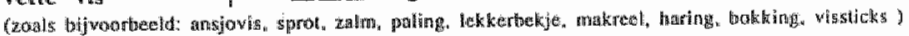

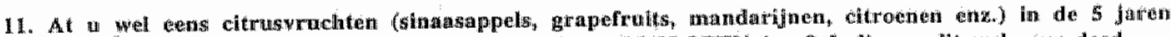

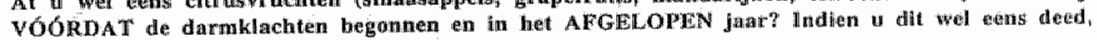
hoeveel at a er dam gemiddeld PUER WEEK?

\begin{tabular}{|c|c|c|}
\hline $\begin{array}{l}\text { aantal citros } \\
\text { wruchten }\end{array}$ & $\begin{array}{l}\text { In de } 5 \\
\text { jaren } \\
\text { vóóRDAT }\end{array}$ & $\begin{array}{l}\text { in het } \\
\text { AfGELOPEN } \\
\text { Jaar }\end{array}$ \\
\hline $\begin{array}{l}0.0 \text { 1 } \\
2 \cdot 5 \\
6-110 \\
11-15 \\
16-20 \\
\text { metandan } 20\end{array}$ & $\begin{array}{l}\square \\
\square \\
0 \\
0 \\
0 \\
0 \\
0\end{array}$ & $\begin{array}{l}\square \\
\square \\
0 \\
0 \\
\square \\
0\end{array}$ \\
\hline
\end{tabular}




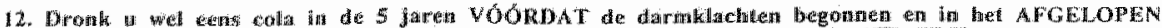

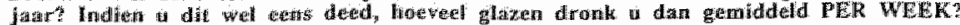

\begin{tabular}{|c|c|c|}
\hline 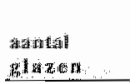 & 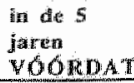 & 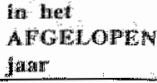 \\
\hline 0 of 1 & 1 & $D$ \\
\hline $2-3$ & 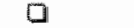 & 9 \\
\hline $0-10$ & 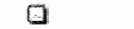 & $\square$ \\
\hline $11 \cdot 15$ & $B$ & II \\
\hline $16-20$ & (I) & 0 \\
\hline meer dan 20 & 1 & 0 \\
\hline
\end{tabular}

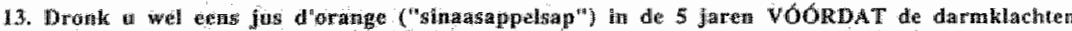

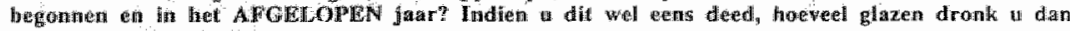
fumäddeld PER WhER?

\begin{tabular}{|c|c|c|}
\hline $\begin{array}{l}\text { gantal } \\
\text { glazen }\end{array}$ & $\begin{array}{l}\text { in de } 5 \\
\text { jarent } \\
\text { VOCRDAT }\end{array}$ & 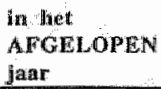 \\
\hline 0 of 1 & 0 & 1 \\
\hline $2-5$ & $\square$ & 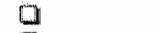 \\
\hline $6 \cdot 10$ & 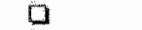 & D \\
\hline $11-15$ & $\square$ & $D$ \\
\hline $16-20$ & DI & a \\
\hline meer dan 20 & 0 & [] \\
\hline
\end{tabular}

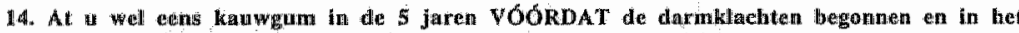

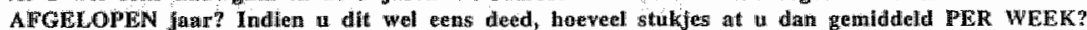

\begin{tabular}{|c|c|c|}
\hline $\begin{array}{l}\text { arantin! } \\
\text { Stukjeg }\end{array}$ & $\begin{array}{l}\text { In de } 5 \\
\text { Jaren } \\
\text { VOORDAT }\end{array}$ & $\begin{array}{l}\text { in linet } \\
\text { AFGELOPEN } \\
\text { Har }\end{array}$ \\
\hline 0 of 1 & $a$ & (1) \\
\hline $2-5$ & $\square$ & 1 \\
\hline $6-10$ & $Q$ & 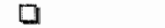 \\
\hline $11 \cdot 15$ & $\square$ & $\square$ \\
\hline $16-20$ & D & $\square$ \\
\hline meer dan 20 & $\square$ & $\square$ \\
\hline
\end{tabular}

15. At u wel wens chocola (repen, marsen e.d.) in de 5 jaren VOORDAT de darmklachten buegonnen en in liet AFGELOPEN jagr? Indien to dit wel eens decd, hoeveel at a er dan gemiddeld PLR WEEK?

\begin{tabular}{|c|c|c|}
\hline aantml & $\begin{array}{l}\text { in de } 5 \\
\text { jaren } \\
\text { vónDAT }\end{array}$ & $\begin{array}{l}\text { An hel } \\
\text { ADGELOPEN } \\
\text { jarr }\end{array}$ \\
\hline 0 of 1 & $\square$ & $\square$ \\
\hline $2 \cdot 5$ & 0 & $\overline{1}$ \\
\hline $6-10$ & $\bar{D}$ & 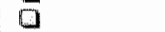 \\
\hline $11-15$ & $\square$ & $\square$ \\
\hline $16 \cdot 20$ & i & $\square$ \\
\hline noer dusis 20 & in & 1 \\
\hline
\end{tabular}

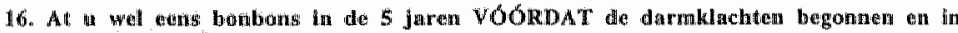

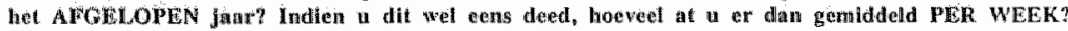

\begin{tabular}{|c|c|c|}
\hline Asutent & $\begin{array}{l}\text { In de } 5 \\
\text { Jaren } \\
\text { YOOLOAT }\end{array}$ & $\begin{array}{l}\text { din lot } \\
\text { AFCRLOPEN } \\
\text { Jate }\end{array}$ \\
\hline 0 of 1 & Q & $\square$ \\
\hline $2 \cdot 5$ & 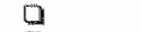 & $\square$ \\
\hline $6-10$ & D & $\square$ \\
\hline$\| 1 \cdot 15$ & $\square$ & $\square$ \\
\hline $16-.20$ & $\square$ & $\square$ \\
\hline mext dat 20 & $\square$ & $\square$ \\
\hline
\end{tabular}




\section{BEROEP}

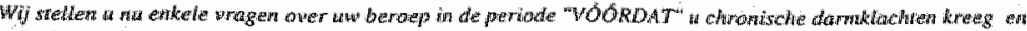

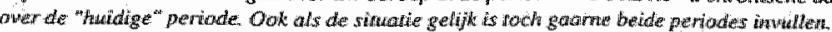

VOORDAT a chronische darmziekte kreeg:

H. Had o betald werk yourdat is chronische darmaiekte kreeg?

10 ja in loondiensu

20 ja, a zellytaridige

$30 \mathrm{ja}_{\text {, }}$ als meverkende in gexinsbedrij

4. D wel orbetaald werk

$5[$ mee -

2. Gal u daaming leding an werkmemers?

10 mee, $h$ geef/gaf gen leiding aan wernemers

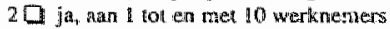

$30 \mathrm{j}$, an 11 tot en met 24 werknemers

40 ja, asn 25 en, meer werknemers

3. Wat was uw beroep?

Het beroep geame ruitm omschrifwen
HUIDIGE situatie:

i. lifect u momented betald werk?

10 in in loondienst

2 [ j,

$3 \mathrm{O}$ ja, als mecwerkende in gezinustredrij?

40 wel onbetaind wert:

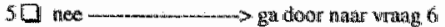

2. Geaft u darbij leiding nan werknemers?

$1 \mathrm{l}$ the, ik geef gean leiding an werkremers

$2 \square \mathrm{ja}$, a an il tot en met 10 werkniemers

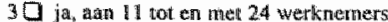

4 (a) aan 25 en mear werknemen

3. Wat is aw huldige heroep?

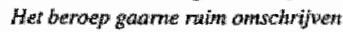

\section{1}

4. Werkte a tofin full-time of part-time?

Full-hinte is 32 wur of meer per week;

Part-bime is minder dan. 32 uir per week

10 full-tine

20: part-time

5. Howeel jaar Had a toen falletime enfof part-time betarild werk gehad?

Full-time is 32 utar of meer per week part-lime is whinder don 32 war per weet

Beide anmoorden invallen indieat van toepasting

I_I fullitime

1 I. I partitime

6. Afs $u$ in het yar voordat uw darmalachtem begonnen geen beroep whoefiende wat was dan op a wan torepassing?

10 was scholier/student

23 werkte in huhstwothden

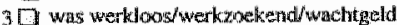

40 was gepensionterd, AOW. AWW VUT

50 . in de $\mathrm{WO}$. AAW

6 W wa in de xhektewt

$7 \square$ averig (bv. dienstphtidhig, vrujwilligerswerk) tw:

7. Wat was het beroep van uw partner? Voor kinderen higer het beroep wan vader bof moedetr

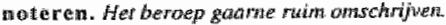

Dit beroep is van: $\mathbb{C}$ partrer

in wadter of mowed
4. Werkt a momented full-time of partitime?

Fuld-time is 32 indr of meer per neek;

Part-tinne üs windter don: 32 war per week

10 fintl-time

20 part-wine

5. Hoeveell jaar heeft u momented full-time en/or part-that betald werk?

Full-time is 32 uw of meer pertweek, Part-tinte ki minder don 32 unr per pweek

Beide antwoorden anwhlen indien wan roepas'sing.

1. I fulltime

1.1_l part-tïme

6. Als momentcell geen beroep witoefont wat is dun op $x$ van toepassing?

1 0 beru scholientstudent

20 werk in huishrouden

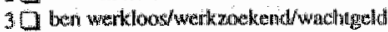

40 ber giepensionerd, AOW,

50 ben in de WAO, AAW

$6[$ bet of de ziektew

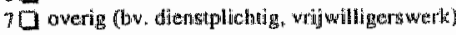
IW.

7. Wat is thet huldige beroep tan uw partner? Voot kinderan hler bet beroep van vader of moed on

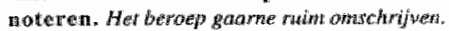

Dit beroep as van: $Q$ pusmer

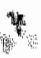




\section{OPLEIDING}

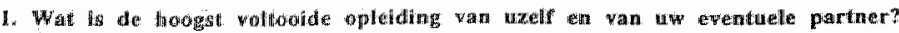

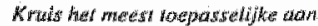

\begin{tabular}{|c|c|c|}
\hline wrelf & pratumer & opletoung: \\
\hline II & II & ILanger algemeen onderwijs: \\
\hline$\square$ & D & 2lager berouponderwijs: \\
\hline
\end{tabular}

basisonderwijs. of een gedeette hierwa

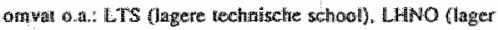

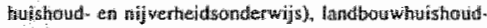

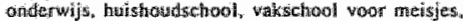
nijuerheidsochool. LEAO, dehailhandes vak )school, lager intatitisch conderwijs; etc.

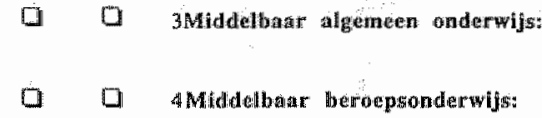

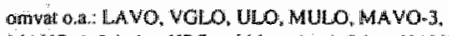
WA YO 4, 3-jarige HBS, middensehool, 3 jaar HAWO

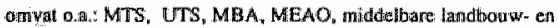
fuinibouwschool, praktijk diploma bowekhouden, ULHWO, MHNO, MSPO, Kliturkweckschooil (opleiding to kleuterleidster),

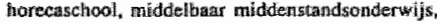
verpleegstersopleiding horlogemakers.vaksethool, NIMA-A. etc.

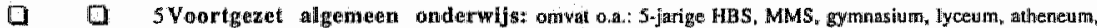
HANO

Q 0 6Hoger beroepsonderwijs:

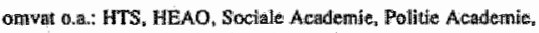
Pedagogische Academile, Kweekschool, hoger kunstondern'ijs, Hogere Zevarartschool, SPD, LO-Akten, HHNO, HSPO, dteriste opleieling, huishoudtiundige, logopedie, mondhygitniste-opleíding. Ieraressen opleiding MO-A, MO C. Hogere Hotelsthool, Hogere Detailamandelsscheol NAMA B.C. Nijenrode, AMBI, ingenteursfase nieuwe: stijl, G.A.II, HBOW akn

D 0 7Hoger algemen onderwijs:

onvat o.A.: kandidatsexamen oude silfjl docioral examen nileuwe sitiol

Q 1 8wetensehappelijk onderwijs:

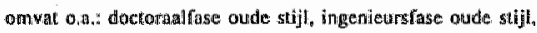
promotie (dr.) NIVRA (slotface), actharis, MO-B, Hogene Krijjgsschool

2. Studetrt wis nof of wolgt a nog een beroepsopleiding?

Dinge

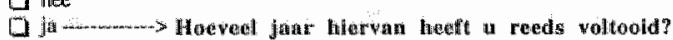

1. J J J 


\section{ZIEKTE / LICHAMELIJKE KLACHTEN EN MEDICIINEN}

1. In well jaar kreeg u de earste darnklachten?

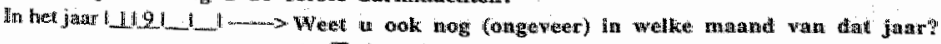

\begin{tabular}{|c|c|}
\hline $\begin{array}{l}\text { of } \square \text { jumuari } \\
02 \square \text { februari } \\
03 \square \text { malart } \\
04 \square \text { april } \\
05 \square \text { mei } \\
06 \square \text { jurni }\end{array}$ & 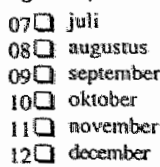 \\
\hline
\end{tabular}

2. In welk jaar bent a hiermee voor het eerst naar de HUISARTS gegaan?

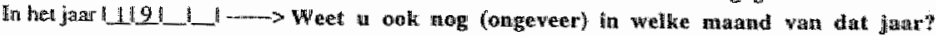
$04 \square$ januaro
$05 \square$ mex
020 frebruari 0.60 juni
$09 \square$ seprember
0301 maart
070 jull
inO oktober
040 april
OB. $\mathrm{D}$ angustus
110 november
120 december

3. lm welk jaar bent $u$ hiermee voor het eerst maar de arts gegaan die de diagnose heeft gesteld (vastscelling wan de atard van die ziekte)?

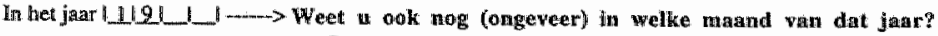
ai $\square$ jantari
$05 \square$ mei
090 september
$02 \square$ febraari
$03 \mathrm{D}$ maar
060 juai
100 oktober
07a juli $\quad 110$ nowember
040 aptil 080 angusturs 120 december

4. In welk jaar is bij a de diagnose ten amzien ran de darmklachten gesteld?

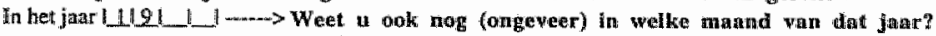

$\begin{array}{lll}01 \square \text { januari } & 050 \text { mei } & 090 \text { september } \\ 02 \square \text { februari } & 06 \square \text { juni } & 100 \text { oktober } \\ 03 \square \text { maat } & 070 \text { juli } & 110 \text { november } \\ 040 \text { apmil } & 080 \text { augustus } & 120 \text { december }\end{array}$

5. Wat was uw gewicht + lengte vö́rởat uw darmkiachten begonmen en in welk jaar was dat? gewicht:

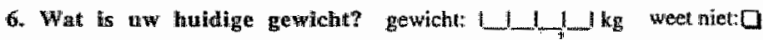

7. Hoeveel welken heeft $w$ het afgelopen jaar niet kunnen werken of niet naar school kunnen gaan i.v.m. darmziekten? 1_t_tweken

8. Heeft de darmziekte we belemmerd in uw oplelding, im uw werk, in uw vrije tijo?

\begin{tabular}{|c|c|c|}
\hline $\begin{array}{l}\text { In apleiding } \\
10 \text { med } \\
2 \square \text { ja } \\
30 \text { gexp thenging }\end{array}$ & $\begin{array}{l}\text { In werk } \\
10 \text { nex } \\
2 \square \text { ja } \\
30 \text { geen mening }\end{array}$ & $\begin{array}{l}\text { In wrije tijd } \\
1 \square \text { inte } \\
2 \square \text { ja } \\
3 \square \text { geer menim }\end{array}$ \\
\hline
\end{tabular}

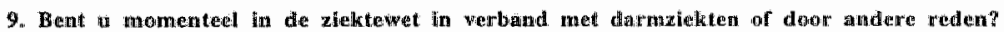
$10 \mathrm{nes}$

20 , in verband met dlarmzivekten

$30 \mathrm{ja}$, door andare reden

10. Bent a monenteell in de WAO in verband met darmziehten of door andere reden?

10 inge

20 ita , in verband meit darmziekcter?

30 jay door andere reden

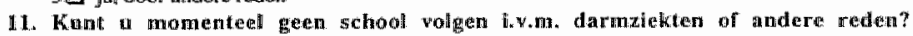

10 noce

$20 \mathrm{j}$, in verband met darmzjekien

$30 \mathrm{jan}$ doom andere reden

40 niet van toepassing 


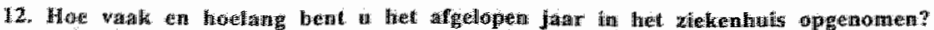

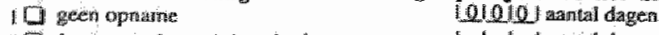

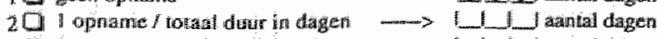

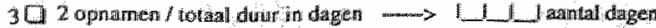

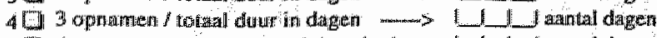

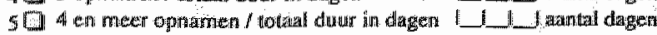

1.3. Bent a geopereerd aich ow blindedarm?

Q1

Q ja H- Hodang is dat geleden?

$$
\begin{aligned}
& \| \square \text { o wh } 4 \text { far } \\
& 205 \mathrm{~m} 14 \mathrm{jarr} \\
& 3[15 \mathrm{um} 24 \text { jas } \\
& 4 \text { प } 25 \text { jaxir en langer }
\end{aligned}
$$

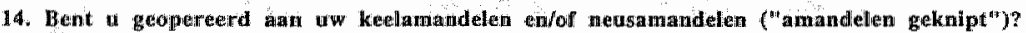

Q1 inee

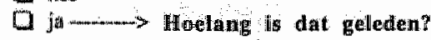

10 o $0 \mathrm{vm} 4 \mathrm{jaur}$

20 t/m 14 jadr

$3 \square 15$ th 24 ja.r.

$4 \square 25$ juar en langer

15. Had o GEWHCHTSKLACHTEN in de 3 manden voordat a de eerste keer een arts ramdpleegre wegens de darmklachten?
10
$2[\mathrm{G}$
3 weet niet

Mu kamen enkete wragen ower zogenande allergische wekten ("owergewatigheids" ziekten)

16. Heeft in als baby alsawworm gethad?

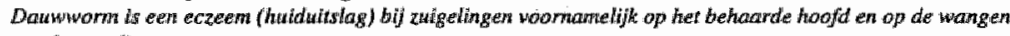
woorkomend)

$$
\begin{aligned}
& 10 \text { nes } \\
& 2 \square \text { ja } \\
& 30 \text { weet niet }
\end{aligned}
$$

17. Heeft u als: kind of op latere leeftidd eczeem gehad (huidnitsiag)?

lo the

$21 \mathrm{j}$ \%

30 nog steeds eczern

40 weet niet

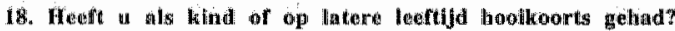

$$
\begin{aligned}
& 1 \text { id nes } \\
& 20 \\
& 30 \text { noy steeds hoo koots } \\
& 40 \text { wet niel }
\end{aligned}
$$

19. Hevi u alsi kind of op latere lectudj asthma gehad?

11 newe

2 ja:

3 Q noy steeds asthman

40 weet miet

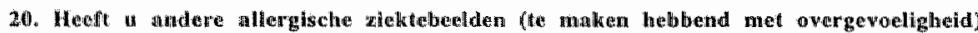
of heeft u dî̀ gehad?

When

O ja, namelijk 
De voligende vragen over "de Pil" / Orale anticonceptie en menopauze alleen door vrouwen beantwoorden.

\section{Pull / Orale anticonceptie en menopauze:}

1. Heeft u de menopauze toreikthent o in de overgang (gewerst)?

प] nee:

D ja, ik tereikte mijn menopauze op mijn ___ lleeftijdsjaar

2. Gebruikt u of heeft u boìt "de pil" (orale anticonceptie) gebruiket?

$\square$ nce, nooir..$- \longrightarrow$ ga naar $\mathbb{R O K E N}$ op de volgende pagim

Q jial $\longrightarrow$ Beantwoond de volgende vfagen:

2a. Gebruikte u de pil op het moment dat de darnziekte word vastgesteld" Q nee

a ja

2b. Was u reeds met die pll gestopt op het moment dat de diarmxielkte werd vastgesteld? Q nee

Q ja

2c. Welk(e) soort(en) gebruikte u in de jarem voorafgaand aan de eerste verschijnselen van tuw darmzlekte?

(Gaame zo preciles mogelijk wemmeiden),

soort:

Q énfise pil (nomnan)

D. exafase pil (mini pil)

D tweefase pil (combinatie pil)

$\square$ driefase pil (combinatie pi)

$\square$ "prikpil" (spuit)

$\square$ weet miet (uneer) welk merk periode

van:

1191_1_119 1.

11191,11911

$1191 \_1121 \ldots$

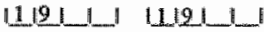

119 1 4189L1

1121_1 1121_1 bij ondertbreking, evemtueel

ze periode vernelden

$1191-4191 \quad 1$

$1191 \ldots$

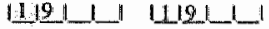

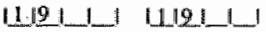

1191_1_.

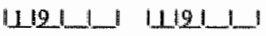

2d. Hoeveel jaar heeft u de pill gebruikt voordat u darmklachten kreeg? 1__ l aantal jaren

2e. Hoeveel jaar heeft u de pal in totaal gebruikt tot nu toe? 1_ laantal jaren 


\section{TOKEN}

1. Weate with weroulat?

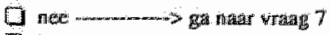

dia

2. Gedurendu swelke periode(n) hedt u gerooki?

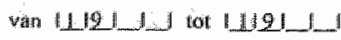

van 1191 . jot 1191,

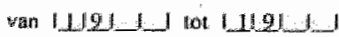

Wan 1121 ind 1019

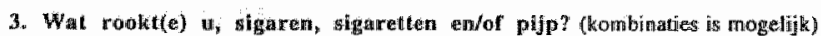

$1[$ sigaran

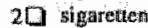

$3[\mathrm{Dip}$

4. Rookt u nog steeds?

Q net_- Ha Hoved Jaren heefit u gerwolkt?

D ja $\rightarrow-\infty>$ ga naar vaag 5

4b. In welk Jaar bent defintitief gestopt met roken?

In $11 \mid 91$. I

GA NAAR VRAAG 6

5. Hoevel rookt a ana sigareften, pijp enfor sigaren?

Sitgaterten:

15 geen

Pijptabakt

Sigaren:

$200-9$ per diag

1 प geen

10

$3 \square 10-19$ per dag

20 minder dan 50 gram per week 20 minder dan 5 per week

4 प $20-39$ per dag

30 meer dan 50 gram per weelk. $3[1$ meer dary 5 per weelk:

5 Q 40 en meer per dag

6. Hoeveel rookte $u$ geniddeld in de tien Jaar voorafgaand an uw eerste darmklachten aan sigaretten, pijp en/of sigaren?

Sigaretten: Pijptabalk:

10 geen 10 geen

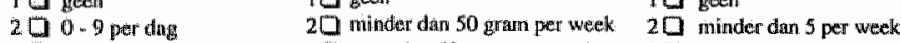

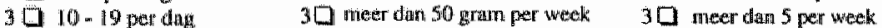

401.39 pier dag

50140 an mer par dag.

7. Howed personon lin ww gexin rookten dagelijks in de jaren voorafgaand an uw darmatekte?

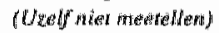

$1 \mathrm{l}$ peen

20 oen

3 니 twe of anee

8. Vorllowefde u dagelijks in en rokerige orngeving (in nw gezin of op ww werkpluk) in de jaren

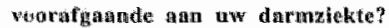

Til nes

Qil jo 


\section{ALGEMENE VRAGEN BETREFFENDE DARMZIEKTE}

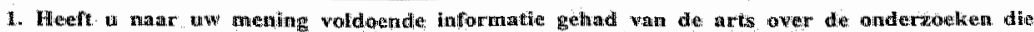
uittgevoerd werdem om een digmose the stellen over uw darmiklachiten?

10 ree

212 jia

30 gen mening

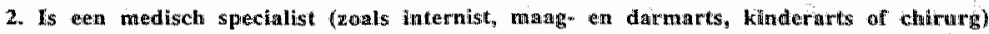

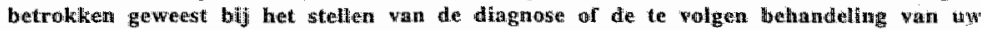
darroklachten?

$1 \square$ neer.

20 ja

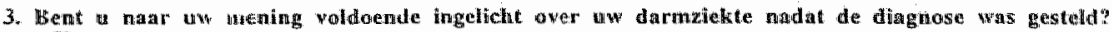
10 nee

$2[1$ ja

3 Geen mening

4. Heeft it vragen over de onderwerpen: voedimg, medikatie, ziloktebeeld, emotionele ververking. patientenvereniging en zojia, van wie denkt u darbbif nuttige Informatie te kunnen krifgen?

(twoeer antwoarden whogelijk)

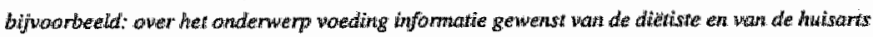

anderwerpen: nee ja-mzoja, informalie gewenst wan:

woeditig $\quad 0$ III

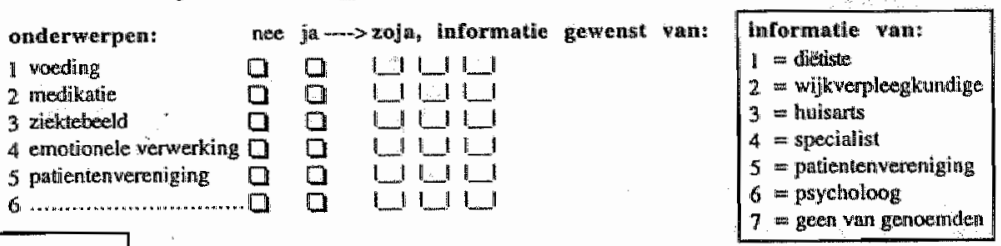

\section{OPVANG}

1. Voelde a zich serieus genomen met betrekking tot un klachten VOGRDAT de diagnose chronische darmajekte werd gesteld? (meer arimoondent mogelijk)
1. mee
$\rightarrow$ met mame nilet door: 10 arts
20 ja
$2 \square$ partine
3. 1 gen theming
$3 \square$ overige familie
$4 \square$ op thet werk

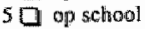

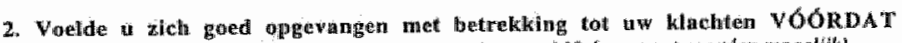

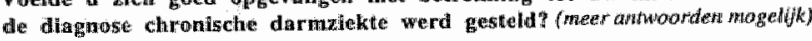

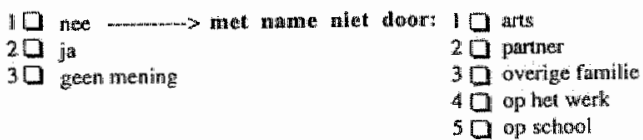

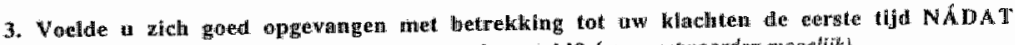

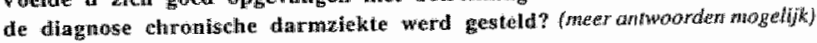

Iiti nese

10 ans

$2 \square$

2 Dartiner

30 geen met the

3 G overige damilic

4 ap hell werk

50 ap school 


\section{OVERIG}

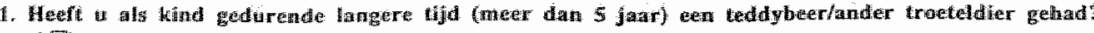
1 Dies

2 j.

$3 \mathrm{D}$ weet wiet

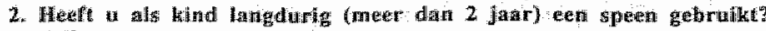

10 new

20 ja

3 in weth nitel

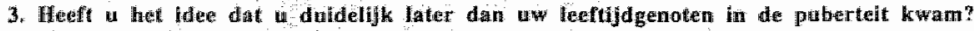

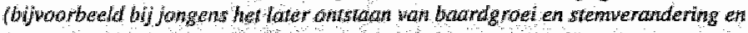

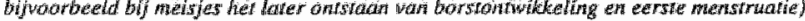

10 mate

20 jầ

$3[\mathrm{dj}$ weet niet

4. Heetit a cen sinstgebit (prothese)?

On noe

II ja Minds welk jaar?

sirids 1.1211

5. Hotvel amalgam-qullingen (grijze) heeft u in ur webit? L_L l l a atantal Q weet nivet

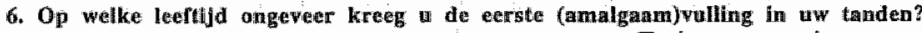
Toen ik 1 l. J jaar ond was. $\quad \mathrm{a}$ weet niet $\mathrm{a}$ niet van toepassing

7. Hoe vak poetste $\mathrm{a}$ w tanden met tandpasta he 5 jaren VOORDAT de darmklachten begonnen en in het AFGELOPEN jaar?

\begin{tabular}{|c|c|c|c|}
\hline & $\begin{array}{l}\text { de } 5 \\
\text { en } \\
6 \mathrm{RDAT}\end{array}$ & \multicolumn{2}{|c|}{ 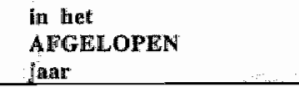 } \\
\hline 010 & meer dan 3 ketr per dag & $01 \square$ & meer dan 3 keer per dag \\
\hline $02 \square$ & $3 \times$ per dag & $02 \square$ & $3 \times$ per daug \\
\hline $03 \square$ & $2.3 \times$ per dag & $03 \square$ & $2-3 x$ per dag \\
\hline 040 & 2 xper dag & $04 \square$ & $2 \times$ par dag \\
\hline os $\mathrm{C}$ & $1-2 x$ per dag & $05 \square$ & $1-2 x$ per dag \\
\hline 060 & X perd dag & $06 \mathbb{1}$ & I. $x$ per dag \\
\hline $07 \square$ & 5 - $6 \times$ per wreetk. & 070 & $5-6 \times$ per week \\
\hline $08 \square$ & $2 \cdots 4 \times$ per week & $08 \square$ & $2-4 \times$ per week \\
\hline $09 \square$ & minder disn $1 \times$ per & 090 & minder dan $1 x$ per week \\
\hline $10 \square$ & nowit: & 100 & noriant. \\
\hline
\end{tabular}

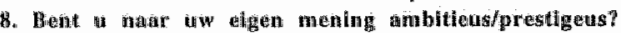

1. Thes nes

20

30 geen menting

9. Ondervond a lin de jaren woorafgatand an de exste klachten van ww darmzlekte

veel psychische satress bij hot witoefenen wan ure buep of het volgen van

cen oplotiding?

10 the

21 j.

30 geen unething

40 miet vin toepassing

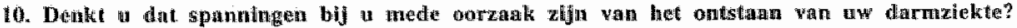

10 nee
$2 \square$ ja
$3 \square$ geen meming 
1.1. Hoe vindt w over het algemeen ww gezondheld?
10 xeer stecth
$2 \square$ sllecht

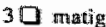
4 Dil grod
$5 \mathrm{DI}$ zeer goed

12. Heeft de ziekte th betemmerd in de relatia met uw levenspgrtner?

10 nee

$21 \mathrm{ja}$

$3 \square$ green mering

4 niet van toepassing

\section{KWALITEIT VAN LEVEN}

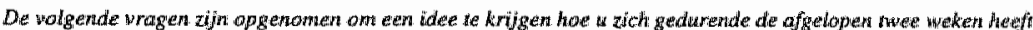

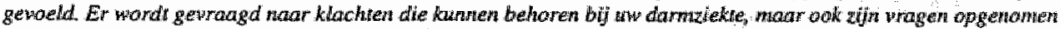

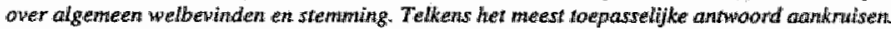

1. Hoe vank heeft $u$ in de afgelopen twee weken ontlasting gelyad in vergelijking meteen rustige fage vala uw darmziekte?

1 ontlasting valker dan ooit

20 extrerem watk

30 erg vask

$4 \square$ matige verhoging in vergelijking met rustige fase

50 enige verhoging in vergelijking met rustige fase

60 lichte verhoging in wergeliyking met rustige fage

70 geen werhioging van aantail malen ontlasting

\begin{tabular}{|c|c|c|c|c|c|c|}
\hline $\begin{array}{l}\text { de hele: } \\
\text { Gijd }\end{array}$ & $\begin{array}{l}\text { growtisite } \\
\text { deet wan } \\
\text { de tijd }\end{array}$ & $\begin{array}{l}\text { een grool } \\
\text { deet villi } \\
\text { de tijd: }\end{array}$ & $\begin{array}{l}\text { een matig } \\
\text { deel van } \\
\text { de tijol }\end{array}$ & $\begin{array}{l}\text { en kllein } \\
\text { deel wan } \\
\text { de tijd }\end{array}$ & $\begin{array}{l}\text { bifina geera: } \\
\text { doel vea de } \\
\text { tijd }\end{array}$ & $\begin{array}{l}\text { helemand } \\
\text { nier }\end{array}$ \\
\hline
\end{tabular}

2. Hoe waak was moeheid of het gevoel "uitgeblust to zijn $n^{\text {"4 }}$ de afgelopen twee welken voor u een probleem?

3. Ho waak was u de afgelopen twee weken gefinstreerd, ongeduidig of rusteloos?

4. Hoe wakk heeft u de afgelopen twee weken school moeten missen of wij moeren nemen val uw werk als gevoldg yan darmprotlemen?

5. Hoe watk heeft u de afgelopen twee weken dunne ontlasting yehad?

6. How wath bent u iri de afgelopen twee weken ongerust geweest ower een eventueel noodzakelijke operatie voor uw darmilekte?

7. Hoe valk heeft $u$ die afgelopen thwee weken een afsprat moeten alleggen of witstellen in werband met uw Garmziekte?

8. Hoe valak hestit u de afgelopen twee weken last gehad van buikknangen?

(1)

2

3

3

4

5

6

7

.




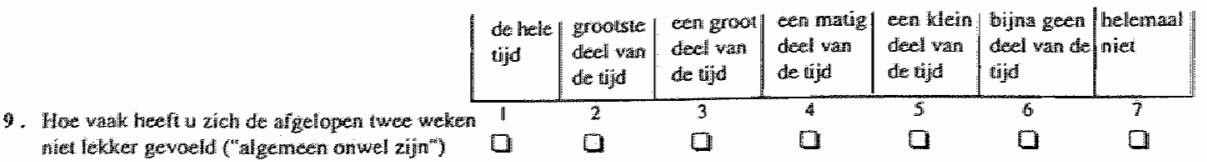

10. How wak heeff u sich de sifgelopen wwe weken

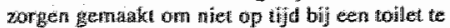

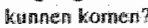

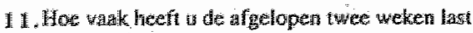

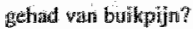

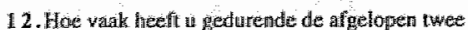
weken problerren gelliad wen goede nachurust te krijgen of werd tu "s nachils steeds wakker?

13. Hoe walk woulde un zich de afgetopen twee weken depressitef of teruergeslagen?

14. Hoc wadk heeft u de afgelopen twe weken gelegenheden vernieden warvan w niet zeker wist dat er ecin tollet in die buturt was?

15. How wable heef tu gedurende de afgelopen twee weken lasth gelnad wan windengheid?

1. 6.Hoc waik heeft w zicly de afgelopen twee weken zorgen gemaktikt over her behouden of verkrijgen van het gewolcht dat u nastreeft?

17. Veel palienten mett chnonische darmziekte maken zich wask zargen of hebben angsten die te raken hebben met hun ziekte. Onder andene zorgen om kanker ve krijgen ${ }_{n}$ zich nooll beter te voelen en angsten otn weer veel last van hun darmziekte te krijgen. Hos walk heeft if dergelijke zorgen gehad gedurende de affgelopen twoe weken?

18 . Hoe wark heeft u gedurende de afgelopen twee weken last gellad wan een opgeblazen gevoel?

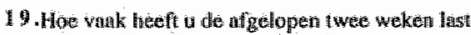
gethat wain bloced werlieg boh de onthasting?

2. 0. Hoo wath heeft th theth gedurende de afgelopen whes weken opgentaten gerould door uw ditmprobtem?

2. Howe writk hefeft a de afgelloper twee weken bet gevol gehadi dat u mara to tollet moest gaan watubij dan exinter geen onthasting howan?

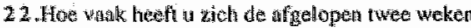

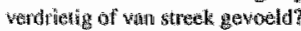

23. Hoe wak heaft tioh de afgelopen twee waken kwaind gnantakt warwwige uw darmziekte? 


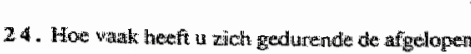
rwer yrekten dioodziek gevonlid?

25. Hoe vatk was is gedurende de afgeliopen twee weken geinitend?

26. Mored energic had $\mathbf{n}$ de afgelopen twe weken?

III rowal geen anergite

20 heel arg weinig energie

$3 \square$ weinig energie

$4 \square$ enige entergie

50 matige hoewedtheid energie

6: 1 weel energie

70 zeer ved energie

27. Hoeveel moeite heef het w de afgelopen twee weken gethost, door uw darmproblamen, om lijd te bestieden nary ontspaminitag of sport?

10 zeer weel moente, ontspanning en sport wanen niet mogeligh

20 veel moeite

30 best wal moetre

$4 \square$ enige moeite

50 weinig moeite

60 praktisch geen moeite

$7 \mathrm{a}$ helemal geen moeite, geen beperking wan sport/ontspinning door danmpmoblemen

28. Hoe vaak heeft in zich gedurende de afgelopen twe weken relaxed en ontspanneri gewoeld?

DI nocil

20 Wein deel van the tiynd

30 enig deel var de tijd

40 en matig derel valt de tijd

50 grobiste boel van de tijel

$6 \square$ bijna de hele tijd

70 de helle tijd

29. Hoe groot was het probleem voor a gedurende de afgelopen twee wahen dat per ongeluk wat anthisting werd verloren?

10 een ernstig probleem

$2 \square$ cen belangrijk probleem

$3 \square$ een makig probleem

4 i enige last

5.1. Weing last

6 bijna geen las

7 ity geen last

30. In welke mate hebben tuw dartoprobleen gedurende de afgelopes twee weken ertoe bigedragen dat er een beperking was in thw sextuele leven?

10 geen sexule activitieit door dirmproblemen

20 zeer grote teperking door darmproblemen

30 grone beperking door diamproblemery

40 matige beperking door damiprobtemen

5 Lil enige beperking dow darmproblemen

$6 \mathrm{DI}$ matawelijks beperking door dariporoblemen

$7 \square$ geen beperking door darmproblemen 


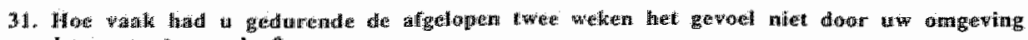
bugrepen the wordon?

10 de hele tijd

201 bilina die thelle fijl

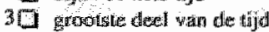

40 een matig deel war de ilijo

50 enig deel virn de tijd

69 een klein det wan de tijjod

$7 \mathrm{~g}$ nogit

32. Hoe tevreden, gollukig of zelfwoldan was u gedurende de afgelopen twee weken met azelf? 10 zeer ontevreden, grootsite deell wan de tijo ongellakikig

2.10 ower het oflow

3 Ojefs nntewreden, angel tikkig

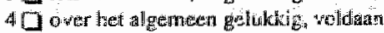

510 teveden, meetste doel var de dijd gellukkig

60 zeer tewrieden "meste deel wan de ijjd gellukkig

70 extreen the wreden, kon niet getuldiger of neer voldan zijm

FARTELIJK DANK VOOR UW MEDEWERKING

Opmerkingen: 
Appendix 3 


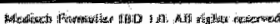

\section{MEDISCH FORMULIER}

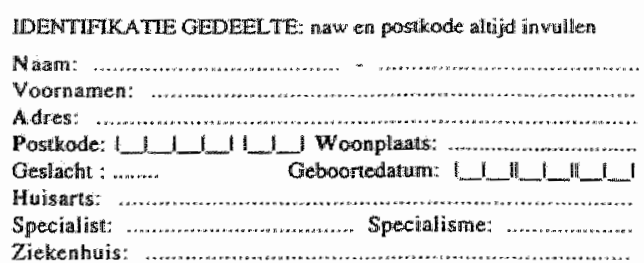

KODER NGEN: KOLODEXMEDEWER KER

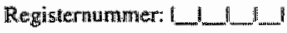

Registern:ummer:

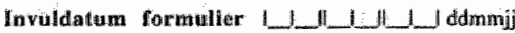

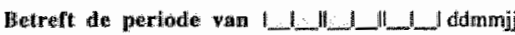

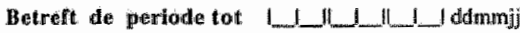

\section{STATUS DN HOD-REGISTER INVULLEN DOOR ONDERZOEKER}

1. Is de pattent in de affgelopen periode overteden?

1 I nee

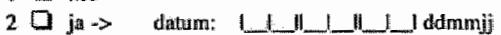

oorsinid:

2. Ig de pathënt in de afgellopen perbode verbuisd naar buitein de regio?

10 mee

2 - ja $\rightarrow$ nieuwe relevante gegevens

wernatdery in het ldentifikatie gedeelte

3. Wh ole pationat in de afigelopen pertode vit behamdeling gogaan vam de sanmeldende arts behalve alls geviolg พtan overluden?

10 mee

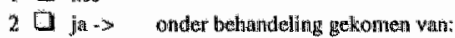
(vernelden in idemtifikatie grodedte)

1 (andere) huisants

$2 \square$ ecn speciatist buiten de rey lio

3 i] sperialisf binnen de regio
Alleen invullen handien idientifkatie gedeelte is ingevold

Woonplats:

Geslacht:

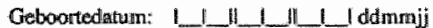

Huisarts:

Specialise: $\quad 1 / 1 \ldots$

Specitalisme:

Ziekenhuiskode: 1_____

Doodsoorzank: I I I IICD 9

Dor hoofdonderzocker in te vullien

Di speciale attentis: voor hoofdonderzoker

O door hoofalonderzoner gezien 


\section{ZIEKENUUISOPNAMEN}

1. Opnameperiode(n) in jekenhuis gerelateerd an chronische darnzifekte gedurewde te half jmar ma le konsult?

10 rxe

$2 \square \mathrm{ja} \rightarrow$ opnamedatum on

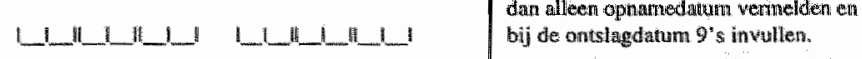

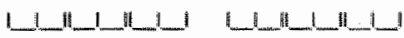

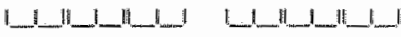

9 onbekend

\section{ANAMNESE}

1. Duur wan de klachten voorafgand aan 18 konsult?

I_L_ aartal maanden $9 \square$ onbekend

Vragen 2 tot em met 6 gaan over de 3 manden yoorafgandid aan le konsult

\begin{tabular}{|c|c|c|c|c|c|}
\hline 2. Frequeatic delaecatie & $\begin{array}{ll}1 & 0 \\
2 & \square \\
3 & \square \\
4 & \square \\
9 & 0\end{array}$ & $\begin{array}{l}<1 \text { mial per dag } \\
1 \text { t/m } 3 \text { manl per dag } \\
4 \text { t/m } 7 \text { moal per dag } \\
>8 \text { mal per dag } \\
\text { onbekend }\end{array}$ & Consistentie & $\begin{array}{l}10 \\
20 \\
30 \\
90\end{array}$ & $\begin{array}{l}\text { nominal } \\
\text { brijig } \\
\text { waterigg } \\
\text { onblekend }\end{array}$ \\
\hline Bloedbijmengling & $\begin{array}{ll}1 & \square \\
2 & \square \\
9 & 0\end{array}$ & $\begin{array}{l}\text { nee } \\
\text { ja } \\
\text { onbekefend }\end{array}$ & sijjobljmenging & $\begin{array}{l}10 \\
20 \\
9\end{array}$ & $\begin{array}{l}\text { noe } \\
\text { ja } \\
\text { onbekend }\end{array}$ \\
\hline
\end{tabular}

\section{Buikpijn?}
10 mex

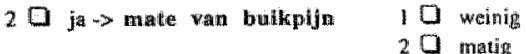
30 etristig
9 anbekend

Lokalisatie builkpijn i

(meer antwoorden magelijk) 20 mecher onder quatiant

3 . linker onder quadrant

40 rechier boven quadrant

\author{
Type bulkpijn i $\mathrm{Q}$ intemitterend \\ 20 konthtu wanwezig \\ 90 onbakend \\ 5 linker bowen quadraint \\ 60 centrat \\ 9 Q onbekend
}


4. Gewichts:s rerlies?
1 [ riec
2.
$101 \mathrm{~km} 2 \mathrm{~kg}$
2. $3 \mathrm{wm} 5 \mathrm{~kg}$
$3 \square 6 \mathrm{k} / \mathrm{m} 9 \mathrm{~kg}$
4. $210 \mathrm{~kg}$

\section{0 ontrekent}

5. Koorts? (> 38 graden $\mathrm{C}$ )

6. Moelnetd?
10 ate
2 (I) ja
$9 \mathrm{D}$ nombekend

$$
\begin{aligned}
& 1 \square \text { nex } \\
& 2 \square \text { jat } \\
& 9 \square \text { onlibekend: }
\end{aligned}
$$

\section{Vragen 7 tot en met 10 bestrijken de hele levensperiode tot 6 malandem ma het le konsult}

7. Is ondersta and ziektebeeld(eni) aanwexig en/of inakt deze deel ult wan woorgesichiedenits?

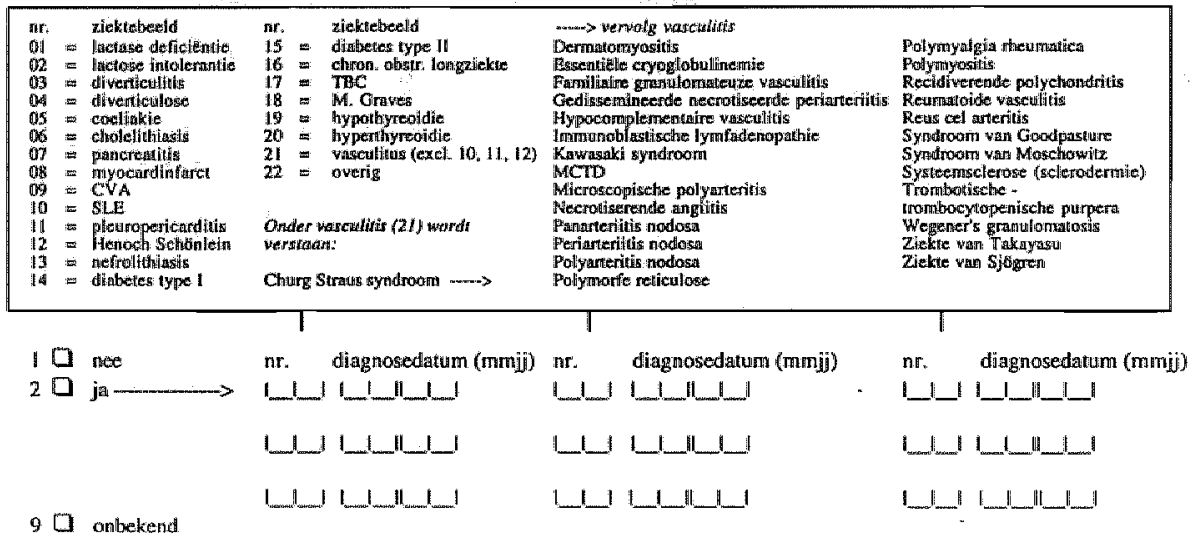

8. Is en appendectomile verricht?

10

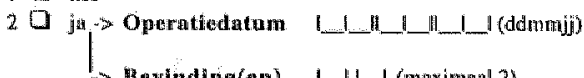
$\rightarrow$ Hevinding (on) L_L I I (maximinal 2)

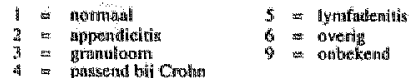

90 anbekend 
9. Is er malliguiteit van het meagdarmbanaal vastigesteld?

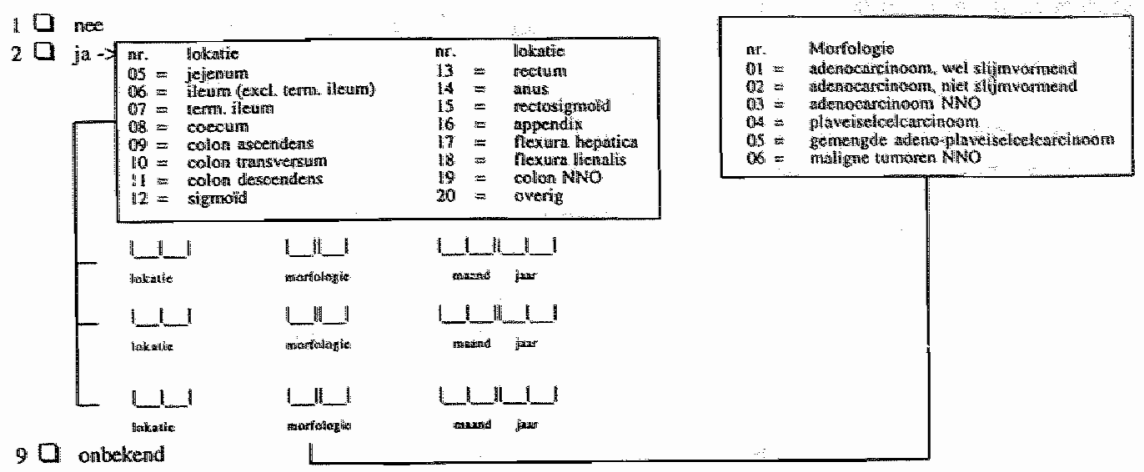

10. Malignitelt (niet onder viragg 9 vermelld) met diagnosedatum?

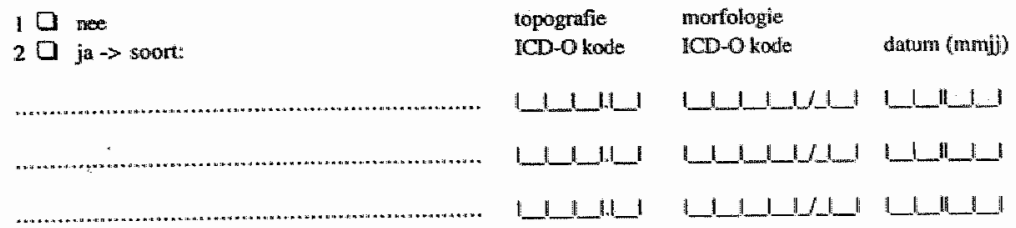

$9 \square$ onbekend

\section{LICHAMELUK ONDERZOEK BU EERSTE KONSULT}
1. Gewicht: 1_L_L lafronden op hele $\mathrm{kg}$
9 onbekend
Lengte: 1_L 1 cm
9 onbekend

2. Distensfie buik?

10 mex

$2 \mathbb{0 j a}$

9 o onbekend

3. Perianalle afwijkingen?

90 mbekend 
4. Aftudfulugen in die mond?

$$
\begin{aligned}
& 10 \text { mee } \\
& 2 \mathrm{~g} a \rightarrow 0 \text { affen } \\
& 2 \text { alcusulcen } \\
& 30 \text { glosistus }
\end{aligned}
$$

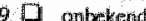

5. Bullkpaluatio pilgnidk?
14 政e

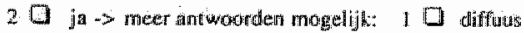
2 II recther onder quadran
4 DI rechicer boven quadrant
5 (I) linker bowera quadrant
$6 \square$ centraal

90 onbekend

6. Palpabele abdominale massa?
1 Gile
2 प jo
9 [ $]$ or bekend

7. Acute buik?
1. 9 nee
2 ए
9 II ontuekend 


\section{LABORATORIUM ONDERZOER}

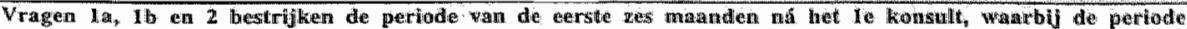
lets ruimer mag womdien genomen naar de huisartsperiode toe,

la Bloedbepaling Wintseh-chemisch/haematologisch

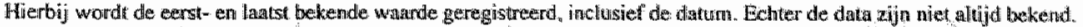

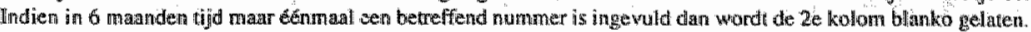
nr. bloedbepaling eerste warde
datum (min) laatste watarde
distum

$01=$ BSE (mm eerste utr)

$1+1$

1.1 I

1_LIIII

\#

$02=\mathrm{CRP}(\mathrm{U} / \mathrm{L})$

L_L_L

1

$1+1$

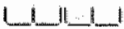

$03=\mathrm{Hb}(\mathrm{mmal} / \mathrm{l})$

LI.1. I

L_L_H_LI

$1+1$ - I

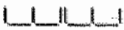

$04=\mathrm{HI}$

LI. I I I

1 I_III_I I

I. H. III

11111

$05=$ trombacyteru $(\mathrm{G} / \mathrm{N})$

L L L L I I

$1+11+1$

1.LLLI I

$1+11+1$

$06=$ kreatine $(\mu \mathrm{mot} / \mathrm{l})$

$1+1$

LL_LILL

I_L I L I I

L LIII I I

\#

$07=$ ureum (mmol)

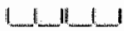

$1+1.1$

1.1. I I I I

*

08 = cholesterol $(\mathrm{mmol} / \mathrm{m})$

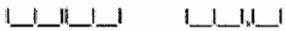

I. III I I I I

$09=\operatorname{ASAT}(\mathrm{U} / \mathrm{l})$

L.1.1.

$1 \div 11+1$

1111

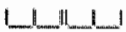

$10=\operatorname{ALAT}(\mathrm{U} / 1$

I.

1 II 1

$1.1+1$

I I I I I

$11=\mathrm{AF}$ (Un)

1L_L1

1._._.

$1+1$

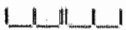

$12=\pi(U)$

LLLLLLI

|_LII_-1

$1+1+1$

I_III_I

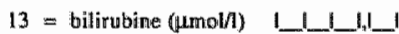

I_II__ I I I I III

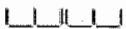

$14=$ total eiwit $(\mathrm{g} / \mathrm{l})$

1.1_L_. I I

I_IIII

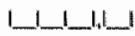

1.11日1-1

is $z$ albumine $(\mathrm{g} / \mathrm{l})$

1 In I I I I I I

$1 \quad 1 \quad$ In 1

I. 1 : U I I

L_III I

in $16=\operatorname{MCV}(\mathrm{ff})$

$1+1$

$1+34$

$1+1$

$1,1.1$

$17=$ ferritine $(n g h d)$

1_1_ 1

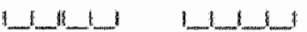

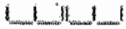

$18=F E$ (umol)

$1+1$

1 1. 1

L I I - 1

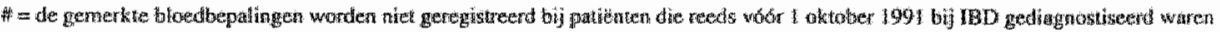


I1 Mrodtepalin serologisich

\begin{tabular}{|c|c|c|c|}
\hline \\
\hline nie. & bi oued bepaling & utsilat & 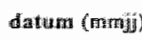 \\
\hline 1 & $=$ yens ana & 1 & LIf I I \\
\hline 2 & $=$ olowridum & $\ldots$ & $1 \ldots 11 \ldots 1$ \\
\hline 3 & $=$ sarmonellar (Widtall) & 11 & H_L_ I I \\
\hline 4 & $=$ entumoebra histolyca & 1 & $1.11 \leq 1$ \\
\hline 5 & $=$ overig: & 1 & 1 \\
\hline
\end{tabular}

2. Mierobiologienti onderzotk

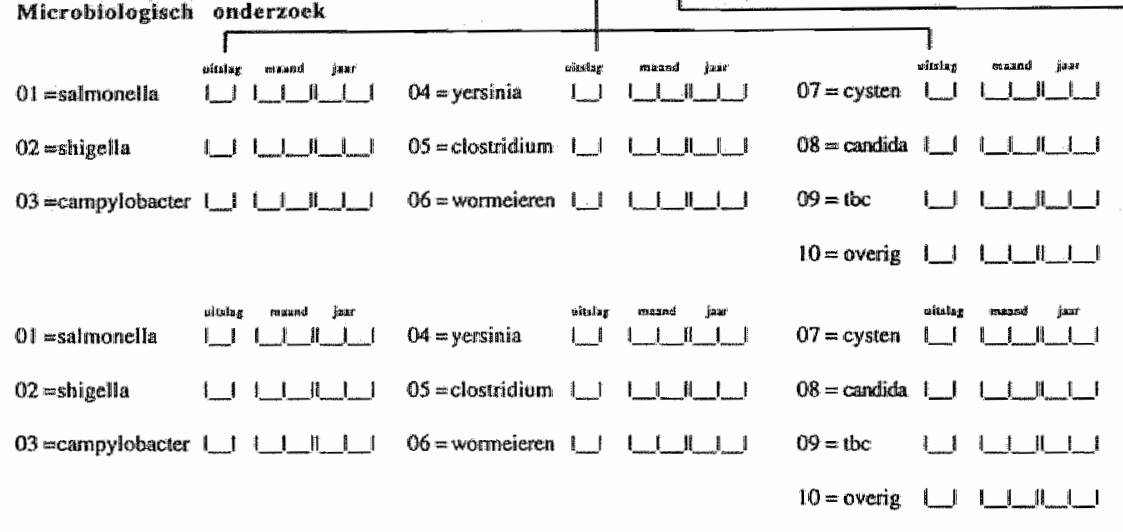
OI $=$ salmonella

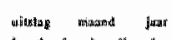
$04=$ yersinia
$07=$ cyster
$02=$ shigella

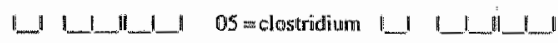
$08=$ candida

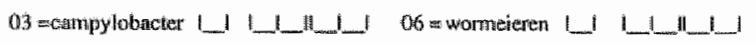

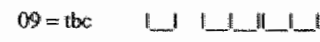

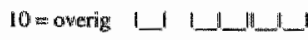

3. Deve vraag is verwallen. 
AANVULLEND ONDERZOEK Vragen I toll en met 3 bestrijken het eerste haif jaar miti fuet lo konswith

1. Welke onderzoeken werden uitgevoerd?

\begin{tabular}{|c|c|c|c|c|c|c|}
\hline \multirow{2}{*}{ 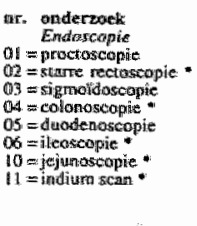 } & $\begin{array}{l}\text { nir. } \\
12= \\
13= \\
14= \\
15= \\
16=\end{array}$ & \multirow{2}{*}{ 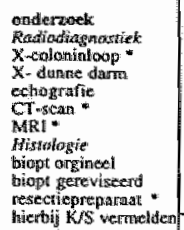 } & & & \multicolumn{2}{|c|}{ 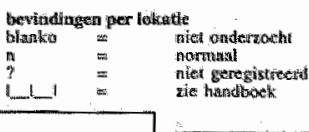 } \\
\hline & $\begin{array}{l}16= \\
21= \\
22= \\
23= \\
=\end{array}$ & & $\begin{array}{l}\text { KKS } \\
1 \\
2 \\
3 \\
3 \\
\text { antantano }\end{array}$ & $\begin{array}{l}= \\
= \\
= \\
=\end{array}$ & 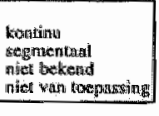 & \\
\hline
\end{tabular}

A

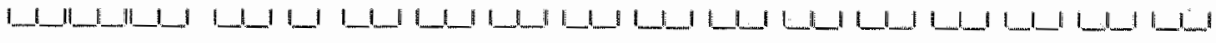

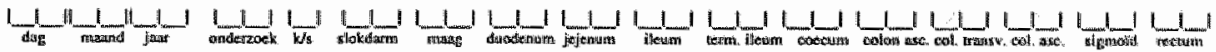

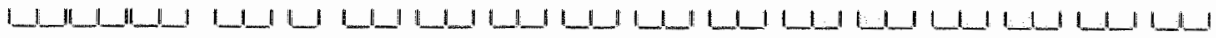

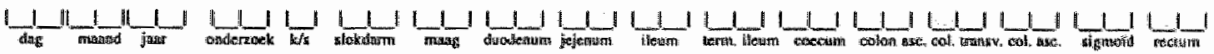

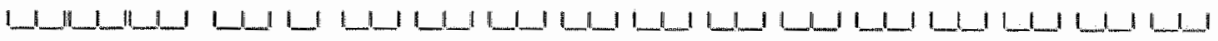

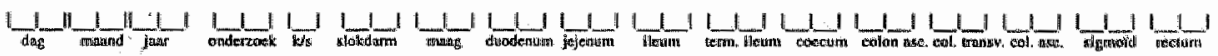

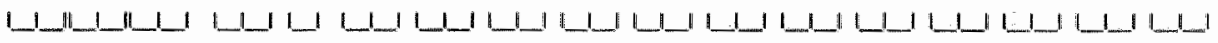

dag

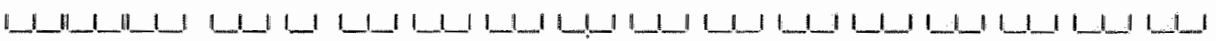

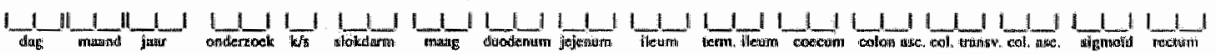

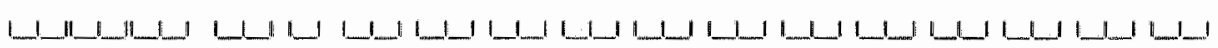

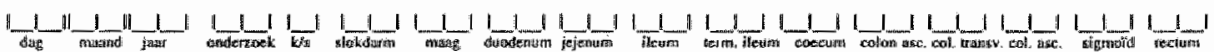

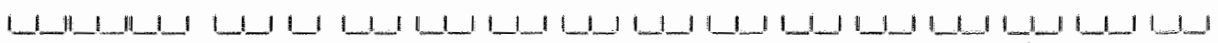

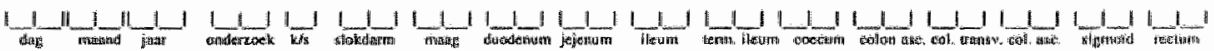

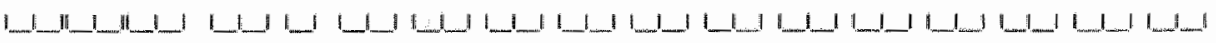

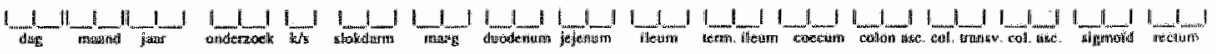
1___a 
2. Lokalisathe ontsteking?

Interpretatie na alle onderzodken ower. fiet lastste hall jaar wan registratie

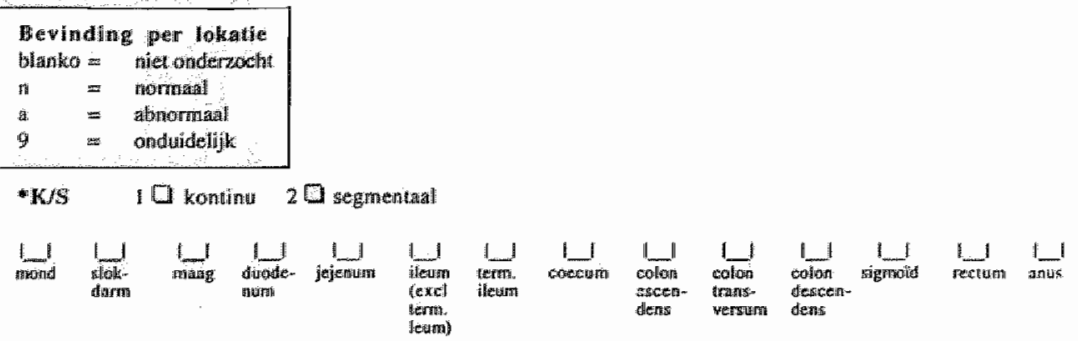

3. Welke diagnose werd dooir ondergenioemde personem gesteld?
$01=$ meker Colitis Ulcerosa
06 - Aspecifieke (onbepanalde) Colitis
$02=$ warschijnilijk Colitis: Ullcerasa
$07=$ onduidelijk
$03 \approx$ Chronissehe Proctitis
$08=$ nomal
$04=$ zeker Morbus Crohn
$09:=$ owerig
OS = waarschijnilijk Morbus Crohn
$99=$ niet ingevuld

Rendlowicopist
Radioloog
Ratholloog

\section{EXTRAINTESTUNALE BEVINDINGEN}

\section{Vragen 1 en 2 bestrijken de hele levensperiode tot 6 . maanden ná het le konsult}

\section{Ia Hepatobilaire diagnostiek verriclat?}

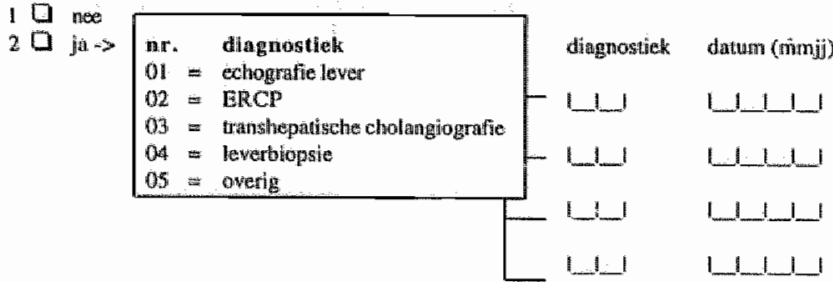

9) 0 onbekend 


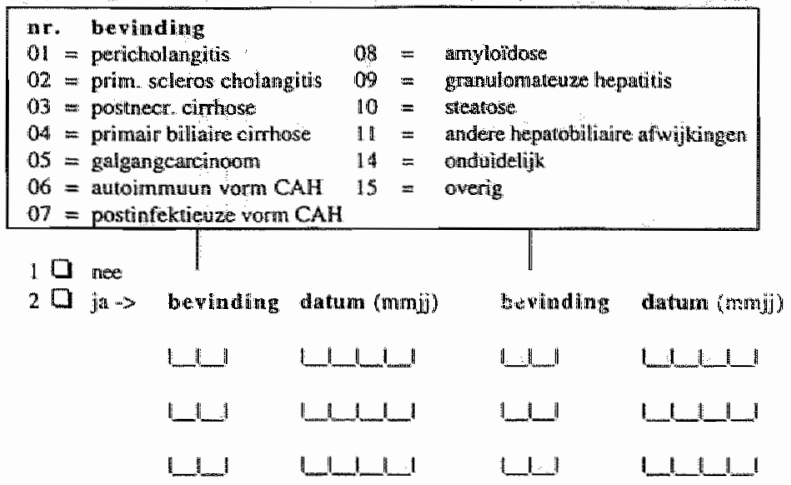

9 $\mathrm{O}$ ontbekend

2. Zijn er andere berindingen met diagaosedatum?

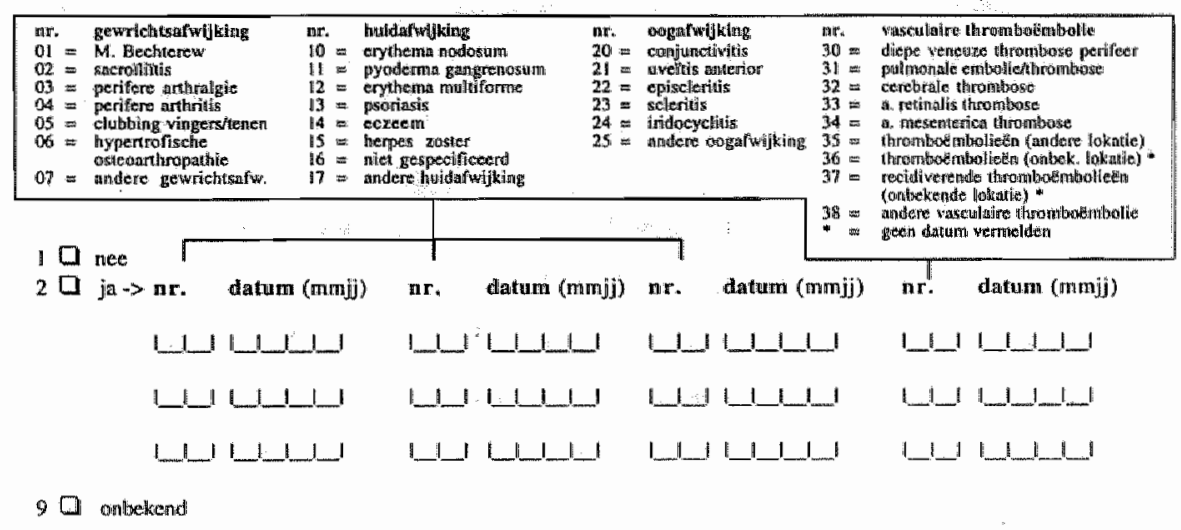




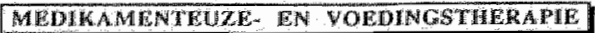

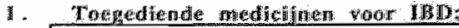

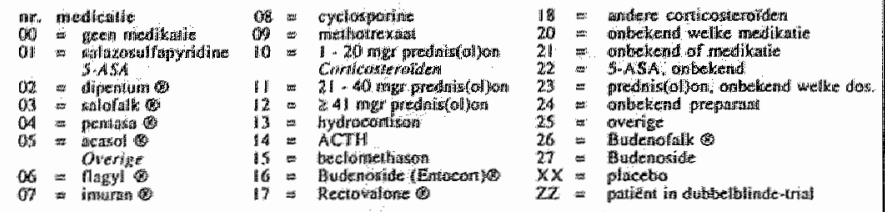

\begin{tabular}{|c|c|}
\hline $\begin{array}{l}\text { Tioudie } \\
1= \\
y= \\
3= \\
3= \\
= \\
y= \\
=\end{array}$ & 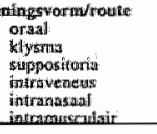 \\
\hline $\begin{array}{l}\text { Data } \\
\text { uhog }= \\
\text { ait }= \\
9=\end{array}$ & 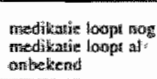 \\
\hline
\end{tabular}

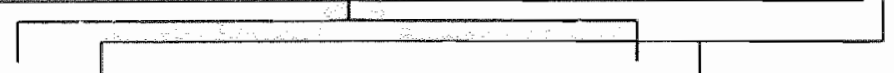

artakend

01121

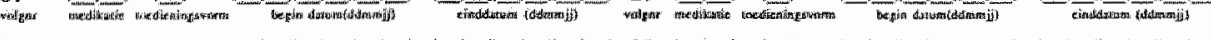

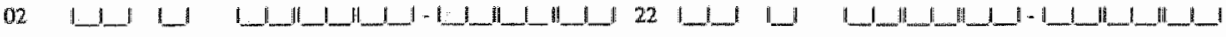

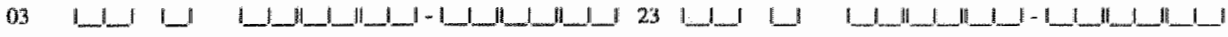

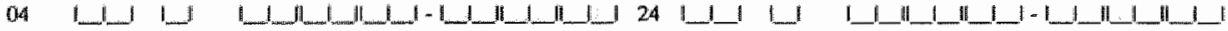

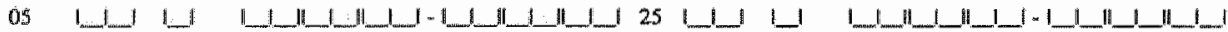

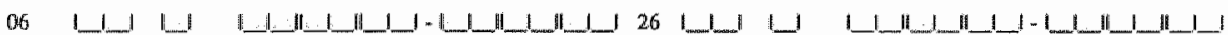

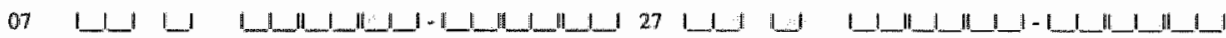

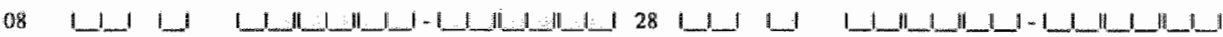

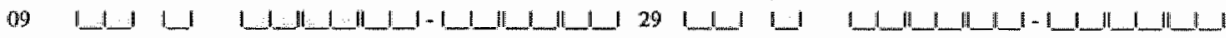

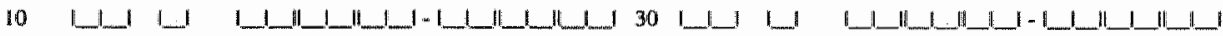

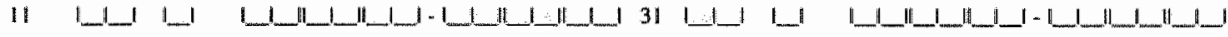

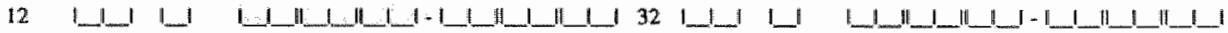

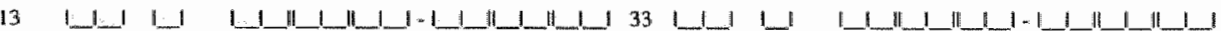

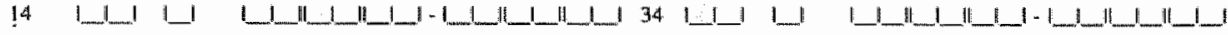

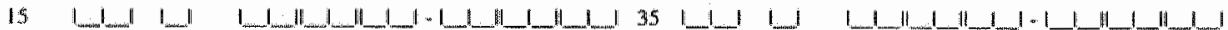

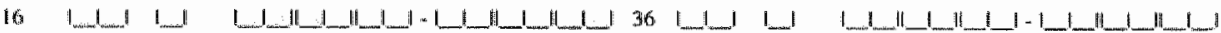

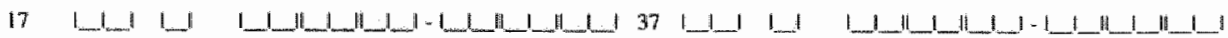

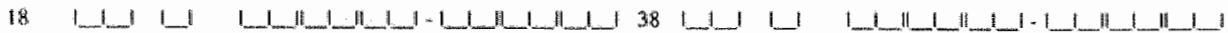

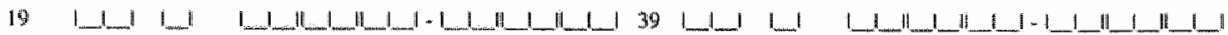

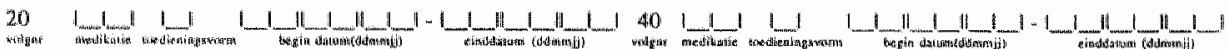

Aantal extra ingevulde taden I_L 


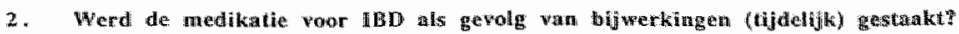

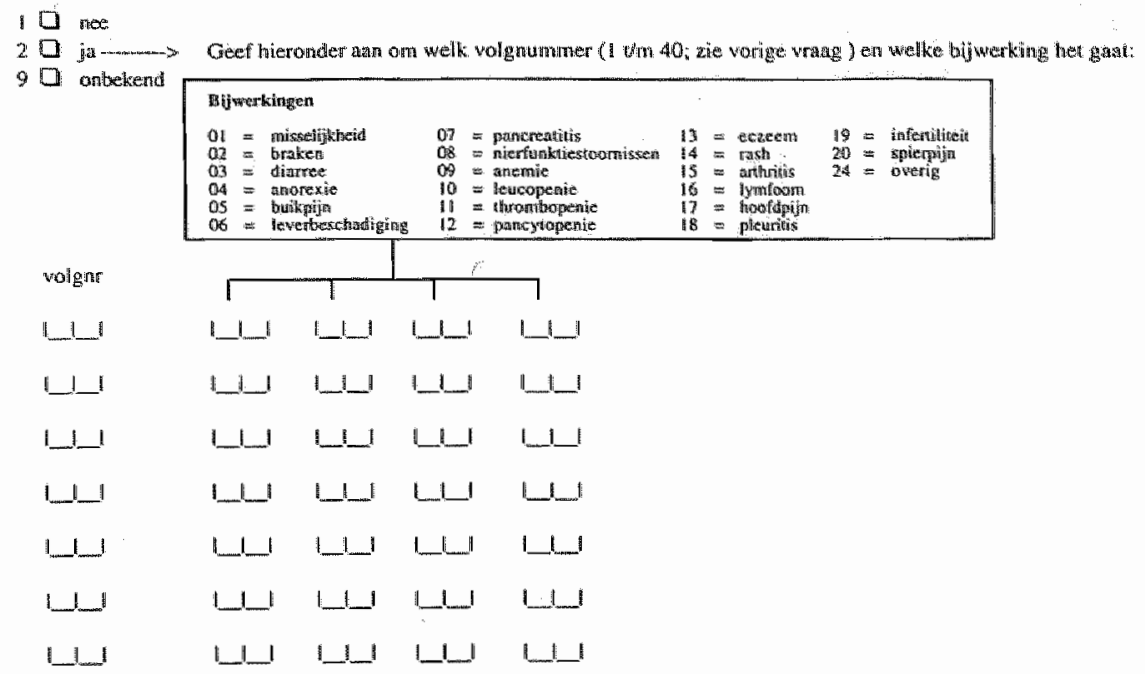

3. Werd medikatie woorgeschreven (of gebrakkt), nhet onder vraag 1 wermeld, in de eerste 6 maanden nát het 1 e konsult?

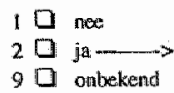

$$
\begin{aligned}
& \text { Soort medikatie Meer antwoorden mogelij (woor witgebreido beschrijving zie hienondert): } \\
& 1 \text { II Acetosal en andere sathicylatieri } \\
& 2 \text { overige INSAID preparaten } \\
& 3 \text { orale anticoagulantia } \\
& 4 \text { maagzurremners } \\
& 5 \text { a cholestyramine } \\
& \text { 6. } 1 \text { overig }
\end{aligned}
$$
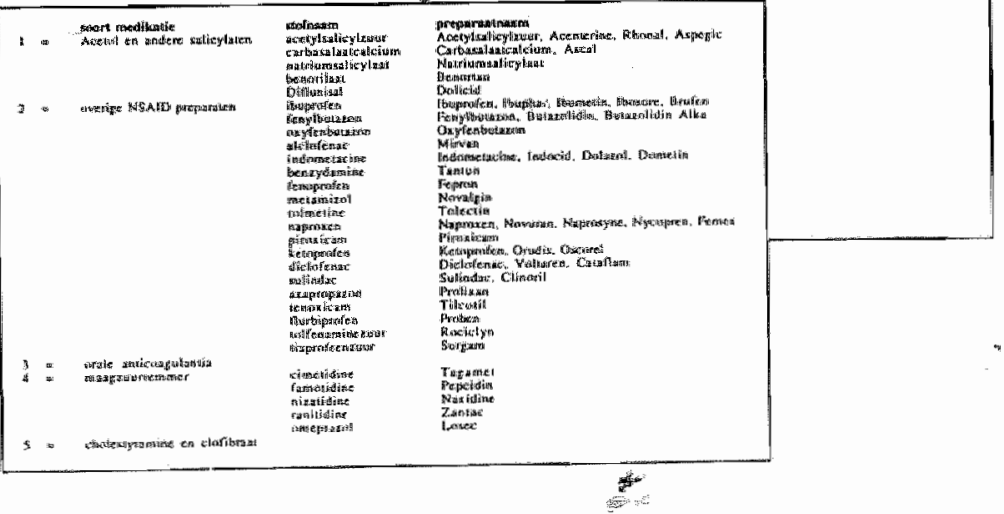


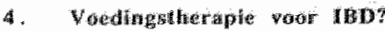

1 Ci riex

2 藏

Vedingsther pipe.

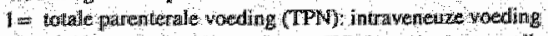

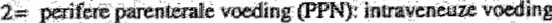

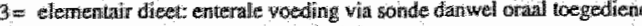

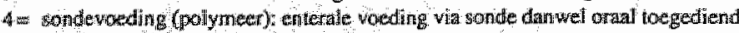

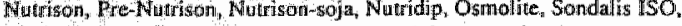

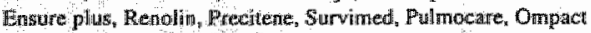

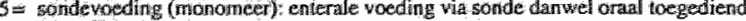

Fexical Wutri-2000, Peptamen, Pepti-2000 (variant), Peptison, Reabilan, Wiwonex

$G$ - sondevoeding (onbekend welk type)

9) Dis onibelkend

\begin{tabular}{|c|c|c|}
\hline me. & begindadam fodm & cinddhatum fodn \\
\hline 1 & 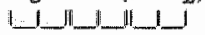 & 1 1_L_III \\
\hline 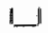 & 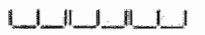 & 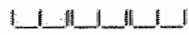 \\
\hline 1 & 1 & 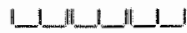 \\
\hline$y$ & $1 \ldots$ & 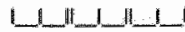 \\
\hline أj & 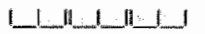 & 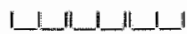 \\
\hline 1 & $1111 \quad 1 \quad 11$ & I_L_H_L_J \\
\hline - & 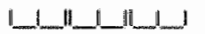 & 1 L If \\
\hline 1 & 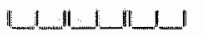 & 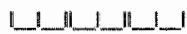 \\
\hline 1 & 1 & 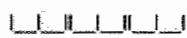 \\
\hline 1 & $1 \quad 1 / 11 \quad 1 \quad 1 \quad 1$ & 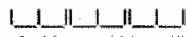 \\
\hline & begindatam (ddmmi & $-\quad 4$, \\
\hline
\end{tabular}

Indien de patient all/nog een voedingstherapie heeft, dan alleen begind akum wermelden er bij de einddaturn 9 s in. vallen. 


\section{OPERATTEVE INGREPEN MAAGDARMKANALL}

1. Darmeselktie?

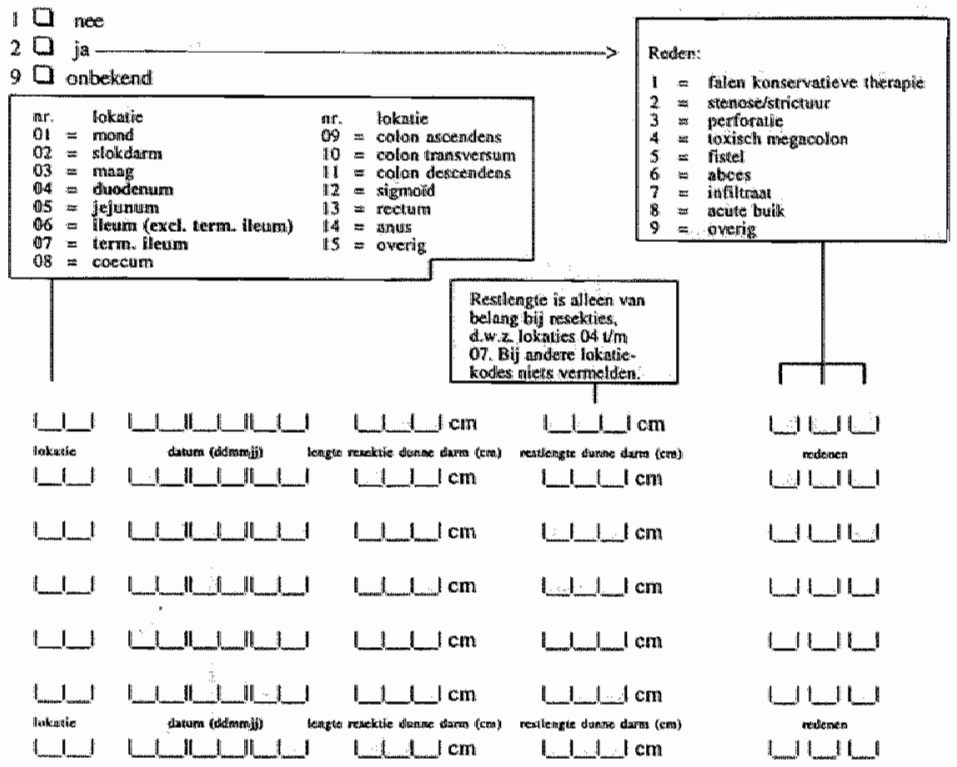


2. Darbes andamose?

$1 \mathrm{CH}$

$2 \mathrm{~d}$ ja

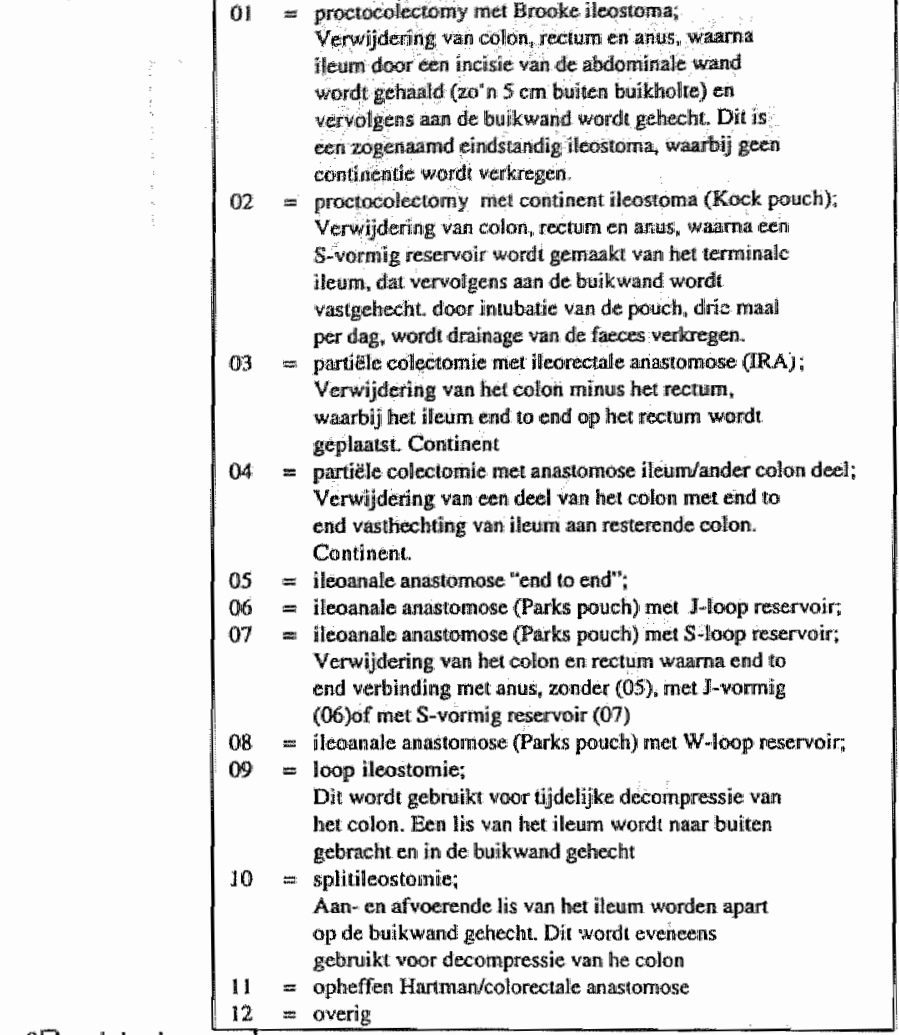

90 onbekend 
3. Bewindingen mogelijk gerelateerd aan operatiewe ingrepen darmresektie en darmanastomesen

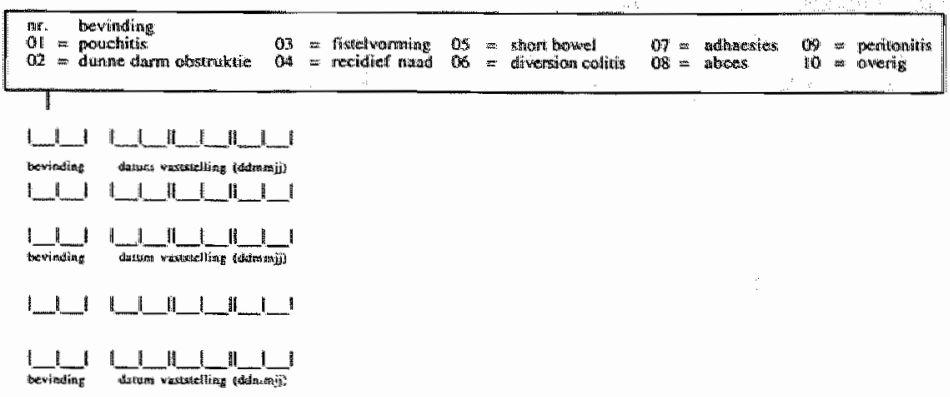

4. Fistelopenatie en verbinding?

10 nee

$20 \mathrm{ja} \longrightarrow$

9.

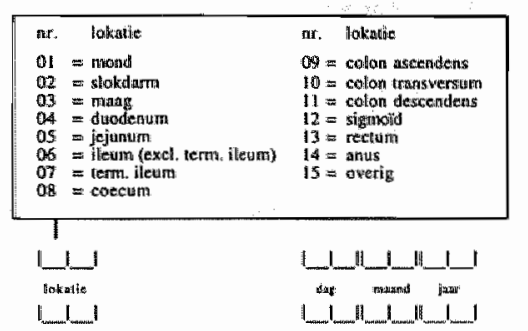

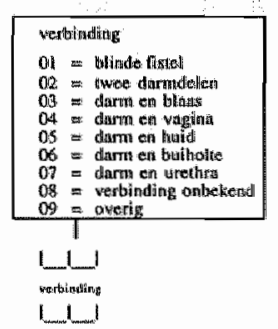

\begin{tabular}{|c|c|}
\hline 11 & $\mid$ \\
\hline Rinkstive & amramat jas \\
\hline $1 \ldots$ & \|\|$\perp\|\|$ \\
\hline 1 & 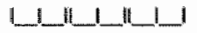 \\
\hline
\end{tabular}

1

wertinutiming

1

$1+1$

5. Overige operaties van het magdarmkanaal in verband met. IBD?

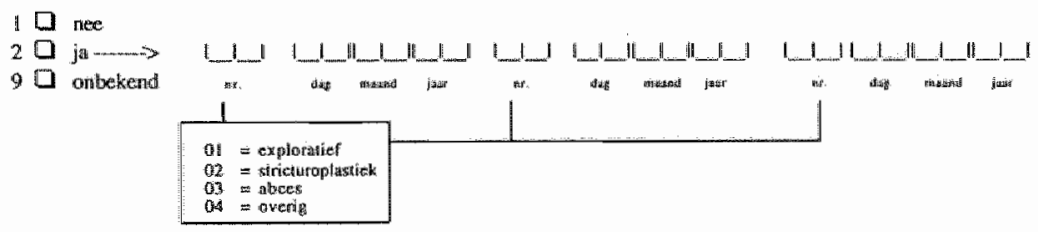




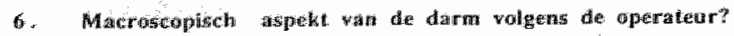

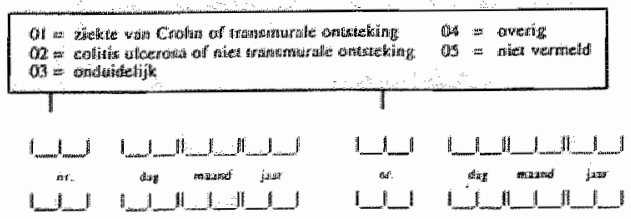

\section{KONKLUSTE (invullen doar panel)}

1. Wat lis de dighnoge wain onderzueker volgems de krikeria wan het CBD projekt?
01 1 zeker Collitis Ulceroger
090 microscopilsthe colitis
02 warsetsinntijk Colitis Ulcerosia
40. Iymfogene colltis

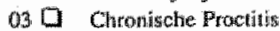
11 1 pseudomembraneuze colins
04 zeken Morbus Crohn
120 besuralinggentercocolitios
os $\mathrm{O}$ warschijalijk Morbus Cron
130 ischaemische colitis
o6 1 aspecinive (onbepaislde) collitis
$14 \square$ infehticuze colitis, te weteri.....
07 Dollagene colitis
is 13 nomal
of [D ensinofiele colitis
$16 \bar{D}$ onduidelijk
170 overig

Spociale attentie voor de onderzoker. 
\% 